\title{
Exploring IT Governance Effectiveness: \\ Identifying Sources of Divergence through the Adoption of a Behavioural-Based Organizational Routines Perspective
}

By

\author{
Allen E. Brown \\ B.A. University of Western Ontario \\ M.B.A McMaster University
}

A thesis submitted to the Faculty of Graduate and Postdoctoral Affairs in partial fulfillment of the requirements for the degree of

\section{Doctor of Philosophy}

In

Management

Carleton University

Ottawa, Ontario

(C) $2014 / 2015$

Allen E. Brown 


\section{ABSTRACT}

This research seeks to broaden and strengthen the holistic understanding of IT governance effectiveness by specifically examining why IT governance systems often fail to produce appropriate or desired IT and organizational behaviours. To address this objective, we investigate and develop a theoretical framework for understanding and explaining the varied sources of divergence that occur during the enactment of IT governance mechanisms. Defined as the difference between desired behaviours and actual behaviours, we argue that the acceptance and consideration of all sources of divergence within the enactment of IT governance mechanisms, is not only necessary, but critical to the appropriate design and maintenance of an effective IT governance system.

Traditional IT governance perspectives, heavily rooted in the structural and normative aspects of oversight and control (i.e. structures), have limited our ability to adequately and fully understand how IT governance performs in practice. Framing IT governance mechanisms as routines, we draw on institutional theory and organizational routines theory as an alternative lens for understanding why organizational behaviours are not always aligned to those expected by IT governance owners. Based on Pentland and Feldman's (2008) generative model of organizational routines, we establish a novel conceptualization for IT governance divergence that posits and delineates three primary sources of IT governance divergence: Representational Divergence, Translational Divergence and Performative Divergence.

Through the in-depth examination of the IT investment planning, prioritization and selection routines within two exploratory case studies, we inductively propose a model for explaining IT governance divergence. We apply a narrative networks approach to frame and analyse qualitative data captured through semi-structured interviews, archival and document review and direct observation. Patternmatching and emergent themes analysis is performed to identify and define first-order and secondorder constructs, along with 15 relational propositions. Given the dearth of theoretically-grounded research in this domain, the central contribution of this study rests in the establishment of a robust theoretical framework of IT governance divergence upon which further cumulative empirical study can be undertaken.

For the practitioner community, the recognition of divergence is necessary for designing IT governance systems that reduce and control negative actor divergence while simultaneously embracing and reacting to instances of positive divergence. In most organizations, significant investment is being made into the implementation of formal IT governance structures and processes despite little empirical evidence as to their effectiveness. By adopting and highlighting a behavioural-based perspective of IT governance effectiveness, we hope to encourage practitioners to move away from the strict normative view of IT governance towards an alternative conceptualization that accepts and accounts for the complex social and individual environments in which IT governance systems are enacted. From this perspective, we argue that IT governance effectiveness can be improved and IT investment failures can be reduced.

Keywords: IT Governance, IT Governance effectiveness, Organizational Routines Theory, Divergence 


\section{ACKNOWLEDGEMENTS}

"It does not matter how slowly you go as long as you do not stop"

-Confucius

This journey, as long as it was, would not have been possible without the unwavering support of a number of selfless and dedicated individuals. First and foremost, I would like to thank my wife, Elvan, for putting her life on hold while I pursued my academic dreams, and for holding down the fort during all those countless evenings and weekends I spent hidden away writing and researching. I would also like to thank my three children, Taydan, Devran and Derya for accepting and understanding that Daddy couldn't always be around to play, even though he desperately wanted to be. Thank you also to my parents and sister for their constant words of encouragement, proofreading, late night counselling and babysitting support.

I am deeply in debt to my amazing supervisor, Dr. Gerald Grant, for his endless professionalism, patience and understanding. He knew exactly when to push and when to sit back and let me vent, something I probably did way too often. Thank you to the members of my committee, Dr. Shaobi Ji, Dr. David Cray, Dr. Benoit Aubert and Dr. Muriel Mignerat for their thoughtful (and very time consuming) review and feedback. Thank you to the graduate committee registrar, Joanne Bree, for her understanding and support. Finally, thank you the organizational sponsors who opened their doors to my research effort and went above and beyond to provide access to their organizations to make this research possible. 


\section{TABLE OF CONTENTS}

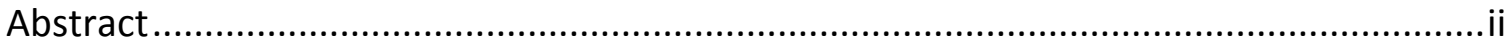

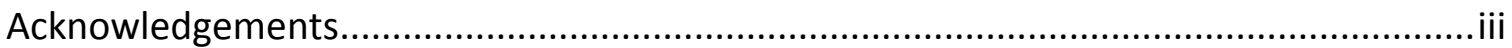

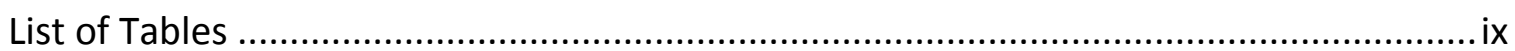

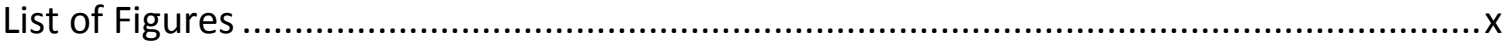

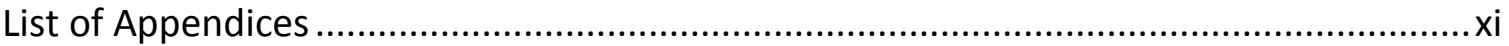

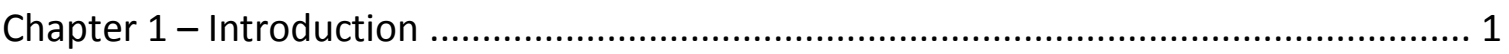

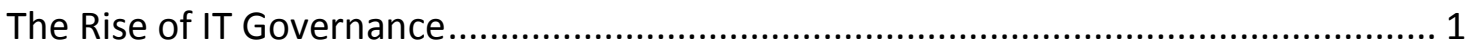

The (In) Effectiveness of IT Governance ………………......................................... 7

Research Motivation and Research Contribution ...................................................... 13

Research Purpose and Contribution................................................................ 17

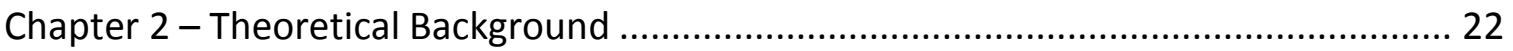

Defining IT Governance Success and Failure.............................................................. 22

Divergence as an Indicator of IT Governance Effectiveness .................................... 25

IT Governance as a set of Mechanisms ................................................................ 28

IT Governance and Sources of Divergence........................................................... 29

The Epistemological Blinders of IT Governance Research ......................................... 33

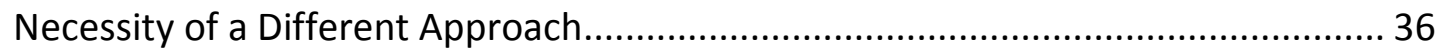

The Diverse Theoretical Perspectives of Divergence ................................................. 38

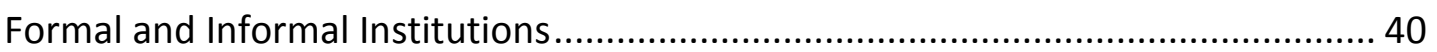

Divergence within Institutional Theory ................................................................ 43

The Various Levels of Analysis in Institutional Theory ........................................... 47

Organizational Routines as a Theoretical Perspective ............................................ 54

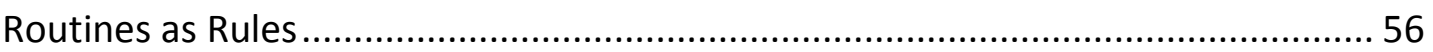

PhD Thesis - Allen E Brown $\quad$ Page | iv 
Routines as Behaviour Patterns

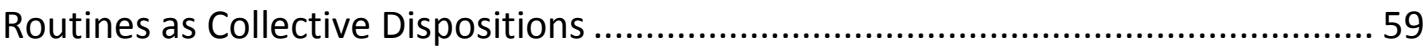

Organization Routines Conceptualization - Dyadic and Triadic perspectives.............. 63

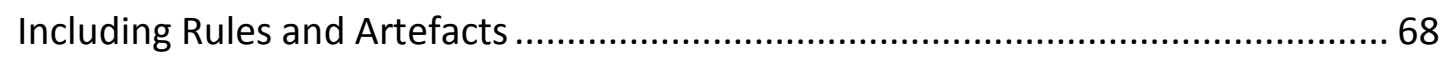

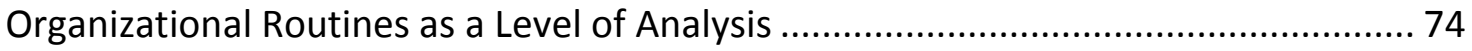

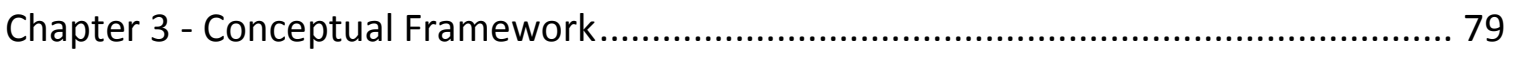

IT Governance Mechanisms and Organizational Routines ................................... 79

Organizational Routines and Information Technology Research ........................... 80

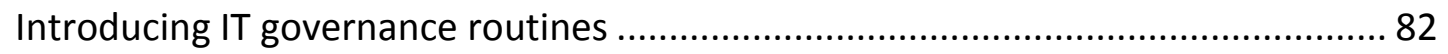

Organizational Routines and Divergence - Towards a Conceptual Framework.......... 84

A Conceptual Framework for Explaining Divergence within IT Governance Routines. 90

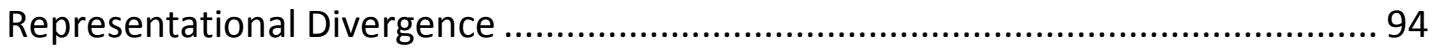

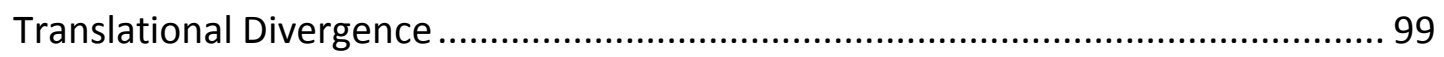

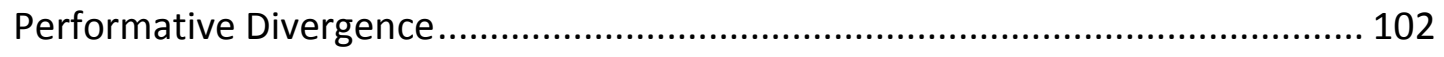

Chapter 4 - Methodology and Research Design ..................................................... 115

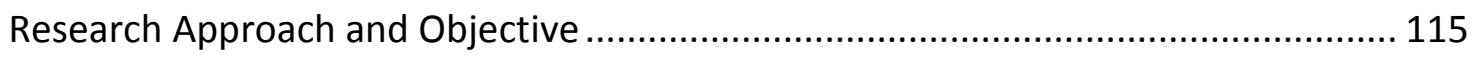

Exploratory Research Design .................................................................. 116

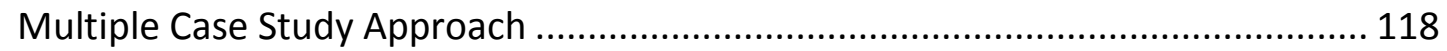

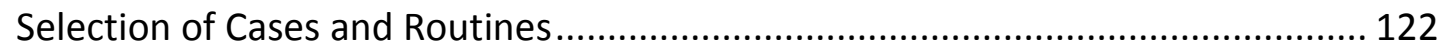

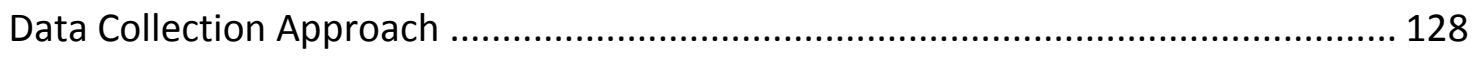

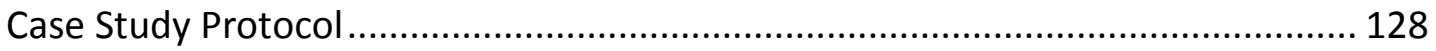

Semi-Structured Interview Protocol ................................................................. 132

Organizational Document Review Protocol ................................................. 138

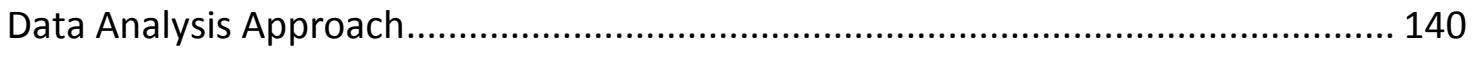

$\begin{array}{ll}\text { PhD Thesis - Allen E Brown } & \text { Page | v }\end{array}$ 
Case Narrative Capture and Identification .................................................... 140

Data Organization and First-Order Codification............................................. 142

Emergence Themes and Second-Order Codification ....................................... 143

Between-case Analysis and Proposition Development..................................... 144

Ensuring Trustworthiness of Our Qualitative Research Approach ........................... 145

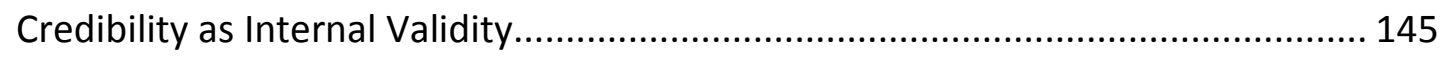

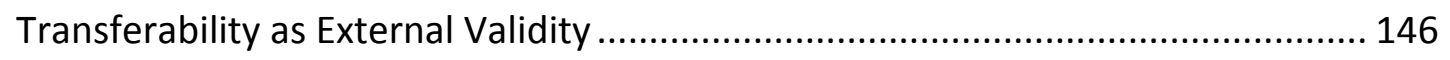

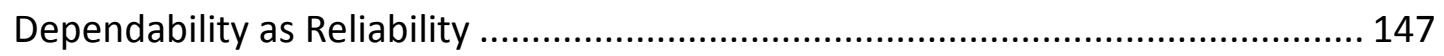

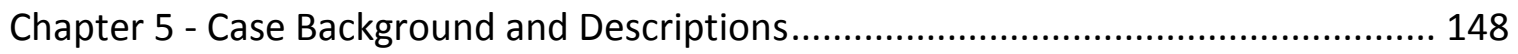

City A - Large Single-Tier Municipality........................................................ 148

City A - IT Investment Planning, Prioritization and Selection Environment ............ 150

City B - Very Large Lower-Tier Municipality .................................................... 165

City B's IT Investment Planning, Prioritization and Selection Environment............ 167

Chapter 6 - Empirical Analysis of Case Studies ................................................... 182

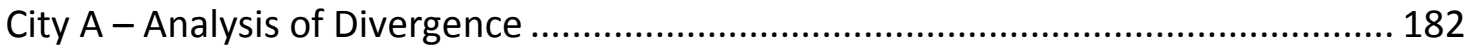

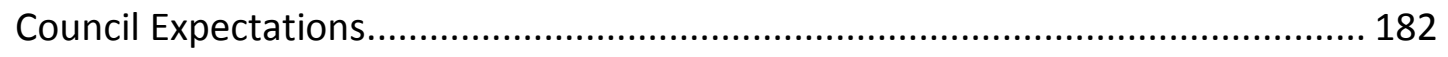

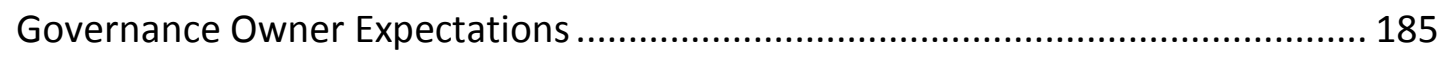

Substantive Divergence ........................................................................... 190

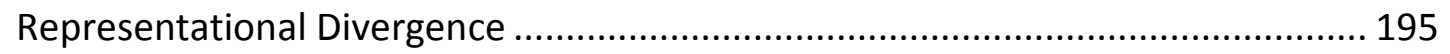

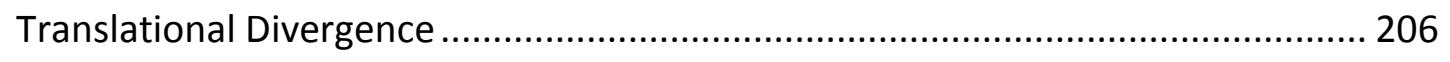

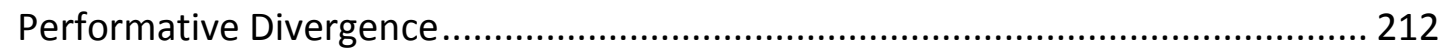

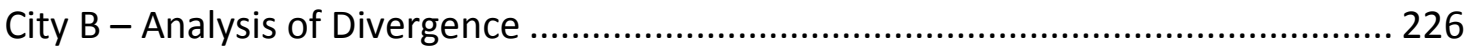

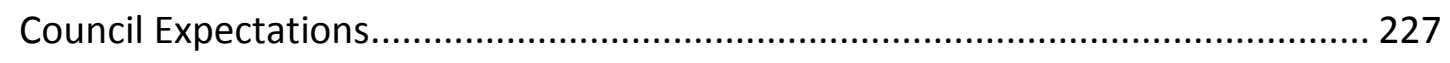

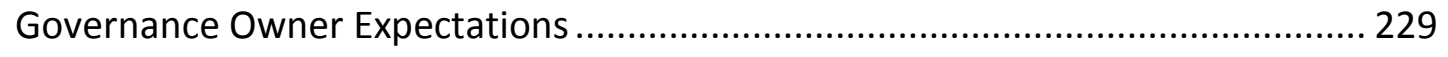

PhD Thesis - Allen E Brown $\quad$ Page | vi 
Substantive Divergence .................................................................................... 231

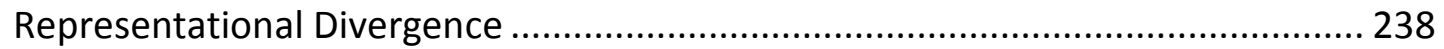

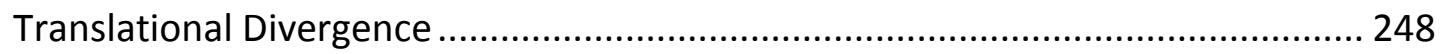

Performative Divergence................................................................................. 255

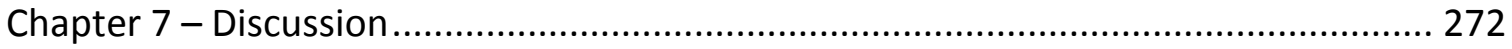

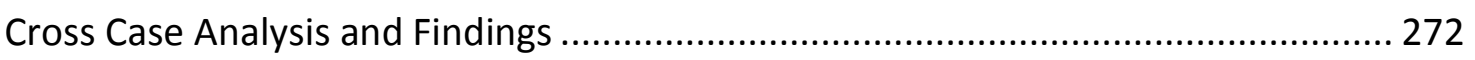

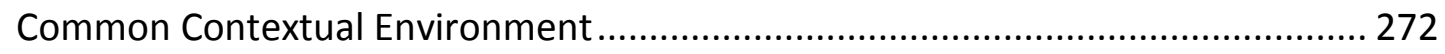

Common Sources of Divergence ..................................................................... 279

A Theoretical Model for IT Governance Divergence ……....................................... 284

Primary Research Question - Factors influencing Divergence ............................... 285

Sub-Research Question 1 - Impact of Artefacts ................................................... 290

Sub-Research Question 2 - Behavioural-Based Sources ........................................ 297

Implications for the Design of IT Governance Routines ......................................... 312

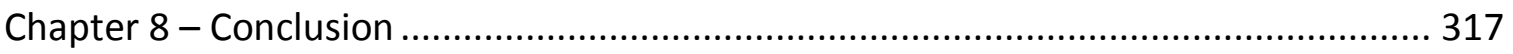

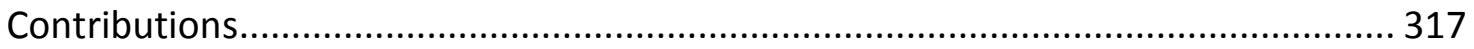

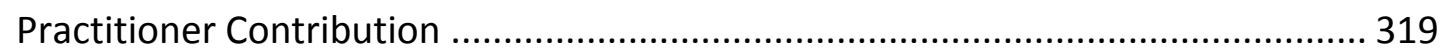

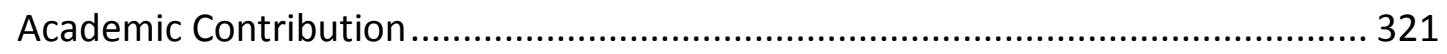

Limitations and Future Research .......................................................................... 324

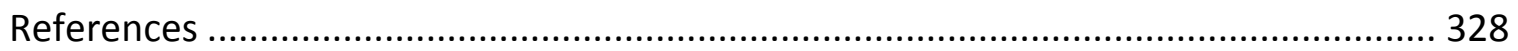

Appendix A - Email to Potential Interview Candidates ................................................. 353

Appendix B - Information for Interview Participants................................................... 354

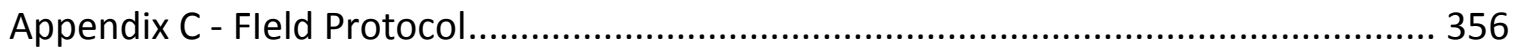

Appendix D - Interview Protocol - Final .................................................................... 357

Appendix E - Draft Interview Protocols - Pre-Test .......................................................... 363

PhD Thesis - Allen E Brown $\quad$ Page | vii 
Appendix F - Informed Consent Document

Appendix G - Transcription Privacy and Confidentiality Agreement.

Appendix H - City A Governance Artefacts

Appendix I - City B Governance Artefacts.

Appendix J - City A Governance Owner Expectations

Appendix K - City A Desired Behaviour 383

Appendix L - City A Actual Behaviour. 384

Appendix M - City A Divergence 385

Appendix N - City B Governance Owner Expectations ....... 386

Appendix O - City B Desired Behaviour.. 388

Appendix P - City B Actual Behaviour 389

Appendix Q - City B Divergence 390

Appendix R - City A Final Divergence Codes 391

Appendix S - City B Final Divergence Codes. 392

Appendix T - Table of Acronyms 393 


\section{LIST OF TABLES}

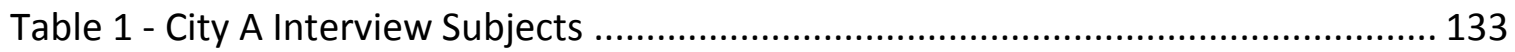

Table 2 - City B Interview Subjects.................................................................... 134

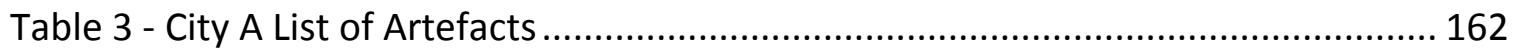

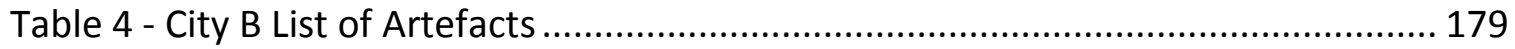

Table 5 - Mapping of Council Expectations and IT Governance Owner Expectations ... 190

Table 6 - Preliminary Assessment of Substantive Divergence.................................... 192

Table 7 - City A Mapping of Governance Mechanisms against Expectations................ 201

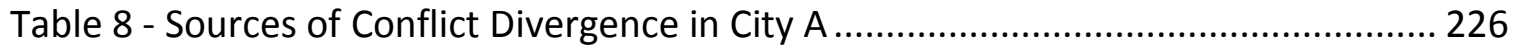

Table 9 - Mapping of Governance Artefacts against IT Ownership Expectations .......... 243

Table 10 - Desired Behaviour of Select Governance Artefacts .................................. 252

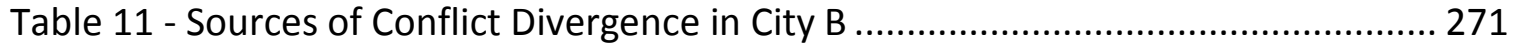

Table 12 - Mapping of ITPPS Expectations in both Cities .......................................... 274

Table 13 - Comparison of Divergence Coding between Cities.................................... 283

Table 14 - Proposition Statements ................................................................... 312

PhD Thesis - Allen E Brown $\quad$ Page | ix 


\section{LIST OF FIGURES}

Figure 1 - Core Source of Divergence in IT Governance .......................................... 30

Figure 2 - Feldman and Pentland's (2005) Dyadic Representation of Routines .............. 65

Figure 3 - The Role of Artefacts and Routines (Pentland and Feldman 2005; 2008) ....... 72

Figure 4 - A Divergence Framework for IT Governance Routines ............................... 91

Figure 5 - Representational and Translational Divergence .................................... 100

Figure 6 - The continuum of Performative Divergence ......................................... 111

Figure 7 - IT investment planning routine for City A (ITGF Guide, Sept 2012) .............. 152

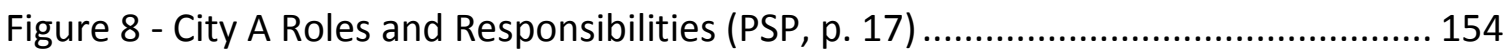

Figure 9 - City B Master Governance Model (GMD, p. 3) ......................................... 170

Figure 10 - Substantive Divergence within City A............................................... 191

Figure 11 - Potential sources of representational divergence within City A ................. 196

Figure 12 - City A Committee Roles and Responsibilities (PSP, p. 17) .......................... 207

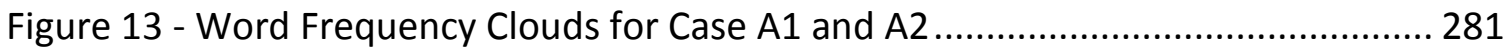

Figure 14 - Theoretical Model for IT Governance Routine Divergence ........................ 285

PhD Thesis - Allen E Brown $\quad$ Page $\mid x$ 


\section{LIST OF APPENDICES}

Appendix A - Email to Potential Interview Candidates ................................................... 353

Appendix B - Information for Interview Participants.................................................... 354

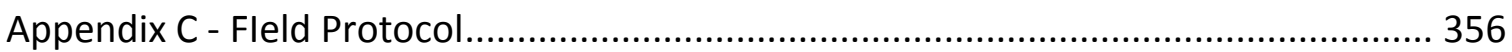

Appendix D - Interview Protocol - Final .................................................................... 357

Appendix E - Draft Interview Protocols - Pre-Test ....................................................... 363

Appendix F - Informed Consent Document .............................................................. 375

Appendix G - Transcription Privacy and Confidentiality Agreement............................... 377

Appendix H - City A Governance Artefacts ................................................................. 378

Appendix I - City B Governance Artefacts................................................................ 379

Appendix J - City A Governance Owner Expectations ................................................ 380

Appendix K - City A Desired Behaviour ...................................................................... 383

Appendix L - City A Actual Behaviour...................................................................... 384

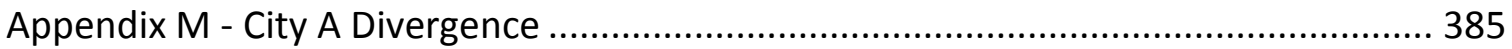

Appendix N - City B Governance Owner Expectations .................................................... 386

Appendix O - City B Desired Behaviour...................................................................... 388

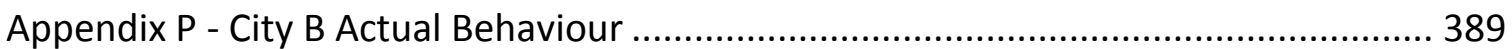

Appendix Q - City B Divergence ............................................................................. 390

Appendix R - City A Final Divergence Codes ................................................................. 391

Appendix S - City B Final Divergence Codes............................................................. 392

Appendix T - Table of Acronyms ................................................................................ 393

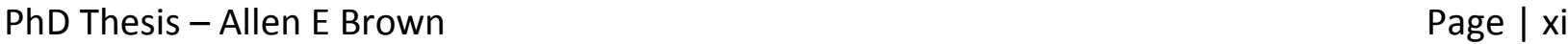




\section{CHAPTER 1 - INTRODUCTION}

\section{THE RISE OF IT GOVERNANCE}

The notion of governing IT assets has become an increasingly common and prominent ideal within most organizations over the past decade. Interest in IT governance has been driven by an increased focus on risk aversion and mitigation, financial accountability and control, as well as a desire to ensure prudent and value-based investment in Information Technology (IT) assets (Brown and Grant 2005; ITGI 2006; Rubino and Vitolla 2014). Given the growing strategic importance of properly managing IT assets, combined with the fact that a significant portion of most of an organization's capital investment budget is spent annually on IT-related investments (Lunardi, Becker and Macada 2009; Gartner 2010; Debreceny 2013), executives and other organizational stakeholders have considerable interest in ensuring that the decision rights and accountability for these investments are properly established, monitored and controlled.

Early conceptualizations of IT governance, often considered as a subset of a corporate governance framework (ITGI 2003; ITGI 2006; Tu 2007; Posthumus, von Solms and King 2010; Debreceny 2013), were strictly concerned with determining the optimal structural arrangements for IT decisions and operations (Brown and Grant 2005; Scott et al. 2006; Williams and Karahanna 2013; Buchwald, Urbach and Ahlemann 2014 ). As such, these frameworks tended to provide little strategic value or interest to organizational stakeholders outside of the central IT group. Over time, however, the focus and breadth of IT governance has increased considerably in accordance with the growing recognition 
and acceptance of IT as a strategic asset able to support and drive the overall strategic mandate of an organization (Weill and Ross 2004; De Haes and Van Grembergen 2009; Wilkin and Chenhall 2010; Debreceny 2013). The result of this increased ambit has been to shift the interest in and importance of IT governance out of the IT group and into the purview of all key organizational decision-makers (Peterson 2004). Executives at all levels and across all domains have started to accept that maximising the value of IT is less about the operation of the technology itself and more about how the IT assets are governed and managed (Peterson, Parker and Ribbers 2002). As such, the oversight and control of IT decision-making in many organizations has moved out of back-office server rooms and has landed squarely within corporate and executive boardrooms (Peterson 2004; Sethibe, Campbell and McDonald 2007).

Despite its importance, a common and universal definition of IT governance does not currently exist (Simonsson and Johnson 2006). The IT Governance Institute, an industryfocused consortium, defines IT governance as "an integral part of enterprise governance and consists of the leadership and organisational structures and processes that ensure that the organisation's IT sustains and extends the organisation's strategies and objectives" (ITGI 2003). Most academic-based definitions of IT governance point to some combination of the structural, procedural and relational mechanisms employed by organizations to ensure proper stewardship and oversight of IT activities and investments, although the underlying assumptions of most definitions vary between authors (Webb, Pollard and Ridley 2006). As prominent researchers in the domain, Peterson (2001), Van Grembergen (2002), Weill and Woodham (2002), and Weill and 
Ross (2004) all put forth converging definitions of IT governance that recognize the importance of all three structural, process and relational governance mechanisms. IT governance, therefore, is more than simply the physical arrangements of the IT organizations, but also the processes and human (and in some cases non-human) interactions that define how, where and why IT decisions are undertaken. From prioritizing IT-related projects to defining individual application controls, IT governance specifies "the decision rights and accountability framework in order to encourage desirable behaviour in the use of IT" (Weill and Ross 2004, p.8). These decision processes are in turn often instantiated and managed by various organizational structures or governance mechanisms, such as steering committees, oversight bodies and executive boards.

As with most social phenomenon, the increasing prominence and importance of IT governance within the practitioner domain has given rise to a web of vendor and industry frameworks, best practices, tools and maturity models, each promising a prescriptive and deterministic approach to establishing proper and effective IT governance. Popular press and academic journals are filled with articles that study, debate and espouse the virtues and promise of IT governance across a variety of topics such as how best to include corporate and executive boards in IT-based decisions (ITGI 2003; Trites 2004; Jordan and Musson 2004; Sethibe, Campbell and McDonald 2007; Posthumus, von Solms and King 2010; Jewer and McKay 2012; Calder 2014; Turel and Bart 2014), how to establish effective and successful IT steering committees (Hoffman, 2004a; Hoffman, 2004b; Schrage 2006; Bowen, Cheung and Rohde 2007; Huang, Zmud 
and Price 2010; Prasad, Heales and Green 2010; Cobanoglu et al. 2013), the role of IT governance in organizational change management (Kamens 2006; Borgman and Heier 2010), proper IT investment prioritization and project portfolio management approaches (Sherer 2004; Bouraad 2010; Frey and Buxmann 2011; Rodriguez and Juiz 2014), alignment of organizational activities with IT governance mechanisms (Leung, 2004; Lewis, 2004; Johnson, 2004; Fonstad and Subramani 2009; Williams and Karahanna 2013), and the connection between IT governance practices and organizational or financial performance (Croteau and Bergeron 2001; Weill and Ross 2004; Boritz and Lim 2007; Gu, Xue, and Ray 2008; Lundardi, Becker and Macada 2009; Smith et al. 2013; Heroux and Fortin 2014).

Despite the significant industry magniloquence, IT governance is not a passing fad. Information technology and information management has become increasingly ingrained in the daily routines of organizational actors. IT is an integral and inseparable aspect of most operations within almost any organization, and as such so are the management, oversight and control of these important, ubiquitous and considerably costly assets (ITGI 2003). IT related investment typically represents upwards of $25 \%$ of an organization's total operating budget and on average accounts for 2 to $7 \%$ of total revenue for most private companies (Gartner 2012). In the public sector, the Canadian federal government reported spending over $\mathbf{C} \$ 8.7$ billion on IT-related projects over a three-year planning period between 2003 and 2006 (OAG 2006), while an estimate of the United States federal spending on IT is close to \$80 billion annually (Pang 2014): an outlay that represents a significant portion of total program-based funding. Therefore, 
given the sheer magnitude of investments being made related to IT, along with the inherent financial and operational risk associated with failed or unrealised IT initiatives, the proper governance of IT activities and decisions is critically important for most organizations.

Beyond the size of IT investments, the rise of IT governance is also born from a number of internal and external pressures facing most modern organizations. Such external pressures include: an increasing focus on corporate control and reporting requirements for corporations i.e. Sarbanes-Oxley, ongoing competitive and time-to-market pressures demanding real-time alignment between IT and business, demand by stakeholders and investors for increased transparency and accountability specifically related to IT spending, and the recognition of the negative impact of IT failures on organization performance (Bharadwaj, Keil and Mahring 2009). Internal pressures include: increasing need to prudently and proactively monitor the return on IT investments and demonstrate the value of IT on organizational performance, ongoing pressure to improve the success rate of IT investments, austerity measures driving IT groups to provide more with less resources, and ensuring that the IT portfolio is consistently positioned to enable the strategic direction of the organization (Keyes-Pearce 2002; ITGI 2003; Peterson 2004; ITGI 2006). Given this set of internal and external pressures, it becomes clear why proper control and oversight of strategic IT investments is top of mind, not only for Chief Information Officers, but for the entire executive committee of most organizations (Peterson 2004). 
By providing transparency, consistency and rigour to IT decisions, the promises and advantages of "proper" IT governance are bountiful and appear to address the many pressures facing organizations. A few of the advantages cited by both industry and academics include: enhanced organizational and IT reputation (Schwarz and Hirschheim 2003; Bowen, Cheung and Rohde 2007), reduced organizational operating costs (Bowen, Cheung and Rohde 2007), increased IT project success (Johnstone, Huff and Hope 2006), better business performance (Weill and Ross 2004; Weill and Ross 2005; Prasad, Heales and Green 2010; Williams and Karahanna 2013; Lunardi et al. 2014), increased return on IT investments (Ribbers, Peterson and Parker 2002; Weill and Woodham 2002; Gu, Xue, and Ray 2008), sustained competitive advantage and market flexibility (Peterson, Parker and Ribbers 2002; Weill and Ross 2005; Broadbent 2005) and the mitigation of corporate risk (ITGI 2003; Xue et al. 2013; Rubino and Vitolla 2014).

Although the majority of the purported benefits of IT governance have proven difficult to demonstrate empirically (Croteau and Bergeron 2001, Simonsson, Johnson and Ekstedt 2010), IT governance has become a common component of most organization's governance, oversight and control landscapes (Trites 2004, Huber 2004). Prominent meta-frameworks such as ISO 38500, the Control Objectives for Information and Related Technology (CoBIT) and IT Infrastructure Library (ITIL) have been widely adopted and provide organizations with a holistic suite of best practices for standardizing, monitoring and controlling IT activities. Overall, IT governance discipline and practice has become well entrenched within both the private and public sectors. In fact as a testament to the importance placed on IT governance by organizational leaders, according to the ISACA 
2012 Governance of Enterprise IT survey, slightly over two thirds of all organizations interviewed by the association have adopted some form of framework or standard for governance and management of enterprise IT assets and services (ISACA, 2012). An earlier study by Deloitte identified an even greater adoption rate, with nearly three quarters of all organisational respondents indicating that they had implemented some form of formal IT governance based on known industry standards (Deloitte, 2005). Within the public sector, a study of US State CIOs found that two-thirds of responding organizations have implemented a formal IT governance framework in order to guide IT decisions (NASCIO 2010). The findings of all these studies point towards the fact that a large number of organizations, irrespective of industry sector, have adopted or are in the process of adopting a formal, enterprise-wide IT governance practice.

\section{THE (IN) EFFECTIVENESS OF IT GOVERNANCE}

Although the potential benefits and advantages of IT governance are well articulated, an understanding and quantification of the actual effect of IT governance on an organization is a somewhat difficult construct to operationalize and measure. Central questions such as whether IT governance actually reduces the number of misguided or unfulfilled IT investments or whether IT governance actually increases the competitiveness or the operational efficiency of an organization are generally avoided or assumed to be true in a great number of IT governance popular press and academic articles (For example, Macdonald 2000; LePree 2002; Leung 2004; Simonsson and Johnson 2008; Prasad, Heales and Green 2010). Terms such as "effective" and "good" IT governance are used frequently (a Google search of "good IT governance" returns over 
90,000 hits), even within the academic literature base, without clear definition and with an implication that these are well defined, easily measured and empirically supported artifacts. Due to this ambiguity, many researchers within the current research base appear to avoid this conceptual conundrum by underlying their work with an implicit understanding that mature IT governance leads to increased organizational performance. As a result, the majority of current prescriptive and best-practice-based studies within the IT governance domain share a common underlying and latent assumption that organizations should necessarily want to move towards a state of "good" IT governance because, after all, IT governance is "good" irrespective of whether it is effective or not (Broadbent and Kitzis 2004).

As an example of this type of study, Prasad, Heales and Green (2010) employ an organizational capabilities perspective as a means for understanding the effectiveness of IT governance practices. In their study, the performance of IT steering committees is treated as a latent exogenous variable or structural instantiation of overall IT governance effectiveness. Beneath the authors' conceptualization is a clear assumption that the establishment of an IT steering committee is synonymous with effective governance. This relationship, in turn, is assumed to be directly correlated with improved business performance. For the authors, the existence of an IT steering committee is implied to equate to effective governance, irrespective of whether the committee actually makes informed and beneficial decisions, or for that matter, makes any decisions at all. This tendency of researchers to imply this unsubstantiated causal relationship between IT governance and organizational performance is specifically 
challenged within two separate responses by Kobelsky (2010) and Paquette (2010) to the study in question.

The inability to draw a strong direct causal relationship between IT governance and organizational performance should not be overly surprising (Soh and Markus 1995). Information Systems researchers have long struggled with defining and operationalizing an appropriate dependant variable for their discipline (Keen 1980) and connecting core IS constructs to overall organizational performance (Brynjolfsson, 1993). This struggle has quite understandably carried forward to the realm of IT governance research. If it is difficult to demonstrate a positive correlation between technology and an organization's performance, then it stands to reason that it would be equally, if not more difficult, to demonstrate a positive relationship between the oversight and governance of this same technology on an organization's performance. A similar difficulty is found with in the domain of corporate governance, where a direct relationship between corporate governance variables and performance has also proven to be elusive (Dalton et al. 1998; Coles et al. 2001). For Croteau and Bergeron (2001), this issue is fundamental for the IT governance research domain, as the failure of the seminal IT governance research studies to establish a direct connection between IT governance and organizational performance has created a significant epistemological roadblock for present day researchers.

In one of the rare studies to attempt to draw a direct correlation between IT governance and organizational performance, Weill and Ross (2004, 2005), examined almost 300 
organizations across 23 counties and found that companies with effective IT governance achieve profits that are on average $20 \%$ higher than similar companies pursuing similar market strategies. For the purposes of their study, "effective" IT governance was defined as a positive assessment of overall governance performance as defined by the individual organization's $\mathrm{ClO}$. Although the conclusion is somewhat implied by the author, they fall short of explicitly declaring the existence of a direct causal relationship between IT governance and organizational performance. This nuance is lost however, on the numerous articles that erroneously point to this study as a primary source of empirical evidence to support the connection between IT governance mechanisms and improved organizational outcomes.

Given the varied and significant organizational pressures to ensure proper oversight and control of IT, it is interesting to note that despite the considerable academic and practitioner focus on IT governance over the last two decades (Brown and Grant 2005), many organizations continue to struggle with fundamental governance practices such as appropriately selecting, implementing and managing IT assets (Marshall and McKay 2004; Jordan and Musson 2004; Johnstone, Huff and Hope 2006; Bharadwaj, Keil and Mahring 2009). From an anecdotal perspective, the popular press remains inundated with examples of IT project failures, cost overruns, security breaches, and poor or inappropriate investment decisions such as cancelling of the $f 11.4$ billion British National Patient Record System (The Telegraph 2011), the corruption of the Royal Bank of Scotland payment processing system which left many citizens without access to their bank accounts (BBC News 2012), cost overruns of 10 times associated with Canada's 
long gun registry (Ottawa Citizen 2000), \$4.5 million in losses associated with the scrapping of the Ontario Provincial's Government's court system upgrade project (CTV 2014), the inability of the Beijing Olympic ticketing system to process required demand for events (BBC 2007), the cancellation of the $£ 98.4$ million BBC Digital Media Initiative (The Economist 2013), and the suspension of the Tokyo Stock Exchange due to a failed trading platform (Wall Street Journal 2012). This is not to mention the recent IT security breaches experienced by Apple, Google, and Facebook (New York Times 2013), Linked-in (Information Week 2012) and TJX (Xu et al 2008). In fact according to Read (2004), almost $90 \%$ of all organizations, regardless of industry type have been affected by some form of IT security breach.

More than mere inconveniences, public IT failures have been shown to have a significantly negative impact on the market value, reputation and internal morale of the offending organizations (Bharadwaj, Keil and Mahring 2009; Park, Keil and Kim 2009). But IT failure is not just a private sector phenomenon; large-scale IT failures equally impact the public sector (The Royal Academy of Engineering and the British Computer Society, 2004; OAG 2006, Goldfinch 2007). In fact, so prominent are IT failures in the public sector that according to Goldfinch (2007) "What distinguishes (IT) failure from other failures in the public sector... is its overwhelming ubiquity" (p. 918). What may be surprising is that not only do IT failures persist; the problem may be actually getting worse for many organizations. In its popular Chaos Manifesto, the Standish Group claims that 2010 saw the highest failure rate for IT projects in over a decade, with $44 \%$ of IT investments being significantly challenged (late, cost overrun or not delivering full 
benefits) and $24 \%$ of IT investments failing outright (cancelled, or not used) (Standish Group, 2010). KPMG found that $49 \%$ of all organizations have experienced at least one recent failure, a number the company feels is considerably underestimated as it only represents the most extreme cases of IT failure (KPMG 2005). Accounting for the public sector, in its 2006 audit of Large Information Technology, Canada's Auditor General found that only 2 of 7 major public IT initiatives met proper audit and control standards and that overall the government has made little progress in its ability to successfully deliver IT projects (OAG 2006).

In the absence of a formal longitudinal study contrasting the adoption and maturation of IT governance and the success rate of IT investments, it would appear that IT failures, irrelevant of how they are defined (Bussen and Myers 1997) continue to plague organizations despite the significant advances and adoption of IT governance and its promise to ensure appropriate technology use, implementation and investment. A brief scan of the IT failure literature reveals a number of plausible explanations for the ongoing inability of organizations to maximize value from IT investments: unrealistic project timeframes, changing or ambiguous requirements, inappropriate technical and managerial skillsets, improper or purposefully falsified IT project reporting, overall misalignment of investments with corporate direction, vendor-influenced and vendorlocked decision making, and unrealistic client and organizational benefit expectations (KPMG 2005; Goldfinch 2007; Bharadwaj, Keil and Mahring 2009; Park, Keil and Kim, 2009, Standish Group, 2010). 
Common to each of the items on this list is that they can be clearly connected to the governance and oversight of IT decisions. This has led many researchers to point to improper IT governance as one of, if not the primary contributor to, IT failure (Macdonald 2000; Sohal and Fitzpatrick 2002; Marshall and McKay 2004; Jordan and Musson 2004; Johnstone, Huff and Hope 2006; Bowen, Cheung and Rohde 2007; Goldfinch 2007; Gu, Xue and Ray 2008). Given the fact that the purpose of IT governance is to provide control and oversight of IT decisions and investments with a goal of encouraging desirable and value-based behaviours and outcomes (KoracKakabadse and Kakabadse 2001; Weill and Woodham 2002; McKay, Marshall and Smith 2003; De Haes and Van Grembergen 2005; Weill and Ross 2004; 2005; Huang, Zmud and Price 2010), it stands to reason that any IT failure necessarily represents a failure in the organization's overall IT governance system (Sohal and Fitzpatrick 2002). In other words, the failure of an IT investment, as defined by the inability of the IT asset to produce the desired and intended benefits, is clearly related to the inability of the IT governance structures, processes and mechanisms to ensure that the desired and intended benefits are produced. This idea that an IT failure represents some level of IT governance inadequacy is a sentiment that is generally echoed within the IT governance community (Sohol and Fitzpatrick 2002; ITGI 2003; Kilcourse 2003; KPMG 2005;

Johnstone, Huff and Hope 2006; Hicks, Pervan and Perrin 2012).

\section{RESEARCH MOTIVATION AND RESEARCH CONTRIBUTION}

Given the discussion above, a significant conceptual inconsistency exists between the rising prominence and adoption of IT governance practices, and the ongoing and 
continual inability of organizations to adequately deliver on IT projects as well as realize an appropriate and positive return on their IT investments. IT governance practices are increasingly adopted, but IT projects continue to fail and IT investments continue to be unable to produce desired returns (KPMG 2005, AT Kearny 2009; Standish Group 2010). The recognition of this inconsistency provides the fundamental motivation for our research effort and our desire to investigate and understand why it is that such a large number of organizations appear to continue to face significant issues related to their IT investments and assets, despite the widespread adoption and implementation of IT governance practices specifically designed to support and guide these fundamental IT activities and decisions. It would seem that at a cursory level, the existence of a formal IT governance system is not sufficient to ensure appropriate delivery and use of IT within an organization (De Haes and Van Grembergen 2005). In fact, for many organizations the adoption and implementation of an IT governance system has been generally unsuccessful in producing appropriate or desired IT-related behaviours or outcomes (Macdonald, 2000; ITGI 2003; Peterson 2004; Rau 2004; Dahlberg and Kivijarvi 2006; Csaszar and Clemons 2006; Ali and Green 2006, Bowen, Cheung and Rohde 2007; Heart, Maoz and Pliskin 2010).

To better understand this apparent disconnect between IT governance adoption and the realization of appropriate behaviours and outcomes we argue in this study that in many organizations, implemented IT governance structures are ineffective at directing and guiding the desired behaviours of organizational actors and decision-makers. Formal IT governance systems do not facilitate desired outcomes for individual organizations 
because they do not account for the numerous structural, human and cultural factors that influence the enactment of IT decisions and performances. As a result of these factors, the actual behaviour of organizational actors often, knowingly and unknowingly, diverges from those desired by the individuals that own and implement the formal governance structures. In many cases this leads to unexpected, unintended or undesired outcomes. At the heart of our research, we seek to answer the following primary research question:

What factors influence the ability of IT governance structures to consistently ensure behaviours and outcomes are aligned with those envisioned and intended by an organization's governance owners and decision-makers?

We posit that by better understanding the sources of IT governance divergence, academics and practitioners will be better able to design and implement governance structures, processes and practices that meet their intended purpose. We believe it is important to understand why current governance systems may not be performing as intended in order to provide substantiated and empirically-validated direction and guidance on how to improve IT governance practices. For us, a first step towards this understanding is the overt recognition that current practices and approaches may not be appropriate, a critical viewpoint that is rarely considered or expressed in the current literature base (Jacobson 2009). Clearly, the underlying assumptions of the majority of the prescriptive IT governance studies are incorrect or at least insufficient, as measured by the sheer volume of ongoing and significant instances of IT failure. Despite this 
evidence, the IT governance literature continues to be dominated by an overwhelming volume of normative studies. Although we share the popular position that with stronger and more effective IT governance, organizations will be better able to ensure an appropriate return on their IT-related investments, we do not agree with the manner in which IT governance systems are determined to be effective. Underlying our position is a belief that to truly understand how IT governance works within structures and practice we need to better understand and identify the various contextual factors that influence how IT decisions are made and how IT activities are carried out. We reject the common assumption that the implementation of IT governance practices equates to having an effective IT governance system.

To explore this idea, and to better understand why IT governance appears not to be delivering as promised, requires a complete reconceptualization of IT governance effectiveness and an improved understanding of the role that IT governance plays within an organization. In this study, we establish a behavioural-based definition of IT governance that defines effectiveness in terms of the level of divergence that exists between the behaviours desired by IT governance owners and those exhibited by IT governance actors. We develop a preliminary research framework, drawn from existing research, to guide our investigation of the sources of divergence that occur within two in-depth exploratory case studies. Through cross-case pattern-matching and a narrative networks approach, we develop and propose a novel theoretical model and set of propositional statements. The purpose of this research is to advance our understanding of the sources of divergence that occur with the enactment of IT governance routines as 
a means to allow practitioners and academics to better understand how IT governance works in practice and, in turn, how to better design appropriate and effective IT governance mechanisms.

\section{Research Purpose and Contribution}

An investigation into IT governance effectiveness is of considerable interest to both practitioners and academics. From an academic perspective the research question and the resulting contribution of this study are both relevant and significant. To date, there is a dearth of studies within the IT governance domain that specifically address IT governance effectiveness and the ongoing implementation and management of IT governance practices (Grant et al. 2006). Traditionally, IT governance research has been focused on selecting and establishing the appropriate structural arrangements with little consideration for what happens within an organization once an IT mechanism has been introduced (Brown and Grant 2005; Willson and Pollard 2009). The vast majority of current IT governance research treats IT governance as a one-time activity (i.e. Prasad, Heales and Green 2010), where the implementation of a particular governance structure is assumed to lead to positive IT performance. In our study, we adopt a novel perspective by seeking to understand the interplay between IT governance systems and the actual decisions and behaviours undertaken within an organization once an IT practice has been implemented. By rejecting the structural and normative positions adopted within the majority of IT governance research (Jacobson 2009), we challenge the notion that IT governance performance is simply a function of adopting and 
implementing the correct set of mechanisms, arguing that a better measure of performance relates to the ability of a mechanism to guide, control and incite a desired set of behaviours. From this perspective, governance is not about designing and implementing formal structures but rather is about influencing organizational action to obtain desired behaviours (Weill and Ross 2004; Huang, Zmud and Price 2010).

Overall, the empirical investigation of IT governance effectiveness along with the recognition that current IT governance practices may not be providing desired results provides a significant and novel theoretical contribution. Within the IT governance literature base, we respond to a number of calls for further investigation into the dynamics surrounding IT governance mechanisms in practice (Willson and Pollard 2009) as well as for the adoption of an alternative ontological conceptualization of IT governance (Peterson, Parker and Ribbers 2002; Ben Boubaker and Nyrhinen 2008; Jacobson 2009). Additionally, through the development of a theoretical model of IT governance effectiveness that reconceptualises IT governance mechanisms in terms of organizational routines, our study also responds to calls from within the organizational literature for an increased understanding of the formal and informal structures influencing organizational behaviour (Becker, Salvatore and Zirpoli 2005; Pentland and Feldman 2005; Feldman and Pentland 2008; Hales and Tidd 2009; Weichbrodt and Grote 2010).

From a practitioner perspective, the primary research question of this study is both relevant and critical to most organizations (Guldentops et al. 2002), given the ubiquitous 
role of IT in enabling most, if not all, major organizational functions and given the considerable investment into technology by organizations in both the private and public sectors (Willcocks and Lester, 1997; Weill and Woodham 2002). Organizations invest in and appropriate IT for a purpose, and effective IT governance guides, supports and incents the subsequent achievement of that purpose (Korac-Kakabadse and Kakabadse 2001). Therefore when IT governance fails, the potential return on any given IT investment is reduced and the overall value of IT to the organization may be minimized (McKay, Marshall and Smith 2003; Marshall and McKay 2004; Dahlberg and Kivijarvi 2006; Bowen, Cheung and Rohde 2007). This is further compounded when considering the amount of financial and human resources expended to design, implement and manage the governance system in the first place (De Haes and Van Grembergen 2009 ; Sylvester 2009; Lundardi, Becker, Macada 2009). Improper or misguided investments in IT, as well as those spent on governing IT decisions become a financial burden on an organization and limit an organization's ability to adequately leverage its investment in IT assets. If we accept that sound and effective IT governance leads to better behaviours and thus better outcomes for IT initiatives (Brown 1997; Korac-Kakabadse and Kakabadse 2001; McKay, Marshall and Smith 2003; Csaszar and Clemons 2006; De Haes and Van Grembergen 2006), then the proper design of IT governance systems is and must be a critical concern for IT and senior management practitioners.

Executives influence the behaviours and activities of organizational actors through the implementation of governance mechanisms (Huang, Zmud and Price 2010; Ferguson et al. 2013). As such, an understanding of the reasons why IT governance systems may not 
be producing desired results directly influences the ability to design and redesign governance practices that do function properly. For practitioners, a better defined governance system requires a focused understanding of what "better" means, a topic that is currently severely understudied within the IT governance literature. Therefore, the overall contribution of this study to practice is an increased understanding of the contextual factors that drive or influence IT governance performance as a means for supporting the definition and design of more effective IT governance systems.

The remainder of the study is organized as follows: Chapter 2 provides an overview of the IT governance literature base with a focus on establishing a definition for IT governance effectiveness based on behavioural divergence as well as arguing the necessity of an alternative ontological and theoretical positioning of the IT governance construct. Identifying a set of sub-research questions, this chapter also introduces our conceptualization of IT governance systems as a set of independent, yet interconnected organizational routines. Drawing on routines theory, Chapter 3 presents a conceptual framework for the investigation of sources of IT governance divergence within individual IT governance mechanisms. The conceptual model provides a preliminary theoretical frame to guide the empirical activities of this study. Chapter 4 outlines the methodological approach employed to collect and analyse our empirical findings and identifies the manner in which we address research validity and reliability in our study. A background and description of the two case studies is provided in Chapter 5 , followed by a detailed empirical analysis of each case in Chapter 6 . Chapter 7 presents the results of our cross-case analysis and culminates in the proposal of a theoretical model for 
understanding IT governance divergence. First-order and second-order constructs are identified and defined, and 15 relational propositional statements are put forth based on empirical findings. Concluding statements, as well as an outline of research contributions and limitations are provided in Chapter 8. 


\section{CHAPTER 2 - THEORETICAL BACKGROUND}

\section{DEFINING IT GOVERNANCE SUCCESS AND FAILURE}

As a first step in investigating the overarching research objective, we establish and clearly define what is meant by IT governance success and failure. As two sides to the notion of IT governance effectiveness, a common understanding of these terms does not currently exist within the IT governance literature base. Given the complexity surrounding this phenomenon, this is not unexpected. As mentioned in the introduction, the dependent variable in most IT governance studies has largely remained ambiguous, often hidden by an implicit or latent assumption that the proper adoption of an IT governance system directly equates to IT governance success. The dominance of this perspective has given rise to an abundance of prescriptive studies seeking to address the necessary elements for successful IT governance without reference to what constitutes successful IT governance, how it is operationalized and how it is measured (Ben Boubaker and Nyrhinen 2008; Jacobson 2009; Guney and Cresswell 2010). As such, the definitions of successful or effective IT governance currently found throughout the literature base tend to focus on the required structural and procedural components of IT governance, rather than on any form of quantifiable performance outcomes or desired behaviours that these components actually deliver (Webb, Pollard and Ridley 2006). As an example of this type of study, Smith (2005) outlines and defines successful governance as a combination of three things: 1) the establishment of a consistent framework for assessing IT expenditures, 2) the existence of an oversight committee to review progress on major capital investments, and 3) IT 
governance mechanisms that play a supporting role in IT performance management processes. For this author, IT effectiveness is clearly measured by the existence of a particular set of IT governance components, rather than by the actual performance (ITbased decisions or behaviours) arising from the system. The fundamental flaw with this perspective is the logical inconsistency associated with defining the success of a phenomenon simply in terms of the phenomenon existing. Clearly IT governance systems are implemented for a purpose and therefore the successful achievement of that purpose cannot be solely measured and substantiated by the mere existence of said IT governance system.

Moving towards the other extreme, success of an IT governance system has also been defined and represented in terms of macro organization outcomes such as successful IT performance (Brown 1997), increased shareholder value (Read 2004), reduced corporate risk (Johnson 2004), increased legitimacy of IT departments (Schwarz and Hirschheim 2003), efficient and effective enablement of business strategies (Rau 2004; Willcocks, Freeny and Olson 2006), increased organizational flexibility (Broadbent 2005), and a strongly implemented IT strategy (Brown 2006). While each of these items clearly represent potential benefits or antecedents related to IT governance, it would be difficult to argue that any of these items represent an internally consistent, valid and operationalized construct for measuring IT governance success. Correlation between the implementation of an IT governance system and any of these outcomes may be empirically defensible, but the establishment of a direct causal relationship between these constructs has yet to be established within the literature base (Lunardi, Becker 
and Macada 2009), and as such these items cannot be considered to provide a valid representation of IT governance effectiveness.

Given the inability to directly link IT governance to organizational performance, a renewed notion of IT governance effectiveness has begun to emerge based on the role that governance plays in guiding organizational behaviours. At the core of this conceptualization is the recognition that perhaps the primary objective of any governance structure is not to directly improve organizational performance, but rather to control and influence individual behaviours within an organization (Weill and Woodham 2002; Weill and Ross 2005; De Haes and Van Grembergen 2006). Through the establishment of behavioural norms, IT governance may then indirectly support the achievement of broader organizational objectives (Chan 2002). Applying this perspective, Weill and Woodham (2002) describe the output of effective governance as a set of desirable behaviours related to the use of IT and note that organizations should design IT governance with desirable behaviours, rather than organizational performance in mind. Weill and Ross (2004) reinforce this position in their widely-cited definition of IT governance as "specifying the decision rights and accountability framework to encourage desirable behaviour in using IT" (p.2). Additionally, in a similar fashion, albeit inverted, both Macdonald (2000) and Verhoef (2007) define effective IT governance as the elimination of undesirable or unintended behaviours.

Citing Weill and Ross (2004), Ali and Green (2006) expand the perspective further by providing insight into the type of behaviours that may be desired, proposing that the 
purpose of IT governance is to encourage behaviours congruent with the organization's mission, strategy, norms and culture. Huang, Zmud and Price (2010), introduce the notion of outcomes into the discussion of behaviours with their assertion that the purpose of IT governance is to “direct and oversee an organization's IT-related decisions and actions such that desired behaviour and outcomes are realized" (p. 289), as do De Haes and Van Grembergen (2006) who point to intended behaviours and outcomes as a measure of a well-balanced and successful IT governance system. By defining IT governance effectiveness in terms of desired behaviours, the messiness of correlating governance to organizational performance can be avoided, freeing up researchers to focus on a more parsimonious conceptualization of an IT governance system.

\section{Divergence as an Indicator of IT Governance Effectiveness}

By combining the definitions of Weill and Woodham (2002), Weill and Ross (2004) and Huang, Zmud and Price (2010), the overarching objective of IT governance can be defined as ensuring that desired or intended behaviours and outcomes of IT decisions, actions and use are encouraged and realized. From this, we argue that effective IT governance can be defined by the extent of divergence that exists between the desired behaviours associated with a specific IT activity and the actual behaviours exhibited by organizational actors when undertaking the activity. Therefore, from a purely theoretical perspective, at its limit, IT governance could be considered fully successful when the collective actual behaviours within an organization exactly match the desired behaviours as defined by key organizational stakeholders or IT governance owners. 
This, of course, could never be possible given the practical inability for any system to maintain a state of prefect alignment given the dynamic and ever-changing environment in which IT decisions are made. As such, a more pragmatic and less structural definition of utopian IT governance effectiveness would be:

An IT governance system that is responsive to the changing demands of IT environments in order to ensure a maximal and continual alignment between desired behaviours as defined by governance owners and those actually enacted by organizational actors.

By defining effective IT governance in these terms, we limit its applicability to organizations that are implementing an IT governance system with a specific purpose to guide behaviour. As opposed to "good" governance which represents an interpretation of the value of a governance system that can change depending on a particular stakeholder's viewpoint, we posit that "effective" governance is a bounded assessment of IT governance based specifically on the alignment between desired and actual behaviours. In this sense, "effective" does not necessary mean "good". Effective governance can be considered "good" or "bad" depending on who is assessing the performance of the system. A stakeholder that prefers the flexibility of a loosely defined governance system (to allow for freedom of agency and decision making) may interpret a highly effective system as being "bad" from their viewpoint.

Our definition of IT effectiveness can then be applied to help define IT governance failure. By strictly adopting the notion of divergence, it is tempting to argue that IT governance failure occurs whenever a significant difference exists between the desired 
behaviours of an IT activity and the actual behaviours that are undertaken. In other words, IT governance fails when the decisions or actions around an IT activity or investment fail to produce the specific behaviours desired by an organization. For example, an IT investment that is misaligned to the overall organizational strategy or the refusal of employees to appropriate and use a new IT system. The issue with this definition rests in the recognition that not all divergence can necessarily be considered undesirable, as organizational actors have been shown to deviate from formal structures as a means of discovering a more efficient and effective manner for accomplishing a particular activity (Meyer and Rowan 1977). As such, we must differentiate at this stage between positive divergence which leads to an actual behaviour that is motivated by an effort to improve on the behaviours prescribed by an IT governance system and negative divergence which results from the existence of an actual behaviour that is less preferable than the desired behaviour. This delineation necessitates a further refinement of our definition of effective IT governance, to include a system that minimizes negative divergence while simultaneously supporting and encouraging positive divergence. Following this revised definition, IT governance failure can then be defined as the repeated existence of significant negative divergence between desired and actual behaviour within an IT situated activity. Although the concept of connecting IT failures to a failure in IT governance is a common practice (Macdonald 2000; Sohal and Fitzpatrick 2002; KIlcourse 2003; Johnson 2004; Marshall and McKay 2004; Jordan and Musson 2004; Johnstone, Huff and Hope 2006), we argue 
that the derivation of this position in terms of negative behavioural divergence has yet to be previously elucidated.

Having established a definition of IT governance success and failure based on the negative variation between expected and observed behaviours, it should be noted that both of these concepts represent the end-points of a continuum for the effectiveness of IT governance. Just as there are degrees of successes and failures in IT projects (Goldfinch 2007), there are also degrees of successes and failures in IT governance. IT governance should not be considered to have completely failed simply because a marginal negative divergence is found to exist between a set of desired and actual behaviours. In this scenario, it stands to reason that the impact of a particular divergence is contingent on the type and size of the particular IT activity exhibiting the divergence as well as in the manner in which the divergence has occurred.

\section{IT Governance as a set of Mechanisms}

When considering the effectiveness of IT governance practices, it must be recognized that an IT governance system is not a holistic, all-encompassing conceptualization, but is rather the amalgamation of a set of tacit and implemented mechanisms and subsystems that work together to comprise an overarching IT governance system (Sambamurthy and Zmud 1999; Weill and Woodham 2002; Peterson 2003; Patel 2003; Van

Grembergen, De Haes and Guldentops 2004; Grant et al. 2007; Simonsson, Johnson and Ekstedt 2010). IT governance, in practical terms, represents a number of decisionmaking structures, business processes and relational mechanisms that work together to 
guide and incent specific organizational behaviour (Weill and Ross 2004; Van

Grembergen, 2007; De Haes and Van Grembergen 2009; Simonsson, Johnson and Ekstedt 2010). Examples of specific instantiations of these mechanisms include steering committees, process diagrams, service level agreements, investment prioritization criteria, and budget processes (Weill and Ross 2004), that, when taken in aggregate, are considered an IT governance system. As such, given the compositional nature of IT governance, it must be recognized that a failure of an IT governance system as defined by the existence of significant negative divergence is actually the result of a failure in one or more of the individual mechanisms that make up the overall system. Therefore to fully understand context around IT governance effectiveness, it is necessary to understand and investigate how the underlying elements of the overall system succeed or fail. Just as when an automobile stops working, it is not the aggregated conceptual container that has failed, but rather one or more of the underlying systems (i.e. engine, drive train, electrical). As such any investigation into the effectiveness of IT governance must necessarily address the effectiveness of the underlying IT governance mechanisms.

\section{IT Governance and Sources of Divergence}

All IT governance failures, as defined by divergence between desired and actual behaviours must be attributed to one of two sources: 1) The IT governance system itself is misaligned to and is innately unable to facilitate the desired behaviours, or 2) The IT governance system is correctly aligned to the desired behaviours, however the system is 
not enacted or followed in a correct manner (either intentionally or unintentionally).

Figure 1 provides an illustration of this point.

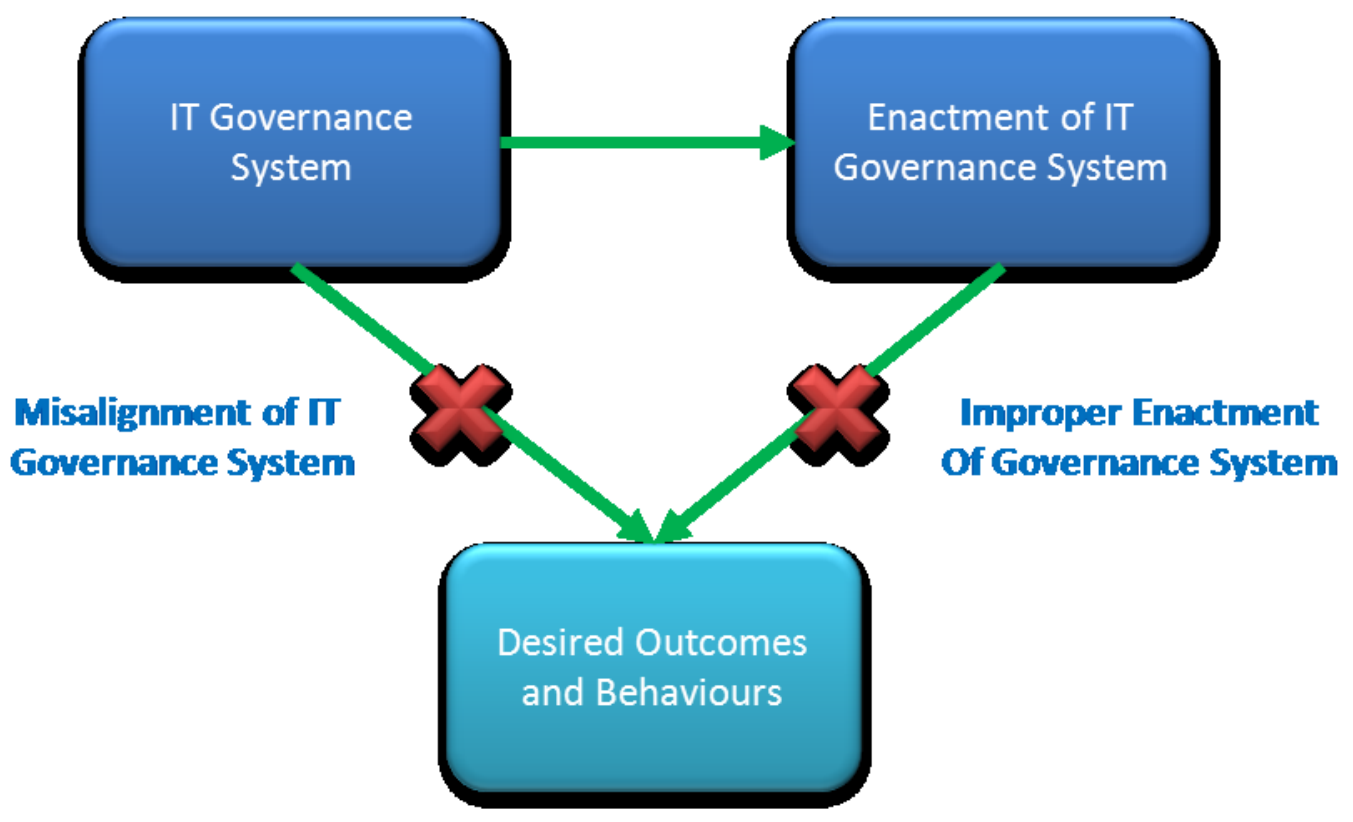

Figure 1 - Core Source of Divergence in IT Governance

In the first scenario, divergence occurs because the holistic IT governance system is incorrectly calibrated with the desired behaviours. An example of this type of activity was observed by the researcher within a large public sector organization. In this particular organization, a formal organizational decision was taken but not published by senior executives to approve and to proceed with as many IT investment proposals under a million dollars as IT resource capacity would allow. At the same time, however, the executive committee responsible for approving investment proposals possessed a formal written mandate to only review potential projects with a projected total cost over a million dollars. Therefore in this example, the formal IT governance mechanism 
as defined by the mandate of the investment committee was in direct conflict with the desired behaviour to approve smaller budget IT projects. Given this obvious disconnect, any strict enactment of the governance process would necessarily lead to existence of divergence, as the actual behaviour would never be able to converge towards the desired behaviour. In this scenario, a positive divergence of actual behaviour would be necessary to align to the desired behaviour of senior executives.

In the second scenario, the IT governance system is logically consistent with the desired behaviours of a particular IT activity; however divergence occurs because the system is not enacted in a consistent or correct manner. Extending the example from above, after the executive committee mandate was rewritten to include the review of all projects, if the committee had chosen unilaterally not to invest in a number of smaller projects, then the source of the divergence would be related to the faulty enactment of an aligned IT governance system. In this scenario, divergence can be observed, not because alignment was impossible, but rather because the actual behaviour of the committee consciously departed from the desired behaviour prescribed by the governance system. The polarity of the divergence could be either negative or positive, depending on the motivation underlying the divergent behaviour. If the intent of the executive committee was to improve the governance system, then the divergence would be deemed positive. However if the motivation for the behaviour was not driven by a desire to optimize the system, and rather, for example a desire to ensure that only the projects owned by the members of the executive committee are approved, then the divergence would be deemed to be negative. 
This is an important distinction: the polarity of divergence is determined by the intent of the behaviour rather than the outcome of the behaviour. We adopt this definition because the measure of outcomes is often subjective in nature and more importantly, the polarity of outcomes is susceptible to change over time. In other words, what appears to be a positive outcome today may, over time, turn out to be a negative outcome in the future. Likewise an output that may be interpreted as negative by some stakeholders may equally be interpreted as positive by other stakeholders: the perspective is relative to those providing the interpretation. The underlying intention of action necessarily provides the most appropriate indicator of polarity as it best reflects the true motivation of the divergent behaviour. Therefore, in our second scenario, the type of divergence displayed by the executive committee would depend on the motivation underlying the decision: was it to seek efficiencies in the process, or was it an overt rejection and repudiation of the governance structure.

The primary research objective of this study is therefore extended to consider why individual IT governance mechanisms as part of a larger IT governance framework are not consistently effective at producing desired or preferred behaviours. Following the logic above for defining IT governance failure, failure of an IT mechanism is therefore considered as an instantiation of the individual mechanism that produces a behaviour that is significantly and negatively divergent from the intended behaviours of the mechanism. In order to address the primary research question, a number of subquestions are investigated as part of this research effort. These sub-questions include: 
Sub Question \#1 - What is the role and impact of formal mechanisms on IT governance routine divergence?

Sub Question \#2 - What factors influence the manner in which individual actors adhere to the formal expectations and structure of an IT governance routine?

To address each of these research question a theoretical perspective is required that allows for the elucidation of sources of negative and positive divergence within individual IT governance mechanisms. Unfortunately, the prominent epistemological perspective within the IT governance domain does not adequately allow for the investigation of such richly contextual constructs. To answer these questions, an alternative theoretical perspective must be adopted.

\section{THE EPISTEMOLOGICAL BLINDERS OF IT GOVERNANCE RESEARCH}

The interest in IT governance effectiveness, as well as the identification and delineation of the two primary sources for IT governance failures highlights a shortcoming within the current IT governance literature. Research within both the academic and practitioner domains is strongly grounded in a structural perspective (Ben Boubaker and Nyrhinen 2008; Jacobson 2009). Underlying this perspective is a belief that formal structures are the most effective and efficient way to organize, coordinate and control the work activities within an organization (Meyer and Rowan 1977), as well as an implicit assumption that the specific work activities undertaken by actors tend to be aligned and conformant to the desired activities as dictated by the formal structures (Gigerenzer 2001; Spender 2009). From a structural perspective, a formal organizational 
structure or mechanism is a tool that can be calibrated to improve the outcome of an organizational activity. In other words, changing a formal structure changes the behaviour of the actors enacting the structure. In addition to the privileging of formal structures, the use of structural rationalism with the IT governance domain is often coupled with the adoption of a normative research approach (Gigerenzer 2001). Normative studies, also referred to as applied research studies (Jacobson 2009), are primarily concerned with the identification of correct set of conditions as well as the preferred end state of a particular organizational activity. In this sense, the normative approach is typically interested in answering the "what", but not the "why" of a phenomenon.

Returning to IT governance effectiveness, studies grounded in a structural perspectives assume that IT governance failures (and in turn IT failures) arise from the implementation of an incomplete or non-optimized IT governance system and as such seek to provide organizations with solutions to move towards a state of effective governance (Jacobson 2009). The net result is an IT governance research base that is now generally acknowledged to be dominated by prescriptive, key factor or bestpractices studies focused on identifying the necessary components of an effective IT governance systems or the correct approach for implementing a robust and successful IT governance framework (Jacobson 2009; Simonsson, Johnson and Ekstedt 2010; Guney and Cresswell 2010). Examples of these types of studies include Nfuka and Rusu's (2010) identification of critical success factors for effective IT governance in the Tanzanian public sector, Bowen, Cheung and Rohde's (2007) investigation of a set of 
factors influencing effective IT governance mechanisms and Larsen, Pedersen and Andersen's (2006) analyses of the of the challenges associated with the adoption of IT governance arrangements and mechanisms.

To be clear, we are not suggesting that the adoption of a structural rationalist frame is erroneous or incorrect. In fact with early IT governance research dedicated strictly to the study of formal governance structures and IT organizational arrangements (Brown and Grant 2005; Willson and Pollard 2009; Wilkin and Chenhall 2010), it is not surprising, nor without merit that the structural perspective has remained prominent within the contemporary literature base. The difficulty arises, however, in the fact that the underlying assumptions of this perspective traditionally do not fully account for the notion of human agency (DiMaggio 1988; Eisenhardt 1989). The structural perspective does not easily allow for the conceptualization that divergence exists within IT governance systems, not only because of a poor formal structure or incorrect implementation, but also because human actors don't always follow formal structures (Emirbayer and Mishe 1998). From an agency perspective, even with appropriate IT governance mechanisms in place, the organizational actors charged within enacting these mechanisms simply may not, either intentionally or unintentionally, adhere to the desired behaviours outlined by these mechanisms. It is for this reason that we argue that the pervasiveness of the structural perspective within the IT governance literature base, by definition, inhibits researchers from even considering, let alone addressing and understanding the second source of IT governance failure identified above. A theoretical lens that doesn't naturally differentiate between structure and agency 
provides little value or perspective in understanding the reasons why divergence occurs between the desired and actual behaviours associated with a particular IT activity or decision.

\section{Necessity of a Different Approach}

The limitations of the dominant structural perspective restrict the ability to adequately investigate IT governance effectiveness. A different theoretical perspective is therefore needed to further advance our understanding with respect to how and why formal IT governance systems either succeed or fail, and to provide an alternative lens for examining specific sources of performance-based divergence. Our view on the need for an alternative perspective is congruent with a number of authors who argue for the importance of institutional-based theoretical conceptualizations of the IT governance construct. For example, in a study on IT governance alignment Avgerou (2000) argues that it is not sufficient to assume that all participants in the organizational management process are rational actors, suggesting that there are a number of informal aspects that may drive the actions of organizational actors. Peterson, Parker and Ribbers (2002), in examining the process nature of IT governance, argue that the rational view of decisionmaking underlying IT governance processes can be problematic. They suggest that this perspective may be inappropriate for addressing the uncertainties and ambiguities that surround IT governance processes. Tu (2007), addressing a specific example of a structural perspective, exposes the notion that organizational actors may require individual incentives in order to follow governance mechanisms, concluding that in the 
absence of appropriate incentives, individuals may not consistently choose to conform to the requirements of formal mechanisms. Ben Boubaker and Nyrhinen (2008), seeking an appropriate lens for explaining organizational choices of governance modes, employ institutional theory, noting that the integration and use of perspectives not grounded in structural rationality are necessary for providing a rich understanding of complex notions such as IT governance. Following these arguments, Paquette (2010) notes that understanding the effectiveness of IT governance is contingent on understanding the connection between governance and employee behaviour, and argues that IT governance is a socially influenced phenomena inseparable from the social environment in which it is implemented.

In the most direct call for a new epistemological and ontological approach to the IT governance research domain, Jacobson (2009) cites the fact that that the current research base has failed to address the real difficulties facing organizations when implementing formal IT governance structures as evidence for the need for researchers to adopt a more diverse theoretical foundation. He argues that rational theories such as contingency theory or transaction cost theory are useful for the development of conceptual models and normative recommendations, but are generally inappropriate theoretical lenses for understanding the broader contextual and social nature of IT governance implementation (a similar argument is made by Christopher (2010) and Davis and Thompson (1994) with respect to agency theory). According to Jacobson, only by understanding the embedded social nature of IT governance can we truly understand how IT governance is operationalized and enacted within an organization. And only 
then can IT governance researchers begin to provide answers to the real issues facing everyday IT governance practitioners. Although specifically calling for an increased use of institutional theory, Jacobson argues the value of a polytheoretic approach to the investigation the IT governance phenomenon that includes both rational and nonrational theories as being necessary for establishing a rich understanding of how IT governance systems work in practice.

\section{THE DIVERSE THEORETICAL PERSPECTIVES OF DIVERGENCE}

Two common and related themes underlie these multiple calls for an alternative theoretical perspective: 1 ) in addition to formal structures, organizational actor actions are also influenced by non-formal means, and 2) as a result of this influence, a gap often exists between the formal rules of an organization and the actual behaviours enacted and exhibited by organization actors. In other words, to adequately address the inner workings of IT governance, and more specifically to address the overarching research question of this study, a theoretical perspective that allows for and accounts for the divergence between desired behaviours and actual behaviours must be adopted.

A set of perspectives not grounded in structural rationalism, falling under the overall umbrella of institutional theory allow for the elucidation of this distinction. Schools of thought arising from the institutional perspective have long privileged the position that individual actors often work outside the confines of formal organizational structures in order to complete various tasks. This position contrasts the strict view of optimization and goal-seeking proposed by traditional economic and organizational rational theories 
(Emirbayer and Mishe 1998; Burns and Scapens 2000; Lazaric 2000; Bevir and Rhodes 2001). With roots in social theory, organizational theory, political theory and economic theory, institutional theory represents an aggregated body of research derived from multiple research disciplines (Carruthers 1995). Although the research from each perspective brings the unique methodological and theoretical lenses associated with that of its native field, the central tenets of the majority of research domains share enough similarity as to be considered part of the same theoretical foundation (Scott 2008). At the core of this foundation is a common belief that distances itself from complete objective or structural rationality, arguing that extraneous forces and social phenomenon, in additional to structural formal forces, lead organizations and organizational actors to often act in non-prescribed and unanticipated ways (Scott 1987; Powell and Colyvas 2008). Work in practice is not always rational but rather, at its essence, is inseparable from the larger social and environmental context of an organization (Meyer and Rowan 1977; DiMaggio and Powell 1983; Elsbach and Sutton 1992). Given this, we argue that the broad institutional perspective provides an appropriate lens for examining and studying divergence between desired and observed behaviours that occur within an organization. Institutional theory, rather than a structural perspective, is necessary for recognizing and studying divergence between desired and actual behaviours within an organization. Three key conceptualizations of institutional theory are central to our study of IT governance effectiveness: 1 ) the distinction between formal and informal institutions, 2) the divergence between structure and agency, and 3) the multiple layers of institutional levels of analysis. 


\section{Formal and Informal Institutions}

Central to the institutional theoretical approach is the recognition that in addition to formalized rules and structures, other social and cognitive factors influence the way in which actors go about their work in organizations as well as in the way that organizations function as a whole (Scott 2004). Therefore, to fully understand how a particular aspect of an organization functions, one must strive to understand both the formal and informal aspects of the particular organizational environment. Based on this notion of dual influences, institutions, as defined by North (1993), are then considered to be the rules-of the game, both formal and informal, that guide and govern behaviour and social interactions. Institutions, however, are not analogous to the different streams of work being undertaken within an organization, and should not be confused with the particular work-related actions undertaken by organizational actors. According to Tolbert and Zucker (1983), institutions refer to organizational influences that meet three criteria: they must be widely followed by the actors within the organization, they must be without contestation or debate, and must exhibit a permanence of function. In this sense an habitual, but unwritten rule that employees take an extended lunch break on Fridays is an institution as much as is a formally published standard operating protocol designed to outline the tasks for completing a particular work activity.

Institutions encompass the cultural, environmental and social structures that lead to action and account for the fact that sometimes work is performed in a particular manner because that is the way it should be done, it could be done, or that it is simply 
the way that things have always been done (Scott 2001, p. 57). This is not to imply that informal institutions are solely the manifestation of ex-ante dispositions. A prominent source of informal norms is also associated with actors attempting to account for specific details that are not accounted for by formal structures (Scott 2001, p. 54). From this perspective, actors create and enact informal norms which in turn can lead to a modification of formal institutions by attempting to "connect the dots" or "fill in the blanks" when following sometimes ambiguous formal institutions (Weichbrodt and Grote 2010). Behaviour of individuals, from an institutional perspective is therefore driven by a complex and often dynamic web of formal and informal institutional influences.

The dichotomy of formal and informal institutional norms is well studied within the organizational studies literature base. In one of the seminal works defining neoinstitutional theory, Meyer and Rowan (1977) argue that organizations use formal institutions as a source of external legitimization and propose that the creation of informal institutions are a natural response to often inefficient formal organizational structures. DiMaggio and Powell (1983), move outside the boundaries of individual enterprises and suggest that the isomorphism found within organizational fields is the direct result of three formal and informal institutional pressures: coercive (the need to be perceived as legitimate), mimetic (the need to follow in response to uncertainty), and normative (the need to adhere to professional standards). Scott (1995) adapts DiMaggio and Powell (1983) to investigate internal organizational forces, arguing that organizational order is maintained through a set of regulative, normative and cultural- 
cognitive forces. In response to these three pressures, individual behaviour is undertaken to avoid punishment, ensure that actions are aligned to their moral obligation, or simply because they can't think of another way of doing the same task. As part of her Nobel Prize winning work on common goods, Ostrom's (2005) institutional analysis and design (IAD) framework distinguishes rules-in-use and rules-in-form as means for explaining the various formal and informal influences on how work is accomplished within an organization. Lastly, Pentland and Feldman, in their work related to organizational routines $(2005 ; 2008)$ refine the concept of ostensive and performative routines as a means for recognizing the explicit and tacit elements of organizational activities.

Regardless of semantic differences, all of these works are consistent in their emphasis that informal contextual norms, in addition to formal structural norms, are important elements to consider when investigating how work is actually undertaken within an organizational setting. The justification for this position, according to Meyer and Rowan (1977), lies in the significant body of research that provides direct empirical evidence for this conceptualization. For IT governance, the adoption of an institutional perspective highlights that we cannot fully understand how IT governance systems perform in practice when we conceptualize these systems exclusively in formal terms. The IT governance mechanisms and structures that currently dominate the normative literature in reality represent only one side of the environment in which IT actions and IT decisions are actually made. IT decisions, like all types of functional decisions, as viewed through an institutional lens is influenced as much by the informal activities within an 
organization as it is by the establishment of formal IT governance practices. Therefore in order to fully understand how organizational actors invoke and enact IT governance situations, it is essential to study and understand individual action within the social and contextual environment in which the behaviour is exhibited. From this perspective, by drawing back from structural rationality and applying an institutional lens to IT governance implementation, we, as a research community, will be better suited to provide a more encompassing perspective on how to implement effective IT governance. Without adopting such a perspective, we argue here that a complete understanding of IT effectiveness (and the way in which IT governance is enacted in practice) proves difficult.

\section{Divergence within Institutional Theory}

Organizational theories grounded in a structural perspective tend to emphasize a tight coupling between formally implemented organizational structures and the behaviours exhibited by organizational actors. In the most extreme structural conceptualization, no distinction is made between the formal rules of an organization and the actual work performed (Feldman and Pentland 2003; Spender 2009). Research that adopts this position treats formal structure and resulting behaviour as one in the same and as such views the manipulation of formal institutions as the primary means for adjusting organizational behaviours. A strict structural perspective does not allow for the ability to recognize that individuals may consciously choose to act in a manner inconsistent 
with the formal structure (Bevir and Rhodes 2001), and as such is unsuitable for considering and studying divergence between behaviour and structure.

In a stark contrast to this position, the institutional school of thought, recognizing that environmental and social norms play an important role in influencing action, acknowledges that actions and decisions often contravene the conventional intended behaviours (Scott 2004). By allowing for a distinction between formal structures and behaviours, institutional theory allows that given opposing institutional forces, actual behaviours are often unpredictable. Instead of acting out of a strict adherence to the formal rules of the organization, or out of an obligation to what or how things should be done, actors often act and make decisions based on habit, familiarity, or other cognitive and cultural dispositions (Powell and DiMaggio 1991; Scott 2001, p. 57). Furthermore, because it would be theoretically impossible to define a formal mechanism that didn't require any improvisation or interpretation by organizational actors, even if an individual wanted to follow a particular formal structure absolutely, they would never be able to fully enact the intended behaviours (Bevir and Rhodes, 2001; Orlikowski 2002; Reynaud 2005; Pentland and Feldman 2005; Weichbrodt and Grote 2010). From this perspective, not only is divergence between structure and behaviour to be expected, it necessarily must exist given the inability of any human artefact to completely prescribe the infinite combinations of potential behaviour.

Meyer and Rowan (1977) directly address the notion of divergence between formal and informal institutions by introducing the term "decoupling". For Meyer and Rowan the 
divergence between formal and informal institutions is not a rejection of organizational control, but rather represents a pragmatic and necessary response to getting work done in an ever-changing and dynamic operating environment. In this sense, it is simply not feasible for formal structures to be flexible or adaptable enough to always be aligned with shifting environmental influences (Scott 2004), a disconnect that was addressed within the organizational literature by the introduction of Weick's (1976) notion of loose-coupling.

It is for this reason that Meyer and Rowan (1977) argue that formal structures, as imposed by organisational stakeholders are fundamentally at odds with rational efficiency, and that decoupling must occur to ensure the survival of competitive entities. A number of formal structures found in organizations, according to Meyer and Rowan are therefore ceremonial in nature and serve only to provide an organization with legitimacy, while the actual work is performed through an integrated set of informal institutions. Pentland and Feldman (2008) extends this idea, arguing that formal routines alone are not sufficient for driving appropriate action because they represent a level of technical determinism that does not exist in actual organizations. Checklists are not always checked, rules will not always be followed and procedures will not always be appropriated, however, work will continue to be done. Formal routines, therefore, are not appropriate proxies for the real enactment of work, because the formality and inefficiency of the formal routines drive organizational actors to diverge and seek alternative performative actions. 
For IT governance research, the notion of decoupling implies that behaviours of organizational actors are much more flexible than is dictated or prescribed by formalized IT governance structures. As a tangential consideration, Meyer and Rowan's (1977) notion of legitimacy provides an interesting consideration that some organizations adopt IT governance structures, not to drive appropriate behaviour, but to provide demonstrable control and formalization of the IT decision-making environment (Schwarz and Hirschheim 2003). In this sense, considerable divergence of action is to be expected, since the true purpose of this type of IT governance system is to provide organizational decision makers with a transfer of accountability, allowing IT leaders to point to failed or unrealized IT investments as implementation or environmental failures rather than their own decision failures. To quote Meyer and Rowan, "quite apart from their possible efficiency, such institutionalized techniques establish an organization as appropriate, rational and modern. Their use displays responsibility and avoids claims of negligence" (p. 344). More likely, and from the most pragmatic position, decoupling of formal IT governance mechanisms occurs to allow governance enactors to bypass inefficient, inflexible or misaligned governance mechanisms as a means to more efficiently or effectively accomplish a particular IT-related activity. This explanation is in-line with findings by Westphal and Zajac (2001) who argue that a significant level of divergence often occurs around core organizational decision-making processes in order to ensure that appropriate decisions are made. Overall, as a means for understanding IT governance effectiveness, an institutional lens privileges, by definition, the existence of divergence between formal IT governance mechanisms and observed behaviour, and as 
such provides an ideal lens for understanding the sources of negative and positive divergence that occur within the enactment of an IT governance system.

\section{The Various Levels of Analysis in Institutional Theory}

Institutions are considered to operate at various contextual levels within organizations, ranging from micro-institutions related to individual actors (Powell and Colyvas 2008) to macro-institutions related to organizational fields (DiMaggio and Powell 1983).

Williamson (1975) classifies distinct layers of institutions within an organization: 1) embedded informal institutions, such as traditions, customs, value and religion, 2) formal rules, such as constitutions, 3 ) governance, made necessary by the vagaries of the first two levels and, finally 4) market and external environment institutions. Therefore, although research grounded in the institutional perspective shares a consistent theoretical lineage, a number of sub-streams have emerged based on the level of analysis employed to investigate the formal and informal norms found in organizations. The use of the correct level of analysis becomes critical when employing an institutional theory lens, because the explanation and norms that affect organizational behaviour are significantly different from those that affect individual decision-making and action. When examining a particular construct at an organizational level (level 4 of Williamson's classification), the limitations associated with adopting a structural view of individual decision-making are minimised since the object of investigation rests in the realm of macro-institutions (Powell and Colyvas 2008). In this type of research the focus is traditionally on the formal institutional norms associated 
with holistic organization activity typically rather than both the formal or informal institutions that influence and guide individual actions within the organization (Zenger, Lazzarini and Poppo 2001). Contrastingly, for research objectives that are investigating activities within the boundaries of an organization (level 1-3 of Williamson's classification), including internal IT governance systems and mechanisms, a nonstructural conceptualization of the individual actors within an environment of microinstitutions is necessary in order to develop a rich understanding of the interplay between formal structure and human agency (Powell and Colyvas 2008). Similarly, Layder's adaptive theory (1994) provides a framework of four layers for understanding human action within an organization: Context, setting, situated activity and self, arguing the necessity of employing an appropriate level of analysis and theoretical perspective when examining phenomenon at each layer.

To account for this individual-level of institutions and to further highlight the need to adopt an appropriate level of analysis for institutional-based analysis, Simon (1957) and March and Simon (1958) introduce the notion of bounded rationality. As some of the earliest indictments of the prevailing use of rational theory in organizational studies, the authors position bounded rationality as a means for explaining why organizational actors do not always appear to make decisions in a rational, maximizing and goaloriented manner. The notion of bounded rationality recognizes that human beings are unable to make fully rational decisions given their inherent inability to obtain and process all the information required to make an optimal decisions. Organizational actors and human beings in general therefore must prioritize and select decision options 
through a process of optimization often referred to as satisficing (Simon 1956), and as such, try to make the best decisions that they can, given the information that they have available. Therefore bounded rationality does not equate to irrationality. However, when viewed through an organizational lens, many individuals activities may appear to be irrational in nature, reinforcing the notion that the micro-level of analysis must be used when trying to understand the institutional norms influencing individual behaviour (Selton 2002). For IT governance, this means that that an organizational level of analysis is not sufficient for understanding the complex dynamic of individual instantiation of IT governance activities and decisions.

In order to understand and study why the output of IT governance mechanism may diverge from intended behaviours, we move away from a structural perspective to one that allows for the consideration of agency. Individuals, in this perspective are not simply mindless rule followers, but are active participants in the enactment of IT governance mechanisms. IT governance systems as they are conceived and developed currently cannot be fully effective because although mechanisms may be put into place, they are not designed to account for the agency of individuals enacting the actual activities that are involved in the IT task. Therefore, given the richness of analysis that can be provided by the adoption of an institutional theoretical perspective, we argue that this position provides the necessary perspective to address the research questions in our study for three primary reasons: 1 ) the ability to account for and study the informal norms that drive and influence individual behaviour when enacting IT governance mechanisms, 2) the ability to account for and represent divergence 
between individual behaviour and desired behaviour as inscribed within formal IT governance structures, and 3) the ability to adopt a micro-level of analysis in order to capture the interplay between individual decision-making and multi-actor activities that occur within an IT governance system.

Although the socio-organizational and economic perspective of institutional theory has been well established within the larger domain of information systems research (for example, Orlikowski 1992), the use of the theoretical lens has been almost entirely absent in the research addressing IT governance (Jacobson 2009). As one of the few exceptions, Ben Boubaker and Nyrhinen (2008) draw directly on DiMaggio and Powell (1983) to argue that institutional forces drive the selection of IT governance modes, but provide little theoretical contribution to understanding the IT governance construct. Given the dearth of application of institutional theory within the domain of IT governance as well as the rising calls within the literature base for an alternative epistemological position, we suggest that the adoption of the institutional perspective within this paper represents a novel and significant theoretical contribution that will allow for a richer and more substantial investigation of IT governance effectiveness, and the IT governance construct as a whole.

The enactment of an IT governance system and its component IT governance mechanisms involves both individual action and multi-actor interactions. As such, our study requires that we adopt a level of analysis that allows us to simultaneously investigate the sources of individual behavioural divergence as well as divergence that 
occurs between the various actors and artefacts (i.e. formal rules, process diagrams, checklists, procedure manuals, etc.) required in the performance of a particular IT governance activity (Howard-Grenville 2005). Referring to Williamson's (1975) classification of institutional layers, we require a level-of-analysis that allows us to view an organization in terms of the first three layers: informal institutions, formal institutions and overarching governance.

To address our unique perspective on IT governance systems, we draw on the notion of organizational routines as a theoretical perspective for investigating divergence within IT governance arrangements. Organizational routines theory provides an appropriate lens to support a non-structural view of IT governance effectiveness, as well as a unique level-of-analysis for studying the social construction and inner workings of a governance system, a level-of analysis that Layder (1994) refers to as a situated activity. To be able to study process divergence of individual mechanisms requires the adoption of a theoretical lens beyond the traditional organizational, group or individual typically employed by IT governance researchers. An organizational perspective allows for an understanding of the macro-performance of IT governance frameworks, but treats IT governance as a singular, black-box construct. A workgroup perspective moves us closer to the individual mechanisms, but does not allow for understanding phenomenon that cut across multiple groups, a similar drawback for the individual perspective. Organizational routines, however, as a theoretical construct, represent a lens that sits between the individual and the organization, between structure and action (Pentland and Rueter 1994), and between setting and self (Layder 1994): a position that 
adequately facilitates the investigation of multi-actor IT governance mechanisms. Organizational routines map directly to the performance of IT governance activities as they represent activities undertaken by individuals within a larger social and environmental context (Lazaric 2011). For some, organizational routines are viewed as the core DNA or genetic material that underlies the behaviour of an organization (Nelson and Winter 1982, Becker 2002, Feldman and Pentland 2003).

Of further importance, organizational routines have been recognized as an appropriate theoretical lens for examining the inherent divergence between the observed and intended behaviour of organizational actors (Pentland and Feldman 2005; Becker, Salvatore, Zirpoli 2005; Feldman and Pentland 2008; Weichbrodt and Grote 2010). This is because organizational routines allow for an understanding of how tasks are accomplished, rather than simply of what tasks are to be accomplished (Becker 2005). For IT governance effectiveness, organizational routines are useful in accounting for the reasons why organizational actors' behaviours do not always adhere to those defined by formal IT governance mechanisms. In fact, even within the organizational routines literature base, a number of calls have been made for further investigation into the notion of divergence and the drivers underlying the interactions between ostensive and performative routines (Becker, Salvatore and Zirpoli 2005; Pentland and Feldman 2005; Feldman and Pentland 2008; Hales and Tidd 2009; Weichbrodt and Grote 2010).

Although the concept of organizational routines has been previously used to examine particular technology issues (Levin 2002; Howard-Grenville 2005; Becker, Salvatore and 
Zirpoli 2005; Levin and Barnard 2008; Pentland and Feldman 2008), at the time of writing, the concept of organizational routines, similar to the overarching institutional theory perspective has yet to appear prominently in the IT governance literature. Considered an appropriate theoretical perspective to examine organizational processes and the manner in which work is accomplished within organizations (Hutchins 1991; Pentland 1995; Orlikowski 2000; Pentland 2003; Becker, Salvatore and Zirpoli 2005), organizational routines have, however, been discussed in connection with a generalized notion of formal governance or organizational structures (Dosi 1995; Coriat and Dosi 1998; Lazaric and Denis 2005). In the case of formal governance, the most prominent use of routines theory has been related to examination of governance control mechanisms and individual motivation (Becker 2004).

Therefore, by adopting an organizational routines theoretical lens, we satisfy calls within the IT governance literature for the adoption of a non-structural ontological position for examining the IT governance construct, as well as calls within the organizational routines literature for increased investigation into the factors associated with divergence between intended and actual behaviours. As a theoretical perspective, organizational routines allow us to examine the divergence of action within individual IT governance mechanisms, and in turn, the overall conceptualization of IT governance effectiveness. 


\section{ORGANIZATIONAL ROUTINES AS A THEORETICAL PERSPECTIVE}

Organizational routines theory represents a rich and diverse perspective for understanding how work is performed and decisions are made within organizations. As a core consideration in evolutionary economics, organizational economics, organizational theory, and business administration (Nelson and Winter 1982; Felin and Foss 2004; Parmigiani and Howard-Grenville 2011), routines represent the basic components underlying organizational behaviour and the way in which work is undertaken and completed (Feldman 2000). The prominence of routines and their subsequent adoption as a theoretical lens within organizational studies is generally accredited to the foundational work in evolutionary economics by Nelson and Winter (1982). For these authors, routines provide a useful theoretical alternative to neoclassical economics for understanding, conceptualizing and studying technologydriven activities within an organizational context (Lazaric 2000). Despite the centrality of routines within the works of the evolutionary economics domain, the overall concept of activities and decisions as routines has appeared in many other organizational theory works such as March and Simon (1958), Cyert and March (1963), and Weber (1978), among others. According to Simon, the first formal use of the term routines, in the context of organizational activities, can be found in Stene (1940).

Over time, the term routine has taken on various meanings, and as such currently represents a confused and complicated concept that remains somewhat ambiguous and ambivalent (Cohen et al. 1996; Dosi, Nelson and Winter 2000; Becker 2001; Becker 2002; Feldman and Pentland 2003; Becker 2004; Becker 2005; Felin and Foss 2009; 
Spender 2009; Weichbrodt and Grote 2010). Within the organizational behaviour literature, routines have been defined in many ways and as such, have become the central element to numerous organizational theories. This widespread and diverse adoption of routines has led Spender (2009) to worry that organizational routines are being used a theoretical panacea able to provide answers to every organizational puzzle. Given its multi-disciplinary roots and widespread appropriation across multiple academic domains, the multiplicity of definitions is not surprising. Organizational routines have been referred to as organizational performance programs (March and Simon 1958), the memory of an organization (Cyert and March 1963), a repository of organizational capabilities (Nelson and Winter 1982; Levin and Barnard 2008; Parmigiani and Howard-Grenville 2011), a set of forms, rules, procedures, strategies and technologies around which an organization is constructed (Levitt and March 1988), the principal means by which organizations transform inputs into outputs (Dosi, Nelson and Winter, 2000), a source of organizational competencies (Cohen and Bacdayan 1994), the genetic material that underlies the organizational structure (Nelson and Winter 1982; Becker 2002; Feldman and Pentland 2003), organizational meta-habits (Hodgson 2003), and coordination mechanisms for organizational action and division of labour (Lazaric 2011). In fact, according to Felin and Foss (2004), the research community as a whole have tried to encompass so many diverse elements into the definition of organizational routines that the concept has become almost as complex and confusing as the organizations they are meant to represent. 
The difficulty in defining organizational routines lies in the fact that within the organizational theory literature base, organizational routines have been largely conceptualized across three distinct ontological positions: 1) routines as rules, 2) routines as behaviour patterns and 3) routines as collective dispositions (Becker 2004). Understanding the various conceptualizations of organizational routines, allows for a greater appreciation of the diverse set of definitions associated with this theoretical lens (Parmigiani and Howard-Grenville 2011) and ensures that the appropriate perspective is adopted to support a particular research objective.

\section{Routines as Rules}

Preliminary routines research, based squarely in the realm of a structural perspective, was focused on the normative, rules-based aspect of routines, privileging the notion that routines were stable, unchanging, repetitive functions within an organization (Feldman 2003). From this perspective routines are considered organizational habits that are unconsciously followed by actors in response to formal organizational rules (Feldman and Pentland 2003). Referred to as standard operating procedures by Cyert and March (1963) and March and Olson (1989), the purpose of routines from this perspective is to reduce the burden of decision-making imposed on organizational actors by formally outlining and prescribing the steps required for actors to complete a particular task. Routines, in this sense, allow for an organizational-wide conservation of cognitive capability by facilitating individuals to "turn off their minds" during rote or repetitive activities (March and Simon 1958). 
This deterministic perspective of routines strongly promotes the notion of “mindlessness" (Gersick and Hackman 1990; Louis and Sutton 1991; Reynaud 2005) by likening routines to the individual habits that unconsciously drive behaviour during repetitive or mundane tasks (Feldman 2003). As such, this position views organizational routines as a singular dimension, one and the same with the formal rules of the organization that are meant to drive desired behaviour. To understand the way work is carried out within an organization, one must only look so far as the formal rules that have been implemented within the organization. From this structural and normative perspective of routines, behaviours are viewed as inseparable from formal control mechanisms within an organization.

Routines as rules are seen as mechanisms for managing, yet maintaining power imbalances (Cyert and March, 1963; Pentland and Feldman 2005; Lazaric and Raybaut 2005; Weichbrodt and Grote 2010), limiting individual freedom (Beck 2004), and stunting organizational efficiency (Cohen and Bacdayan 1994). As a result, definitions of routines from this perspective tend to privilege the fixed and formal nature of action within an organization (D'Adderio 2008), and studies adopting this approach are typically concerned with establishing a causal relationship between the holistic, or "black box" notion of formal routines and overall organizational performance.

\section{Routines as Behaviour Patterns}

Noticeably absent from the perspective of routines as rules, is the concept of agency and the recognition that individuals often consciously or unconsciously choose to 
behave in a manner inconsistent with the formal structures of an organization. From this perspective, individuals, rather than mindlessly following instruction, tend to choose the way that they behave from a large repertoire of potential actions, and as such their behaviour is not only the result of unconscious activity but rather that of effortful accomplishments and conscious decision-making (Pentland and Rueter 1994; Parmigiani and Howard-Grenville 2011). As such, this alternative conceptualization of organizational routines decomposes the singular view of the construct with the objective of recognizing that the actual behaviours of individual organizational actors are separate from the formally defined rules of an organization. Nelson and Winter's (1982) definition of organizational routines as "regular and predictable behaviour patterns of firms" (p.14) underlies the behavioural perspective of routines and at the time represented a significant shift in the conceptualization of routines towards a nonstructural, non-normative theoretical position. Building from Nelson and Winter (1982), Cohen and Bacdayan (1994) and Feldman (2000) observed that routines were not stable and fixed ideals but rather an adapting and morphing organizational phenomenon. This led to Feldman and Pentland (2003) defining organizational routines as "repetitive, recognizable patterns of interdependent actions, carried out by multiple actors" (p. 95), a position that not only privileges behaviours over structure but also stresses the collective nature of routines.

By defining organizational routines in terms of behaviour patterns (Feldman and Pentland 2003), interaction patterns (Becker 2005), or recurring action patterns (Cohen 2007) necessarily assumes that routines involve more than one organizational actor. As 
opposed to the notion of habits, a concept related to explaining individual patterns of actions, routines represent the coordinated, sometimes choreographed interplay of multiple individual behaviours (Cohen et al. 1996; Dosi, Nelson, Winter 2000). From this perspective, organizational routines can be viewed as one ontological step above habits (Hodgson, 2003), as they account for the shared customs and institutions that provide for an integrated and common interpretation of formal organizational structures (Wittgenstein 1995). Since most organizational work is performed by more than one individual, the view of routines as behaviours has become the dominant perspective within the literature as it provides an appropriate lens for examining the performance of multi-actor activities (Becker 2005).

\section{Routines as Collective Dispositions}

A less prominent conceptualization of organizational routines considers routines as a set of collective behaviours that can be triggered by individuals as needed (Hodgson and Knudsen 2004). Arguing that the view of routines as representing behavioural patterns does not adequately account for the underlying source of collective behaviours, proponents of the collective disposition position define routines as a set of "if-then" rules that can be invoked collectively in response to specific organizational stimuli (Egidi and Narduzzo 1997; D’Adderio 2008; Iannacci and Hatzaras 2012). In this view, organizational routines are considered patterned sequences of learned behaviour that are individually stored but shared across multiple actors (Cohen and Bacdayan 1994). 
Noting that Nelson and Winter tended to sway between the notions of collective behaviours and collective dispositions, Hodgson (2003) argues that to truly understand the nature of routines, one must look beyond the observed collective behaviour of organizational actors and into the innate underlying mechanism that drives collective action. Viewing routines as a genotype rather than a behaviour phenotype, Hodgson positions routines as "meta-habits" that are grounded in both the organizational structures and the individual habits of organizational members - a sort of organizational analogue for individual habits (Hodgson 2004). The rationale for this perspective lies in the observation that when an employee returns to work after a weekend they are still able to execute routines, therefore some portion of the routine must be internally stored (Hodgson 2003). A similar position is adopted by Lazaric and Raybaut (2005) who argue that routines are both a set of inert temporarily dormant repertoires (dispositions) as well as a base of knowledge that is used and performed daily (behaviours).

As a result of these various ontological conceptualizations, organizational routines are viewed as many separate things by many different people (Spender 2009). Irrespective of the positioning, however, a number of common characteristics of organizational routines have emerged from the various definitions of routines:

1. Organizational routines are recognizable, selectable and sequential patterns of action, behaviour and interaction (Cohen and Bacdayan 1994; Pentland and Rueter 1994; Cohen et al. 1996; Becker 2002; Feldman and Pentland 2003; Pentland 2003). 
2. Organizational routines are collective, involving multiple actors (Cohen and Bacdayan 1994; Becker 2002; Feldman and Pentland 2003, Becker 2005; Becker, Salvatore and Zirpoli 2005; Weichbrodt and Grote 2010).

3. Organizational routines are a set of actions that are repetitive or recurring (Cohen et al. 1996; Becker 2002; Feldman and Pentland 2003; Becker 2004; Hodgson 2004). Not all recurring patterns of action however are routines, for example rules of thumb (Cohen et al. 1996).

4. Organizational routines are comprised of a set of interdependent actions (Feldman and Pentland 2003; Becker, Salvatore and Zirpoli 2005; Cohen and Bacdayan 1994).

5. Organizational routines both facilitate and constrain behaviour (Becker 2004; 2005; Becker, Salvatore and Zirpoli 2005; Pentland and Rueter 1994; Orlikowski 2000; Feldman and Pentland 2003)

Based on these characteristics, it becomes evident that a good portion of work that is accomplished within an organisation can be conceptualized in terms of organizational routines (Feldman 2003), although exactly how much organizational behaviour can be reasonably considered to be a routine remains a debatable topic (Felin and Foss 2009). The core of the debate is not related to the common set of characteristics listed above, but rather the belief as to whether an organizational routine can be said to exist even if it is never enacted. From a behavioural pattern perspective, routines are only truly routines when they are enacted, in other words, they must be enacted to exist (Abell, 
Felin and Foss 2008; Pentland and Feldman 2008). The performance of a routine is therefore a necessary and inseparable aspect of the routine itself. Without a performance, the routine does not exist. This understanding is in direct contrast to the collective disposition perspective were routines exist regardless of whether they are physically instantiated or not (Abell, Felin and Foss 2008; Pentland and Feldman 2008). In this sense, routines are inert objects that exist within the collective psyche of an organization, irrespective of whether they are ever physically enacted. The fundamental delineation of a routine from both perspectives is the same: an aggregated set of activities involving multiple actors as a means for completing an organizational activity however the necessity of performance is where the two perspectives differ. This difference has significant implications for academic investigation.

Given that our research objective is based on understanding the negative and positive divergence that can occur during the enactment of an IT governance mechanism, it is clear that we require a conceptualization of organizational routines that allows us to observe and elucidate the sources of divergence between desired behaviours and actual performances. Performances represent the physical manifestation of the IT governance mechanism, and as such represent the observable output of routines divergence. Of interest to organizations, and therefore by extension of interest to our study, are not the un-enacted dispositions of a governance routine, but rather the real-life performances being undertaken in response to the imposition of a formal governance mechanism. As such, we inform our study with the behavioural perspective of 
organizational routines adhering to the position that routines only exist as a combination of latent and observable manifestations.

\section{ORGANIZATION ROUTINES CONCEPTUALIZATION - DYADIC AND TRIADIC PERSPECTIVES}

Of particular interest to the research objective of this study is the fact that a conceptualization of routines as behavioural patterns provides a theoretical lens that, by definition, allows for the elucidation of divergence between the intended behaviours prescribed by an organization's formal structures and the actual behaviours exhibited by organizational actors. Whereas the routines-as-rules perspective upholds the strict rationalistic ideal that organizational action is indistinguishable from formal rules, the behavioural perspective accounts for the fact that, when enacted, collective actions do not always conform to strict, formal institutions.

March and Simon (1958), arguing against the prevailing classical economic perspective introduce the notion of divergence to the routines discussion by positing that organizational routines (in the form of formal rules) are not defined as fixed and stable artefacts, but rather loosely coupled performance programs that allow individual and organizations to react to ever-changing environmental conditions. Organizational routines, from this perspective, are defined as both the actions arising in response to formal rules, as well as the rules themselves. With this distinction, divergence between rules and behaviours is not only accounted for but should in fact, be expected because 1) individual personal goals tend to conflict with the formal goals of an organization, and 
2) an individual's ability to grasp or directly follow every single minute nuance of a rule may be limited (Spender 2009).

Similar to other social phenomenon, and following from the wider institutional notion of loose coupling, the non-structural perspective of organizational routines embodies a duality of organizational structure and individual agency (Markus and Robey 1988). Behaviour within the context of routines is considered to be constrained by both the cognitive structures of an individual as well as the physical and social structures of the organization (Pentland and Rueter 1994). The recognition of this dual-aspect of organizational routines has manifested itself in number of semantically different, but conceptually similar descriptions of this duality, including: work recipes vs. how work is delivered (Becker et al. 2005), representation vs. realization (Cohen et al. 1996), cognitive vs. behavioural aspects (Feldman 2000), representation of routines vs. representation from routines (Hales and Tidd 2009), concrete vs. abstract behaviour (Lazaric and Denis 2005), representation vs. performation (D’Adderio 2009), adopted vs. espoused performances (Spender 2009), actual routines vs. empirical routines (lannacci and Hatzaras 2012), the designed organization vs. the lived organization (Spillane et al. 2010) and disposition vs. behaviour (Hodgson 2003).

Feldman and Pentland (2003), drawing on the works of Latour (1986) as well as Feldman (2000)'s observation on the performance of routines, argue that routines are comprised of two aspects: ostensive (structure) and performative (behaviour). The ostensive aspect, represents the cognitive interpretation of the formal structures of an 
organization, and enables and constrains activity by providing "the ideal or schematic form of a routine...the abstract generalized idea of the routine" (p. 101). The ostensive is not to be confused with the formal structure itself (i.e. a physical artefact), but rather the collective interpretations and understanding of the ideal state of the routine. In contrast, the performative aspect represents the individual one-off enactments of the routine. Performances are the "specific actions, by specific people, in specific places and at specific time" (p. 101), and represents the routine in practice. Combined, the performative provides the physical instantiation of the routine, as prescribed by the ostensive interpretation. Figure 2 reflects this dyadic perspective of organizational routines.

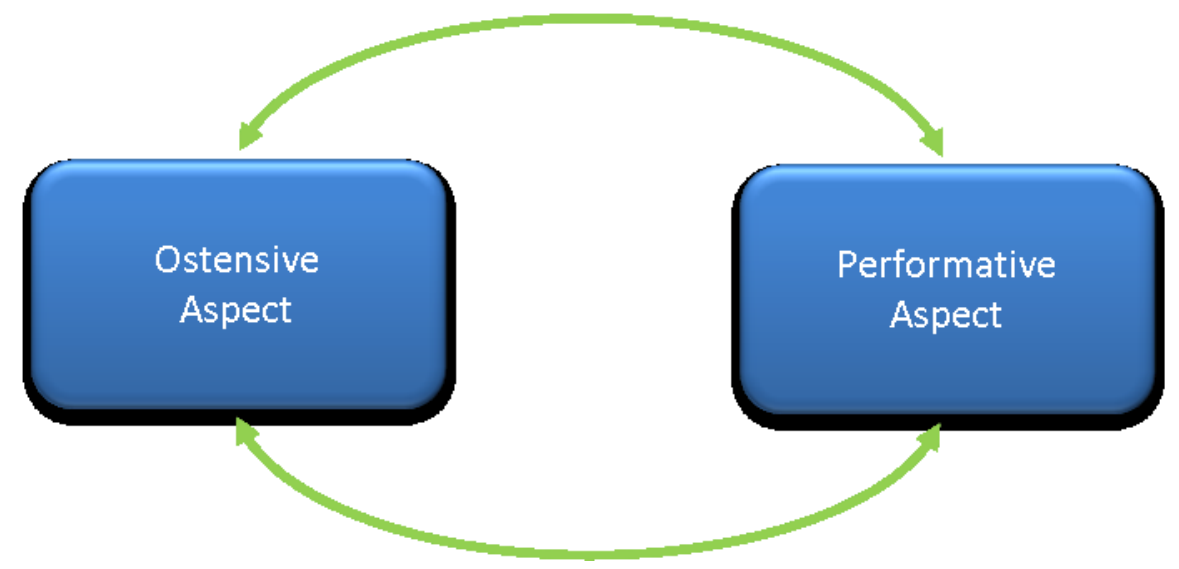

Figure 2 - Feldman and Pentland's (2005) Dyadic Representation of Routines

Although the framing of the concept of routines in this manner directly supports the notion of structure and agency, the authors take the argument further by suggesting that not only does the ostensive aspect enable and guide the performative as is commonly accepted, but the performative aspects also creates, maintains and modifies 
the ostensive. Underlying this reciprocal or generative relationship, and in fact underlying the novelty of this proposition, is the purposeful conceptualization of the ostensive aspect of the routine not as a tangible rule or artefact, but rather as an individual's cognitive interpretation and understanding of the formal structure.

This nuance significantly modifies both elements of the traditional structure-agency discussion by establishing the ostensive simultaneously as the objective elements of a routine, the ideal form of the routines and the subjective understandings of the organizational individuals, while the performative represents a novel instantiation of the ostensive understanding (Feldman and Pentland 2003). From this perspective a particular enactment of a routine is believed to influence how organizational actors interpret the formal structure guiding their behaviour, which in turn may influence how the formal structure is interpreted in future enactments. The cognitive manifestation of the formal rule therefore can change over time, even if the underlying artefact, such as a standard operating procedure, does not change. It is for this reason that organizational routines are viewed as playing a significant role in the organizational change literature (Cohen and Bacdayan 1994; Feldman 2000; Becker, Lazaric, Nelson and Winter 2005; Van Der Steen 2008). The reciprocal relationship does not mean that every single performance necessarily modifies the ostensive understanding of a routine (Howard-Grenville 2005; Pentland and Feldman 2005) as particular managerial structures may inhibit the ability for the formal aspect of routines to be modified, or a particular divergence within a performance may not warrant a modification of the ostensive structure of the routine. 
Related to the divergence between intended behaviour and actual behaviour, the ostensive-performative interpretation of routines raises two important considerations: 1) divergence between performances is likely given that ostensive interpretations can vary amongst organizational actors (Pentland and Feldman 2005), 2) divergence is not necessarily bad, as it represents a natural mechanism by which organizational routines evolve and by which individual actors seek process and organizational efficiency (Pentland and Feldman 2005; Spender 2009). Divergence from this perspective maps directly to our argument that differences between expected and actual behaviours is always present, and can be motivated by either negative or positive intentions.

The dyadic conceptualization of organizational routines allows for the recognition between the actual behaviour patterns that constitute a routine and the managerially desired patterns of behaviour (Becker, Lazaric, Nelson and Winter 2005). This position provides a framework for identifying and observing the divergence between the desired state and actual enactment of a routine by separating the structural elements of the routine from the observed behaviour. Where this conceptualization falls short, however, is that by only including two dimensions, this perspective conflates the purely structural elements of a routine with the cognitive interpretation of the formal elements in the name of theoretical parsimony. Clearly the physical artefact (i.e. a written rule, a formal process document, a checklist, a procedure manual) is distinct from an individual's interpretation of the physical artefact. By introducing the role of artefacts into the discussion of routines allows for an even deeper understanding of how work is performed as well as the sources of divergence within organizational behaviour. 


\section{Including Rules and Artefacts}

On the periphery of the behavioural routines discussion is an understanding of the role of formal artefacts and rules in the overall conceptualization of routines. Different from the technical deterministic routines-as-rules ontological position that views routines in terms of formal structures, the consideration of rules here is related to understanding the role of formal artefacts within a definition of routines grounded in the dyadic notion of structure and behaviour (D'Adderio 2008). If we accept the duality of routines to represent the cognitive interpretation of rules as well as the individual instantiations of the cognitive interpretation, then it becomes incumbent to also understand the relationship and interplay between the physical structures of an organization and these two aspects. Although a body of literature exists that examines rules and artefacts within organizations, very little research exists that attempts to understand the connection between rules, artefacts and organizational routines (Cohen et al. 1996; Grote 2004; Reynaud 2005; Weichbrodt and Grote 2010).

From a practitioner standpoint, the understanding of the role of artefacts within the context of routines is a critical component of routines theory because, in practice, managers define and implement rules and artefacts; they do not define and implement interpretation and performance. Rules and artefacts represent the levers and controls by which managers seek to shape the ostensive aspect of a routine and engender the performance in desirable ways (Feldman and Pentland 2003; Pentland and Feldman 2008). Managers have little control or influence over the cognitive interpretations of 
formal structures by individuals or over the exact behaviours of those actors enacting the formal structure. What they can control is the manner in which formal structures are defined, implemented and maintained.

In this sense, artefacts and written or formal rules are the physical manifestations of desired behaviours and outcomes as defined by organizational stakeholders. Artefacts can be tangible, explicit items such as written rules and standard operating procedures, or intangible items such workflow rules or decision rules imbedded in technology (Pentland and Feldman 2005; Pentland and Feldman 2008). Cohen et al. (1996) broaden the notion of physical structures, arguing that organizational practices, global and local language, and stories are other sources of formalized influence on the enactment of routines. Although a colloquial view of rules and artefacts would suggest that artefacts are the tangible tools for implementing non-physical rules, the two are generally used interchangeably in the organizational routine literature to represent the implemented manifestation of desired behaviours. In this sense, an artefact is a rule, and a rule is an artefact (Weichbrodt and Grote 2010). Rules, according to Weichbrodt and Grote, serve to reduce the ambiguity of carrying out a job and attempt to align behaviour to organizational objectives. Often seen as being negative and restrictive, rules are also viewed by organizational theorists as a necessary and valuable instrument of organizational conduct (Beck 2004).

In the dyadic perspective of organizational routines, Feldman and Pentland (2003) do not distinguish between the physical and cognitive level of the ostensive aspect of 
organizational routines. According to D'Adderio (2008), this is a considerable oversight given that routines as a set of collective behaviours are distributed across a complex web of artefacts and as such "neglecting to include the tools and artefacts in the study of routines dynamics can only provide at best a partial picture" (p. 770). In order to better frame empirical research, artefacts must be considered along with the ostensive and performative aspects of organizational routines (Hales and Tidd 2009). As a result, to account for this important construct, a number of authors have extended the discussion on organizational routines to include a third dimension related to artefacts and rules.

In an extensive investigation into organizational rules, Reynaud (2005) argues that rules and routines are interrelated but distinct constructs, and that routines act as a means for dealing with the incompleteness of rules. Rules will always be applied in the light of knowledge, customs, practice and context, and as such will never strictly determine or guide behaviour. Supporting the notion that a distinction must be made between the intent of a rule and its interpretation, Reynaud posits that rules are arrangements awaiting interpretation, while routines are rules already interpreted. This position is echoed by Spender (2009) who identifies behavioural routines as the local and temporary solution to the incompleteness of rules. Formal rules, according to Spender are inherently under-determining and require the ostensive aspect of organizational routines to help account for logical gaps in the artefact. Cohen and Bacdayan (1994) distinguish between standard operating procedures and routines, observing that artefacts are explicitly formulated as normative constructs and as such are inherently 
inefficient. The authors point to the fact that "working-to-rule" implies organizational actors work in a manner different than usual as evidence that rules are not one in the same as efficiency-driven organizational routines. Hales and Tidd (2009) similarly argue that artefacts are separate but connected to routines by proposing a triadic conceptualization of routines that includes the notions of representations, formal routines and performances. Finally, Weichbrodt and Grote (2010), introduces the notion of formal and informal rules into the routines discussion by delineating the use of artefacts as a means for differentiation. Informal rules, according to the authors, are represented by ostensive aspects of a routine for which a formal artefact doesn't exist. Contrastingly, formal rules, comprised of both supporting aspects (to reduce complexity) and restricting aspects (to increase control) are necessarily supported through the implementation of artefacts. For Weichbrodt and Grote, rules, on their own are abstract and only exist when instantiated by routines (a position similarly argued by D'Adderio 2008).

In Pentland and Feldman (2005), the authors address one of the conceptual limitations of their dyadic perspective by introducing artefacts in response to the observation that artefacts have been increasingly used by researchers as an empirical tool for collecting data related to the ostensive aspect of routines. A clear distinction is made by the authors that artefacts, although related to routines, sit outside the conceptual border of organizational routines. Acknowledging that artefacts may serve as a useful proxy for the ostensive aspect of a routine to facilitate empirical analysis, they strongly caution against the theoretical danger of conflating the conceptualization of the two constructs. 
Maintaining the generative nature of their system, Pentland and Feldman suggest that artefacts can simultaneously codify, prescribe and direct organizational routines at the same time as being modifiable physical manifestations of organizational routines.

Figure 3 shows Pentland and Feldman's triadic conceptualization of organizational routines.

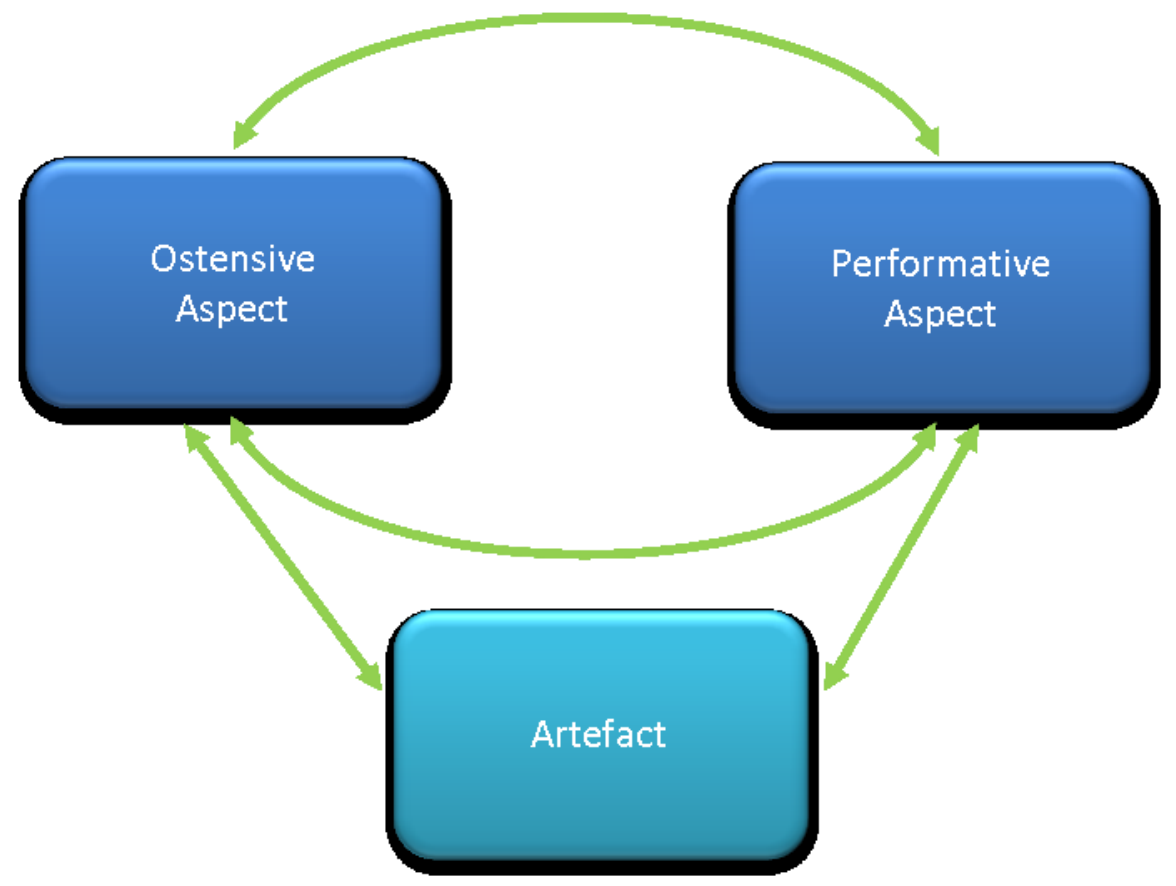

Figure 3 - The Role of Artefacts and Routines (Pentland and Feldman 2005; 2008)

The authors extend their discussion of artefacts in a later paper (Pentland and Feldman 2008), highlighting the role that artefacts play in the design and implementation of routines. Providing a stronger emphasis on the role of artefacts in influencing routines, the authors argue against solely designing routines around artefacts given the technical deterministic fallacy that they naturally embody. As a slightly different conceptualization D'Adderio (2011) collapses the notion of artefacts and Pentland and 
Feldman (2005)'s definition of the ostensive aspect of organizational routines, recognizing them as congruent notions. The author however maintains the triadic conceptualization placing artefacts and formal rules as the interface and mediator between the ostensive vision of the routine and the actual performance of the routine.

Common to all these studies is the notion that artefacts are separate and distinct from organizational routines, and that as such must be considered a third element outside of the dyadic view of routines. Most studies that address the role of artefacts recognize that although related to routines, artefacts cannot be considered to be the routine (Hales and Tidd 2009). They are, for most researchers, a closely connected, but external compliment to the conceptualization of routines. Where disagreement arises within the literature is with the direction of the relationship between artefacts and organizational routines. For Pentland and Feldman (2005) the relationship is bi-directional: artefacts influence organizational routines, but organizational routines also influence the creation and design of artefacts. In fact, according to the authors, artefacts have much less impact on organizational behaviour than would be conventionally assumed or hoped for by organizational managers who seek to employ artefacts in order to shape and guide actions. The multi-directional relationship is supported by Hales and Tidd (2009) and Lazaric (2000), the latter of whom argues that rules and routines are two sides of the same coin, with rules being defined as modes of expression abstracted from routines, and routines arising out of the necessity to address the inherent incomplete nature of rules. Contrastingly, researchers that approach the discussion from the position of understanding formal rules, tend to view the relationship as unidirectional, with 
artefacts strictly influencing the development of routines. For example, Reynaud (2005) and Weichbrodt and Grote (2010), both view the establishment of routines as a reaction and coping mechanism to the implementation of formal rules within an organization. Finally, lannacci and Hatzaras (2012) also argue that a unidirectional relationship exists, but that artefacts are simply physical instantiations of the existing ostensive aspect of a routine, on par with any other performative aspect of a routine.

\section{ORGANIZATIONAL ROUTINES AS A LEVEL OF ANALYSIS}

Although a singular definition of routines remains elusive, central to all three ontological conceptualizations is the recognition that organizational routines are not only an important theoretical position for understanding how organizations accomplish tasks but that they also represent a unique level-of-analysis for examining organizational phenomena. Nelson and Winter (1982) originally proposed using routines as a unit of analysis for capturing changes in the economy from an evolutionary perspective (Becker 2002), however within the organizational literature this position has been appropriated and adapted to an organizational context. Organizational routines represent a collection of actions that sit between individual activities and the organization as a whole (Becker et al. 2005) and provide for a processes-oriented view of an organization. This unique positioning allows researchers to address questions that they would otherwise not be able to address with a traditional level of analysis such as the individual, group or organization (Levin and Barnard 2008, Feldman and Pentland 2008). 
Organizational routines rest between the structure and action within an organization (Pentland and Rueter 1994), providing a wider lens than traditional behavioural-based theories and a narrower lens than macro-economic, group and organizational theories. The strength of this position lies in the ability to simultaneously investigate the interplay of multiple organizational actors at the same time as considering the specific contextual factors of a particular work activity (Lazaric 2011). Organizational routines allow researchers to expose and investigate change on a micro-level that would otherwise be undetectable or unexplainable at a macro-level (Becker et al. 2005; D’Adderio 2008). From this perspective, organizational routines, as a unit of analysis allow researchers to observe and capture the manner in which tasks are actually carried out and accomplished in practice (Becker, Salvatore and Zirpoli 2005; Becker and Zirpoli 2008), making organizational routines central to the methodological consideration of capabilities and organizational evolution (Lazaric 2011). For Pentland and Feldman (2005), organizational routines are a critical unit of analysis for answering many organizational science questions, and as such, provide an appropriate unit of analysis to conceptualize and study the multi-actor enactment of IT governance mechanisms within practice.

For some authors, however, there is a concern that the current dyadic and triadic conceptualizations of organizational routines are incomplete as a theoretical construct and therefore, as a level-of-analysis only allows for a cursory and partial examination of organizational phenomenon (D’Adderio 2008; Felin and Foss 2009). At the center of the majority of these critiques is the belief that the conceptualization of organizational 
routines has become too macro-oriented (Abell, Felin and Foss 2008), and as such under-represent the role of individual action and interaction (Howard-Grenville 2005). Organizational routines research has shifted from the individual to the collective and from the observable to the non-observable over time (Felin and Foss 2004), and hence the behavioural perspective of organizational routines that so overtly rejects the black box concept of routines as defined by the structural rules-based perspective, is guilty of creating a black box effect as well (Layder 1993). In most dyadic and triadic conceptualizations of routines, individuals are defined and operationalized as a set of observable and explicit behaviours and do not account for such things as individual decision making, interactions, interests, perceptions, goals, expectations (Felin and Foss 2009), motivation (Witt 2011), emotions, experience (Cohen 2007) and reaction to social norms (lannacci and Hatzaras 2012). In fact from a critical realism perspective, lannacci and Hatzaras (2012) argue that social institutions and norms are more important to understanding behaviour within routines than any rule, duty or technical artefact.

Therefore, at the heart of the argument for a more micro-perspective of organizational routines is a call to further decompose the performative aspect of the routine to better understand why organizational actors act the way they do, as well as the factors that influence their collective enactment of a routine. To fully understand organizational routines, and to better define artefacts that may be successful at guiding behaviours, we need to understand the processes by which actors exhibit behaviour. If the purpose of understanding organizational routines is to determine how to affect or change them, 
then it must be recognized that managers, in part, do this at a micro-level by influencing individual decision making (Abell, Felin and Foss 2008).

Howard-Grenville (2005), in an ethnographic study on road mapping routines motivated by the need for an improved micro perspective, extends the ostensive-performative view of routines to account for the impact of individual incentives on the collective performance of routines. In essence, this perspective positions individual influence as a mediating variable between the physical representation of an artefact and the subsequent collective behaviour of the organizational actors. Van Der Steen (2008) addresses individual influence within the context of organizational routines by employing individual scripts as representative of individual dispositions. Similarly, DeBoer and Zandberg (2010), providing a further critique of the macro hegemony of organizational routines theory, examine personality traits as a means for understanding housekeeper performance that diverges from formal standard operating procedures. Finally, Lazaric (2011) argues that methodological individualism is a necessary and essential requirement for even understanding organizational routines that span across organizational borders.

The push towards the inclusion of a micro-perspective of organizational routines does not represent an outright rejection of the current macro-perspective, but rather a call for a multi-level conceptualization of organizational routines. By integrating the two perspectives, it allows for a more powerful and encompassing examination of how work is completed within an organization (Salvato and Rerup 2011; Lazaric 2011; Vromen 
2011). Therefore, given our requirement to simultaneously understand IT governance divergence at both the individual and collective action levels, it is necessary that we adopt a multi-level perspective of organizational routines as the unit of analysis for our study. Based on this perspective, the following chapter defines and presents our conceptualization of an IT governance routine as well as the development of our conceptual framework that underlies the empirical investigation of this study. 


\section{CHAPTER 3 - CONCEPTUAL FRAMEWORK}

\section{IT GOVERNANCE MECHANISMS AND ORGANIZATIONAL ROUTINES}

The generalized concept of governance appears sporadically within the organizational routines literature, although any purposeful integration of the two concepts has largely been neglected by researchers to date (D'Adderio 2008). When governance is mentioned in relation to organizational routines, it is either tied to the rationalist notion of rules as a genotype of actions (Hales and Tidd 2009) or in terms of a representation of the formal dimension of pluralistic routine conceptualization (Cohen et al. 1996; Coriat and Dosi 1998; Burns and Scapens 2000; Becker 2004; Van Der Steen 2008). Nelson and Winter (1982) in their original conceptualization of organizational routines argue that governance represents the formal aspect of organizational performances that are ultimately connected and inseparable from the cognitive interpretation of an individual routine (Becker 2004). From this perspective, governance systems are conceived as a set of formal structures that enable, limit and influence behaviour patterns, either deliberately or not, within a particular organizational domain (Becker 2005).

Becker, Salvatore and Zirpoli (2005) and Becker and Zirpoli (2008), although not directly addressing the concept of governance, define the difference between how tasks should be carried out according to standard operating procedures and how they are actually carried out in practice as the "governance gap" of a routine. For the authors, this gap represents the observable discrepancy between the ostensive aspect of a routine and its individual performance, noting that any consistent level of divergence between these two aspects implies the existence of a structural deficiency in the overall governance 
system. Parmigiani and Howard-Grenville (2011), alluding to the notion that governance systems are made up of a set of individual mechanisms, argue that formal IT governance mechanisms can be used to align the interests and objectives of multiple parties enacting cross-organizational routines. Like Becker and Zirpoli (2008), the authors stop short of providing any further conceptual integration between governance and organizational routines despite Cohen et al. (1996) and Bevir and Rhodes' (2001) earlier assertions that pluralistic, structural conceptualizations are necessary to better understand the governance of economic organizations.

\section{Organizational Routines and Information Technology Research}

Given the lack of integration between the general notion of governance and organizational routines, it is not surprising that there has been even less crosspollination between the organizational routines literature base and that of IT governance. As one of the few works that indirectly integrates the two domains, Levin and Barnard (2008) investigate and define a core set of routines that can be found within the domain of technology management. In this study, the authors' broad definition of IT management inherently, although not overtly, encompasses many of the routines that would be associated with IT governance mechanisms; however the authors do not attempt to explicitly make this connection. Similarly, Verhoef (2007) explores the relationship between formal IT governance rules and organizational behaviours, but fails to draw explicitly on the concept of organizational routines, choosing to ground the study in the literature related to bureaucratic rules. Related to 
our subject area, the author finds that although IT governance rules can sometimes drive desired organizational behaviour, at other times they may be ineffective, or worse, drive undesired behaviours.

Despite the lack of direct connection between routines and IT governance, the conceptualization of organizational routines can be found within the wider domain of information technology research. Levin (2002) explores organizational routines effectiveness in technical road mapping routines; Howard-Grenville (2005) also focuses on a road mapping process as a means to further understand the persistence of routines; Pentland and Feldman (2008) employ an organizational routines perspective to examine reasons behind a failed software implementation; Becker, Salvatore and Zirpoli (2005) apply organizational routines as an analytical perspective in examining the product development process at an engineering center; and finally Pentland, Haerem and Hillison (2010) draw on routines as a unit of analysis for examining technologybased invoice processing routines.

We argue that organizational routines provide an ideal theoretical position with which to understand the sources of divergence within IT governance systems and mechanisms. Despite the dearth of research that directly integrates IT governance with organizational routines, a precedent has been established in the use of routines as a theoretical lens within technology-based contexts and for understanding how work is performed within an organization (Hutchins 1991; Pentland 1995; Orlikowski 2000; Pentland 2003; Becker, Salvatore and Zirpoli2005; Lazaric and Denis 2005). 
Defining IT governance practices in terms of routines allows us to elucidate and demark the various layers of activities and as such allows us to pull apart the structural and human agency contributions of a particular governance performance. Furthermore, this provides us a lens to observe and identify the areas of divergence between artefact, ostensive and performative layers of the organizational routine, something that would not be possible using an individual, group or organizational-wide level of analysis.

\section{Introducing IT governance routines}

We posit that IT governance mechanisms can be defined as a specific instantiation of the pluralistic, behavioural-based conceptualization of organizational routines. Similar to organizational routines, in a general sense, IT governance mechanisms involve the design and implementation of formal practices by management as a means to guide and control the actions and decisions undertaken by organizational actors (Peterson, Ribbers and O'Callaghan 2000; Ribbers, Peterson and Parker 2002; Weill and Woodham 2002; Peterson 2004; Van Grembergen, De Haes and Guldentops 2004; Weill and Ross 2004; Van Grembergen 2007; Huang, Zmud and Price 2010). Therefore, although IT governance mechanisms themselves are typically formal structures which would relate only to the artefact aspect of an organizational routine, the overall intent of their implementation can be characterised more widely - as the establishment of a desired set of collective behaviours. Supporting this position is Weill (2004) who states that "enterprises with effective governance have actively designed a set of IT governance mechanisms...that encourage behaviours consistent with the organization's mission, 
strategy, values, norms, and culture" (p. 3). The enactment of IT governance mechanisms cannot be considered solely in a deterministic manner since the definition of governance as a means to constrain, incent or guide behaviours necessarily privileges the notion of individual agency and freewill. The output of IT governance, therefore is an instantiation and enactment, by way of organizational actors, of the formal structures defined by the governance owners (Moldoveanu and Martin 2001; Coles, McWilliams and Sen 2001; Tu 2007; Christopher 2010). Each performance of an IT governance activity is unique and as such the divergence of performance is continually challenging and modifying the ostensive understanding of the more formal governance structure.

By combining the notion of formal IT governance mechanisms as artefacts, processes, procedures and methodologies (Peterson, Parker and Ribbers 2002; Peterson 2004; Johnstone, Huff and Hope 2006; Verhoef 2007; De Haes and Van Grembergen 2009), with a behavioural-based triadic conceptualization of routines, we define "IT governance routines" as a type of organizational routine that is specifically aligned to the overall IT governance system of an organization. From this perspective IT governance routines encompass the collective and enacted behaviours that are derived from, and in turn potentially influence, the establishment of formal IT governance mechanisms within an organization. This conceptualization respects the pragmatic position that formal IT governance mechanisms, rightly or wrongly, represent the primary levels with which organizational authorities seek to control or guide individual action. More importantly, however, by decoupling the formal and behavioural aspects 
of IT governance, it provides a pluralistic lens by which we can more thoroughly examine the performance and effectiveness of IT governance mechanisms.

The consideration of IT governance structures in terms of IT governance routines represents an alternative perspective on the phenomenon that is in line with Weichbrodt and Grote's (2010) observation that overall rules-based systems such as quality standards or governance need to be "translated" into organizational routines to be fully understood and implemented. As a contrast to the dominant structural perspective within the IT governance literature base, the conceptualization of governance structures as routines allows for an institution-based, non-structural conceptualization of the IT governance construct. By building on the pluralistic view of organizational routines in a manner that also accounts for the micro factors influencing individual action, we establish a unique conceptual lens that allows us to better understand the factors driving divergence in IT governance performances. This lens provides the foundation for the establishment of a conceptual framework that guides our empirical analysis.

\section{ORGANIZATIONAL ROUTINES AND DIVERGENCE - TOWARDS A CONCEPTUAL FRAMEWORK}

The conceptualization of IT governance routines as the means by which IT governance systems and strategies are enacted and operationalized within an organization allows for the study and understanding of the varied sources of divergence that lead to behaviours that are misaligned with those that are expected or desired. Understanding why divergence occurs within IT governance routines further allows academics and 
practitioners to better design and implement governance arrangements that support the enactment of appropriate patterns of IT-related behaviours (Cohen and Bacdayan 1994; Pentland and Feldman 2008). Through the establishment of more robust governance mechanisms, the effectiveness of holistic IT governance systems, as defined by the degree of negative divergence between desired and actual behaviours, can naturally be improved and ultimately the number of incorrect IT-related decisions and actions can be reduced. For Becker, Salvatore and Zirpoli (2005), the recognition and understanding of divergence within routines is an essential tool for governance designers:

"Being able to describe the gap between the ostensive level of organizational routines (routines-as-rules, standard operating procedures, norms) and their performative level (routines-as-behaviour, recurrent interaction patterns) prepares the ground for designing governance mechanisms that can address it. A powerful description of organizational behaviour clearly boosts the possibilities for designing interventions of organizational change and organizational development that improve the governance structures that govern organizational behaviour" (p. 25)

Accepting that divergence is inevitable in any social system, IT governance authorities are then faced with two basic options for decreasing the discrepancy between desired and actual behaviours: 1) increase direct oversight and control on all IT-related 
activities in an attempt to limit and correct any observable acts of divergence whether positive or negative, or 2) accept that divergence will always exist, and define IT governance routines in a manner that embraces the fact that routines evolve and change over time (Pentland and Feldman 2005). The first approach privileges the aspect of control within a governance structure and naturally leads to a theoretical limitation of applicability, as it would be extremely inefficient, not to mention essentially infeasible to directly oversee every action and decision undertaken within an organization. In fact, only by completely removing all traces of the human factor and controlling for all external factors can a set of actions be fully controlled (Becker 2005; Reynaud 2005; Pentland and Feldman 2008). Although depending on context, even fully-automated routines have been shown to exhibit some divergence (Pentland, Haerem and Hillison 2011).

The second approach recognizes that IT governance routines, like organizational routines are recursive and regenerative (Pentland and Feldman 2005). Routines change and evolve over time (Feldman 2000; Howard-Grenville 2005) and cannot be considered in terms of declarations of management desires, but rather as living phenomena responsive to a multitude of forces impacting performance and decision making (Pentland 2003; Feldman 2003; Becker 2004; Felin and Foss 2004; Becker et al. 2005; Pentland and Feldman 2005; Grote, Weichbrodt and Gunter 2006; Wolf 2007; Cohen 2007; D’Adderio 2008). Parmigiani and Howard-Grenville 2011; Rerup and Feldman, 2011; lannacci and Hatzaras 2012). From this perspective, formal governance structures have a limited ability to control behaviour, and in turn governance authorities have a 
limited ability to control individual divergence (Becker et al. 2005). Divergence therefore becomes a critical concern for those attempting to implement effective IT governance systems in that it provides an overt mechanism for gathering pertinent feedback on the formal structures of the system. By misunderstanding or misinterpreting the motivation driving divergence with the performance of IT governance routines, managers necessarily lose the opportunity to either reposition formal structures in response to positive divergence or strengthen and refine the same structures as a means of limiting negative divergence.

The pluralistic conceptualization of routines not only brings the notion of divergence to the forefront of the organizational routines discussion, but also motivates researchers to ask why divergence exists. At a general level, divergence between expected and desired behaviour has been explained in terms of overt resistance to managerial control and power (Keen 1981; Hirschheim and Newman 1988; Burns and Scapens 2000; HowardGrenville 2005), organizational actor self-interest (Bevir and Rhodes 2001; Becker et al. 2005; Grote, Weichbrodt and Gunter 2006), conflicting social norms and informal institutions (Lazaric 2000; Becker and Knudsen 2004; Becker, Salvatore and Zirpoli 2005; Lukka 2007; Wolf 2007; lannacci and Hatzaras 2012) and honest misinterpretation of formal mechanisms (Burns and Scapens 2000; Pentland and Feldman 2005). Commonly accepted to represent a disjoint between the ostensive aspect of a routine and the performative aspect, divergence is considered both a healthy and desired organizational phenomenon in the case were actors forego formal structures as a means for seeking out technical efficiencies (Becker et al. 2005; Pentland and Feldman 2005; Wolf 2007) 
and an undesired phenomenon in the case of purposeful sabotage of formal organizational structures (Nelson and Winter 1982). Divergence is not however, one and the same with organizational routines change, a notion which has garnered considerable interest within the organizational studies domain. Although the former has been identified as a confounding factor in the latter (Feldman 2000), divergence of performance does not have to necessarily lead to the permanent shift in the manner in which work is undertaken. Divergence can appear sporadically and inconsistently in a manner that does not give rise to the creation of informal routines or a repositioning of the formal structural elements of a routine (Becker, Salvatore and Zirpoli 2005).

In this vein, numerous studies across multiple contextual domains employ organizational routines as a unit of analysis to investigate and explain divergence between expected and observable behaviour (e.g. Cohen and Bacdayan 1994; Pentland and Rueter 1994; Feldman 2000; Howard-Grenville 2005; Lukka 2007; Van Der Steen 2008; Spillane et al. 2010; DeBoer and Zandberg 2010), however only a small set of these studies, directly or indirectly, address and isolate the specific factors that underlie the particular instances of observed divergence. The conclusions of these studies tend to be, as with most studies on the dynamics of routines in general, overly contextual (Pentland, Haerem, Hillison 2010) and insufficiently empirically validated (Becker 2001; Felin and Foss 2004; Becker, Salvatore and Zirpoli 2005; D'Adderio 2008; Becker and Zirpoli 2008; Felin and Foss 2009). As a result, the understanding of the underlying factors of organisational routines divergence is limited to a set of disconnected, incomplete and unverified propositions. At present, there exists very little, if any 
research within the organizational routines literature base that seeks to develop a holistic and empirically supported understanding of the various sources of divergence that occur within the varied aspects of organizational routines. Our study aims to provide a broad theoretical framework for understanding areas of divergence within IT governance practices through the identification and integration of the multiple sources of divergence within an IT governance routine performance.

This dearth of research has led to calls for increased consideration of the interaction between artefact, ostensive and performative aspects of routines (Becker et al. 2005; Pentland and Feldman 2005; 2008), increased conceptualization of the role of artefacts in the overall dynamics of routines (D'Adderio 2008), increased focus on individual influences and decisions as causes for divergence (Howard-Grenville 2005; Van Der Steen 2008; Felin and Foss 2009), and an increased focus on the understanding of how routines operate within practice (Pentland and Feldman 2005; Hales and Tidd 2009). In terms of understanding divergence, Pentland and Feldman (2005) argue that we need to better understand the internal structure of organizational routines, and by unpacking routines, social and behavioural sciences can be used to explain variations among ostensive and performative aspects. Similarly, Weichbrodt and Grote (2010) in their attempt to understand fluctuations between formal rules and enacted patterns of behaviour, propose that further investigation is needed to understand the specific conditions that impact and influence the performance of organizational routines. 
In response to these calls for research within the organisational routines literature, as well as to satisfy the need for a non-structural theoretical perspective of IT governance systems, we propose a conceptual framework to support our investigation into the factors leading to divergence within IT governance routines. The framework, based on the adoption of the behavioural perspective of organizational routines allows for delineation between formal structure and agency, a position that is recognized as the best approach for empirical research related to organizational routines (Pentland, Haerem, and Hillison 2010). With the empirical application of organizational routines at its infancy (Becker, Salvatore and Zirpoli 2005; Becker et al. 2005), and relatively little existing theoretical or empirical investigation into the notion of divergence (Weichbrodt and Grote 2010), the conceptual model provides a theoretical foundation for our investigation of IT governance divergence.

\section{A CONCEPTUAL FRAMEWORK FOR EXPLAINING DIVERGENCE WITHIN IT GOVERNANCE ROUTINES}

Building on the Pentland and Feldman (2008) pluralistic conceptualization of organizational routines as a generative system, we propose a conceptual framework to classify and isolate the sources of divergence within IT governance routines. The framework suggests that observable divergence between the formal IT governance mechanism and the actual collective enactment of the activities associated with the governance routine is a latent representation of a number of underlying, distinct sources of divergence. In this sense, the true divergence of an organizational routine 
can be defined as a function of all individual instances of discontinuity that occur within a particular performance.

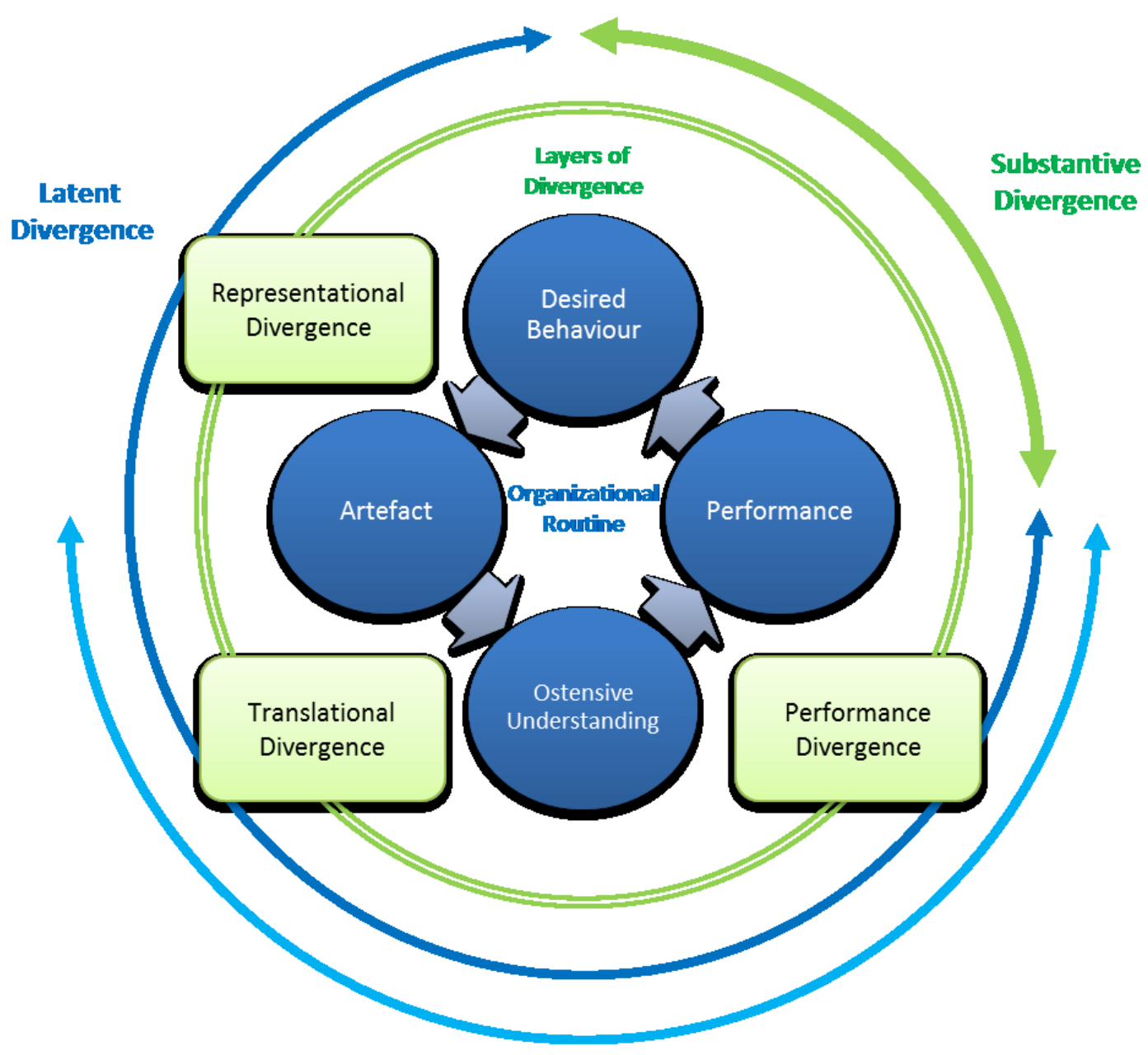

Observable Divergence

Figure 4 - A Divergence Framework for IT Governance Routines

At the center of the framework, shown in figure 4 is an appropriation of Pentland and Feldman's (2008), triadic conceptualizing of an organizational routine that has been expanded to account for the set of desired behaviours as defined by the owners of a particular IT governance routine. Although subtle, this adjustment is important, as we 
argue it is necessary to recognize the two separate, yet complimentary, dimensions of the ostensive aspect of a routine. Not only does this aspect represent the cognitive interpretation of a particular set of artefacts, it also represents the ability of organizational stakeholders to adequately prescribe their desired behaviour within an artefact. Without this distinction, the depiction of Pentland and Feldman's model could be interpreted in a manner that artefacts and formal structures adequately and completely represent the intentions of the governance owner and that any resulting divergence between artefact and understanding is due solely to the inability of actors to appropriately interpret the desired behaviours transcribed in the artefacts themselves. Pentland and Feldman's model does not allow for the consideration that formal artefacts may be systemically misaligned with the intentions of those individuals who are responsible for designing the artefacts.

The middle layer of the framework accounts for the three proposed aggregate sources of divergence within an IT governance routine: representational divergence (between desired behaviours and artefacts), translational divergence (between artefacts and ostensive understanding) and performative divergence (between ostensive understanding and performance). A fourth type of divergence, labelled substantive divergence, is the manifestation of the other three sources of divergence and represents the full difference between the behaviours as desired by the organization and those actually exhibited in the enactment of a particular IT governance routine. Following this model, if the observed performance of a routine does not match the intended behaviour, it follows that one or more of the following has occurred: an 
artefact was incorrectly positioned, the ostensive understanding was misaligned, or an individual purposefully or inadvertently swayed in their performance. As discussed previously, given that divergence can be either negative or positive, the relationship between these three types of divergence cannot be linear. Substantive divergence (SubDiv) is therefore defined not as a straight summation of underlying divergence, but rather as a non-linear function of representational divergence (RepDiv), translational divergence (TranDiv) and performative divergence (PerfDiv).$$
\text { SubDiv }=f(\text { RepDiv, TranDiv, PerfDiv })
$$

Following from this definition, the effectiveness of an individual IT governance routine can be measured by the degree of difference between the desired behaviour of the routine and the substantive divergence that occurs during a particular enactment of the routine. The overall effectiveness of an IT governance system is thus determined by the aggregate divergence found across the total number of IT governance routines within the system, with each routine subject to both positively and negatively motivated divergence. It is through the identification of the potential universe of divergence that governance designers are better able to account for and address the various sources of variation that may occur within the enactment of a governance mechanism.

As shown in the outer ring of the conceptual framework, substantive divergence does not equate to the observable divergence within a particular routine. Observable divergence occurs between artefact and performance, or more specifically the physical 
artefact of the routine and its physical manifestation. This type of divergence is considered observable, because it occurs between two observable endpoints: one representing the formal structure of the routine and the other representing the actual enactment of the routine. Missing from this equation, however, is the divergence that may exist between the intention of the governance designers and the behaviour prescribed by a physical artefact. Not directly observable, this source of divergence must also be considered when assessing the effectiveness of an IT governance routine since it relates directly to the ideal state of the mechanism. Substantive divergence therefore represents the true divergence of routine, including both the observable and unobservable sources of potential variability.

\section{Representational Divergence}

Representational divergence describes the separation that occurs between the intentions of IT governance owners or authorities and the formal structures that are implemented within an organization. Central to this type of divergence is the notion that even if the formal elements of an IT governance routine were able to be enacted in an absolute and exacting manner, the resulting performance would not, and in fact could not, reflect the exact underlying behaviours sought by the governance designers. Variation of this type represents potential "design flaws" within the IT governance routine and manifests itself through two ways: purposeful and non-purposeful divergence. 


\section{Non-Purposeful Representational Divergence}

Non-purposeful representational divergence reflects the fact that it is theoretically impossible to design a governance mechanism that exactly reflects all the thoughts and desires of IT governance designers (Reynaud 2005; Grote, Weichbrodt and Gunter 2006; Weichbrodt and Grote 2010). Unlike Pentland and Feldman's (2005; 2008) conceptualization of the ostensive perspective of routines, which is typically discussed in terms of a cognitive disconnect between the formal technical design of a routine and the understanding of the artefact by organizational participants, non-purposeful representational divergence accounts for a disconnect between the cognitive intentions of the governance designers and the physical artefacts that they implement. Although sometimes implied, this decomposition has generally not been made explicit within the literature base, where the two sides of the ostensive aspect are typically conflated to represent a single divergence between the intentions of governance designers and the resulting interpretation of organization actors.

Formal structures and artefacts are formed and implemented by organizational management and authority (Lazaric 20011) as a means for prescribing particular behaviour and controlling process variance (Pentland 2003). Designers implement formal rules and artefacts in the hope of guiding and controlling appropriate behaviour; however, any explicit instantiation of a conceptual ideal is necessarily incomplete and as such cannot ever completely prescribe a set of collective behaviours (Reynaud 2005; Weichbrodt and Grote 2010). This difficulty of representation has been long studied by 
linguists, such as Chomsky (1980) and Searle (1983). Notwithstanding the inability to account for all behavioural circumstances, artefacts as guideposts that direct and drive collective action can also be configured or conceived incorrectly. In this sense, even if it were theoretically possible for organizational actors to fully comprehend and follow a particular formal structure, the outcome would still be divergent given the fact that the artefact could never be properly designed to reinforce the underlying intentions or set of actions or decisions (Cohen et al. 1996).

It is this structural, but unconscious misalignment between desired behaviour and formal structures that conceptually defines non-purposeful representational divergence. A hypothetical example of this type of divergence would be an IT investment decision process that includes a prioritization checklist that is not aligned with the architectural direction of an organization. If the desired behaviour, as defined by senior decisionmakers is the exclusive approval of IT activities that conform to the future-state architecture of the organization, a structural misalignment would exist if the embedded logic of the prioritization checklist resulted in the recommendation of a number of nonaligned investments. In this case, any strict adherence to formal artefacts within a particular performance would lead to a distinct divergence from desired behaviours.

\section{Purposeful Representational Divergence}

The second form of representational divergence occurs when IT mechanisms and governance routines are not implemented with the intention to drive appropriate behaviour but rather as a false structural instrument for the organization. In this case, 
artefacts and formal structures are naturally unable to serve as appropriate proxies for desired behaviour because they have been intentionally misaligned by the governance owners. The explicit representation of the routine is therefore detached from the desired behaviours of the IT governance mechanism.

One reason for this type of structural misalignment is tied to the notion of legitimacy. Legitimacy is a fundamental element of neo institutional theory but has appeared less frequently within the organizational routines literature. Related to the basic duopoly between structure and agency, legitimacy was originally posited by Meyer and Rowan (1977) to describe the tendency of organizations to implement formal structures, not as a means for driving operational efficiency, but rather as a means for providing an outward appearance of control and stability. By establishing a set of industry-accepted formal structures, organizations assured stakeholders that decisions and actions were supported and undertaken in a conventional manner, even if the underlying performances do not conform to these formal structures. At the core of this purposeful deception is the notion that formal structures do not necessarily lead to efficient enactment of organizational processes (Pentland and Feldman 2005), and as such formal governance structures may be implemented, not to drive desired behaviour, but rather to provide a ceremonial appearance of control. Formal IT governance artefacts, therefore, may be designed and implemented, not in line with the underlying desired behaviours, but rather in line with the conventional approach expected by organizational audiences (Pfeffer and Salancik 1978). As an example of this type practice, MacLean and Behnam (2010) present a case where a formal compliance 
program was implemented by an organization in response to charges of deceptive sales practices. In their study, the authors clearly highlight that the compliance program was only put in place to satisfy an external illusion of control, while the offending practices were encouraged to continue. Adherence to the formal governance structure, in this case, resulted in actors moving away from the behaviours desired by the organization management committee. Overall, legitimacy is bestowed on organizations whose formal structures, values and beliefs appear congruent with socially accepted norms (Vergne 2011) even if the informal activities of the organization are considered to be illegitimate (Elsbach and Sutton 1992).

For IT governance routines, the notion of legitimacy allows for the possibility that formal IT mechanisms are designed simply to provide a level of demonstrable control and formalization of the IT decision-making environment and of the overall IT governance system (Schwarz and Hirschheim 2003). Therefore, as with non-purposeful representational divergence, the strict adherence to the formally implemented structures would necessarily lead to a divergence between action and intended behaviour (Lukka 2007). In this sense, the governance designers would actually look for divergence to provide a consistency between the true desired behaviours and the actual behaviours of the routine, despite the overlay of a fallacious formal structure.

A more nefarious example of purposeful representational divergence that lies outside the realm of interest for this study arises when organizational authorities intentionally design misaligned formal structures as a means for preserving self-interest. In these 
cases, the formal structures allow for a distancing between senior officials and the invocation of decisions through a governance mechanism, because the more formal the legitimizing structure, the more "under control" an organization would appear, and the less culpable becomes the organizational decision-makers (Scott 2004; Lipson 2006). IT failures, in this instance, despite the direct responsibility of organizational decisionmakers can be attributed to uncontrollable or unforeseen external factors, rather than on poor organizational management. This also allows organizational authorities to push their personal agendas under the guise of a ceremonial formal structure (Becker 2004).

\section{Translational Divergence}

As the second dimension of the ostensive understanding of routines, translational divergence accounts for the discrepancies between the behaviours inscribed on formal artefacts and the interpretation of those formal artefacts by the enactors of a routine. Holding constant any conscious behavioural divergence by actors, translational divergence occurs at a cognitive level where an unconscious misinterpretation of an appropriately defined artefact leads to the instantiation of a misaligned performance (Feldman 2000; Lazaric 2000; Becker et al. 2005; Lazaric and Denis 2005; Lazaric and Raybaut 2005; Feldman and Pentland 2008). While artefact-embedded representations of rules and formal structures are introduced to design and manage routines, their actual interpretations can sometimes escape the original intentions of the governance designer (D'Adderio 2008), and as such, although artefacts can serve as a proxy for the ostensive aspect of routine, they cannot be viewed as one in the same, as a result of 
translational divergence (Feldman and Pentland 2008). Figure 5 distinguishes between the two dimensions of the ostensive aspect of routines.

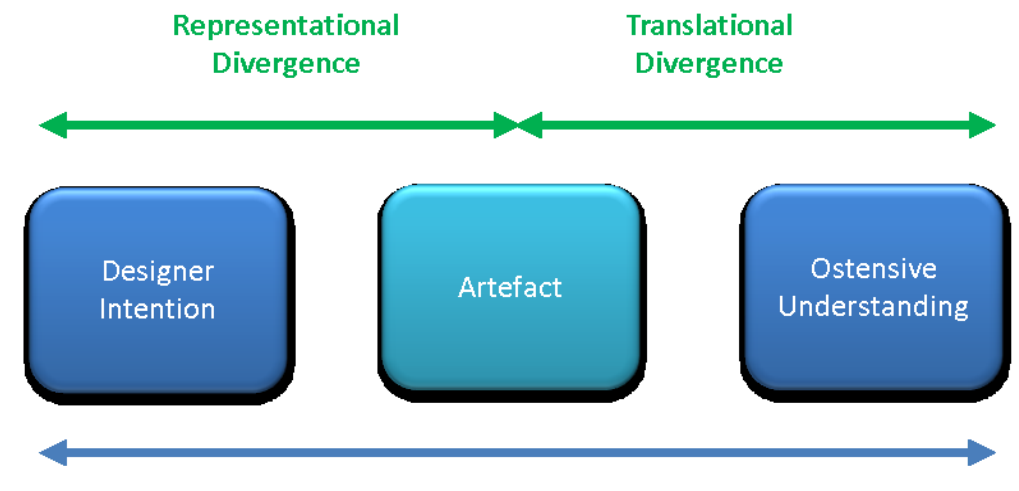

Ostensive Divergence - Pentland and Feldman $(2005 ; 2008)$

Figure 5 - Representational and Translational Divergence

Similar to non-purposeful representational divergence, the underlying source of translational divergence lies in the fact that formal structures cannot be designed to reflect all possible contextual permutations and complexities within a social system, and as such, artefacts do not necessarily act as expected in encoding or cuing routines (Parmigiani and Howard-Grenville 2011). Formal structures, in the form of rules are unable to exactly specify the actions and decisions of actors (Weichbrodt and Grote 2010) and must be applied or implemented in the context of individual knowledge, customs, practice and context (Reynaud 2005). Because the prescribed behaviour is incomplete, organizational actors must interpret and fill in the blanks during each enactment of the routine, resulting in varied cognitive understandings of the routine not only between various actors within a routine, but also within various performances of the routines (Pentland and Feldman 2007). Additionally, when diverse interpretations 
occur between a number of actants within a performance, it is often the individual with more power that controls the collective interpretation of the routine (Feldman and Pentland 2003; Howard-Grenville 2005; Weichbrodt and Grote 2010)

The collective interpretation of insufficiently ascribed artefacts leads to an interesting situation within most organizations where consistently and universally accepted interpretations of formal structures can become unofficial and potentially misaligned proxies for the formal aspect of the organizational routines (Beck 2004). When this happens, the enactment of the IT governance routine becomes driven by the serendipitous collective interpretation of the routine and is essentially detached from the intended behaviours as prescribed by governance designers. Once this happens, the informal routine and subsequent performance becomes no longer governed by a formally-implemented artefact (Weichbrodt and Grote 2010). This unofficial representation of the routine, once established and integrated into the fabric of an organization, tends to persist until the artefact is adjusted or the interpretation is directly addressed and eliminated by organizational management (Reynaud 2005). It is the presence of translational divergence (and to a lesser extent non-purposeful relational divergence) that leads Pentland and Feldman (2008) to argue against artefactcentered assumptions in designing organizational routines. The myopic focus on artefact manipulation is considered to be largely misguided for two reasons: 1 ) there is limited evidence that artefacts have a significant and deterministic impact on the enactment of organizational routines and in fact, play a limited role in influencing 
routines (Bevir and Rhodes 2001; Becker et al. 2005; Hales and Tidd 2009), and 2) it distracts designers from concentrating on influencing and directing organizational patterns of action, since "overestimating the importance of the ostensive leads managers to underestimate the importance of the adjustments and improvisations that people undertake to make the routine work" (Feldman and Pentland 2003, p. 103). For IT governance designers, this is a critical observation as it underlines the fact that simply redesigning IT governance mechanisms may not make an IT governance system more effective. Desired behaviours, therefore, cannot be unilaterally imposed on an organization simply through the implementation of formal structures. Designers must focus on influencing behaviours, not tinkering with artefacts.

\section{Performative Divergence}

The final source of divergence within IT governance routines occurs between the individual's cognitive understanding of the formal structure and their decision to behave in an alternative manner. Performative divergence therefore privileges the notion of agency and occurs when an organization actor fully understands the way they should act as prescribed by a formal structure, but either is unable or purposefully chooses to act differently (Burns and Scapens 2000). Performance divergence is the most visible form of divergence and has been observed in many organizations (Dougherty 1992; Adler et al. 1999; Feldman 2000; Becker, Salvatore and Zirpoli 2005; Howard-Grenville 2005); although oftentimes the explanation is conflated with translational divergence. The shift in performance arising from an actor's wilful decision to stray from their 
understanding of a particular routine can be as subtle as a minor adjustment to the cadence of a routine, or as significant as a full rejection and reluctance to comply with any of the desired behaviours of a routine (Pentland and Feldman 2005).

Becker, Salvatore and Zirpoli (2005) refer the disconnect between the ostensive level of organizational routines and their performance levels as a "governance gap" that if fully understood "boosts the possibilities for designing interventions of organizational change and organizational development that improve the governance structures that govern organizational behaviour" (p. 25). Performance divergence, therefore, can act as a feedback loop for governance designers as to the effectiveness and appropriateness of their formal IT governance mechanisms. In fact, this connotation is central to Pentland and Feldman's $(2005 ; 2008)$ conceptualization of organizational routines as a generative system and is explicitly indicated by the bi-directional arrows connecting the ostensive and performative aspects in their depiction of the two aspects. As the observable manifestation of an IT governance routine, the performance aspect can be clearly delineated from the behaviours prescribed by a formal rule or structure; however, the degree to which the divergence is the result of an ostensive misunderstanding versus a purposeful departure of behaviour is significantly less overt. In practice, it is often difficult to untangle the technological, social and individual aspects of organizational routines in order to understand the dynamics underlying performance divergence (Becker et al. 2005). As a means to better understand these dynamics, performance divergence is conceptualized in terms of four primary types of divergence: corrective, repudiation, capabilities and conflict divergence. 


\section{Corrective Performative Divergence}

Corrective performative divergence occurs when individual actors consciously sway from their ostensive understanding of a routine in order to correct or improve a set of perceived deficiencies in the formal representation of an IT governance routine. Most often, this type of performance divergence arises in response to the presence of purposeful or non-purposeful representational divergence that has created a latent disconnect between the desired behaviours of the routine and the formally implemented artefacts. When organizational actors believe that the structural elements of a routine are purely ceremonial or have been inadvertently misaligned, they may choose to divert from the former structure as a means for better aligning to what they believe to be the intended purpose of the routine as envisioned by governance designers. In this sense corrective performance divergence, representing divergence between the ostensive understanding of a routine and enacted behaviour, may actually reduce the overall amount of substantive divergence in a routine, by balancing out and correcting for the existence of representational divergence.

Corrective performance divergence is further evidence that some types of divergence have a positive impact on the effectiveness of routines and on the performance of an organization as a whole, and directly reinforces the proposition that divergence cannot always be considered in a negative light (Weichbrodt and Grote 2010). While the rulesbased literature would argue that divergence is all negative and results from individuals attempting to circumvent the power and control embedded in formal structures, the 
behavioural-based literature recognizes that divergence often results from individual actors looking to fill in holes in the formal rules, adapt to external or unforeseen environmental shocks or improve the effectiveness and efficiency of performances (Pentland and Feldman 2005; Lazaric and Denis 2005; Wolf 2007; Weichbrodt and Grote 2010). This is not to say that corrective divergence only occurs in terms of overt ceremonial or misaligned formal structures. Through the repetitive enactment of routines, organizational actors are able to detect new opportunities to improve organizational performance and seek to make those adjustments in subsequent instantiations of the routine (Wolf 2007). Actors continually tinker and seek refinement of routines (Nelson and Winter 1982) and as such this introduces the notion of temporal delay in divergence. Over time, these minor adjustments move the enacted behaviours, and thus the manifestation of the routine, further away from those prescribed by the ostensive aspect of the routine (Feldman 2000; Pentland 2003), however, the impact of divergence may not be noticed immediately. Whether accounting for misaligned artefacts or simply a natural shift in the enactment of routines, the common rationale behind this type of divergence is a motivation to better align the performance of a routine with the intended behaviours.

It is precisely because of corrective divergence, that substantive divergence was defined earlier as a function of the underlying sources of divergence, rather than a net summation of those sources. Given the offsetting nature of the various sources of divergence, it is theoretically possible to have a minimal difference between the desired and actual behaviours of a particular routine, even when significant representational 
and performative divergence exists. It is also precisely because of corrective divergence that a command and control governance system that is strictly based on limiting variance within the performance of an IT governance routine is argued here to be significantly susceptible to representational divergence and is generally ineffective at supporting organizational efficiency. Cohen and Bacdayan (1994) provide a clever support to this position by noting that when organizational actors "work-to-rule", it implies that work will be undertaken in a less efficient manner.

\section{Repudiation Performative Divergence}

While corrective performance divergence represents an actor's conscious decision to divert from their ostensive understanding of an IT governance routine in order to improve the particular routine, repudiation performance divergence represents the exact opposite behaviour. In this type of divergence, actors purposefully divert their behaviour as a means for wilfully rejecting the managerial control embedded within the formal structure of the routine. Although scarcely addressed within the organizational routines literature, resistance has been studied within the IT domain (Keen 1981; Hirschheim and Newman 1988). Reasons for this type of extreme divergence range from outright organizational sabotage (Nelson and Winter 1982) to a general resistance to following rules (Burns and Scapens 2000), to a denunciation of the bureaucratic power imbalance that is encapsulated within the organizational routine (Emirbayer and Mische 1998). The latter is related to Nelson and Winter's (1982) conceptualization of 
organizational routines as a "truce" designed to broker organizational conflict and power discrepancies.

Feldman and Pentland (2003) cite the positions of Braverman (1974) and Burawoy (1979) that the creation and enforcement of organizational routines can be viewed as a primary mechanism for the domination of labour by management. This view is clearly grounded in the ontological perspective of routines as rules and suggests that routines are instruments of managerial control used to dictate the actions and behaviours of individual actors. Therefore, from a critical theory standpoint, routines represent the inherent conflict that exists between management and labour within organizations: the ostensive aspect of a routine representing the power of management, and the performative aspect representing the power of labour (Feldman and Pentland 2003).

The notion of power thus becomes a construct of interest for IT governance routines, when considering performance divergence (Howard-Grenville 2005; Lazaric 2011). If actors perceive that the formal structures related to the routine are designed specifically to eliminate all sources of agency, the resulting performance may represent a complete rejection of the formal structure and purposefully divert behaviour away from the understood purpose of the routine. For IT governance designers, this means designing governance structures that balance the organization's desire to guide and direct behaviour while respecting an individual's free will (Lazaric 2011). 


\section{Capabilities Performative Divergence}

Capabilities Performative Divergence sits between the extremes of corrective and repudiation divergence, and accounts for the scenario where organizational actors are ready and willing to follow the behaviour prescribed by the IT governance routine but do not have the appropriate skillset or organizational support to adequately perform the required activities without divergence. The notion of IT governance capabilities was first addressed by Peterson (2000), who defined IT governance capabilities as the maturation of process, structures and stakeholder relationships and their subsequent ability to influence IT activities. The author later refined this position in Peterson, Parker and Ribbers (2002), arguing that IT governance effectiveness is predicated upon two core elements: the methodological comprehensiveness of the IT governance system and the social capabilities of IT governance stakeholders. Extrapolating from this perspective, IT governance can only be as effective as the individual actors' ability, as well as an organization's process maturity, to properly enact the IT activity in a manner that is true to the defined desired behaviour. Enactors of routines therefore, must not only have the desire, but also the power and technical or social capability, to enact the routine in a manner consistent with the desired behaviours (Levin 2002). Capabilities performative divergence is therefore defined here as divergence that occurs when desired behaviours are clearly understood by a willing set of individual actors, however, gaps in organizational or individual capabilities limits (or completely restricts) the ability to adequately enact these behaviours. 
The direct relationship between capability maturity and IT governance or organizational routines performance is sparsely discussed within the two literature bases (Debreceny and Gray 2013). As one example, Prasad, Heales and Green (2010) explore the relationship between IT-related capabilities and IT governance, finding a correlation between the effectiveness of IT steering committees (as a proxy for IT governance effectiveness) and the maturation level of a number of IT capabilities, namely top management commitment, shared organizational knowledge and flexible IT Infrastructures. The direction of this relationship however, based on the authors' structural model is only tested one way, leading to the conclusion that "our results indicate that effective IT steering committees indeed helps in developing and sustaining firm's IT-related management and infrastructure capabilities" (p. 226). The authors do not overtly consider the other relational direction: that the maturation of IT capabilities might actually improve the effectiveness of IT governance systems. This study is criticized for confusing causation and correlation in the attempt to link the larger concepts of IT governance to IT firm performance (Kobelsky 2010; Paquette 2010), an argument that also holds true for the relationship between IT governance and IT-related capabilities. Contrastingly, Debreceny and Gray (2013) adopt a similar approach in their examination of IT processes maturity, as a measure of IT capability, and its effect on IT governance. The authors, however, allow for a circular relationship between the two constructs and conclude that "IT capability in general and IT process maturity in particular is an important component of IT governance" (p. 184). 


\section{Conflict Performative Divergence}

The final source of performative divergence encompasses all other factors that lead individuals to stray from their ostensive understanding of an organizational routine. Figure 6 presents the four types of performative divergence as representational positions along a continuum of underlying intentions of behaviour. Conflict-based performative variation is therefore not motivated by overtly positive or negative intentions, but rather recognizes that organizational actor behaviours and decisions are often made in the context of numerous competitive influences. These types of divergence are labelled as "neutral", since they are not overtly driven by either a positive or negative motivation, although their outcome may result in either a positive or negative divergence on the overall IT governance system. Although the resulting behaviour of these actions may resemble those driven by corrective or repudiation forces, the underlying rationale for those behaviours are not the same.

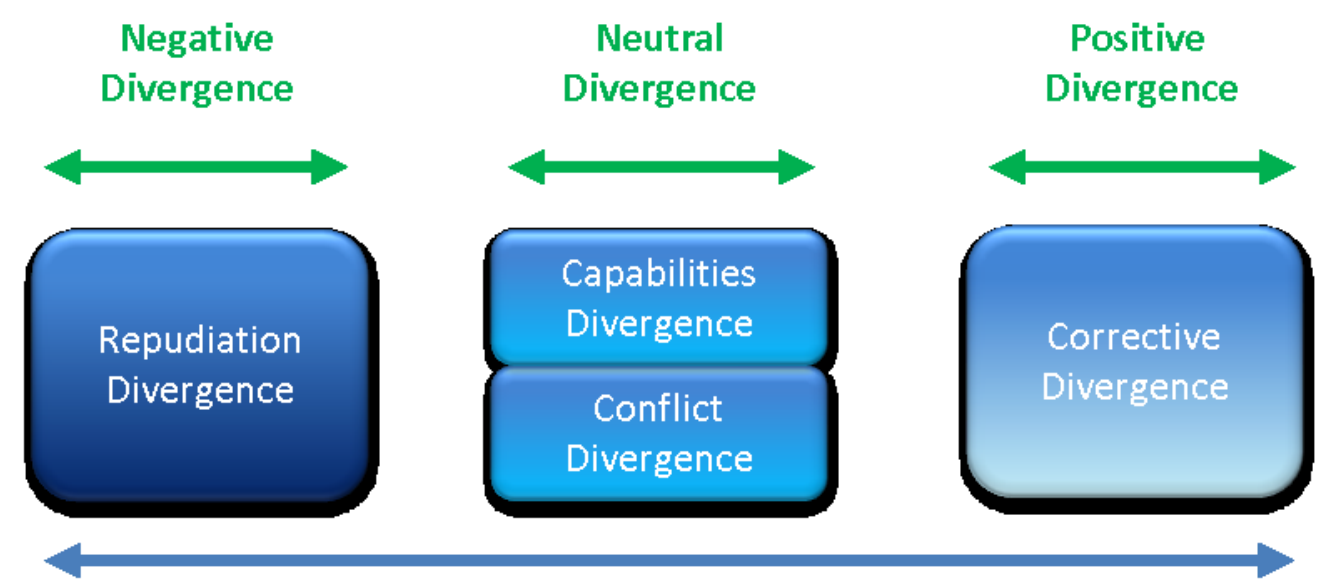

Performative Divergence intention 


\section{Figure 6 - The continuum of Performative Divergence}

Within the organizational routines literature, a number of relatively recent studies have attempted to identify and understand the various forces that drive and motivate individuals to enact performances that diverge from their ostensive understanding of the underlying routine. Rationales for performance divergence include items such as misalignment with individual incentive models (Markus and Keil 1994; Markus and Benjamin 1997; Bevir and Rhodes 2001; Becker 2005; Becker et al. 2005; Grote, Weichbrodt and Gunter 2006; Pentland and Feldman 2008; Witt 2011), adherence to dominant social, cultural and relational norms (Bevir and Rhodes 2001; Grote, Weichbrodt and Gunter 2006; Lukka 2007; Spillane et al. 2010), preservation of selfinterest (Howard-Grenville 2005; Weichbrodt and Grote 2010), reliance on organizational experience (Edmondson et al. 2001; Feldman 2003; Howard-Grenville 2005; Pentland, Haerem and Hillison 2011), lack of interpersonal trust between actors or conflicting personality traits (Levin 2001; DeBoer and Zandberg 2010) or improvisation to address external contextual shocks (Feldman and Pentland 2003; Wolf 2007).

As an example of this type of research, Howard-Grenville (2005), in a nine-month ethnographic study of organizational routine flexibility, examined a technology road mapping routine within a single high-tech manufacturing organization. Arguing that Feldman and Pentland's (2003; 2005) dyadic conceptualization of organizational routines did not account for how individuals' intentions influence performance, she posits a conceptual model that places the individual intentions of each actor within the 
routine as a set of mediating constructs that sit between the ostensive aspect of a routine and the enacted performance. The author concluded that agency does matter to the performance of routines and that each individual actor, while potentially drawing on past experience to positively alter future performances, may also use particular enactments of a routine to advance both personal and organizational goals. The relative divergence of the collective effort is then dictated by the respective power held by each of the actors involved in the enactment of the routine. The study, overall, stresses the need to better understand the micro-dynamics of organizational routines and the author ultimately argues that the individual aspect of routines needs to be further examined (Abell, Felin and Foss 2008; D’Adderio 2008; Salvato and Rerup 2011; Vromen 2011).

Burns and Scapens (2000) and Lukka (2007) look to understand the role of informal norms within performance divergence and suggest a four-dimensional conceptualization of organizational routines that includes rules, routines, institutions and performances as the primary aspects. Underlying the model is the belief that a set of taken-for-granted assumptions and social/environmental norms impact and shape organizational action. Spillane et al. (2010) adopt a similar model to study the impact of external pressures facing school administrators as a driver for decoupling actual behaviour from that prescribed by formal structures. The authors conclude that not only does individual behaviour divert from legitimizing formal structures, but it also diverts from the underlying efficiency-driven instantiation of the routine due to the latent social and relational institutional norms. The findings echoed a much earlier study of Obega PLC 
by Scapens and Roberts (1993) that found that formal rules were not consistently or strictly followed because they were inherently in contrast with the ingrained institutional norms of the organization. Finally, in a study of invoice processing routines, Pentland, Haerem and Hillison (2011) find that little divergence occurs in organizational routines as a result from external shocks, but rather it is the individual experiences of organizational actors that significantly cause changes in subsequent performances of a routine.

While some research has begun to investigate the notion of conflict performative divergence, an overall understanding of this important aspect of organizational routines remains in its infancy. Studies of this nature are typically exploratory and contextuallybased, with little cumulative understanding between the various empirical studies (Becker, Salvatore and Zirpoli 2005). Concepts are discussed in general terms (such as individual incentives) but little research has yet to be undertaken that explicitly decomposes and explores the nature of each of these generalized concepts. This dearth of research has led to Weichbrodt and Grote (2010) noting that significant research has been undertaken on the overall conceptualization of routines but arguing that to fully understand the underlying dynamics of organizational routines, further study is needed to explore the drivers and rationale behind individual and collective performance divergence.

Overall, our proposed conceptual framework identifies three core sources of divergence within IT governance routines, including the definition of substantive divergence as a 
latent representation of the true divergence within a particular instantiation of routine. Embedded in this conceptualization is the recognition that divergence can be both positive and negative, measured by the motivation underlying the movement towards or away from the tacit desired behaviours envisioned by governance owners and designers and that multiple layers of divergence can occur and may even conflict within a single governance performance. We argue that an understanding of these sources of divergence within individual mechanisms is central to understanding IT governance effectiveness at a holistic level, and as such, we propose to further refine this conceptual frame through a multi-case exploratory approach. The next chapter provides an overview of the methodology and research approach that we employ in our study as a means for gathering and analysis empirical examples of IT governance divergence within two government organizations. 


\section{CHAPTER 4 - METHODOLOGY AND RESEARCH DESIGN}

\section{RESEARCH APPROACH AND OBJECTIVE}

The overall objective of this study is to broaden and strengthen an understanding of IT governance effectiveness by exploring and elucidating the sources of divergence that occur within individual IT governance routines. Not surprisingly, given the dearth of existing empirical research related to IT governance in practice, a general understanding of divergence and more specifically an understanding of the factors that influence or impact divergence has yet to be fully studied or established within the literature base. Based on our extensive review, an existing cumulative base of operationalized constructs and relationships, or in other words, a theoretical articulation of divergence does not currently exist. As such a proposed framework does not appear to be available to be leveraged or tested in support of our research objective.

With this recognition, the overarching approach and contribution of our study is to establish a theoretical conceptualization of IT governance divergence. By adopting an exploratory and inductive approach, we draw from observation in order to establish a theoretical foundation upon which further empirical study can be undertaken and upon which further propositions can be developed and tested. In the absence of an existing theoretical base for understanding IT governance divergence, we seek to build theory within the scope of our research.

The primary output of this study, is the development of a "theory for explaining" IT governance divergence where the end product of the theorizing process is in fact the 
proposal of a theory itself (Gregor 2006). Through the inductive identification of patterns and categories of observations within two exploratory case studies, we identify and propose a set of constructs and initial propositions as means for establishing the basic building blocks of the theorizing process (Richards and Morse 2007; Corbin and Strauss 2008). The resulting outcome provides a contribution to the initial stage of knowledge accrual (Yin 1984; Benbasat, Goldstein and Mead 1987) by positing a novel theoretical conceptualization that is simultaneously original and interesting, as well useful in its application (Corley and Gioia 2011).

\section{Exploratory Research Design}

We employ an exploratory case design to facilitate the collection and analysis of empirical data in support of our objective to inductively build a theoretical base upon which further study of divergence and IT governance effectiveness can be undertaken. Exploratory case studies are considered an appropriate design for identifying and specifying a theoretical set of research questions, constructs, propositions or hypotheses (Yin 1984; Benbasat, Goldstein and Mead 1987; Yin 2003; Pare 2004; Gregor 2006) when addressing phenomenon where 1) little is currently known about the phenomenon, 2) the current perspectives are considered inadequate due to insufficient empirical substantiation, and 3) there is a conflict or lack of connection between prevailing conceptual understandings (Eisenhardt 1989; Broadbent and Weill 1993;

Darke et al. 1998). 
All three of these criteria have been shown to exist for the study of IT governance divergence as evidenced by the atheoretical predisposition of the normative and prescription-oriented roots of the IT governance literature (Peterson 2001; Jacobson 2009). In fact, through our literature review, it was very difficult to identify any studies within the current literature base that explicitly posit or test a set of theoretical constructs and relationships related to IT governance divergence.

Typically, exploratory research can be performed without any preconceived theoretical conceptualizations as a means to limit bias and allow for unconstrained observation (Eisenhardt 1989; Dube and Pare 2003; Pare 2004). However, we have chosen to adopt an a priori conceptual framework to provide context and guidance to our initial investigation. This approach, seen as an equally valid exploratory methodology (Eisenhardt 1989; Dube and Pare 2003) better supports the development of specified constructs (Eisenhardt 1989) while reducing the superfluous descriptive narrative of case studies (Yin 1981). The conceptual model proposed in chapter 3, grounded in existing literature, represents our "first cut"" at identifying a set of explicit theoretical statements that can be later modified, adopted and validated based on the findings of our empirical investigation (Miles and Huberman 1994, pp 91).

During our qualitative coding analysis, the conceptual framework for IT governance routines is employed as a classification and encoding taxonomy to guide and support the empirical investigation of specific divergence constructs. The three types of divergence (representational, translational and performance) identified within the 
framework represent the first level of constructs that are used to support the identification and elucidation of second-order constructs central to the development of an explanatory or predictive theoretical model (Lee 1985; Gregor 2006). Our conceptual framework therefore provides a starting point for the identification of internally valid and clear (Suddaby 2010) constructs related to sources of divergence found within IT governance routines, while also serving to inform the semi-structured interview protocols and the initial unstructured data coding schema.

\section{Multiple Case Study Approach}

Data is gathered through the in-depth study of two case organizations. The case approach permits us to capture a rich, multi-actor, narrative-based understanding (Pentland and Feldman 2008) of the second-order constructs that lead to the presence of divergence within an instantiation of an IT governance routine. The use of case studies is well-grounded in both the IT governance and organizational routines literature bases.

In general, a case study approach allows for the examination of a phenomenon in its natural environment and is an appropriate methodological tool for investigating phenomena for which an existing body of research is either insufficient or primarily anecdotal (Yin 1994; Pare 2004). Case studies are preferable to standard experimental or survey designs when the number of variables exceeds the number of observations to be made as is the situation when investigating most socially-embedded activities (Yin 
1981; Benbasat, Goldstein and Mead 1987; Lee 1989; Yin 1994; Miles and Huberman 1994).

It is precisely for these reasons that case studies have been widely employed by researchers within both the IT governance and organizational routines domains as a means for understanding the contextually-dependant behaviour of their respective research foci. Within the organizational routines literature, while the routines-as-rules conceptualization has lent itself to variety of quantitative and laboratory-based research approaches (Cohen and Bacdayan 1994; Felin and Foss 2004; Lazaric and Raybaut 2005; Cohen et al. 1996), the behavioural conceptualization of organizational routines has been considerably more difficult to operationalize and study due to the tacit and dynamic nature of individual and collective action and decision-making (Cohen et al. 1996; Feldman and Pentland 2003; Reynaud 2005; Feldman and Pentland 2008). This haziness of construct operationalization (Hodgson 2004), along with the inherent inseparability of organizational routines from the complex organizational environment in which they are enacted (Pentland and Feldman 2005), has naturally lent itself to the rich contextual analysis provided by a case study approach (Lee 1985; Benbasat, Goldstein, and Mead 1987; Bourgeois and Eisenhardt 1988; Dyer and Wilkins 1991; Eisenhardt and Graebner 2007).

As examples of this type of approach within the organizational routines literature, Becker, Salvatore and Zirpoli (2005) adopted a longitudinal case study for their exploratory study into the use of organizational routines as an analytical perspective in 
the analysis of a product development process at an engineering center. Lazaric and Denis (2005) employed a case study in order to investigate how the cognitive aspect of an organizational routine evolves with the introduction of a new ISO standard within a meat processing firm. Other examples of the use of case studies to explore organizational routines can be found in Feldman (2000), Levin (2002), Howard-Grenville (2005), Becker, Salvatore and Zirpoli (2005), Lukka (2007), D’Adderio (2008), Van Der Steen (2008), Hales and Tidd (2009), Spillane et al. (2010), DeBoer and Zandberg (2010), Pentland, Haerem, Hillison (2010), and Rerup and Feldman (2011).

The case approach is also widely accepted as a valid research strategy within the broader information systems literature base (Benbasat, et al. 1987; Lee 1989; Orlikowski and Baroudi 1991; Alavi and Carlson 1992; Klein and Myers 1999), and as such, is also a dominant research approach within the IT governance literature. This should not be overly surprising given the prominence of the normative and prescriptive positions adopted by most researchers within this domain. Examples of case study-based analysis addressing IT governance can be found in Brown (1997), Sambamurthy and Zmud (1999), Peterson (2001), Peterson, Parker and Ribbers (2002), Schwarz and Hirschheim (2003), Weill and Ross (2004), Chin, Brown and Hu (2004), De Haes and Van Grembergen (2005), Ali and Green (2006), Johnstone, Huff and Hope (2006), De Haes and Van Grembergen (2006), Larsen, Pedersen and Andersen (2006), Bowen, Cheung and Rohde (2007),e, Liang and Boulton (2008), De Haes and Van Grembergen (2009), Willson and Pollard (2009), Ko and Fink (2010), Othman et al. (2011), Chong and Tan (2012), Debreceny and Gray (2013), Williams and Karahanna (2013) among others. 
For our study, we specifically adopt a multiple case research design as means for providing us with broader access to empirical observations. Given the specificity of our research domain, multiple cases were deemed necessary to ensure that we could collect sufficient data to support the development of a valid theoretical model.

The use of a multi-case approach has been argued to be valuable for highlighting repeatable phenomena (Leonard-Barton 1990; Zivkovic 2012) and is widely considered to be more appropriate than a single case approach for developing robust and reliable theoretical constructs (Bourgeois and Eisenhardt 1988; Yin 1994; Dube and Pare 2003). Within this approach, constructs and relationships can be more precisely delineated since accurate definitions and an appropriate level of construct abstraction is better achieved through the use of multiple cases (Eisenhardt and Graebner 2007). By observing the same phenomenon across multiple contextual environments, the multicase approach increases the internal validity of derived constructs and relationships resulting from the analysis of data by allowing for recursive pattern matching between theory and the multiple sets of empirical evidence (Campbell 1975, Bourgeois and Eisenhardt 1988; Pare 2004; Gibbert, Ruigrok, and Wicki 2008). The result is a set of theoretical assumptions that are defensible, plausible, based on sound logical and causal reasoning and deeply grounded in varied empirical evidence (Eisenhardt and Graebner 2007; Gibbert, Ruigrok, and Wicki 2008).

Although a multi-case approach is often used a means for maintaining the external validity of research and for ensuring that findings are generalizable to other 
organizations (Yin 1981; 1994; 2003; Gibbert, Ruigrok and Wicki 2008), given the theorybuilding objective of this paper, we employ a multi-case approach as a means to support the generalization from empirical data to theory. This approach, referred to as contextual generalizability (Tsang and Williams 2012), analytical generalization (Yin 1984, 1994), and empirical statement to theory (ET) generalization (Lee and Baskerville 2003), represents an acceptable response to generalization within case-based qualitative studies within the IT domain (Walsham 1995; Pare and Elam 1997; Klein and Myer 1999).

\section{Selection of Cases and Routines}

\section{Selection of Case Studies for Empirical Analysis}

The two cases within this study were selected based on theoretical and convenience sampling, chosen for their theoretical relevance and accessibility, rather than their statistical appropriateness (Eisenhardt 1989; Weill and Olson 1989; Chan and Huff 1993). Theoretical sampling was employed because it is generally deemed more appropriate than random or stratified sampling when the objective of a study is to develop theory rather than test theory (Eisenhardt and Graebner 2007), and because the organizational sponsors were willing and interested in supporting significant researcher access to their organizations. As a means for ensuring a literal replication between cases that leads to predicting the same results (Yin 1981; Pare 2004) and for controlling the influence of extraneous and confounding factors (Bourgeois and Eisenhardt 1988), both cases have been chosen from the same industry vertical and 
were predetermined to provide suitable environments for investigating IT governance divergence (i.e. The organization has an IT governance system in place, the IT governance mechanisms have been operationalized, and key stakeholders have an interest in understanding how the system is functioning). In other words, the cases were selected because of their homogeneity, because divergence should be "transparently observable" (Pettigrew 1988; Eisenhardt 1989), and because both organizations were willing to support the research effort.

Both cases are municipal governments within the province of Ontario. The public sector provides an interesting research bed for IT governance given the magnitude of investment in IT made by government departments, the public attention received by IT failures or mismanagement, a typically high level of IT governance adoption and oversight based on the need to be transparent and accountable, and the fact that in most public sector organizations, individuals that enact the IT governance mechanisms are not influenced by the same profit-maximizing behaviour as would be found in the private sector (Pang 2014). Municipal government environments provide a further advantage in that typically their IT budgets are smaller than their provincial and federal counterparts, and as such IT investments are more rigidly controlled and monitored.

\section{Selection for Routines to Study}

As defined by our conceptual framework, we adopt organizational routines as the unit of analysis for our study. Organizational routines have been widely argued to be an appropriate unit of analysis for explaining how variance arises within organizational 
activities and how selection and decisions take place within a recurring temporal period (Becker 2002). The use of organizational routines is a novel conceptualization with in the IT governance literature, however they have been prominently employed in other domains such as organizational change (Feldman 2000; Howard-Grenville 2005; Daneshvar et al. 2012), organizational rules and control (Lukka 2007), knowledge management (Lewin et al. 2011; Sharapov 2012), and organizational learning (Zollo and Winter 2002). Although organizational routines are difficult to conceptualize and are often defined in an implicit, rather than explicit manner (Cohen et al. 1996; Becker 2001; Feldman and Pentland 2003; Felin and Foss 2004; Reynaud 2005; Becker 2005, Pentland and Feldman 2005; Feldman and Pentland 2008), the operationalization, specification and codification of routines in our study is supported by 1) explicitly defining IT governance routines as the set of interconnected and collective activities related to the implementation of formal IT mechanisms (as defined by decision-making bodies, business processes and formal documentation), and by 2) adopting a narrative network approach for expressing the various layers of patterns that are generated through the specific enactment of a particular routine (Orlikowski and lacono 2001; Pentland and Feldman 2005; Pentland and Feldman 2007; Feldman and Pentland 2008).

When selecting a routine to investigate, our objective was to choose a routine that is ubiquitous in its existence within most organizations, related to important and impactful decision making, and able to be easily delineated and decoupled from the larger IT governance system. The latter is important for ensuring that the IT governance routine selected can be adequately observed and studied. 
Identifying a superset or candidate set of potential IT governance routines is difficult, given that little (if any) existing research has attempted to conceptualize IT governance mechanisms in terms of organizational routines. In this absence of a cumulative base of research specific to IT governance, we draw on Levin and Barnard's (2008) framework of technology management routines to inform our selection. In their study, Levin and Barnard identify and categorize 27 routines related to the management of technology in large organizations, grouped by three core dimensions: production of scientific and technological knowledge, transformation of knowledge into IT artefacts, and matching of IT artefacts with user requirements. Their model does not specifically address IT governance, however a number of their identified routines overlap with the same structural, process and relational mechanisms typically found with IT governance literature (Sambamurthy and Zmud 1999; Weill and Woodham 2002; Peterson 2003; Grant et al. 2007; Simonsson, Johnson and Ekstedt 2010).

At the core of Levin and Barnard's framework (termed an inside-out model of technology management) are routines related to the planning, evaluation and adoption of particular technology innovations. Although the context of their study was largely focused on technology product-line release decisions, the elements hold true in a traditional IT environment where organizations spend considerable time and effort on the planning, prioritization and selection of internal IT investments. Understanding and deciding on which IT activities to undertake in a given period and in which order is an essential and necessary undertaking for all organizations that formally invest in the 
development and/or purchase of IT services (Larsen, Pedersen and Anderson 2006;

Bowen, Cheung and Rohde 2007).

In most organizations the ongoing demand for IT resources (both monetary and skilled workers) by business-line stakeholders significantly outstrips an organization's ability or willingness to supply or acquire those services. To account for this, organizations typically establish some degree of formal decision-making as a means for reconciling the surplus of demand and ensuring that the most appropriate IT investments are addressed ahead of the others. The components of this formal routine include the identification, definition and intake of proposed IT-enabled investments (planning), the implementation of a methodology to assess, compare and rank project proposals against one another (prioritization), and then ultimately a decision and organizational agreement on which projects will be pursued and which will not (selection). Failure of these mechanisms result either in the assignment of IT resources to misaligned, inappropriate or undesired investments, or the erroneous rejection of IT activities that are critical to the enablement of organizational success.

Given the importance of this set of activities to the overall IT governance system, we have selected the "IT investment planning, prioritization and selection" (ITPPS) routine as the focus of our empirical analysis. The activities surrounding the ITPPS routine clearly meets the definition of an organizational routine as it represents a recognizable, selectable and sequential pattern of action (Cohen and Bacdayan 1994; Pentland and Rueter 1994; Cohen at al 1996; Becker 2002; Feldman and Pentland 2003; Pentland 
2003) that involves multiple actors (Cohen and Bacdayan 1994; Becker 2002; Feldman and Pentland 2003, Becker 2005; Becker, Salvatore and Zirpoli 2005; Weichbrodt and Grote 2010), that reoccurs over time (Cohen et al. 1996; Becker 2002; Feldman and Pentland 2003; Becker 2004; Hodgson 2004), is comprised of a set of interdependent and related actions (Feldman and Pentland 2003; Becker, Salvatore and Zirpoli 2005; Cohen and Bacdayan 1994) is designed to facilitate and constrain behaviour (Becker 2004; 2005; Becker, Salvatore and Zirpoli 2005; Pentland and Rueter 1994; Orlikowski 2000; Feldman and Pentland 2003) and has a core or important role within the organization (Becker, Salvatore and Zirpoli 2005). Although it is theoretically impossible to absolutely isolate a routine from its broader social system (Pentland and Feldman 2005), the ITPPS routine does represent a set of activities that can be sufficiently delineated and examined with limited influence from other organizational events given that it is very specific in its purpose and is viewed as a stand-alone event for most stakeholders within the organization.

A further advantage to investigating the ITPPS routine is the ability to observe subroutines within the larger system as well as multiple instantiations of the performance of the routine. This ability to break down the larger routine into smaller, observable sub-routines (such as focusing on only the mechanism and artefacts surrounding the prioritization process), as well as the fact that this routine is generally performed on an annual or semi-annual basis within most organizations, provides the opportunity for several levels of observation and analysis. Investigation of multiple replications of the phenomenon, regardless of whether it is undertaken within a single case or between 
multiple cases, is considered sufficient for providing an appropriate basis for analytical generalization (Eisenhardt 1998; Pare 2004; Gibbert, Ruigrok, and Wicki 2008) and allows for both within-case nested (Yin 1994) and cross-case analysis (Eisenhardt 1998).

\section{DATA COLLECTION APPROACH}

\section{Case Study Protocol}

A case study protocol outlines a set of guidelines that govern the conduct of research before, during and after the research project (Maimbo and Pervan 2005). A strong case study protocol minimizes the potential for the introduction of procedural errors or bias while also ensuring transparency and repeatability of the overall case study approach (Yin 1994; Pare 2004; Gibbert, Ruigrok, and Wicki 2008). Following the framework posited by Maimbo and Pervan (2005), the remainder of this chapter provides the elements of the case study protocol that we employed during our research.

To support our empirical investigation, qualitative data was collected within each case through 1) semi-structured interviews with various levels of stakeholders associated with the ITPPS routine, and 2) archival document review including pertinent organizational strategic documents, meeting minutes, committee terms of references, templates, frameworks, historical systems records and other routine artefacts. Observation was implicit in the researcher's involvement of the on-site interview activities, but was not used as a formal data collection strategy for this research.

From a methodological perspective, the formal data collection process was designed to allow for the ability to isolate and separate the desired and actual behaviours of the 
ITPPS activities across various empirical sources. This multi-source and multiperspective approach to observing and analysing routines is consistent with organizational routines theory (D’Adderio 2008; Feldman and Pentland 2008; Lazaric 2011) and has been adopted regularly within other empirical case studies of organizational routines as a means of ensuring and supporting construct and internal validity (i.e. Feldman 2000; Levin 2002; Pentland 2003; Howard-Grenville 2005; Becker, Salvatore and Zirpoli 2005; Lukka 2007).

To initiate the collection of empirical data for our study, organizational sponsors from each of the two municipal governments were identified and contacted by the primary researcher. In both cases the head of the internal IT functional team served as the organizational sponsor given their inherent interest in the performance of their organization's IT governance framework and their willingness and ability to facilitate access to other senior managers within the city. A preliminary exploratory planning meeting between members of the city and the research team provided an initial levelset of research objectives and sponsor expectations. At this meeting, sponsors were asked to provide an overview of the general state of the IT governance system within their organization (with a specific emphasis on their ITPPS routines) and to provide researchers with a preliminary list of potential interview subjects. The sole criteria for candidature at this stage was that individuals either had to be involved in the design or implementation of the organization's ITPPS routine, or be an active participant in the ongoing performances of the routine. Both sponsors provided the research team with an initial list of roughly twenty-five potential interview candidates spanning various 
management levels and business units within their organizations. Subsequent names were provided by the sponsor to as the research effort progressed.

Non-probability sampling (specifically purposive/expert sampling) was used to generate the interview sample group from this initial sampling frame, due to the specificity of the initial selection criteria. Given the strict limitation of the potential sample population, a more traditional probability sampling approach was deemed inappropriate because it would have unnecessarily reduced the research sample. Purposive/Expert sampling was prudent given that our objective was understanding the behaviours and expectations surrounding a specific governance routine and not drawing out a generalized behaviour across the organization (Given, 2008).

Based on the original sponsor list, the primary researcher reached out to each individual candidate in order to schedule a mutually-agreeable interview time. To facilitate the interview process, the primary researcher blocked a month of time within both cities as a means for clustering each set of interviews and to allow respondents adequate flexibility to schedule an appointment around their daily schedules. As a testament to the level of participation and interest within both cities, only one interview candidate originally put forth by the organizational sponsor was unwilling or unable to find a suitable interview time and eventually requested not to participate within the study. All other candidates, with the exception of those on leave (vacation, personal, etc.) made themselves available to participate in the study. 
Initial contact with interview candidates was made through email. The introductory email included a brief summary of the overall objective of the research effort, a statement regarding the support and endorsement of the organizational sponsor, a participant information sheet as approved by the University's Ethics Board, and a set of potential interview times. A copy of this communication can be found in Appendix A, and a copy of the participant information sheet can be found in Appendix B. Participants were asked to respond to the email with their consent to participate in the study and preferred interview times.

The majority of interviews were conducted on site at a location of convenience for the individual participant (i.e. in their office, or a boardroom). Four telephone interviews were used to meet with specific candidates in the case where in-person interviews could not be coordinated. The objective of the interview process was to draw out examples of divergence within the ITPPS routine in two ways: 1 ) through direct discussion of divergent practices (i.e. "I chose not to complete the template, even though I knew I was supposed to" and 2) through the development of a multi-source narrative of the routine that could be used for identifying less direct, systemic or latent examples of divergence.

To guide the data collection process, and to ensure the reliability of the methodological approach, a field protocol was established for the primary researcher. The formal protocol can be found in Appendix C. Additionally, in support of the case study protocol, all empirical data and documentation collected through the data collection 
phase of the research effort was logged and stored in a formal case study database.

This central repository served as a means for consolidating all empirical research related to the two cases and enhances the reliability of the overall case design (Yin 1994; Pare 2004).

\section{Semi-Structured Interview Protocol}

Forty-seven interviews were conducted across both organizations (25 in City A, 20 in

City B and two initial sponsor discussions) over a period of four months for a total of 50 hours of interview recordings and almost 700 pages of transcription data (416 pages in City A and 276 pages in City B). Interviews spanned various departments and various levels within the organization, ranging from Deputy Chief Administration Officers to junior analysts in order to ensure an appropriate cross-section of responses were obtained from each case, and that an overall narrative of the routine could be developed from multiple perspectives. The list of interview subjects for each city is shown in Table 1 and Table 2. The actual position title of each of the candidates is "genericized" to respect the confidentiality of the respondents but to allow for an understanding of the relative reporting level of each of the individuals.

\begin{tabular}{|l|l|l|}
\hline Participant & Type & Generic Role \\
\hline A1G101 & Owner & Executive - IT \\
\hline A1G102 & Owner & Senior Manager - IT \\
\hline A1G103 & Owner & Senior Manager - IT \\
\hline A1G104 & Owner & Senior Manager - IT \\
\hline A1G105 & Owner & Analyst - IT \\
\hline A1G106 & Owner & Senior Manager - IT \\
\hline
\end{tabular}




\begin{tabular}{|l|l|l|}
\hline A1G107 & Owner & Senior Manager - Governance \\
\hline A1G108 & Owner & Manager - IT \\
\hline A1G109 & Owner & Manager - IT \\
\hline A1G110 & Owner & Senior Executive \\
\hline A1G201 & User & Manager - Business Line \\
\hline A1G202 & User & Manager - Business Line \\
\hline A1G203 & User & Manager - Business Line \\
\hline A1G204 & User & Director - Business Line \\
\hline A1G205 & User & Manager - Business Line \\
\hline A1G206 & User & Director - Business Line \\
\hline A1G207 & User & Manager - Business Line \\
\hline A1G208 & User & Manager - Business Line \\
\hline A1G209 & User & Analyst - Business Line \\
\hline A1G210 & User & Senior Executive \\
\hline A1G211 & User & Analyst - Business Line \\
\hline A1G212 & User & Director - Business Line \\
\hline A1G213 & User & Manager - Business Line \\
\hline A1G214 & User & Senior Executive \\
\hline A1G215 & User & Director - Business Line \\
\hline
\end{tabular}

Table 1 - City A Interview Subjects

\begin{tabular}{|l|l|l|}
\hline Participant & Type & Generic Role \\
\hline A2G101 & Owner & Senior Manager - IT \\
\hline A2G102 & Owner & Director - Governance Committee \\
\hline A2G103 & Owner & Manager - IT \\
\hline A2G104 & Owner & Manager - IT \\
\hline A2G105 & Owner & Senior Manager - IT \\
\hline A2G106 & Owner & Director - Governance Committee \\
\hline A2G107 & Owner & Executive - IT \\
\hline A2G108 & Owner & Senior Executive \\
\hline A2G109 & Owner & Manager - Corporate Planning \\
\hline A2G110 & Owner & Senior Manager - IT \\
\hline A2G201 & User & Director - Business Line \\
\hline A2G202 & User & Manager - Business Line \\
\hline A2G203 & User & Director - Business Line \\
\hline A2G204 & User & Manager - Business Line \\
\hline A2G205 & User & Director - Business Line \\
\hline A2G206 & User & Manager - Business Line \\
\hline A2G207 & User & Director - Business Line \\
\hline
\end{tabular}




\begin{tabular}{|l|l|l|}
\hline A2G208 & User & Director - Business Line \\
\hline A2G209 & User & Director - Business Line \\
\hline A2G210 & User & Manager - Business Line \\
\hline
\end{tabular}

Table 2 - City B Interview Subjects

Two semi-structured, open-ended interview protocols were developed to support these interviews: one tailored to governance owners and one tailored to governance users. Interview candidates, based on the original list provided by the organizational sponsor, were divided into two groups and were interviewed using one of these two protocols. The final protocols for each of these two groups can be found in Appendix D.

The first subject group, consisting of governance designers and owners were selected to provide a general managerial context the IT governance system, to understand the overarching purpose of the routine, and to establish the baseline set of expected behaviours and outcomes for the routine. The latter two items support the identification and classification of representational divergence.

At this stage it is important to acknowledge that identifying "ownership" of routines and institutions within any organization is not a simple endeavour (Becker, Salvatore and Zirpoli 2005). In the case of municipalities, an argument could be made that ownership of the IT governance routine lies with the Chief Administration Office, the senior executive table, city council, the mayor, or even the voting constituents. Therefore, for the purposes of our study, our ownership group is defined as the senior members of the city, as identified by the organizational sponsor, who are responsible and accountable for ensuring that the IT governance mechanisms surrounding the ITPPS routine are 
sufficient and appropriate. In that sense, ownership is defined in a purely pragmatic, rather than theoretical manner, focused on the individuals that have an invested interest in defining the desired behaviours associated with the performance of the ITPPS routine.

The second subject group represents the set of actors within the organization who are actively and directly involved in the instantiation and performance of the ITPPS routine. The focus of the second set of interviews was to understand how the routine was actually enacted in practice and to draw out examples of translational and performative divergence.

The questions were fairly similar within both protocols, with only a slight shift in focus on expectations vs. actual behaviours for the respective interview groups. Given the exploratory nature of this research, the protocols were not followed directly, but rather used as a guide to spark and guide conversation with the interviewee. The value of the semi-structured interview process in exploratory research is in the gathering of insight and understanding, rather than in soliciting specific detailed answers to specific questions (Newton 2010). The interview protocols were refined prior to use through two rounds of pre-testing with a third organization in which the primary author had significant and appropriate contacts. After each round or pre-testing the instrument was adjusted based on feedback from the respondents and the primary researcher's field notes. Changes to subsequent versions of the interview protocol were primarily related to adjusting the flow, timing and order of questions, as well as ensuring that 
questions were not leading or inherently biased. All draft iterations of the instrument are provided in Appendix E.

Each interview candidate who participated in the process was assigned a unique code based on location (A1, A2) and type of interview (G1 - Governance Owner, G2 Governance Actor) in order to maintain anonymity of respondents. For example, the interview candidate at the first municipality that participated in the first interview based on the governance owner protocol was identified as A1G101. No connection was made within the interviews to the actual identity of the individual interview participant. The matching of individual names and their respective interview codes were only known by the primary researcher and was recorded within a single password protected file on the researcher's personal computer.

Each session began with a set script and list of activities to ensure a common approach to each of the interviews. The script included an overview of the background of the researcher and the project, an outline of how the researchers were sponsored into the organization and an assurance that all responses will remain private and confidential. IT governance effectiveness and the manner in which the organization plans, prioritizes and selects IT investments were highlighted as the primary focus of discussion and interview questions, but the topic of divergence was not discussed. Although the term "divergence" could be found in the participant information form, it was purposefully avoided during this introduction as means to protect against introducing any potential social biases such as hypothesis guessing or experimenter expectancy bias which would 
subsequently threaten the validity of any constructs introduced as part of the theory building process (Cooke and Campbell 1979). As a last step of the introduction process, all interviewees signed and dated duplicate copies of an Informed Consent agreement prior to participating in the formal interview (See Appendix F).

Although the individual times varied, interviews typically lasted around 60 minutes, and were guided by the primary researcher to maintain focus on the planning, prioritization and selection activities within the respective organization. As was expected, on a few occasions participants attempted to use the interview time as a means to provide general feedback on the perceived performance of the overall IT function within their organization, but in these cases, the interviewees were quickly and politely steered back on topic by the researcher.

Where interviewees crossed the boundaries of both user groups, topics were discussed that solicited feedback on both perspectives. The focus of the interview was adjusted to account for the area of expertise of the individual participant (i.e. the interview with the most senior member of the executive team at location A2 had a greater emphasis on expectations and desired behaviours of the routine, rather than the more specific instances of divergence that may occur within the enactment of the routine). Topics that would directly identify the interview respondent within their responses were avoided if possible by the primary researcher.

Interviews were recorded using a personal audio recorder and field notes were captured by the interviewer during the discussion. The field notes were used to highlight direct 
examples of divergence, outline specific governance mechanisms (artefacts, committees, decisions/behaviours) as part of the overall routine narrative, and identify emergent governance themes (i.e. horizontality is an informal expectation, but does not yet appear in any official documentation). The notes were also used to capture "leads" on additional documentation or potential interview candidates that could be followed up on at a later date (i.e. snowball sampling).

After each interview, field notes were typed (within 24 hours where possible) and stored electronically. Audio recordings were downloaded from the recorder and saved in a password protected folder on the primary researcher's computer. To support the analysis of the interview data, all audio files were transcribed verbatim by an external organization (See Appendix G for endorsement) and were reviewed by the primary researcher for accuracy and completeness. The electronic transcriptions were also stored securely by the researcher and were verified to have been deleted from the individual transcriber's system.

\section{Organizational Document Review Protocol}

In addition to interviews, an initial set of documentation relevant to each organization's ITPPS routine was collected from each of the organizational sponsors. This initial documentation was used to: 1 ) develop a general understanding of the planning, prioritization and selection landscape within the organization, 2) identify the set of artefacts associated with the overall narrative of the routine, and 3) highlight any expectations of governance owners that may be articulated within strategic publications 
(i.e. the Municipal Strategic Plan as an extension of city council expectations). Additional documentation was identified and gathered as discovered during the interview process.

Documentation collected during the interview process was stored securely by the primary researcher, and where possible was collected in electronic format to more easily support subsequent data analysis. Publicly available, external facing documentation (i.e. strategic plans, council meeting minutes, etc.) was collected directly by the primary researcher before and during the interview periods within both organizations. The final list of documentation gathered for both organizations can be found in Appendix $\mathrm{H}$ and Appendix I.

The collection and analysis of organizational documentation in addition to interview data facilitates the identification and determination of the distinct layers of narratives associated with performance of the ITPPS routine (Pentland and Feldman 2007; Feldman and Pentland 2008; Pentland, Haerem, Hillison 2010; Lazaric 2011) and also addresses construct validity by allowing for multiples measures of the same phenomenon (Pare 2004). Our triangulation of empirical data and multi-source approach (Denzin 1984; Stake 1995; 2000) limits biases (Eisenhardt and Graebner 2007) and results in a stronger substantiation of the resulting theoretical constructs and propositions (Bourgeois and Eisenhardt 1988; Eisenhardt 1989; Benbasat, Goldstein and Mead 1987; Gibbert, Ruigrok, and Wicki 2008). 
A complete document review also allows for the positioning of the formal IT governance artefacts (formal rules, process definitions, procedures, checklists, etc.) within the overall routines narrative, and serves to support and validate any potential structuralbased divergence or general contextual considerations that may not be evident or observable during the interview process (Cohen and Bacdayan 1994; Pentland and Feldman 2007; Pentland and Feldman 2008). In this respect, formal artefacts related to ITPPS can be treated as nonhuman actants within the overall social system of the organization routine, able to provide a unique and non-verbal perspective of the routine's overall narrative (Latour 1991; Pentland and Feldman 2007).

\section{DATA ANALYSIS APPROACH}

The case data analysis approach of the study roughly follows the four primary steps of case analysis outlined in Yin (1981): 1) case narrative capture and identification, 2) tabulation of meaningful events and first-order codification, 3) in-case analysis to identify emergent themes and explanations, and 4) between-case analysis to examine commonalities and develop second-order propositions and hypothesis.

\section{Case Narrative Capture and Identification}

All electronic documentation, including interview transcripts and field notes was loaded into the NVivo computer-assisted qualitative data analysis software (CAQDAS) for coding and analysis. The empirical data for each of the two case studies was entered, grouped and coded separately, however both cases were included under the same NVivo project to allow for both within-case and cross-case analysis. Each of the 47 
individual interview subjects was identified as a unique research node (labelled the same way as their interview code) which allowed for all documentation relevant to a particular individual to be linked together (i.e. A1G101's interview transcripts, follow-up transcripts, field notes and complete artefact templates would be grouped together under a single node). By following this approach, individual responses could be subsequently grouped or queried by a number of respondent-specific characteristics (organizational level, gender, interview group, etc.).

Leveraging the diverse set of empirical data captured within the NVivo tool, individual ITTPS routine narratives were created for each of the two cities. Given that the direct observation of all elements of the routine would not have been feasible through a single data collection methodology, the use of two separate interview protocols along with the integration of routine artefacts into the analysis process allowed us to identify examples of divergence that could not have emerged through interviews alone. By comparing the expectations of senior organizational members against the implemented artefacts and committees, we were able to identify and elucidate otherwise latent structural disconnects within the governance mechanisms. This two-phase approach to defining, observing and analysing routines is consistent with that proposed within the organizational routines literature (D’Adderio 2008; Feldman and Pentland 2008; Lazaric 2011) and limits biases by using information from multiple diverse perspectives (Eisenhardt and Graebner 2007). Overall, the establishment of methodological triangulation (Stake 2000) through the gathering of multiple perspectives or stories of the same routine narrative, including those from the position of artefacts (non-human 
actors), allows for a richer description and visualization of the routine, and in turn allows for greater visibility in the underlying factors driving substantive divergence (Bourgeois and Eisenhardt 1988; Sutton and Staw 1995; Pentland 2003; Becker, Salvatore and Zirpoli 2005; Pentland and Feldman 2007; Becker and Zirpoli 2008).

The representation of each City's routine narrative was captured in Microsoft Visio, and includes three separate perspectives: the desired state of the routine, the actual state of the routine, and the high-level identification of areas of divergence between the desired and actual states. The third depiction of the ITPPS routine in each city provides the starting point for subsequent first-order and second-order codification of empirical evidence.

\section{Data Organization and First-Order Codification}

Coding of all the qualitative data was performed according to Saldana (2009) and involved one round of "pre-cycle" coding and three iterative cycles of formal coding. Source documentation for the coding process included interview transcripts, interviewer field notes, internal organizational documentation (i.e. IT governance framework documents) and external organization documentation (i.e. minutes from council meetings). All coding was performed within NVivo by the primary researcher and each cycle of coding involved significant iteration and refinement.

As a pre-cycle, initial labels were developed to group all relevant data into a set of large, overarching categories as a means to organize the vast volume of data in a manner that would support a more detailed level of analysis in the subsequent coding cycles. Major 
categories at this stage included the individual artefacts and decision bodies within each organization's planning, prioritization and selection processes, general background on the organizations' IT governance structure, emergent themes and observations (i.e. lack of a clear prioritization process and approach), and any overt and direct examples of divergence. For the purposes of this pre-cycle of coding, the term "categories" is used in the most colloquial sense, not meant to represent the aggregation of an existing set of codes (Lewins and Silver 2007), but rather as a means for providing a logical segmentation and organization of source data. Sources were mapped against multiple dimensions where required. The idea during this phase of coding was to ensure that no piece of data was prematurely coded and to provide a first pass to identify references that pointed toward examples of divergence. Divergence was identified in direct examples only (i.e. hearsay and rumour were not included) and were coded under a single overarching category. No attempt was made at this stage to assign a descriptive or value code based on the type of divergence outlined in the proposed framework. As a first pass, Case A had 43 sources and 221 references of divergence and Case B had 32 sources and 101 references of divergence. Cross-case analysis of divergence was not performed during the pre-cycle of coding.

\section{Emergence Themes and Second-Order Codification}

For the first cycle of coding, all references within the category of divergence were coded based on the first impressions and initial thoughts of the primary researcher. This is an approach that is consistent with Saldana's (2009) outline of initial coding, where the 
analysis of the empirical data gives rise to a set of emerging patterns and codes. Where common themes of divergence emerged, individual references were grouped against the same code. In-vivo coding was used sparingly, with most codes at this stage being assigned as descriptive or process-oriented labels. The end result of this first cycle of coding was a full encoding of all initial references of divergence into a set of unique and pattern-based codes for each of the two cases. This pattern-matching approach strengthens the internal validity of the constructs that arise from within each case study (Bourgeois and Eisenhardt 1988; Pare 2004; Gibbert, Ruigrok, and Wicki 2008).

No cross-case analysis was undertaken at this stage, however where possible the wording of labels was aligned between both sets of codes in order to maintain a common language and approach. Individual sources were mapped against multiple divergence codes where possible (i.e. Interview candidate transcripts may mention various examples of divergence) resulting in an inflated sum of the total number of sources citing examples of divergence. This does show, however, that examples of divergence were prevalent throughout the interview process.

\section{Between-case Analysis and Proposition Development}

During the second cycle of coding, individual second-order divergence-related codes were reassessed and each of the codes were then re-categorized into one of the three framework categories (Representational, Translational and Performative) forming the basis of our proposed theoretical model. An iterative loop between the proposed second-order constructs within each case and our resulting theoretical model was used 
to assess patterns of divergence that span between the two case studies (Eisenhardt 1989). According to Eisenhardt and Graebner (2007), the theory building process occurs via recursive cycling among the case data, emerging theory and the extent literature. The ability to map codes against each of the three categories in our original framework validated the use of the first-order framework as an initial guideline for classifying example of divergence. A final cycle of coding involved the further reviewing, refining, and recoding of divergence references within our proposed model, resulting in the positing of our theoretical constructs and propositional statements.

\section{ENSURING TRUSTWORTHINESS OF OUR QUALITATIVE RESEARCH APPROACH}

Given the qualitative nature of our research study, we draw on the works of Lincoln and Guba (Guba 1981; Lincoln and Guba 1985; Guba and Lincoln 1989; Lincoln 1995), as well as the more recent work of Shenton (2004) as a guide for ensuring the integrity of our research approach, and in turn, the trustworthiness of the findings and conclusions of our study. Offered as an alternative to quantitatively-oriented assessment criteria, Guba and Lincoln propose a set of criteria for judging the soundness of qualitative research. Each of these criteria was accounted for throughout the design and execution of this study.

\section{Credibility as Internal Validity}

Adhering to Guba (1981), we account for internal validity through the establishment of credibility in our methodology and research approach. Specifically, credibility is established through the triangulation of data collection through the use of both 
interviews and documentation review (Mathison 1988; Brewer and Hunter 1989), triangulation of different informants through the use of multiple interview protocols (Van Maanen 1983), triangulation across different sites and different business units within each of the cities (Shenton 2004), establishing an honest rapport with organizational sponsors and interview candidates (Shenton 2004), use and subsequent refinement of an initial research framework (Miles and Huberman 1994), development of rich case descriptions prior to presenting analysis and conclusions (Shenton 2004), and finally the use of multiple cases to support a more broad collection of research data and within-case pattern matching (Campbell 1975, Bourgeois and Eisenhardt 1988; Pare 2004; Gibbert, Ruigrok, and Wicki 2008).

\section{Transferability as External Validity}

The transferability of our findings to a larger population is not a primary objective of this study, given the exploratory and preliminary theory-building nature of this research. Nevertheless, we strive to maintain a level of transferability in two ways: 1) by employing a multi-case approach to strengthen our process of deriving theory from description (Yin 1984; 1994), and 2) providing sufficiently rich detail surrounding the individual cases (Chapter 5) as well as our implemented case methodology (previous section) as a means to clearly articulate the context of our study. By establishing a clear context, other researchers can then decide if the findings are transferable to their particular areas of interest and can chose whether or not to apply our conclusions to their research (Marchionini and Teague 1987). Richness, in our case, has been chosen 
over wider generalizability as per Lee and Baskerville's (2003) definition of ET Generalizability which represents research that is focused on translating empirical observations to theoretical constructs.

\section{Dependability as Reliability}

As a means for ensuring the consistency of findings when studies are replicated within the same context, using the same methods and the same participants, Lincoln and Guba (1985) argue that increased credibility leads to increased dependability within the domain of qualitative research. To this end, we provide an in-depth methodological description in our study (this chapter), including research design and implementation, detail of data gathering methods and approach and interview protocol and candidate selection process to allow others to repeat the study within the same context and employing the same approach (Shenton 2004). The establishment of a case study protocol, including a field protocol (Appendix C), also serves to increase the dependability of the study (Yin 1994; Pare 2004; Gibbert, Ruigrok, and Wicki 2008).

To set the foundation for our empirical analysis and theory development, the following chapter provides an overview of the IT investment planning, prioritization and selection environments in each of our two cases. 


\section{CHAPTER 5 - CASE BACKGROUND AND DESCRIPTIONS}

\section{CITY A - LARGE SINGLE-TIER MUNICIPALITY}

City $A$ is among one of the largest 50 municipalities in Canada with a population well over 100,000 . The city is classified as a single-tier municipality that is politically separate from, but geographically located within a larger county census division. Recognized as one of the most intelligent communities in the world by the Intelligent Community Forum (ICF), the city's biggest employers include government, education, health care and tourism.

The city is governed by a city council consisting of a mayor and 12 councillors who are elected for a term of four years. At the time of study, the city was in full preparation for an election, as the current council was in the final months of its term. As with most municipal governments, the sitting council is responsible for administering and operating almost 40 business and service units including road maintenance, building and licensing, fire services, transportation, solid waste management, long term care, recreation and cultural awareness. Unlike many municipalities, City A owns and operates a centralized utilities organization on behalf of city residents. The utilities organization manages water, wastewater, gas, electrical and fibre optics services as a standalone company but shares common corporate resources with other city departments.

Internally, the city is organized into six service groups: 1) legal and corporate affairs, 2) finance and information systems, 3) corporate and strategic planning, 4) transportation, 
facilities and emergency services, 5) community services and 6) public works. The heads of each of these service groups, referred to as commissioners, along with the Chief Administration Officer (CAO) make up the city's Corporate Management Team (CMT). The CMT is the senior most non-elected governance body within the city and manages all day-to-day activities of the city staff. The IT organization, led by the CIO is one of two divisions within the finance and information systems department.

The mandate, direction and objectives of the city are set out in the city's Strategic Plan. The purpose of the plan is to promote council priorities and provides a foundation to guide development of departmental plans, service delivery models and budgets. The plan spans the term of each city council and is reviewed annually to ensure that it remains aligned with changing needs of the community. The current plan is built around six priorities ranging from the enabling of economic development to creating and protecting municipal greenspaces. Underlying these priorities is a set of programs and actions that lay out the manner by which each of objectives of the strategic plan will be met. City performance is published in a traditional annual report as well as a publicfacing citizen report card which is produced as part of the municipal performance measures program.

Within the city, the IT division is responsible for managing and maintaining the organization's corporate data and telephony infrastructures and distributed computing environments. The team is also responsible for developing, maintaining and hosting inhouse and custom-off-the-shelf applications, including a number of highly-specialized 
GIS-based solutions. In 2011, the IT division underwent significant change. The group, which historically reported directly to the CAO, was repositioned under the City Treasurer in an effort to consolidate and streamline corporate, internal functions. A new $\mathrm{ClO}$ was hired and given the explicit mandate to transition the IT organization from a low-value order-taker to one that supports and drives the modernization of the city's service delivery models. As one of his first orders of business, the CIO set out to revamp and renew the city's IT governance framework.

\section{City A - IT Investment Planning, Prioritization and Selection Environment}

In 2012, the IT division led a complete overhaul of the manner in which IT investments are made within the city. At the core of this effort was the publishing of a formal IM/IT Governance Framework (ITGF) focused on establishing an enterprise-wide approach to the management of IT decisions and maturing the IT-related professional disciplines within the city (i.e. Project Management, ITIL, etc.). Governance of technology and information management was positioned by this new model to be the responsibility of leaders within all departments, rather than solely residing with the IT group. This enterprise approach aligned to the CAO's ongoing focus on breaking down historical organizational silos and running the city as a singular, consolidated entity.

Despite the objective of the city's ITGF to foster an enterprise-wide and business-led approach to the management of IT assets, the IT group, and specifically the CIO clearly remains seen by organizational stakeholders as being the true owner of the ITPPS 
routine. This position, however, does not appear to be explicitly recognized through any formal decision or documentation.

"Although technically, I mean, it's sort of delegated to me from the executive, that's my opinion because they approve it and they endorse it, but it's really my responsibility". (A1G101, CIO)

"I would say it would be the ClO that is the owner" (A1G108)

"I would say the IT (Group)" (A1G202)

Prior to the new governance model, the majority of IT investment decisions were made in an informal, ad-hoc basis. Each business line approached the IT group individually, and prioritization, when it was done, only considered the other requirements of the requesting client. IT resources were assigned to projects on a first-come, first-served basis which resulted in business lines that moved first or pushed the hardest receiving a bulk of the services by the IT group in any given year. Departments with smaller budgets or less visible service mandates often had to look to external service providers to fulfil their IT needs. When discussing the history of IT within the city, this period is often referred to as the "wild west" by city staff.

As a complementary document to the ITGF, the Project Planning, Selection and Prioritization (PSP) Policy provides the organization with a set of roles, responsibilities, committee and artefacts necessary to support an enterprise-wide approach to IT investment management. The importance of this process is outlined in the introductory paragraph of this document: 
"A formal intake and assessment process is a leading practice in public sector IM/IT support organizations, and a key indicator of the relative maturity of the IM/IT support processes within public and private sector organizations. Intake processes take an idea from concept to project or initiative, or stated another way - from the imaginary to the real...Project intake and selection is about identifying the right projects for the City to invest in." (PSP, p. 5)

The city delineates between project planning and project management as a means for defining when planning ends and execution begins. Once an IT investment has been defined, approved and placed within a prioritized queue, the project intake governance cycle is complete and the project management oversight process begins. The bulk of the project intake activities typically take place once a year in alignment with the overall city fiscal budgeting process, but business clients are not limited to only this period for submitting any in-year or unexpected IT service requirements. Figure 7 shows the flow of activities (sub-routines) within City A's ITPPS routine.

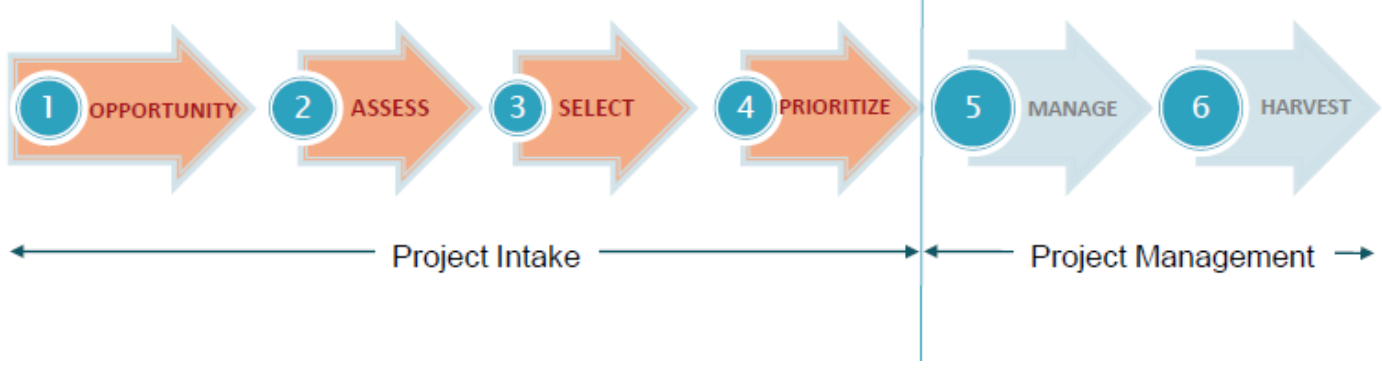

Figure 7 - IT investment planning routine for City A (ITGF Guide, Sept 2012)

To support this flow of decision making, the PSP outlines the various lists of committees and artefacts (referred to as tools) that have been established as part of the 
implementation of this governance structure. Not surprisingly, the actual enactment of these routine mechanisms in practice varies from this ideal state both as part of a conscious evolution and maturation process that has taken place since the original publishing of the PSP, as well as the less overt modification and interpretations of committee mandates and artefact templates.

\section{IT Governance Committees}

The membership, mandate and terms of reference for each of the IT governance bodies is defined within the ITGF, while the PSP more specifically outlines the responsibility and accountability of these governance bodies within the City's ITPPS routine. Roles and responsibilities are defined in the RACl (Responsible, Accountable, Consulted, and Informed) chart in Figure 8. Decision making bodies are highlighted in pink.

\begin{tabular}{|l|c|c|c|c|c}
\hline \multicolumn{1}{|c|}{ Category of Decision } & $\begin{array}{c}\text { Business } \\
\text { Sponsor }\end{array}$ & $\begin{array}{c}\text { IT Steering } \\
\text { Committee }\end{array}$ & $\begin{array}{c}\text { IT Advisory } \\
\text { Board }\end{array}$ & $\begin{array}{c}\text { IT Working } \\
\text { Groups }\end{array}$ & $\begin{array}{c}\text { Chief } \\
\text { Informa } \\
\text { tion } \\
\text { Officer }\end{array}$ \\
\hline $\begin{array}{l}\text { Define opportunity or } \\
\text { business need }\end{array}$ & A & A & & C & I \\
\hline $\begin{array}{l}\text { Complete Opportunity } \\
\text { Definition (OPD) and Project } \\
\text { Scoring Matrix (PSM) }\end{array}$ & I/C & & C/R & $\mathrm{A}$ \\
\hline $\begin{array}{l}\text { Review OPD/PSM for } \\
\text { consistency \& accuracy }\end{array}$ & I & & I/C & & $\mathrm{A}$ \\
\hline Identify portfolio category & $\mathrm{I}$ & $\mathrm{C}$ & $\mathrm{A}$ \\
\hline $\begin{array}{l}\text { Consolidate and report } \\
\text { results of assessment and } \\
\text { categorization }\end{array}$ & $\mathrm{I}$ & $\mathrm{A}$ & $\mathrm{R}$ & $\mathrm{I}$ & $\mathrm{C}$ \\
\hline $\begin{array}{l}\text { Assess resource } \\
\text { requirements and develop } \\
\text { preliminary IS\&T workplan }\end{array}$ & $\mathrm{I}$ & $\mathrm{I}$ & $\mathrm{I}$ & $\mathrm{I}$ & $\mathrm{A}$ \\
\hline $\begin{array}{l}\text { Approve IS\&T Workplan } \\
\text { (projects and priorities) }\end{array}$ & $\mathrm{I}$ & $\mathrm{A}$ & $\mathrm{C} / \mathrm{R}$ & $\mathrm{C} / \mathrm{R}$ & $\mathrm{C} / \mathrm{R}$ \\
\hline $\begin{array}{l}\text { Communicate and publish } \\
\text { workplan }\end{array}$ & $\mathrm{C}$ & & & $\mathrm{C}$ \\
\hline Dispute Resolution & & & & & \\
\hline
\end{tabular}


Figure 8 - City A Roles and Responsibilities (PSP, p. 17)

Corporate Management Team (CMT) / IT Steering Committee (ITSC) - At the top of the city's governance hierarchy is the corporate management team, consisting of the Chief Administrative Office, Departmental Commissioners, City Treasurer and City Solicitor. This committee is responsible for overseeing and monitoring all program activities and ensuring that individual departments are working in a co-ordinated and focused manner and are aligned to the goals and objectives set out in the city's strategic plan. CMT proper isn't meant to play an active role in the planning, prioritization and selection of IT investments (as evidenced by its lack of inclusion in the RACl chart above). However, the $\mathrm{ClO}$ is responsible for regularly updating a separate sitting of this committee, branded the IT Steering Committee (ITSC) on all major decisions impacting the use and adoption of IT within the city.

According to the governance decision flow, ITSC is accountable for approving all IT investment decisions, but in practice, ITSC is simply a 15 minute period of an existing CMT governance meeting (in other words, a governance committee known as ITSC does not formally exist on its own) and regardless of title, this body has repeatedly indicated that it is not interested in reviewing or approving detailed IT project plans or prioritization decisions, even though this activity is explicitly outlined within the IM/IT governance framework as one of four primary ITSC responsibilities (ITGF, p. 21).

As the most senior member of the city staff, the CAO, and by extension, CMT, technically has the authority to overturn or redirect IT investment decisions. This power 
is rarely, if ever, exercised. CMT / ITSC does, however, on occasion weigh in on large scale, enterprise-wide IT decisions, but only in terms of providing strategic advice or direction. The trigger for when CMT/ITSC would like to be informed on large-scale investment decisions, however, does not appear to be explicitly defined.

"I am not fully conversant with the thresholds, but if there is a significant investment in a project then it does come to CMT for corporate buy-in, or if it has the breadth of the application for the whole corporation obviously it will come there." (A2G108, CMT member)

In one particular occasion, CMT/ ITSC was asked to provide guidance to the organization on whether to pursue the implementation of an enterprise resource planning system, and essentially provided the selection decision on behalf of the city. The decision, in this case, was to postpone the investment based on the fact that the organization wasn't ready to take on the scope of this particular project. In terms of prioritization, this decision wasn't a rejection of the concept but simply a request that additional preparation work would need to be undertaken prior to actively pushing the IT project forward.

"A year before that they came to CMT and CMT said we weren't quite ready, that the organization wasn't quite ready. It's not just that CMT simply looks at the financial capacity of the organization to proceed with ERP, it will look at the state of organizational readiness because people are involved internally". (A1G110) 
In the majority of cases, the $\mathrm{ClO}$ simply provides CMT /ITSC with a prioritized list of activities and for the most part, this governance body has informally delegated the approval of this list to lower-level committees. When asked directly whether the $\mathrm{ClO}$ is seeking approval from CMT/ITSC, one business sponsor ambiguously responded "I think it's an FYI" (A1G210). A Commissioner added:

"If it's more departmental application then obviously it doesn't come there if there is a minimal involvement, minimal investment, if the departments have budgets, sufficient funds and if they have a capacity to sort out the level of involvement that the IT organization has to input in there." (A1G110)

IT Advisory Board (ITAB) - The IT advisory board is comprised of a set of divisional directors within the city, as well as the Vice-President of the utilities organization. The board has a formal mandate to recommend and endorse all IT project investment decisions, ensure cross departmental coordination and implementation of corporatewide systems, and resolve IM/IT governance issues as required (IM/IT Governance Framework, p. 22). Like ITSC, ITAB is meant to be a separate sitting of an existing director committee, however the delineation (as well as membership) between the director committee and ITAB is unclear to most organizational members interviewed. In addition, significant confusion also exists between the labels of ITSC and ITAB, with many staff using those names interchangeably to describe the commissioner-level and director-level committees. According to a set of published FAQs:

"The IT Advisory Board (a committee comprised of all City Directors/utilities) considers the consolidated input from the project sponsors, combined with 
information from IT on resource capacity and availability, project interdependencies, technical risks/opportunities, etc.. The ITAB applies a corporate perspective while advocating on behalf of their respective department, and recommends a 3-year workplan to the IT Steering Committee (ITSC)" (FAQ, downloaded from Internal Project Planning Wiki)

For input, ITAB receives an update on in-flight project statuses, as well as a prioritization result for any newly submitted IT projects. As an output, the committee is expected to address any cross-organizational or project management issues within existing projects (i.e. a change in schedule for a project that implicates multiple business lines), and endorses any changes to the approved and prioritized project list. Timing of the ITAB meeting is irregular (typically bi-annually), however the director committee meets once a month providing a more frequent schedule that can leveraged by the $\mathrm{CIO}$ as required. Outside of the ITGF and PSP, formal terms of reference do not exist for ITAB. According to the $\mathrm{ClO}$,

"The only thing that are terms of reference for that group that we agreed to was that each director would not necessarily challenge the others on the importance of that to their particular department, that was a thing they felt really strong on and I went along with it but I do have some concerns on that...maybe they should put their corporate cap on a little bit more and they could influence their colleagues a bit more." (A1G101)

The ITAB committee currently struggles with mandate. Given the turn-over rates at the director level, there appears to be considerable confusion regarding membership of ITAB: is it all directors within the organization or a subset of directors that provide a 
sufficiently corporate-wide view on IT decision making? When asked directly during interviews, many directors were unsure if they were part of the ITAB committee or not.

"Yeah, I know we talked about (a terms of reference for ITAB). I think we actually did get one, but it was pretty well soon after we had developed it, we kind of evolved to the model of it being just the whole Directors Group. You know, I don't think that they ever get to formally, formally ever approve anything, to the Directors Group" (A1G212)

"I am a director so I believe I'm on the IT steering committee." (A1G215)

The second quote provides an example of a director who is unaware of the difference between the ITAB and ITSC governance bodies, and is equally unsure of whether they, as a director, are a part of one or the other.

Strategy and Planning Committee (SPC) - The Strategy and Planning Committee, also referred to as the IT Project Review Committee (IT PRC) meets bi-weekly to discuss ongoing and newly submitted IT-enabled projects. With the support of the IT Project Management Office (PMO), the committee is responsible for gathering, reviewing and clarifying all solution development requests submitted by business line clients as well as identifying emerging trends and technologies that may impact City operations.

Comprised of the CIO, IT managers, the PMO lead and the chief enterprise architect, SPC provides an initial selection, prioritization and scheduling of all internal IT projects that will be undertaken by the city. It is important to note that this committee only has visibility into IT investments that are communicated to the internal IT group (i.e. if a 
business unit purchases a hosted solution from an external vendor, this investment would not necessarily be assessed by SPC).

In order to rank projects, individual requests are given a business value assessment score ranging from Very High to Very Low based on a number of factors including capacity, complexity, alignment to strategic direction and alignment to architectural standards. According to the PSP, business clients are expected to complete an Opportunity Definition Form (OPD) and Business Value Project Scoring Matrix (PSM) as mandatory inputs to the SPC decision process. In practice however, the IT PMO typically completes the business value assessment and provides the client and SPC with an initial prioritization score.

"By the time it gets to that project review meeting, it's been sort of ranked and scored (By the PMO)" (A1G101)

"the PMO basically does the actual scoring based on the responses to the (opportunity definition) form...At the PMO level when the plan initiation takes place that is when a score is made around or an assessment is around, 'does this have to be done just with internal resources? If so do we have the resources to implement it? And if not does the project have enough? Is it funded enough to bring in external resources and can we get those resources and get them to work with us to implement in a way that is of benefit to the enterprise." (A1G204)

As an output of the SPC's activities, the committee reviews and approves individual project progress, establishes a portfolio based summary of project statuses, and maintains the formal prioritized list of approved projects in a document called the 
Project Selector Dashboard. All these documents are provided to ITAB and ITSC for reference; however in practice they are not typically reviewed by these senior governance bodies.

ERM Steering Committees- As a peripheral governance body to City A's ITPPS routine, the ERM steering committees oversees and manages service requests for the enterprise human resource management system (PeopleSoft) and the corporate financial system (SAP). Comprised of functional leads for all areas of the city, these bodies, along with their sub-working groups, triage and assess IT project requests that impact these systems. Small requests are captured and managed as bug fixes or minor enhancements and are prioritized within the maintenance queue for the ERM applications, and larger requests are routed back through the more formal investment intake process. Currently the ERM Steering Committees only has visibility into those projects that are brought to them directly by business sponsors. Other than through informal channels, a trigger doesn't exist to route opportunity proposals submitted through the IT investment routine back to the ERM Steering Committees if the respective ERM system could be considered as a possible solution for the particular business requirement.

\section{IT Governance Artefacts}

A number of artefacts impact the ITPPS routine within City A. Table 3 provides a highlevel summary of these artefacts. 


\begin{tabular}{|c|c|c|}
\hline Artefact & Type & Description \\
\hline City Strategic Plan & Strategic & $\begin{array}{l}\text { Outlines the four-year strategic direction and objectives } \\
\text { of the city. All investment activity within the city must } \\
\text { align to plan. }\end{array}$ \\
\hline $\begin{array}{l}\text { IM/IT Governance } \\
\text { Framework (ITGF) }\end{array}$ & Strategic & $\begin{array}{l}\text { Provides the overarching IM/IT Governance principles } \\
\text { for the role of IM/IT decision making in the City. Brief } \\
\text { mandate statements are provided for each governance } \\
\text { body. }\end{array}$ \\
\hline $\begin{array}{l}\text { IM/IT Governance - } \\
\text { Project Intake, } \\
\text { Selection and } \\
\text { Priority Setting (PSP) }\end{array}$ & Strategic & $\begin{array}{l}\text { A supporting policy to the IM/IT governance framework } \\
\text { that specifically addresses the process flows, decision } \\
\text { rights and tools/templates related to the planning, } \\
\text { selection and prioritization of IT investments. }\end{array}$ \\
\hline $\begin{array}{l}\text { Architectural } \\
\text { Principles }\end{array}$ & Strategic & $\begin{array}{l}\text { Provides a roadmap and set of principles for all IT } \\
\text { activities and investments within the City. }\end{array}$ \\
\hline $\begin{array}{l}\text { Opportunity } \\
\text { Definition Form } \\
\text { (OPD) }\end{array}$ & Template & $\begin{array}{l}\text { Project proposal template to be completed by the } \\
\text { business client for any new IT-enabled project requests. }\end{array}$ \\
\hline $\begin{array}{l}\text { Project Statement } 1 \\
\text { and } 2\end{array}$ & Template & $\begin{array}{l}\text { For approved projects, the project statements, along } \\
\text { with the ODP form constitute the official project charter } \\
\text { for all IT-enabled projects. }\end{array}$ \\
\hline $\begin{array}{l}\text { Project Scoring } \\
\text { Matrix (PSM) }\end{array}$ & Template & $\begin{array}{l}\text { A business value assessment spreadsheet completed by } \\
\text { the business sponsor and IT PMO prior to project } \\
\text { approval and prioritization. }\end{array}$ \\
\hline $\begin{array}{l}\text { Project Selector } \\
\text { Dashboard }\end{array}$ & Inventory & $\begin{array}{l}\text { A full list of all projects currently being undertaken (or } \\
\text { planned to be undertaken) by the IT group ranked by } \\
\text { business value. }\end{array}$ \\
\hline $\begin{array}{l}\text { Eclipse Project } \\
\text { Management }\end{array}$ & System & $\begin{array}{l}\text { The Eclipse system contains all project proposal } \\
\text { information and rankings as well as all project status }\end{array}$ \\
\hline
\end{tabular}




\section{Table 3 - City A List of Artefacts}

In conjunction with the release of the PSP, three key templates were developed and released to the organization in support the overall ITPPS governance process within City

A. These templates include: 1) Opportunity Definition Form, 2) Project Scoring Matrix and 3) Project Selector Dashboard.

Opportunity Definition Form (OPD) - This form provides the primary mechanism by which business sponsors identify their needs and requirements for new IT-enabled investment projects to the IT group. It is a mandatory template that must be completed and approved by the business line director before a project request can be made to IT. The purpose of the form is to capture a brief synopsis of the intent of the IT investment, the current business and technical situation, the business service(s) affected or impacted, the target case for change, and the circumstances that are driving the need for this project. Additionally, according to the PSP, the OPD supports the City's transition to ensure that all IT projects are aligned to the council objectives as outlined in the City Strategic Plan.

"The OPD identifies which of the Corporate Strategic Plan priorities and commitments does this initiative contribute to and how, as well as the benefits and/or return on investment expected. The benefits are described in business terms such as improving service levels or customer satisfaction, increasing productivity, eliminating duplication of effort, generating efficiencies and savings, deferral of capital or operating expenditures, 
reducing risk of litigation or public embarrassment, achieving regulatory compliance, etc." (PSP, p. 11)

The completed form is initially submitted to the IT PMO for review and refinement. During this process, numerous revisions and clarifications may be made with the business sponsor before the form is presented to the SPC committee for approval and prioritization. Following its first tabling at SPC, the IT managers add IT-related elements to the submission, including resourcing constraints, scheduling issues and specialized technology requirements. The form is then re-presented to the committee for final approval and formal prioritization. Following approval, a second set of templates, the Project Statement 1 and Project Statement 2 templates are completed by an assigned project manager, and together with the OPD form comprise the official Project Charter. Subsequent project management and software development lifecycle templates are completed as part of the execution phase of the project.

Project Scoring Matrix (PSM) - The PSM is the second core document that forms the foundation of a business-sponsored project opportunity proposal. The matrix, which is based on the Fujitsu Value Model, generates a weighted average score for each project based on six dimensions: 1) legislative compliance, 2) strategic fit, 3) business outcomes, 4) financial implications, 5) business risk, and 6) technological risk. The purpose of the form is to provide the IT governance committees with a quantitative assessment of relative value of each of the project proposals to support the subsequent prioritization of all business requests. The PSM is meant to be completed by the business sponsor, as they are best positioned to describe the business-value of their 
project proposal. In practice, however, the majority of PSM templates are completed by the IT PMO with or without client collaboration.

The introduction of the PSM as part of the City's ITPPS routine directly reinforces the CIO's mandate to ensure that all IT decisions are aligned to the overall direction of the City. Business sponsors now not only have to demonstrate that their IT investment requirements are aligned to the organization's strategic direction, but also that their overarching business requirement is aligned. Business projects that are unaligned are unable to score highly on the PSM, and as such are unlikely to be actioned by the IT group. At the time of study, detailed financial assessments (ROI, hurdle rates, breakeven), and business/technical risks were not required as part of the input for completion of the PSM.

Project Selector Dashboard - According to the PSP, the purpose of the "dashboard" is to:

"provide a quantitative assessment of the project/initiative in order to assess the relative business value of IM/IT investments against a range of criteria, including regulatory compliance, strategic alignment/fit, business outcomes, and financial measures" (PSP, p. 11)

Overall, the Project Selector Dashboard provides the aggregated results of business value assessments for all projects. All project proposals (as well as all ongoing projects) are listed within the dashboard in declining order based on business value scores. As a visual guide, this tool allows SPC, ITAB and ITSC to review and refine the relative 
prioritization scores for all project demands on the IT group. The nuance of ranking based on relative importance is critical to the $\mathrm{ClO}$ since the number of projects that can be undertaken by the organization in any given year is directly dependent on IT resource availability and capacity. From this perspective, a business value score of High doesn't guarantee that a project will be completed by the IT group - as it would depend on the number of other projects that also carry a High and Very High ranking. By overlaying a capacity-based "waterline" on the dashboard, City decisions-makers are provided with a clear picture on which projects are most likely to be completed by IT in a particular time period.

\section{CITY B - VERY LARGE LOWER-TIER MUNICIPALITY}

City B is one of the top 25 largest municipalities in Canada with a population over 200,000 . The city is the largest lower-tier municipality that is part of an overarching regional municipality area. The city is responsible for the delivery and support of services to citizens that are not provided by the upper-tier government. As examples of this co-services model, fire services are provided by City B, however police and ambulance services are provided by the regional government. Likewise, City B is responsible for water distribution, but the regional government is responsible for water supply and water services (i.e. water treatment plants).

The city has a strong European ancestry and a population that is predominantly Caucasian. Only 15\% of citizens self-identified as a visibility minority in the 2011 national census. Primarily a blue-collar workforce, the economy has traditionally been 
grounded in manufacturing; however finance and insurance sectors are slowly becoming the most dominant employers in the city. Unemployment rates are slightly below the national average with a seasonally-adjusted average of $6.8 \%$.

City B is governed by ten councillors, each representing a city ward, and a mayor. Four councillors at large sit with the mayor on the council of the regional municipality. The mayor and councillors sit for a term of four years, with elections occurring in late October. The city staff is led by a Chief Administrative Officer and three Deputy Chief Administration Officers (DCAOs), who each head one of the three City Departments. A number of core administrative functions, such as marketing, communications and strategic planning report directly into the CAO. The IT group, which is currently led by an interim $\mathrm{ClO}$, is one of a number of internally-focused divisions within the Finance and Corporate Divisions Department.

As with most municipalities, the direction and objectives of the city are mapped out in a four-year strategic plan set out at the beginning of each government's term. The current plan is built around six core priorities, including improving the quality of life of all city residents and revitalizing the downtown core. The plan is underpinned by two foundational strategies to support the development of city employees and ensure the government operates in an efficient and effective manner. As part of the second foundational strategy is a commitment to ensure that technology supports the timely provision of information for city decision-makers as well as provides innovative and diverse channels for communication with city constituents. In addition to the strategic 
plan, the city's Corporate Leadership Team (CLT) publishes a three-year business plan that outlines all the projects that city staff will undertake in support of the city's core services and council priorities.

City B's IT team is comprised of 53 full-time individuals working within three service groups: Client Services and Infrastructure, Project and Planning, Business Systems and Database. The division is considered a strategic partner for city programs and services, and is responsible for the planning, development and management of the City's information technology systems. The team is responsible for supporting eight core enterprise applications (SAP, PeopleSoft, etc.), over 1300 end users across 50 different city-owned sites, and 2140 end user computing and communication devices.

\section{City B's IT Investment Planning, Prioritization and Selection Environment}

In 2009, the city commissioned the development of a Corporate Technology Strategic Plan (CTSP) in order to provide a framework that ensures the city's business technology continues to support an efficient and effective government. A central focus of the CTSP process was "to define how the City would go about evaluating and prioritizing business technology requirements and systems" (CTSP, p. 9). The plan was approved by council in 2010 , with implementation activities commencing at that time.

Prior to the implementation of the CTSP, IT investment decisions at the city were made on an ad-hoc basis, with most divisions proposing and implementing program areaspecific solutions. Many investments were based on "chasing upgrades" where business lines were interested in obtaining the latest gadgets or the latest functionality with little 
to no justification of the business need being solved by the investment. A corporatewide IT governance committee did not exist, and all prioritization decisions were made on an individual basis between the project's sponsor and the IT management team. Core corporate systems were identified and managed in an integrated manner; however business areas had no obligation to consider leveraging these systems when bringing forth new requirements. According to the CTSP, at the time, the city had a "lack of corporate level technology governance and leadership" and clients saw the IT environment as one of control, not one of enablement.

Original recommendations from the CTSP included: 1) implementation of a directorlevel IT governance committee charged with IT decision making regarding direction, investments, policy, and standards, 2) implementation of an IT Portfolio Evaluation committee charged with evaluating and prioritizing new project proposals for recommendation forward to the IT Governance Committee, 3) establishment of a corporately-endorsed prioritization ranking criteria, 4) refinement of existing core enterprise system working groups to establish clear reporting relationships to other governance bodies, and 5) creation of an IT Planning and Projects function within the current IT organization.

The implementation of these activities were planned to be undertaken over a five year period. Up to the point of our research study, some recommendations were completed, while others remain works-in-progress. A number of changes to senior leadership during this period has led to some refinement and repositioning of the originally 
envisioned IT governance model. Membership and mandate of IT governance bodies have been modified and supporting artefacts have evolved based on their maturation path.

The current IT governance framework is captured in the city's Governance Master Document (GMD). Although written in 2012, the document remains in draft form and has not received formal endorsement from the city's senior management and/or council. The document was authored by the IT group, and as of yet has not been shared widely to the rest of the organization. The primary focus of the document is to provide clarity and accountability to the ITPPS routine and ensure that the "right" projects are being worked on. The intent of the overall IT governance model is to "ensure that the technology initiatives which are undertaken are the most important, or are those that will return the most value to the City as a whole" (GMD p. 2). Figure 9 provides an overview of the IT governance framework as it is documented within the GMD. 
IT Governance Model

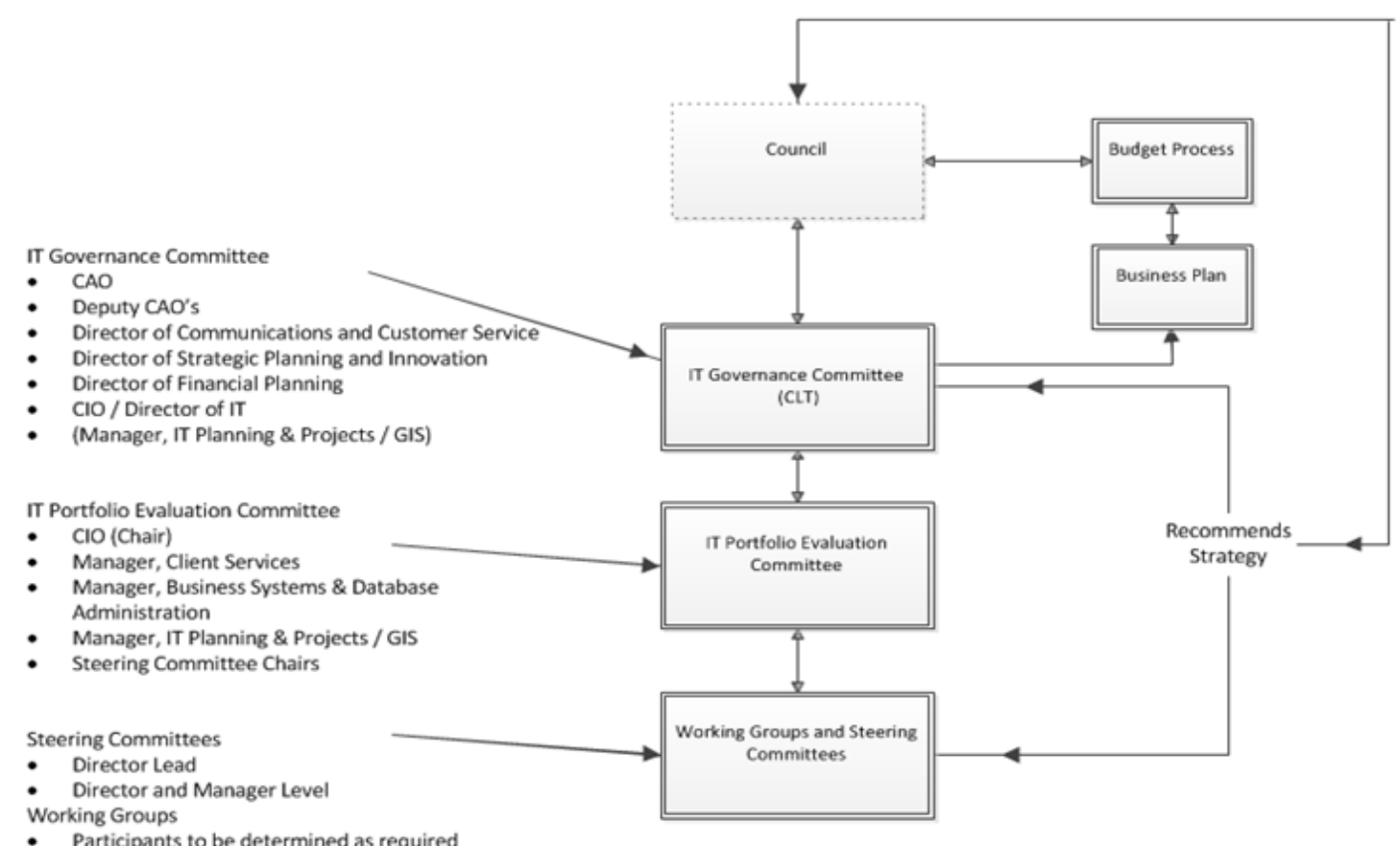

- Participants to be determined as required

Figure 9 - City B Master Governance Model (GMD, p. 3)

Based on interviews, and observation, the actual implementation of the IT governance

framework has led to a reality that is significantly different than that outlined above.

Although some of the names of the committees remain the same, the mandate of each

of these groups as well as the flow of decisions and accountabilities have evolved

differently than depicted. As a means for outlining the current IT governance

environment, a description of IT governance committees and artefacts is provided.

\section{IT Governance Committees}

Corporate Leadership Team (CLT) - The corporate leadership team is the most senior

governance body within the city responsible for oversight of all city planning, fiscal and 
operational activities. Membership includes the CAO and the three DCAOs according to the city's municipal code, however a number of directors, including the director of communications and the director of strategic planning are considered permanent members of this committee. Other directors are invited to committee meetings as required and as needed.

The role of the CLT in IT governance is tenuous at best. The body doesn't see itself as an IT project approval committee and is not interested in the minute details of IT projects status and progress reports. Although, the GMD describes the committee's role as being responsible to "evaluate projects and its merits and recommend priority, ranking, resourcing and budget and impacts/changes to other project in rank or priority" (GMD, p. 13) when presented with an entire list of all active and proposed IT projects at one of the first IT governance discussions the $\mathrm{CIO}$ was asked to scale back considerably on the type of information that IT brings to this committee. Since then, the role and mandate of $\mathrm{CLT}$ in the routine of project selection and prioritization has been unclear to most stakeholders.

According to the $\mathrm{ClO}$, the body is still struggling with understanding its role:

"Well, the expectation for CLT has changed a little bit. They have made it known that they weren't interested in the detailed level so they've really requested that we bring strategic updates to them that we bring any issues that need to be followed up from the prioritization process. So we more or less, I don't want to say we inform them. They are still at the top level approval body and if there was a contentious issue it would go to them in 
terms, so they are kind of the rubber stamp to the information that's being provided." (A2G107)

A number of other participants echoed the notion that this committee was simply a rubber stamp for project approvals. When asked whether CLT provides any decisions on projects selection or prioritization, one director on a lower governance committee responded: "I don't think they do. No, I don't think they do. I think they're comfortable ... I don't know why they'd challenge anything" (A2G102). The comfort level, according to a member of the CLT comes from knowing that another governance body is capable of making the prioritization and selection decisions, leaving CLT free to address more strategic IT issues:

"And I think the realization came very quickly that many of those decisions can actually be made level lower and that CLT increasingly has an interest in focusing on these strategic projects like customer service of any service like implementing mobile technology, internal collaboration and the ERP agenda that it's less about approving five timeline extensions that no one really cares about on a helpdesk backup system upgrade." (A2G108)

IT Portfolio Evaluation Committee (IT-PEC): The IT-PEC committee is the most senior IT decision-making body within the organization. While CMT addresses a variety of corporate and strategic domains, IT-PEC is exclusively "responsible for evaluating (and challenging) new project proposals and applying the corporately endorsed (IT Governance Committee approved) ranking criteria for evaluation of technology projects" (CTSP, page 31). Members of this committee include the leads of all eight core enterprise application steering groups, the $\mathrm{CIO}$ and two managers of the IT group. PhD Thesis - Allen E Brown 
Given that the leads for the core systems are all from business lines outside of IT, the membership ensures director-level engagement by both business and technology representatives in planning, prioritization and selection activities. The mixedmembership was an explicit approach to ensuring that the city's program areas take a more active role in IT decision making.

From almost all accounts, IT PEC is a poorly functioning governance body:

"I personally don't understand the purpose of it." (A2G203, IT-PEC Member), "There hasn't been a lot of meaningful dialogue at those meetings with the group around the table. I think it's almost like it's a rubberstamp level at that point without the discussion." (A2G102, IT-PEC Member)

"Some of them (IT PEC members) are quite inexperienced. I mean we have somebody from IT putting it all together and leading and I found it is not working well with me... I just think we need to have better direction." (A2G106, IT-PEC Member)

"I wouldn't call it a decision making group more of a collaboration and consultation forum." (A2G208, CMT member)

Currently, no formal Terms of Reference (ToRs) exist for the IT-PEC committee outside of the GMD and clearly the performance of the committee reflects this lack of mandate and direction. Almost every single member of the IT-PEC interviewed cited the fact that IT-PEC is a governance body searching for a purpose and a raison d'etre. Decisions are not made at this committee as projects arrive already pre-prioritized and pre-selected 
by the IT group. Project extensions and scope requests are dealt with on a one-on-one basis outside of the governance structure. IT steering committees plan and prioritize investments against core enterprise systems and team leads simply provide a summary of decisions to the other IT-PEC members. After all this is done, there is a feeling amongst IT-PEC members that there is nothing left to discuss or decide within a sitting of this committee.

IT Steering Committees - Eight steering committees represent each of city's eight core enterprise systems: Finance (SAP), Revenue / Customer Information (CIS), Human Resources (PeopleSoft), Operations/Work Order (CityWorks), Licensing and Enforcement (AMANDA), Spatial data (GIS suite), Facilities booking (CLASS) and Fire Systems. Each of these steering committees is led by a business line director whose program area corresponds the most directly with the core functionality of the enterprise system (i.e. The SAP steering committee is led by the Director of Finance). Membership is granted to senior individuals from teams who interact with or rely on the information within the core system. Although each has a slightly different structure, the IT steering committees are supported by a network of workgroups and sub-steering committee groups made up of specific user and system support teams.

Core system steering committees are responsible for planning and overseeing maintenance and upgrades to the core enterprise system. The steering committees are not funded directly for the stewardship of these systems and must draw on user-base budgets to support the ongoing upkeep of the system. In addition to generating annual 
workplans, the steering committees are also responsible for evaluating, screening and prioritizing enhancements and modifications to the current system configuration. Small projects are prioritized and approved within the steering committee; however larger scale projects, such as the roll-out of a new module within SAP, are brought to IT-PEC for approval and for scheduling.

IT Management Committee - The IT Management Committee is the only IT governance body that is solely comprised of IT personnel. As the most senior IT decision making authority, the IT Management Committee is made up of the $\mathrm{CIO}$, three IT managers and a set of Business Systems Project Managers (BSPMs). The BSPMs are a relatively new role within the city representing IT resources that are embedded into one or more business program areas in order to solicit requirements from business sponsors and help facilitate the submission of IT investment proposals on behalf of their clients.

The IT Management Committee meets weekly to review the progress of current IT projects, as well as evaluate and rank any new IT project submissions. The committee maintains a master list of all active and proposed projects and publishes this list periodically for organization-wide consumption. When a new project is proposed, the BSPM presents an overview of the project, including scope, objectives and benefits for discussion by the committee. If there are any outstanding questions that the BSPM is not able to answer at the time, they will follow up with the business sponsor and represent the proposal at a subsequent committee meeting. This cycle repeats until the project is fully scoped, and the IT Management committee feels it has sufficient 
information to formally approve (or reject) the proposal. Once approved the project receives a priority ranking between 1 and 4 based on the importance and urgency of the request. The recommendations of the IT Management Committee are then taken biannually to IT-PEC for formal endorsement.

It is interesting to note the IT Management Committee was not identified as an IT governance body within the proposed IT Governance framework of the CTSP, however it later appears within the GMD with an objective to "review new project proposals, opportunities and project change requests to determine/recommend where the projects fit in the schedule" (GMD, p. 31). In complete contrast to the CTSP (but in alignment with the GMD), and according to many interview participants, the IT Management Committee does rank and prioritize IT investments, but typically not on their business value, but primarily with respect to the IT shop's capacity and resource requirements.

"So the goal when it's brought to the IT management meeting, it's for everyone to look at and say, "Yeah I have seen it, I understand it, I'm in agreement with it." and then in between when they are doing those scoping and developing that project charter that's when they are really participating if they have any resource requirement in there so that's their role." (A2G107, IT Management Committee member)

"There may be things they ask clarity on like what are the resources that are required to support it and to go back and make sure we have that documented or right now infrastructural costs the way we assign costs to 
servers there is not a formal process." (A2G105, IT Management Committee member)

The IT Management Committee strives to say "yes" to as many IT investment proposals as possible. The consultative approach adopted by the committee allows business sponsors to receive feedback, adjust and refine, and then ultimately resubmit their proposal. Rarely, if ever in fact, do business sponsors ever receive an outright rejection to their proposal. At the most, they may have their project ranked low or rolled into another similar or symbiotic project.

"A project being rejected...No I can't think of anything being rejected" (A2G101, IT Management Committee member)

"I think that we do have the opportunity to reject projects. It's just I don't think I have actually seen it" (A2G104, IT Management Committee member)

For all intents and purposes an approval with a priority ranking of 4 is a soft rejection. Although the definitions of the ranking are not accompanied by specific service level guarantees, projects with a rank of 4 are deemed to be addressed on a "best-efforts" basis and realistically could sit in the queue for months, if not years, depending on the volume of higher priority items within the process. As such, the IT Management Committee is often more concerned with placing projects within its delivery schedule rather than prioritizing each project based on a criterion of merit such as alignment to strategic priorities and cost-benefit analysis. 


\section{IT Governance Artefacts}

Table 4 provides a summary of all key artefacts related to the ITPPS routine for City B. It should be noted although the artefacts listed in the table are directly related to the ITPPS, they are by no means the only artefacts that play a role in the routine. Peripheral artefacts include council issues sheet templates, corporate business case templates, budget worksheets, SAP-based financial forecasts, divisional operating plans and SDLCbased design artefacts.

\begin{tabular}{|c|c|c|}
\hline Artefact & Type & Description \\
\hline City Strategic Plan & Strategic & $\begin{array}{l}\text { Outlines the four-year strategic direction and } \\
\text { objectives of the city. All investment activity within } \\
\text { the city must align to plan. }\end{array}$ \\
\hline $\begin{array}{l}\text { Corporate } \\
\text { Technology } \\
\text { Strategic Plan }\end{array}$ & Strategic & $\begin{array}{l}\text { Sets the five year direction for IT transformation. } \\
\text { Provides objectives and targets for IT activities, } \\
\text { including governance. }\end{array}$ \\
\hline $\begin{array}{l}\text { Governance Master } \\
\text { Document }\end{array}$ & Strategic & $\begin{array}{l}\text { Outlines the city's IT governance framework and } \\
\text { provides draft Terms of Reference for all governing } \\
\text { bodies. }\end{array}$ \\
\hline Project Scope Form & Template & $\begin{array}{l}\text { Preliminary project proposal template to be } \\
\text { completed by client and BSPM when submitting a new } \\
\text { IT investment request. }\end{array}$ \\
\hline $\begin{array}{l}\text { Project Charter } \\
\text { Template } \\
\text { (Light/Regular) }\end{array}$ & Template & $\begin{array}{l}\text { After initial project scoping is complete, the BSPM } \\
\text { completes a Project charter that clearly outlines roles, } \\
\text { expectations and timelines for any approved project. }\end{array}$ \\
\hline $\begin{array}{l}\text { Project Tracking } \\
\text { Sheet }\end{array}$ & Inventory & $\begin{array}{l}\text { The project tracking sheet provides the status of all } \\
\text { active projects, including final project rank and }\end{array}$ \\
\hline
\end{tabular}


expected delivery timelines.
APEX
Systems
The APEX system contains all project proposal
information and ranking levels. APEX is a home-grown
project management tool that is currently being used
to provide project status reports.
System and Program Operational The roadmaps provide a schedule and sequencing of Area Roadmaps planned IT investments against core systems and individual program areas.

\section{Table 4 - City B List of Artefacts}

Out of the list above, two of the artefacts are identified as the most critical to the ITPPS routine: The Project Scope Document and The Project Charter Template.

Project Scope Document - The project scope document is required to be submitted by any business sponsor wishing to engage the IT group in the development or purchase of an IT-enabled solution. The scope document is a one-page template that addresses the "who, what where, when and why" of any project proposal. It also solicits a high level budget estimate and identifies the source of funding for the project, which many clients find difficult to assess at such an early stage of planning. From the answers provided to the various questions in the scoping document the BSPM is able to assign an initial ranking to the project based on project importance and project urgency that is provided to the IT Management Committee along with the scoping document itself.

The introduction of the form into City B's ITPPS routine has forced business sponsors to think through their project requirements prior to approaching the IT group. With the help of the Business Systems Project Managers (BSPMs) assigned to each department, 
clients now have to consider their role and readiness for an IT project before identifying it as a potential investment. The result of this reflective period has been a drastic reduction in the number of superfluous IT-enabled project requests that are passed on the IT group. In fact, since the adoption of this template the potential project list has dropped from 200-300 items to just over 50.

"So we have come a long way, I don't know if you have talked about the project numbers. When we started I don't know how many projects were funded and we are now down to dozens, right. And so that is a testimony in itself to how we have been able to get our arms around the portfolio" (A2G108)

Project Charter - The project charter template (light or regular) is used to capture additional project planning information beyond the initial idea outlined in the scoping document, such as schedule, milestone, constraints and parameters, and project team structure. Formally the project charter is to be written by the BSPM after receiving approval to proceed with a project, and as such this should not be considered an artefact in the ITPPS process. The charter however is important for two reasons:

1) For larger projects, the IT management committee and IT-PEC may ask for a project charter to be developed before deciding on a formal ranking and prioritization. Additionally, projects that are submitted directly to city council for approval may require a project charter as well as a business case to receive funding and endorsement. Therefore the project charter is sometimes part of the decision-making process on project acceptance and sometimes not. 
2) Given that the project scope document is extremely succinct, IT investment decisions are made with very little project-based information. As such, projects can get into the investment and prioritization process with a limited scope statement that can then change considerably when the project charter is written. This is important because currently the city does not have any governance mechanism to review or reconsider projects once they have been initially approved and ranked. On occasion projects have morphed into a considerably different set of activities, once the project passed the initial scope approval stage.

Based on the ITPPS environments in each organization and guided by the interview and document review data, the following chapter provides an in-depth analysis of sources of divergence identified within the two case studies. A subsequent cross-case, aggregated analysis is then presented in Chapter 7. 


\section{CHAPTER 6 - EMPIRICAL ANALYSIS OF CASE STUDIES}

\section{CITY A - ANALYSIS OF DIVERGENCE}

To understand the sources of divergence within City A, we first need to understand the expected behaviour and expected outcomes of the overall ITPPS routine. For City A, expectations for this routine are captured from two sources: council expectations and governance owner expectations. The former drives and informs all business decisions and activities within the organization and the latter more specifically addresses the ITPPS routine.

\section{Council Expectations}

As a starting point, council expectations can be drawn for the City's Strategic Plan (CSP). The CSP provides city staff with a set of investment priorities by laying out the overarching strategic direction of the city over a four year period. Central to the plan are six areas of primary focus: 1) maintaining and enhancing infrastructure, 2) enabling economic development, 3) rejuvenating brownfields, 4) facilitating affordable housing, 5) creating and protecting greenspaces, and 6) developing proactive community plans (CSP, p.15). Although somewhat abstract and distant from the ITPPS process, at a highlevel, these strategic pillars provide insight into the types of investments (both business and IT-enabled) that council would expect.

Diving deeper into the CSP, council (along with the CMT) make a few specific mentions of Information Management and Information Technology activities and expectations. 
As part of eight administrative initiatives designed at improving the way in which city staff services the needs of constituents, two initiatives related to IM/IT are mentioned:

- "review and improve technology solutions and corporate systems and processes to gain improvements in information and eliminate duplication and manual processes across the corporation through system integration"

- "increase use of technology for council meetings and public engagement" (CSP, P. 11)

Distilling the wording of these initiatives, it can be drawn out that the city council expects that any decision-making surrounding IT investments consider 1 ) the reduction of redundancy and overlap of existing systems, 2) provide value by automating horizontal and manual processes, 3) support an integrated system architecture approach and 4) drive innovative public-facing service channels. The true motivation for the last expectation is explained by one CLT member:

"Our council has decided that on one of its key priorities is to improve customer service, particularly customer service that hopefully results in economic growth through development in the City...I'm not suggesting disagreeing with that decision, simply there is an example of where our governing body who are elected officials, who are politicians have identified that as a direction that's really important." (A1G210)

The most direct manner in which council has provided its expectations of the behaviour of the IT investment routine is found in its approval and endorsement of the City's IT Vision and Strategic Technology Plan. The plan, based on the vision to "transform the 
(IT) department from what was once a back-office set of technical support services to a trusted business partner and a value-added enabler of the business" (ITGF, P. 7) outlines two overall council expectations: 1) The IT group focus on professional development (i.e. improve project management capabilities, adopt an ITIL operational governance model, improve configuration and incident management routines), and 2) Increase business participation in the management and oversight of IT-enabled projects.

The second item directly addresses the expectation that the governance surrounding IT investment decisions is a city-wide concern, and no longer just the concern of the IT group. As the top public servant in City A, this Chief Administration Officer supports this position as evidenced by his focus on ensuring the organization moves away from operating as distinct and separate business units and towards operating as a single strategic entity (FN G1 Sponsor). The CAO recognizes that for the IT group to be successful, the rest of the organization must be involved in IT decision-making:

"we all have our roles to play in helping that organization be successful and, so while he, you know, supports the departments running the businesses the way they see fit, he also understands or he also makes it very clear that there are parts of the organization, particularly the support departments like IT for example that have a role to play in making that successful...so that does require co-operation and an understanding, and he does push them to make their (IT investment) intentions known as much as possible" (A1G101) 


\section{Governance Owner Expectations}

Expectations of the overall IT Governance system and specifically the ITPPS routine are derived from interviews within the A1G1 group as well as three key pieces of documentation: The IM/IT Governance Framework (ITGF), the Project Selection and Priority Policy (PSP) and the published IT Architectural Standards. Although, like any artefact, the IT governance documentation is susceptible to a level of representational divergence, these items are not used as artefacts within the performance of routine and therefore provide a reliable manifestation of the expectations of the City's IT governance owners.

At the time of research the ITGF was incomplete and unpublished. However, the section on governance of project selection and priority setting was completed and this text was approved by CMT and council in 2012. The overall purpose of the ITGF is to "provide the reader with an overview of IT Governance, management principles and service delivery processes, and the accountability / decision-making framework that clarifies the responsibilities and accountability of each decision-maker or decisionmaking body" (p6). In addition to outlining the governance mechanisms associated with the planning, prioritization and selection of IT investments, the document has placeholders to address the governance of decisions related to the service delivery model, approval of strategic and operational plans, technical architecture choices, information architecture choices, dispute resolution, operational decisions, changes to policy instruments, resource allocation service level agreements and priority setting. 
The PSP, as a testament to the importance of the IT investment routine within the larger IT governance system, unlike the ITGF is fully completed and was also approved by senior management and council in 2012 alongside the straw man of the ITGF. According to the PSP, the purpose of the ITPPS routine within the City is "about identifying the right projects for the city to invest in" (PSP, p. 5). To support the selection of "right projects", the PSP outlines the various governance mechanisms (committee structures and templates) that have been implemented in support the IT investment decisionmaking routine.

As the final manifestation of IT governance owner expectations, the published IT Architectural Principles provide a set of core values that underlay all decision-making related to IT assets within the City. These ten principles include: 1) Architecture Driven by Business Need, 2) Architecture Driven by Enterprise Vision, 3) Buy Before Build, 4) Compliance with Technology Standards, 5) Compliance with Application Development Standards, 6) Enterprise Dynamic Security, 7) Reuse of Services, Applications and Infrastructure, 8) Systems Continuity and Disaster Recovery, 9) Documented Designs and Architecture, and 10) Continuous Consolidation. As a set, the architectural principles provide a framework by which IT investment decisions must be made. Different than the ITGF and the PSP, the principles don't directly prescribe the minute behaviours associated with the ITPPS routine, but rather describe an evaluation criterion for defining the "right" IT investments. 
When interviewing members of the IT governance ownership group, soliciting the expectations of the ITPPS routine proved to be more difficult a challenge than might be thought. Although many governance owners felt that the routine was functioning well, they were not able to easily define the expected behaviours and outcomes. The question of "what does good look like" proved to be significantly elusive for many governance owners to answer. The question was often answered indirectly or not answered at all. The nuance of this observation cannot be overstated: IT governance owners were generally positive about the performance of the routine, but at the same time could not easily articulate the expected behaviour of the routine. The answer to this dichotomy rests in the fact that for most governance owners, "effectiveness" of the routine was related to maturation, existence of mechanisms, and the adoption of a formal structure. For the IT governance owners, the effectiveness of ITPPS routine was not generally viewed in terms of an alignment between expected and actual behaviours.

"I think it is developing in the right direction. Yes. In the past 18-24 months I have seen significant improvement not only in communication and defining of the processes around how we do things but in the inputs from the business clients. I would really say it is coming along nicely" (A1G102)

"We're definitely doing a much better job, than we were seven years ago. Another way of putting this, it's getting better all the time. There's surely is room for improvement. I haven't heard of anybody who's suggesting that decisions that have been made that didn't work out that had significant impacts on either on a corporate or departmental level. I think in that sense, it's working, I'm sure like most things, it can get better." (A1G110) 
"we defined and developed a process over the past two to three years and communicated and educated and pushed and pushed to get the processes in play. So it is getting better." (A1G102)

"I think well, we have made a good step" (A1G101)

"I know that (the $\mathrm{ClO}$ ) is doing a lot of work to try and get that process streamlined and make sure that IT stays relevant. I think that there is a conscious effort to get IT from an order-taker role to a strategic partner role." (A1G104)

As with any organization, the ultimate output of the City's ITPPS routine is a clear, definitive and defined list of IT-enabled projects that the organization will be undertaking in any given period. Given that the capacity to deliver on IT projects is finite (even when outsourcing the majority of IT activities, organizations are still constrained by their ability to oversee and manage multiple external sources of delivery as well as the ability to pay for all these external services), the purpose of the routine is to facilitate the development of a work plan for the IT group that ensures an optimum allocation of IT capacity and resources to the IT needs and requirements of the organization. From this perspective, we can define the overall expectations of the routine in more tangible terms, namely the governance owner's expectation of the composition and make-up of the final approved IT-enabled project investment list. Thus, according to the core governance documents and from interviews with the IT governance ownership group, the expectation of the ITPPS routine is the proposal of a set of approved investment activities that are: 
1. Directly and overtly aligned to city priorities and strategic direction

2. Based on clearly articulated business value propositions

3. Reflect the need to balance between corporate-wide and business-specific benefits

4. Favourable to projects that promote horizontal alignment and existing system reuse

5. Prioritized by the business, for the business and based on business needs

6. Established as part of the bi-annual corporate planning process

The substantiation of the IT governance owner list of expectations is presented in Appendix J. Overall, when comparing the expectations of the IT governance owners and those of city council, there is a clear relationship between the two sets of expectations. Table 5 provides a mapping of the two sets of expectations.

\begin{tabular}{|l|l|}
\hline Council Expectations & IT Governance Expectation \\
\hline existing systems & $\begin{array}{l}\text { Favourable to projects that promote horizontal } \\
\text { alignment and existing system reuse }\end{array}$ \\
\hline $\begin{array}{l}\text { Provide value by automating horizontal } \\
\text { and manual processes }\end{array}$ & $\begin{array}{l}\text { Based on clearly articulated business value } \\
\text { propositions }\end{array}$ \\
\hline $\begin{array}{l}\text { Support an integrated system architecture } \\
\text { approach }\end{array}$ & $\begin{array}{l}\text { Favourable to projects that promote horizontal } \\
\text { alignment and existing system reuse }\end{array}$ \\
\hline $\begin{array}{l}\text { Drive innovative public-facing service } \\
\text { channels }\end{array}$ & $\begin{array}{l}\text { Directly and overtly aligned to city priorities and } \\
\text { strategic Direction }\end{array}$ \\
\hline Business-Led ownership of IT decisions & $\begin{array}{l}\text { Prioritized by the business, for the business and } \\
\text { based on business needs }\end{array}$ \\
\hline
\end{tabular}


Table 5 - Mapping of Council Expectations and IT Governance Owner Expectations

The close mapping of expectations obviously represents the strength of alignment between the two stakeholder groups. As the only point of contention, council is very specific through the CSP that it would favour IT investment decisions that drive innovative public-facing service channels. The IT governance ownership group does not privilege this mandate above and beyond any other elements of the city strategic direction and objectives. We choose not to add this as a separate specific expected behaviour because the overarching theme of improving customer service is outlined in the CSP as one of six corporate strategies, and as such would be considered in more broadly defined IT governance owner expectation.

\section{Substantive Divergence}

Based on our proposed framework, the amount of substantive divergence found within IT investment routine within City $A$ is strictly a function of the underlying representational, translational and performative sources of divergence. As such by discussing those individual sources of divergence, we in turn can then provide an assessment of the degree to which substantive divergence exists within the organization. On a holistic level, as identified in Figure 10, through a preliminary comparison of the set of overarching expectations by the IT governance group to the actual behaviour of the ITPPS routine, we can easily identify a couple of clear examples of substantive divergence that can direct and inform our analysis in subsequent sections. 


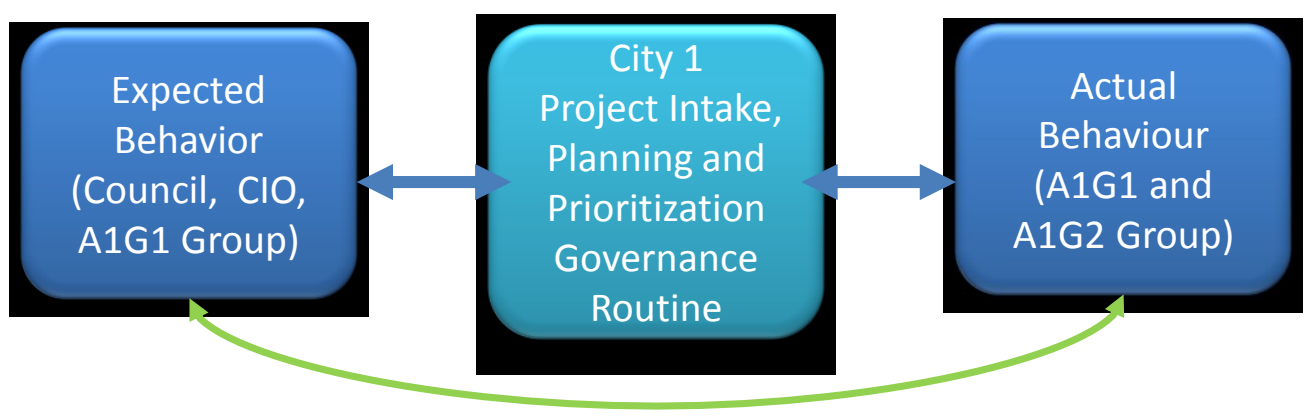

\section{Substantive}

Divergence

Figure 10 - Substantive Divergence within City A

By overlaying the expectations of city council and IT governance owners on the high-

level descriptions of the routine as presented within the ITGF and PSP documents

(including the outline of specific mechanisms as part of this routine), we can quickly

assess whether these expectations can be achieved through the implementation of the

proposed governance structure. Although specific, artefact-based divergence will be

discussed as part of the analysis of representational divergence, Table 6 provides a high-

level assessment of whether the desired behaviours are supported by the overall set of

mechanisms implemented by the organization.

\begin{tabular}{|l|l|}
\hline Expected Behaviour & Preliminary Assessment \\
\hline $\begin{array}{l}\text { IT Investments directly } \\
\text { and overtly aligned to } \\
\text { city priorities and } \\
\text { strategic direction. }\end{array}$ & $\begin{array}{l}\text { Appears to be well supported. The current IT investment } \\
\text { list is prioritized based on a business value assessment } \\
\text { score. This score is heavily weighted on the alignment of } \\
\text { an IT investment proposal and the strategic priorities of } \\
\text { the city. }\end{array}$ \\
\hline $\begin{array}{l}\text { IT Investments based on } \\
\text { clearly articulated } \\
\text { business value } \\
\text { propositions }\end{array}$ & $\begin{array}{l}\text { Appears to be well supported. The current IT investment } \\
\text { list is prioritized based on a business value assessment } \\
\text { score. The articulation of business value propositions } \\
\text { (excluding financial cost/benefit analysis) is required as } \\
\text { part of the assessment activities required when a } \\
\text { proposal is submitted for consideration. }\end{array}$ \\
\hline
\end{tabular}




\begin{tabular}{|l|l|}
\hline $\begin{array}{l}\text { IT Investments that } \\
\text { reflect the need to } \\
\text { balance between } \\
\text { corporate-wide and } \\
\text { business-specific } \\
\text { benefits }\end{array}$ & $\begin{array}{l}\text { Difficult to determine level of support. The current IT } \\
\text { investment list is categorized by client department, with } \\
\text { no indication or prioritization based on the corporate } \\
\text { nature of the investment. How the list represents a } \\
\text { "balance" between corporate and business line } \\
\text { applications is unclear. }\end{array}$ \\
\hline $\begin{array}{l}\text { IT investment decisions } \\
\text { favourable to projects } \\
\text { that promote horizontal } \\
\text { alignment and existing } \\
\text { system reuse }\end{array}$ & $\begin{array}{l}\text { Appears to be unsupported. A number of projects on the } \\
\text { current IT investment list provide overlapping functions } \\
\text { to existing application (i.e. multiple systems currently on } \\
\text { the list that house basic personnel, HR-related } \\
\text { information including HASTA, Firehouse and PeopleSoft). }\end{array}$ \\
\hline $\begin{array}{l}\text { IT Investments } \\
\text { prioritized by the } \\
\text { business, for the } \\
\text { business and based on } \\
\text { business needs }\end{array}$ & $\begin{array}{l}\text { Appears to be well supported. The current IT investment } \\
\text { list was "approved" by business-based IT governance } \\
\text { bodies. }\end{array}$ \\
\hline $\begin{array}{l}\text { IT Investment decision- } \\
\text { making established as } \\
\text { part of the bi-annual } \\
\text { corporate planning } \\
\text { process }\end{array}$ & $\begin{array}{l}\text { Appears to be unsupported. The current IT investment } \\
\text { list contains projects that have been submitted } \\
\text { throughout the year. Mechanisms to ensure that all IT } \\
\text { investment planning is performed as part of the bi-annual } \\
\text { corporate planning process do not appear to exist. }\end{array}$ \\
\hline
\end{tabular}

Table 6 - Preliminary Assessment of Substantive Divergence

Overall there appears to be a general and cursory alignment between the desired and actual behaviours of the ITPPS routine (as evidenced between the expected behaviours list and the formally published IT investment project list). However, based on this preliminary assessment, two behaviours appear to be significantly misaligned and unsupported: 1) the desire to favour IT investment projects that promote horizontal alignment and existing system reuse, and 2) the desire to ensure that IT Investment decision-making is established as part of the bi-annual corporate planning process.

The notion of ensuring IT Investments leverage existing City applications or address multiple business line requirements is a central architectural principle of the 
organization. The current investment list knowingly contains a number of system development activities that could be addressed through existing corporate applications. As the most glaring example of this, current projects from the fire group (Firehouse), housing (Goldcare), and transportation (HASTA) all represent applications that could clearly be addressed through integration with the central Enterprise Resource Management solution for HR (PeopleSoft). A similar situation exists with the realm of financial-based systems.

"We have probably 10 different payment methodologies for paying things like pet licensing, for property taxes, for tickets and so on. Different providers, different processes... Each department does their own thing with their own members." (A1G104)

The fact that the City has active projects that overlap in functionality is definitely not unique. Most organizations struggle with this situation. What's interesting in the case of City $\mathrm{A}$ is the fact that reuse and horizontality are explicitly defined as core expectations of the ITPPS routine. Nothing within the current set of IT governance mechanisms (be it committee terms of reference or process artefacts) appears to reinforce a prioritization or selection of projects that demonstrate potential for reuse. IT steering committees have been established to drive prioritization of activities within the purview of a particular corporate system (PeopleSoft or SAP), however there doesn't appear to be any formal connection between these committees and those implemented to support the IT investment routine. As we'll see in the discussion on 
corrective divergence, this gap in formal structure is not lost on the members of the IT management group.

The second example of substantive divergence evidenced within the most recent output of the ITPPS routine is the fact that the list of IT investment projects reflects a set of business demands that have been brought forward to the IT organization throughout the entire year. Given that nothing in the current governance mechanism directly supports the entry of business requirements as part of the bi-annual planning cycle, the actual behaviour of routine actants should not be surprising.

"what I have seen is that if I look at the number of projects that we are working on that have been formally approved by our IT steering committee for example, I'm seeing that actually decline over time, so a greater percentage of projects are unplanned" (A1G101)

"For example we have got one as of late which is a centralized maintenance management system that we are looking at implementing. It was nowhere on the radar and actually caught our $\mathrm{CIO}$ and his staff by surprise." (A1G110)

Even within the IT group, the behaviour to submit IT investment requests outside of the formal planning window was facilitated.

"I had that actually occur last year, where with departments, and I suspect it wasn't intentional but I just think it was, perhaps they weren't aware or didn't understand the implications, but they came forward and said 'I have money in my budget that I have to spend by the end of the year, and I want to buy this system' and, you know, I didn't take that and say 'okay, well here 
is our process...but here is what I propose that we do and then we sat down and, and we found a way to protect the money, so that a) it took the pressure off the table and b) we have isolated the work within a specific program area and got that program to re-prioritize the work so that it then became a priority for them but didn't really affect the rest of the corporation." (A1G101)

As evidenced by these two examples, at a high-level, substantive divergence exists within City A. Despite the fact that the expectations between the two distinct stakeholder groups are tightly aligned, the manner in which the ITPPS routine is instantiated in the City leads to an observable level of divergence between expected behaviours and actual behaviours. Drawing from the overall narrative of the ITPPS routine (presented in Appendices K, L and M), and grounding in our proposed research framework, the following sections provide an in-depth analysis of the various sources of governance divergence that are found within City A.

\section{Representational Divergence}

Within City A, IT governance owners have established a set of IT governance mechanisms to support and guide the expected behaviour associated with the planning, prioritization and selection of IT investments. The responsibility for the establishment of these mechanisms falls on the $\mathrm{ClO}$ (which in itself represents an element of representational divergence when considering that a key expectation of city council is to "increase business participation in the management and oversight of IT-enabled projects"). In support of the ITGF and the PSP, the CIO has put into place two primary 
mechanisms to support the IT investment routine: artefacts (templates, decision frameworks, dashboards) and decision-making bodies (guided by terms of reference and mandate statements). The identification of representational divergence involves a comparison between the expected behaviours of the IT governance ownership group, and the ability of the IT governance mechanisms to support these behaviours. Figure 11 provides an overview of the potential areas of representational divergence within City A's ITPPS routine.

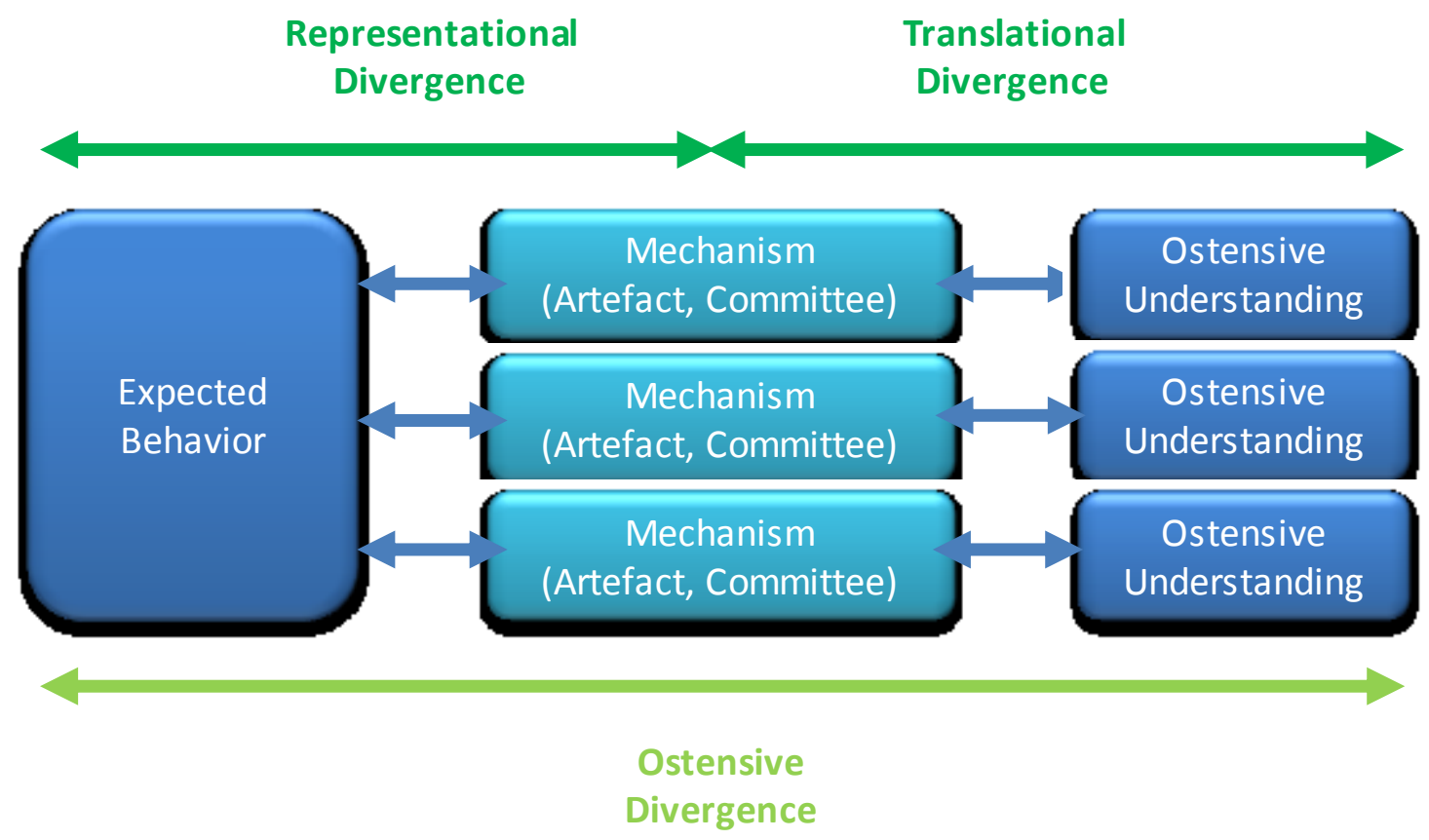

Figure 11 - Potential sources of representational divergence within City A

\section{Representational - Purposeful}

Purposeful representational divergence occurs when IT governance owners implement governance mechanisms that knowingly contradict the expected or desired behaviours of the participants of a particular routine. This result of this behaviour is a set of 
governance mechanisms (and potentially an entire IT governance system) that is ceremonial in nature, put in place to provide legitimacy or the façade of control and not for the purposes of driving or guiding a certain type of behaviour. In City A, this situation manifests itself in two separate ways when we consider the role of council in the budgeting and investment decision-making versus the role of the ITPPS routine.

As with most public sector organizations, the City undergoes an extensive annual planning process where individual departments and divisions determine what activities they will undertake within a given time period, along with the associated budget forecasts required to support these activities. Through this process, business line plans are prioritized against one another and the selected activities are aggregated to commissioner-level projections that are ultimately presented to city council for approval. At this time both an operating and a capital budget are set for each organization. The IT group, similar to any other business unit within the organization participates in this process to forecast salary, contracting and capital pressures to deliver on its own internal projects.

Where the disconnect occurs is that inherent in the approval process for business unit budgets is an implied endorsement to proceed with projects that may or may not depend on services provided by enablement groups within the city, namely IT, HR, Procurement, Legal and Facilities. To extend this logic, if a particular project is approved within the annual budgeting process, and this particular project requires capacity and resources from the IT group to support its delivery, then what authority do the decision- 
making bodies within the IT Investment planning routine have to select or not select these projects. From this perspective, the ITPPS routine is not really responsible for the planning or selection of IT investments. All that is left is the prioritization of projects, and even at that, only from the perspective of scheduling projects against skillset and capacity constraints. Through this lens it is difficult to argue that the ITPPS routine is not simply ceremonial and that the "real" decision-making is made within a separate annual budgeting routine. The implications of this scenario are profound, as what's left over is that IT group being responsible for scheduling and queuing a number of competing business priorities: the exact situation that the entire IT Investment governance structure was put into place to avoid.

"And then those plans are vetted through CMT- the Corporate Management Structure and from there each of the departments, each of the business units takes the corporate objectives and reaches departmental objectives which may or may not include requests for applications or requests for technology investments and when those technology investments are identified they are supposed to come and be vetted through IT for an architecture review, for assessment of the IT impact. That doesn't always happen consistently." (A1G104)

"Then we look at when do we need this and if it's something I really need, it's like, 'how do you move this up', with the list of so many other things to be done? Normally the only way that I have found it could be done, is through a directive with council. If council has said we need this done, it has to be done" (A1G202) 
The second example of purposeful representational divergence within the City is related to the ability for certain stakeholders to "trump" the prioritization process. This situation is definitely not unique to the City, and may well be unavoidable in any bureaucratic organization, however it must be acknowledged as a significant source of divergence. In this scenario, despite all the governance mechanisms put into place to ensure that IT investment decisions are aligned to City direction, demonstrate value, reflect both corporate and internal pressure and leverage reuse and horizontality, at any given time, the Mayor or a member of council can inject a priority project.

"I think maybe you know priority set by council could bump the process or the mayor or the CIO. I may be speculating a little bit here too but I think here is that process, intake, scored, here is what the results of the scoring, if there is priority of council or the executive team that it didn't make it through, I think they can trump. I think." (A1G103)

"If mayor wants something it jumps the queue and doesn't have to go through the same process" (FN A1G107)

"I don't know specifically, my impression though is, it automatically sort of jumps to the highest priority based on that it came from a city council sponsored task force" (A1G109)

The fact that the council feels that it has the "right" to circumvent the very governance routine that it endorsed and approved is not the major concern here, the bigger concern is that assumption that the Mayor or council are able to assess the relative importance of IT-investments and understand the impact of injecting a new demand on the system. 
"I find like with council whenever one uses the word digital, they're like, 'yes!'. They don't even know what it is; it's just like, 'online map - \$180,000'. 'Sure.' I was like, 'are you kidding me?' It's amazing I just think they don't understand it at all and they think it sounds really smart and so they're just like ok. (When discussion with another executive) I said, 'I think the community is going to care, but I don't know if the political people even know what that is." (A1G213)

The inherent conflict here is the authority of the IT governance committee members to make any significant decisions related to IT investments or have any control over the prioritized list of IT investments the IT group will be working on. In the absence of this level of accountability, then the structure can only be described as ceremonial. Not in a nefarious sense of the word, it appears that there is a tangible level of support for this governance structure, however without better integration into the overall budgeting process, the effectiveness of the ITPPS routine will be significantly constrained.

\section{Representational - Non-Purposeful}

Non-purposeful representational divergence reflects the implementation of governance mechanisms that even if followed directly would not result in a performance that is aligned to the governance owner's expectations. In other words, non-purposeful representational divergence arises from a misalignment in the encoding of desired behaviours on the physical artefacts that are put in place by governance owners to support the structural side of a governance routine. Within the analysis of City A, a number of examples of this type of divergence was observed and coded. 
To understand this type of divergence, we first need to assess the core mechanisms within the City's ITPPS routine against the expected behaviours as defined by the IT governance owners. Table 7 provides a summary of this analysis.

\begin{tabular}{|c|c|c|c|c|c|c|}
\hline $\begin{array}{l}\text { IT Governance } \\
\text { Artefact or } \\
\text { Committee }\end{array}$ & 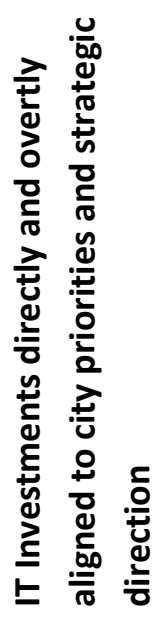 & 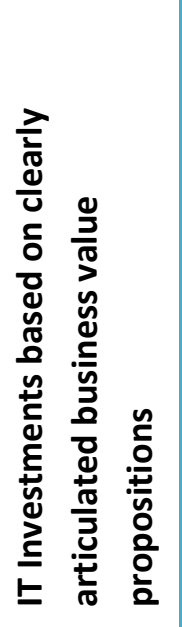 & 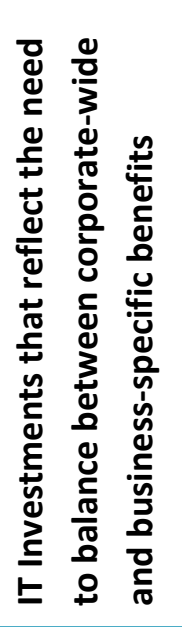 & 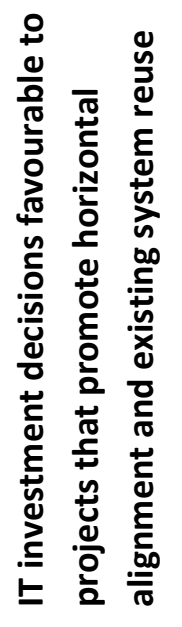 & 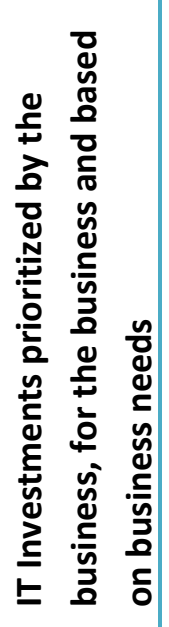 & 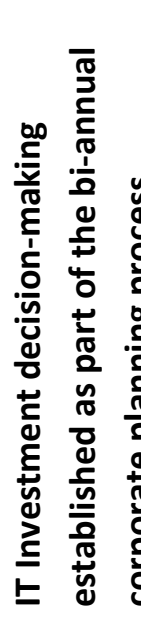 \\
\hline $\begin{array}{l}\text { Opportunity } \\
\text { Definition }\end{array}$ & No & Yes & No & No & Yes & No \\
\hline $\begin{array}{l}\text { Project Scoring } \\
\text { Matrix }\end{array}$ & Yes & Yes & No & No & Yes & No \\
\hline $\begin{array}{l}\text { Project Selector } \\
\text { Dashboard }\end{array}$ & Yes & Yes & No & No & Yes & No \\
\hline Project Statement 1 & No & Yes & No & No & No & No \\
\hline Project Statement 2 & No & No & No & No & No & No \\
\hline ITSC (CMT) TOR & Yes & Yes & No & No & Yes & No \\
\hline ITAB TOR & Yes & Yes & No & No & Yes & No \\
\hline $\begin{array}{l}\text { SPC / IT } \\
\text { Management }\end{array}$ & Yes & No & No & No & No & No \\
\hline IT ERM TOR & \multicolumn{6}{|c|}{ Not available from city stakeholders } \\
\hline
\end{tabular}

Table 7 - City A Mapping of Governance Mechanisms against Expectations

What is evident from this analysis is that the IT governance ownership group has placed a significant emphasis on ensuring the governance mechanisms associated with the ITPPS routine strongly support three of the expected behaviours: alignment of investments with City direction, decision-making based on clear value propositions and 
that the IT-investment decisions are made by the organization as a whole and not just IT. This is visible by the number of "yes" scores in each of those three columns (a yes represents that a particular mechanism supports the expected behaviour either directly or indirectly based on its location/purpose within the overall routine).

Even more interesting is the fact that three of the expected behaviours are not supported at all by any of the mechanisms associated with this governance routine.

Despite the fact that the IT governance owners expect that the routine produce a list of investment projects that balance corporate and business-line needs, account for horizontality and reuse, and align with the bi-annual corporate planning process, the mechanisms put in place by the owners don't provide any support or guidance for these behaviours. The ODP is not designed to capture any of this information, the PSM does not produce increased business value scores for these types of project proposals and the terms of references of ITAB and ITSC do not provide a mandate to support any of these expectations. For these three expectations, non-purposeful representation is not simply a misalignment of mechanisms, but rather a complete absence of any type of mechanism within the routine that would support these expectations.

A specific example of non-purposeful representational divergence is found when we examine the specific scoring mechanism of the PSM. One section, labelled "Business Risk" contains a number of questions designed to assess potential roadblocks to the successful implementation of the proposed investment opportunity. In this section of the PSM, the higher the score, the less attractive the proposal. One of the questions 
within the business risk section relates to the number of departments "that will be involved with this technology-enabled solution" - the more departments, the higher the risk score. On the surface, this is a very fair question. It is common project management knowledge that the more stakeholders that are involved in a project, the more complex the project becomes and the less likely that it will be delivered on time, on scope and on budget. The issue of divergence arises in the fact that the involvement of multiple departments in investment projects is exactly the behaviour that the IT governance owners want from the IT investment routine. Horizontality of solutions across departmental siloes is a major objective of the CAO, however within the PSM (one of the most critical artefacts of this routine), the notion of horizontality is actually viewed as a negative for investment proposals.

As a second example of non-purposeful representational divergence, the ITGF and IT governance owners identify the ITAB committee as the primary governance committee responsible for providing a corporate lens to project prioritization. This mandate supports the expected behaviour that IT investment decisions are made by the business and for the business.

"Recommending corporate and departmental investment priorities to the IT Steering Committee (ITSC) with due consideration for the impact of the investment and the capacity of the organization to successfully implement the anticipated change." (ITGF p. 22) 
"The ITAB applies a corporate perspective while advocating on behalf of their respective department, and recommends a 3-year workplan to the IT Steering Committee (ITSC)." (ITGF FAQ)

"(ITAB) looks at some of the major investments that need to be made, to look at whether or not they align themselves with strategic direction or key corporate initials, so they rate them in terms of level of investment and then they come back to the corporate management team to see what we proceed with." (A1G110)

To support ITAB decision-making the IT PMO (based on involvement within the SPC) provides ITAB with a list of potential projects, ranked by the business sponsor selfidentified business value score. From there, the expectation is that ITAB members discuss and determine a recommended corporate-wide prioritization of IT investment opportunities. Divergence however, arises when the $\mathrm{ClO}$ explains the terms of reference for this committee:

"The only things that are terms of reference for that group that we agreed to was that each director would not necessarily challenge the others on the importance of that (project) to their particular department. That was a thing they felt really strong on and I went along with it but I do have some concerns on that, but some that I thought they might maybe they should put their corporate cap on a little bit more and they could influence their colleagues a bit more." (A1G101)

The result of this decision is that the governance body whose sole responsibility to provide a corporate prioritization of disparate business-line proposals has a terms of reference that dictate that the committee members will not challenge the business 
value of other committee member projects. If prioritization is based on business value scores, and ITAB is not mandated to challenge these scores, then no prioritization can possibly be done by this committee (as will be discussed in the following section on translational divergence). As such, this is a clear example of where a formal mechanism (the ToRs of a governance body) are in direct conflict with the expected behaviour of the governance owners (that ITAB provide a business-led prioritization of investment projects), ensuring that the expected behaviour could not be met through this mechanism.

Smaller examples of non-purposeful divergence are related to the expectation that business sponsors be more involved in the overall IT investment decision-making routines. Despite this expectation, a number of peripheral components of the routine counteract this expectation: 1) the PMO resides within the IT group and as such is viewed by business-lines as an IT entity and an IT responsibility, 2) the artefacts for the IT investment routine are posted on a WIKI page only available to the IT group, 3) business sponsored IT investment proposals are championed by IT managers and brought through the governance process by the IT managers, and 4) the ITGF and PSP were authored by the $\mathrm{ClO}$. The net result of these structural contradictions is a general culture that the IT group is still responsible for the IT investment routine and ultimately the resulting investment decisions.

"You know, and that is the cultural aspect of the organization. I mean, in my opinion it should be the business unit was leading, it should be a business 
unit project supported by IT, not an IT project trying to get support from a business unit." (A1G104)

\section{Translational Divergence}

Translational divergence is most prevalent within the City in the manner in which each governance body has interpreted its role and purpose in the ITPPS routine. At the core of this disconnect is the declaration by both ITSC and ITAB members that they are not responsible for the evaluation and prioritization of individual IT-enabled projects.

According to both the ITGF and the PSP, the ITAB committee is responsible for recommending a prioritized project workplan to ITSC, which in turn is responsible for approving this workplan. Figure 12 is taken directly from the PSP (emphasis added).

\begin{tabular}{|l|c|c|c|c|c|}
\hline \multicolumn{1}{|c|}{$\begin{array}{c}\text { Category of } \\
\text { Decision }\end{array}$} & $\begin{array}{c}\text { Business } \\
\text { Sponsor }\end{array}$ & $\begin{array}{c}\text { IT Steering } \\
\text { Committee }\end{array}$ & $\begin{array}{c}\text { IT } \\
\text { Advisory } \\
\text { Board }\end{array}$ & $\begin{array}{c}\text { IT } \\
\text { Working } \\
\text { Groups }\end{array}$ & $\begin{array}{c}\text { Chief } \\
\text { Information } \\
\text { Officer }\end{array}$ \\
\hline $\begin{array}{l}\text { Define } \\
\text { opportunity or } \\
\text { business need }\end{array}$ & A & & C & \\
\hline $\begin{array}{l}\text { Complete } \\
\text { Opportunity } \\
\text { Definition (OPD) } \\
\text { and Project } \\
\text { Scoring Matrix } \\
\text { (PSM) }\end{array}$ & A & & & C & I \\
\hline $\begin{array}{l}\text { Review OPD/PSM } \\
\text { for consistency \& } \\
\text { accuracy }\end{array}$ & I/C & & & C/R & $\mathrm{A}$ \\
\hline $\begin{array}{l}\text { Identify portfolio } \\
\text { category }\end{array}$ & I & & I/C & & $\mathrm{A}$ \\
\hline $\begin{array}{l}\text { Consolidate and } \\
\text { report results of } \\
\text { assessment and } \\
\text { categorization }\end{array}$ & I & & I/C & C & $\mathrm{A}$ \\
\hline Assess resource & I & & & & \\
\hline
\end{tabular}




\begin{tabular}{|l|c|c|c|c|c|}
\hline $\begin{array}{l}\text { requirements and } \\
\text { develop } \\
\text { preliminary IS\&T } \\
\text { workplan }\end{array}$ & I & A & R & I & C \\
\hline $\begin{array}{l}\text { Approve IS\&T } \\
\begin{array}{l}\text { Workplan } \\
\text { (projects and } \\
\text { priorities) }\end{array}\end{array}$ & I & I & I & I & A \\
\hline $\begin{array}{l}\text { Communicate and } \\
\text { publish workplan }\end{array}$ & C & A & C/R & C/R & C/R \\
\hline Dispute Resolution & C & & & \\
\hline
\end{tabular}

Figure 12 - City A Committee Roles and Responsibilities (PSP, p. 17)

Having both of these committees together responsible for selecting and prioritizing IT investment opportunities on behalf of the City is directly in line with the overall expectation that business, and not the IT group own this routine. What became clear, however, during interviews with members from these two committees is that they do not see this activity as part of their role.

For ITSC, members see their role as providing oversight to large IT investments (similar to a project steering committee) or providing overall strategic guidance to the IT decision-making process, but not in reviewing or assessing trade-offs between individual project prioritization.

Interviewer: "So CMT is not interested, they are not a necessary approval step for a departmental specific business line application investment?" Interviewee: "No, they are not." (A2G110, ITSC member)

"But if there is a significant investment in a project then it does come to (ITSC) for corporate buying or if it has the breadth of the application for the whole corporation obviously it will come there. If it's more departmental 
application then obviously it doesn't come there if there is a minimal involvement, minimal investment" (A1G110, ITSC member)

\begin{abstract}
"It's (purpose is) understanding what the needs are and the goals of the City and then understanding from the IT Group as well as the key sponsor" (A1G210, ITSC member)
\end{abstract}

For ITAB, committee members are generally unclear on their role in terms of project prioritization.

"Recollection at the time was that at the end of the day it didn't result in any particular changes to the, to the work plan or the level investment in, in technology" (A1G101, ITAB member)

"ITAB) is essentially the directors across the corporation. The projects of highest prioritizations are reviewed with the directors, unless, I have less understanding of how those get prioritized." (A1G206, ITAB member)

"I would have like to have seen more strong opinions on where we should be spending our investment dollars and pushing back on some things that maybe we shouldn't have put on the list" (A1G101, ITAB member)

To account for the fact that ITSC and ITAB do not see their roles as providing push-back or prioritization of individual project proposals, the slack is picked up by the IT management group (IT PMO and SPC) to have to work with business sponsors and challenge business value scores, weigh projects against one another and defend the ultimate prioritization on behalf of the City. In doing so, SPC undermines their own position by taking the business-lines off the hook for prioritization. ITAB has nothing to 
do when it comes to prioritization because SPC and the IT PMO have done all the leg work. If an individual project prioritization (based on business value score) is way off base, it should be the responsibility of the director of the business unit to explain this score, not the responsibility of the IT group.

"So the forms (OPD and PSM) aren't purely scientific, like we are not getting good scientific answers. So there is some subjective nature to them. Usually (the PMO and SPC) will scrutinize them and adjust, and we just do that right on the form. So we will tweak it and, you know, get back to the business unit with, here is how we adjusted it. Sometimes we do interviews with the business units if don't understand why they scored things so high." (A1G106)

"I just, I guess I find it interesting that IT takes the first crack of prioritization because, ultimately it's business folks that really know the business and know the prioritization." (A1G212)

"Either the client can fill that out or as often as not somebody from IT will assist the client to go through the form... For Opportunity review and the PMO basically does the actual scoring based on the responses to the form." (A1G104)

The other example of translational divergence occurs in the manner in which business sponsors (as well as the IT group) have interpreted the OPD form. The expected behaviour for this form is that business sponsors provide a justification and assessment of their business needs. The key here is that the OPD is for defining projects in terms of business opportunity and not a solution-based opportunity. 
"(The OPD) should focus on describing the business drivers that create the need, such as the demand for new or additional services, the opportunity to deliver services more efficiently, and/or the opportunity to provide better services to citizens. The OPD should highlight how this initiative will accomplish the Corporation's strategic objectives and priorities as documented in the City Strategic Plan and the Departments Operational Plan. It should avoid describing specific technologies or solutions if at all possible" (ITGF FAQ)

"...that is complete what we call an opportunity definition form, so, which is really problems that they are trying to solve" (A1G101)

Two items arise when we examine the interpretation of this artefact. In the first case, the IT group does not recognize that this template needs to be completed by the business sponsor because 1) the opportunity should be defined in terms of a business problem, and 2) the business "owns" the IT-enabled project, not the IT group. The result is that the IT group incorrectly understands their role to be support and sometimes even write the OPD (and PSM) for business clients.

"And often, from my experience, I find sometimes, often I am helping the business write those project opportunity forms." (A1G103)

"Either the client can fill that out or as often as not somebody from IT will assist the client go through the form." (A1G104)

"We are finding a lot of case and a lot of cases, though an analyst or a manager, an IT manager has to get in there and help reformulate it... Usually we don't get that at the same time we have to request it or help them write it." (A1G106) 
"The initial assessment of high and medium is done by us, (the IT group)" (A1G101)

The result of this translational divergence is that oftentimes the IT group is not only responsible for championing the project through the governance routine, they are also responsible for defending the opportunity definition and business value score - because they are the ones who wrote these. This completely undermines the IT governance owner's expectation that IT decisions are being made by the business organizations.

As a second issue related to the OPD, when business clients do complete the form on their own, there appears to be a significant misunderstanding that the opportunity must be business-oriented and not technology-oriented. As per one business sponsor:

"Sometimes it's just we become aware of new solutions that are available. I work with other revenue people in other municipalities and ask how they do things, that's usually our greatest source of inspiration and you know, so as we become of what they do and they use their software to do things and we also want to use them or see if that's a solution that will work for us." (A1G203)

A sentiment that is validated by members of the IT group:

"Sometimes we see to that. There will be identification of what the solution should be, like even maybe the name of the product development that is not the purpose of this, this is just to identify what the opportunity is that we need to deal with" (A1G108) 
"You know, it is not supposed to be solution oriented, it is supposed to be opportunity oriented, it tends to be, 'hey we want to implement $X$, and you didn't tell anything about Y or what together that is. "' (A1G106)

\section{Performative Divergence}

Performative divergence was the most difficult type of divergence to observe and identify during the course of the analysis of City A. Examples of performative divergence were drawn primarily from interviews with the A1G2 group and those members of the A1G1 group that were involved in the repeatable performances of the routine.

\section{Corrective}

Corrective divergence exists when the behaviours of governance actors divert from those guided by misaligned formal mechanisms as a means to increasing the alignment between expected behaviours and actual behaviours. In City A, two examples of corrective divergence were captured, both of which were performed by the SPC governance committee. In the first example, the committee fills in a gap caused by an instance of non-purposeful representational divergence - namely the absence of any formal mechanism to support the expectations that the IT investment routine privileges projects that promote horizontal alignment and existing system reuse. To account for this gap and despite not having this as a formal accountability, the SPC committee has taken it upon itself to try and identify common functional requirements and reuse opportunities amongst the varied IT investment proposals submitted for consideration. 
"For common items, (the SPC committee) looks for commonalities and endorses the corporate view" (FN G1 Sponsor)

"typically stuff it would first come to the attention of IT and they would then be saying,' tell us about your need and okay you do have a need for this and you want to buy software $X$, but the system that's in the City that we have decided we're going to stay with that continues to meet a lot of needs and can hopefully have additional departments use it is system B and here's how it works'." (A1G210)

"so a lot of the stuff that comes out of the business units is business unit centric, So we are finding over the years that there needs to be some corporate perspective on things and so if you are reactive only to you know "I need this," it is bad kind of direction that your corporate initiatives don't happen, so you don't corporate ERP or corporate information management, you are doing all these side little initiatives." (A1G106)

The second example of corrective divergence represents an effort to improve inefficiency in the current IT governance routine. As part of the formal structure outlined in the ITGF, the ITAB committee meets two to four times a year. The original basis for this level of frequency was most likely to align the investment planning routine to the larger corporate planning cycle (something, as discussed, that has never happened), but in its current state more accurately reflects a confused mandate (why meet more frequently, when the committee isn't even sure of it role). In a perfect instantiation of the routine (that envisioned by the IT governance owners) all of the business owners would bring forward their IT-enabled project requests to be approved and prioritized by ITAB and ITSC twice a year to support the integration between the 
two planning processes. The reality, however, is that projects are put forward for consideration at all times of the year. Given this, to have a project proposal formally approved and ranked, a business sponsor would have to wait until the next sitting of the ITAB committee. In many cases this is not feasible, and as such the ClO has implemented an approval process that allows IT projects to be worked on before receiving formal ITAB endorsement.

"so we also have a mechanism by which we can intake those things (in year project proposals) and if they meet certain criteria, we will initiate them without having to go back and start the whole re-planning process or reprioritization process" (A1G101)

Interviewer: But you wouldn't wait for the ITAB (to start working on an urgent or legislative mandated project). Interviewee: We wouldn't wait for ITAB, right" (A1G108)

\section{Repudiation}

The coding of repudiation-based divergence within City A (after a review with City B data) highlighted two distinct scenarios of the outright rejection of managerial control associated with the implementation of IT governance investment mechanisms. One scenario was aligned to what we predicted we would see within our divergence framework: actants who felt that the mechanisms associated with the ITPPS routine constrained their agency by moving IT investment decisions outside of their span of control or influence. An unanticipated scenario that became evident through the interview process, however, was behaviour of rejection that was neither motivated by 
positive actions (corrective) nor negative actions (repudiation). In this case, actants rejected the formal governance routine by simply not participating in it. This behaviour, classified as avoidance divergence was coded separately to distinguish it from the more nefarious definition of repudiation divergence. Avoidance divergence is discussed in the next section.

As discussed within the purposeful representational divergence section, City A undermines the authority of its IT investment decision-making bodies by disconnecting this routine from the larger annual corporate planning process. Not only does this threaten the effectiveness of the ITPPS governance routine, it also provides an out for those business stakeholders who wish to circumvent the formal mechanisms of the investment routine. In support of this, a number of interviewees highlight the fact that a number of business clients believe that because they have approved funding for a particular IT investment that the formal prioritization routine does not apply to them.

"there is also partner agencies, they operate independently, but to save money they partnered with us to provide IT services, so there is a whole bunch of them that are like that, so they have some independent decision making authority and to combine with their own sort of needs they, you know, probably legitimately in most cases, they go and, you know, get what they could get." (A1G109)

"Also budgets- and I am going to be a little vague here I guess- but if I understand correctly the departments have a technology budget line and I don't believe that necessarily there is any joint planning that is going with IT, right? They go off and go buy their own thing." (A1G103) 
"And then those plans are vetted through CMT- the Corporate Management Structure and from there each of the departments, each of the business units takes the corporate objectives and reaches departmental objectives which may or may not include requests for applications or requests for technology investments and when those technology investments are identified they are supposed to come and be vetted through IT for an architecture review, for assessment of the IT impact. That doesn't always happen consistently. It is sometimes that doesn't happen until the application is actually procured or even sometimes when they start the implementation, and they say "we are going to need some service or we are going to need some storage" or whatever. Then they come to us and say "Oh by the way we are bringing this in and we are going to need you." (A1G104)

For many business sponsors the motivation for avoiding the IT investment mechanisms, even if funding is available, lies in the perception that the routine provides an unnecessary burden and a potential roadblock to achieving their business objectives, or may result in answers that a business unit does not want to be locked into.

"So then you also get other people who are aware of the process- what the process is supposed to be or other people who don't see IT as a strategic enabler- they see them more as a hindrance to the process- they will often go to RFP without us and bring us in at the last minute." (A1G104)

"Yeah some of the challenges too and it is subtle again is that the business units, you know, they figure a way to work themselves out of the queue a little bit. Like they still need infrastructure people but some of the business units have um, and with kind of, it didn't happen on their own, they discussed it at the senior levels, they end up with a little bit of their own IT staff like analysts or project managers where they, you know, they find... so in that 
case they have a capacity of their own and they are subject only to their queue so that is one of the challenges whether it is good or bad-if the business unit believes that they needed IT bad enough to get FTs out of it to work on their projects, the city has allowed that to happen" (A1G106)

"They are getting frustrated because they feel like they are not listened to; they are getting frustrated because they feel like it is a waste of their effort. It needs to be more of an interactive process I think... They know that the project is likely to go forward because this person wants it and because it is relatively simple to do, but they still have to do a whole bunch of documentation, right? (A1G105)

"Or they don't trust process in terms of - they think it is going to be more of a hindrance than a help to them or they really don't understand the IT impacts. You know they will be told by the vendors that the solution is fully standalone, that you don't even need IT in order to implement this particular solution" (A1G104)

Oh yeah, well, I think there are always other avenues (if I don't like the answer from the process). There were always other avenues before this process came into play. (A1G207)

\section{Avoidance}

By far the most common form of avoidance divergence was a lack of awareness of business sponsors towards the existence of the ITPPS routine. Unlike in pure repudiation divergence, actors are not consciously choosing to reject the IT investment routine, but rather are simply not aware that they should be pushing their IT projects 
request through this routine. From this perspective, the communication and marketing of the routine has not been adequate within the various City departments and divisions.

"I think for me the biggest thing that stands out to me is that the whole process is not well understood by all the business units. I think that the IT folks understand it and they know what is supposed to happen but I am not sure that that has been socialized with all of these business units so that they understand that just about everything they do has some kind of an IT structure impact." (A1G105)

"I think that the, at the director level they are (aware of the ITPPS), I think as you push down a little bit in the organization, they are probably less so" (A1G101)

"The governance plan went to council and it was heralded as this great new wonderful thing, right, but there's never been anything come down to our level to say okay, this is what it means. Where is the Coles notes version? I don't know, like I don't want to plough through 70 pages of... I started reading it and thought, 'okay, this is going to be great', and then its like, 'okay, I don't have time for this'"' (A1G203)

"Often it feels like, again, when I get in consultation with a business area and they start describing a project and we need this time from IT, you know when I sort of mention like here is our process, they are like they don't seem to know." (A1G103)

"If a business client understands the internal process, if they have been around long enough and feel like IT is an enabler, they will bring IT in as a partner in the process. There is actually a guide but I don't know that everybody is necessarily aware of it. (A1G103) 
The dominant manifestation of this behaviour is a business unit prioritizing and purchasing IT solutions without engaging the IT group, or participating in the ITAB or ITSC prioritization process.

"You can use Transit's implementation of their scheduling software. We had no clue to all of a sudden they're like, 'here's our plan, we need a resource for this time period'...Yeah, that's the major one right now, but there is supposed to be co-ordination, but it doesn't always happen, where you have these external business units that will go out and purchase software and then all of a sudden they're like, 'oh, we need to tie in to ERP, so we need your resource now'." (A1G211)

"I think it is because they are not aware of the process. They don't realize that there is a process out there that they are supposed to follow, or they honestly don't believe there is going to be as much impact to IT and the enterprise as it comes out, as it comes to $B A$, as it they are starting the implementation phase and like realize the resource they are going to need to make this thing go." (A1G104)

"Often, the challenge may not be that somebody's trying to beat the system, but they may not have a proper understanding of how we're trying to decide, make decisions about technology or in fact what technology already exist that will meet some or all of their needs." (A1G210)

"I think I probably should, because IT should be aware of what we're doing, but nobody said, 'thou shalt do this' and therefore I'm going, 'okay'. I'm just going to do it." (A1G203)

"And that whole Opportunity Definition step is sort of bypassed; the whole prioritization is bypassed, because this has to get done." (A1G211) 


\section{Capabilities}

Among other things, underlying the expected behaviours of the ITPPS routine within City $A$ is the assumption that business units know what they need from IT, are able to articulate and estimate the business value of that need, and lastly, that members of the governance committees can make informed prioritization decisions based on the sponsor articulation of these needs. Capabilities-based performance divergence reflects the reality that none of these three assumptions can necessarily be held to be true and as such divergence exists within the routine based on the collective actors' inability to perform the actions required to adhere to the governance expectations.

1. Business sponsors are not able to always adequately forecast and articulate their IT investment needs which leads to a number of unplanned or poorly submitted project investment proposals being assessed by the IT governance committees.

"Business is not able to articulate need correctly - therefore the whole process falls down" (FN for A1G107 - Asked not to be recorded)

"There is a number of projects that are coming through from departments that are new that they didn't identify or only recently came up with and so it suggests to me that our long term planning and identification of potential opportunities where technology can be involved needs some work" (A1G101)

"So I guess generally at this stage he just wanted to kind of accept people on their word. That's why it's fine, but when you then going to get is, a whole bunch of wild guesses." (A1G212) 
2. Even if business sponsors are able to articulate their IT investment needs, at times they are unable to build a business case as to why this need is important and why this project is important to both their own department and the city as a whole.

"I think we're very early in the process. I don't even think we do a good job with identifying when our needs are, like what our projects should be. What do we need to make business look good or be functioning? I don't think we're that... well educated on business planning to know what we need to do." (A1G102)

"So if there is a corporate strategic initiative like that land development thing then it will end up getting points. So there is not a big business case, at the city we are not very strong that way with the formal business cases." (A1G106)

"(filling out the OPD and PSM)... Yeah. That part confused me a little bit actually because I didn't really understand what I was doing at that point." (A1G105)

"Like risk assessments and just cost of ownership, because sometimes people don't think of that, like a Midas offer, it costs not as many dollars, so l'll just buy it, what's the big deal. They don't think about the cost of owning it over time and the time of the people that have to de-bug it and troubleshoot it and all that stuff." (A1G209)

"But the one key thing that I find very consistent is that people generally underestimate the amount of effort required within their own business unit for change management and to cut off the resources within their own operating unit for training, for training the trainer for leadership for change management, people underestimate that. They just assume that IT is going 
to implement that for them and they will come in on Monday and they will sign in and they will start using this. They forget about all the testing and all the queuing and all the integration pieces that are required." (A1G104)

3. And even when IT investment demands are understood and their value propositions are well articulated, this one business sponsor is concerned that the IT governance committees that review the proposals may not have the capability to make and appropriate decision.

"Here's what I don't know, what training is there for those folks, or is this a case where they end up on a committee, based on their title. Their position in the hierarchy may not necessarily translate into being able to evaluate IT projects." (A1G207)

\section{Conflict}

As the final category of performative divergence, conflict divergence represents behavioural divergence based on institutions or norms that divert actants away from performing in the manner that is understood to be desired by IT governance owners. Table 8 provides a summary of the conflict-based sources of divergence that were identified through the analysis of interview data. The table provides a grouping of manifest behaviours in terms of their underlying motivation, along with the supporting substantiation from the empirical data.

\begin{tabular}{|c|c|c|}
\hline $\begin{array}{c}\text { Motivation } \\
\text { / Driver }\end{array}$ & $\begin{array}{c}\text { Description of Conflict } \\
\text { Behaviour }\end{array}$ & Interview Substantiation \\
\hline
\end{tabular}




\begin{tabular}{|c|c|c|}
\hline $\begin{array}{l}\text { Cultural } \\
\text { Norm }\end{array}$ & $\begin{array}{l}\text { Strong embedded culture of } \\
\text { "siloed" decision-making leads } \\
\text { to business sponsors and } \\
\text { committee members unable } \\
\text { to adopt a corporate-first } \\
\text { viewpoint. }\end{array}$ & $\begin{array}{l}\text { - } \text { "One of the big challenges right now for } \\
\text { our municipality is that there is a culture } \\
\text { of independent business units...They } \\
\text { really very much are independent } \\
\text { business units and they think that way. } \\
\text { So there is very little data sharing. There } \\
\text { is very little standardization. There is } \\
\text { very little coordination to the point } \\
\text { where in the extreme example, you could } \\
\text { have parks go down the street and rip the } \\
\text { street up and put in new infrastructure in } \\
\text { that street and paint it and then a few } \\
\text { months later utilities will come through } \\
\text { when they will rip back in that same } \\
\text { street they will put natural gassing. And } \\
\text { when the population sees that kind of } \\
\text { stuff it is duopolistic." (A1G104). } \\
\text { "So, I think it's part and parcel of what a } \\
\text { municipality is, so it's really, uh, it's a } \\
\text { group of, to a large degree, independent } \\
\text { like a business, as opposed to one, you } \\
\text { know, a company that is in one line of } \\
\text { business... And so, I think it's probably a } \\
\text { challenge culturally to break that down, } \\
\text { to say, to get enough communication } \\
\text { happening between them, to say well } \\
\text { 'you guys are doing a point of sales } \\
\text { system this year, these other groups are } \\
\text { doing point of sale system this year, these } \\
\text { guys may do one in } 3 \text { to } 5 \text { years, why } \\
\text { don't we all just get together, take one } \\
\text { product that can service everyone's } \\
\text { needs, um, I don't know how realistic it is } \\
\text { but, um, I think it's kind of a structural } \\
\text { issue." (A1G109) } \\
\text { "culture where, where it was every } \\
\text { department for themselves, and, um, you } \\
\text { squawk the loudest, you could sneak out } \\
\text { if you wanted, um, that's not the case } \\
\text { now" (A1G101) }\end{array}$ \\
\hline $\begin{array}{l}\text { Power and } \\
\text { Clout }\end{array}$ & $\begin{array}{l}\text { Prioritization decisions are } \\
\text { influenced by the size of the } \\
\text { requesting department, as } \\
\text { well as their perceived } \\
\text { political clout within the City. }\end{array}$ & $\begin{array}{l}\text { "And you know I mean, I think some } \\
\text { departments have very strong leaders } \\
\text { who will push their needs ahead of } \\
\text { everybody else, and I mean I don't think } \\
\text { it's great. You know that's...but we need } \\
\text { strong leaders. But doesn't necessarily } \\
\text { mean that that's a priority for the city at }\end{array}$ \\
\hline
\end{tabular}




\begin{tabular}{|c|c|c|}
\hline & & $\begin{array}{l}\text { this time, or you know that somebody } \\
\text { who has another project shouldn't have a } \\
\text { higher priority. I don't know the way you } \\
\text { do that but... That's life I guess. That's } \\
\text { the world, how it works" (A1G208) } \\
\text { - they also have expectations that, that } \\
\text { when they would like to do something } \\
\text { that requires our involvement, they } \\
\text { expect us to be there at the table, so, so } \\
\text { that becomes a, decision that the } \\
\text { executives of the organization have to } \\
\text { make, say 'okay so even though this may } \\
\text { be very low value to the corporation as a } \\
\text { whole it's important to (The Utilities } \\
\text { Group), so we think it should be on your } \\
\text { list for this year'." (A1G101) } \\
\text { "If it really has a lot of weight behind- } \\
\text { weight coming from the senior } \\
\text { management or otherwise has a high } \\
\text { visible priority, it needs to be done ASAP, } \\
\text { or whatever pressure points that may be, } \\
\text { we deal with it as is." (A1G102) } \\
\text { "I could take a different strategy if I had } \\
\text { the power of numbers behind me, right" } \\
\text { (A1G207) }\end{array}$ \\
\hline $\begin{array}{l}\text { Informal } \\
\text { Norms }\end{array}$ & $\begin{array}{l}\text { Decisions and actions based } \\
\text { on informal relationships } \\
\text { circumvent formal } \\
\text { governance mechanisms. }\end{array}$ & $\begin{array}{l}\text { - "Yes. So, if I have like a friend or } \\
\text { somebody in IT, I can go, 'I really think we } \\
\text { should do this', or 'push this through', or } \\
\text { 'do something', or 'make it happen', or } \\
\text { whatever, right." (A1G203) } \\
\text { "I think, from what I noticed, is that they } \\
\text { actually have... I'm sure you've met like } \\
\text { (some of the IT managers) I feel like they } \\
\text { let me jump ahead of the queue } \\
\text { sometimes, because they like me first of } \\
\text { all, and I think also they know that we } \\
\text { have capacity, so I think sometimes } \\
\text { people... like they have a huge list of } \\
\text { things that people want, but maybe in } \\
\text { certain departments there's not the } \\
\text { people that have the technical } \\
\text { knowledge." (A1G213) } \\
\text { "It is pretty informal I think. And that is } \\
\text { the problem; it is who you know....You } \\
\text { can potentially move your projects faster } \\
\text { by talking to the right people." (A1G105) }\end{array}$ \\
\hline
\end{tabular}




\begin{tabular}{|c|c|c|}
\hline $\begin{array}{l}\text { Competing } \\
\text { Priorities }\end{array}$ & $\begin{array}{l}\text { Pressure to move program } \\
\text { forward leads to attempts to } \\
\text { "game the system" to ensure } \\
\text { a particular project proposal } \\
\text { receives a high rank and } \\
\text { prioritization. }\end{array}$ & $\begin{array}{l}\text { - "Uh, I think cases where, I think, uh, } \\
\text { people understand, you know, quote end } \\
\text { quote the game, not to be cynical, but } \\
\text { they understand why the questions are } \\
\text { being asked, and so they will do their best } \\
\text { to put a positive spin knowing that the } \\
\text { more that they can do that and associate } \\
\text { this project the project with specific } \\
\text { initiatives at a corporate level, that, you } \\
\text { know, get a higher ranking... (A1G109) } \\
\text { "And, you know, in theory you could link } \\
\text { any initiative to our customer service } \\
\text { right? (speaking about linking any project } \\
\text { to corporate priorities)" (A1G109) } \\
\text { "Well like I mentioned if they get their } \\
\text { own resource, it games it a little bit. We } \\
\text { have seen, I don't know, fudged } \\
\text { (numbers)... you get these opportunity } \\
\text { definitions where the guys say he is going } \\
\text { to save you four hundred thousand a } \\
\text { year." (A1G106) } \\
\text { "The clients often ask what the math is } \\
\text { behind the scenes so they can score } \\
\text { these things." (A1G103) } \\
\text { "As in the case of most organizations, you } \\
\text { have people who can really know how to } \\
\text { exploit that kind of utility. And they } \\
\text { know that they can make any claim they } \\
\text { want because they know there's going to } \\
\text { be a whole, a whole bunch of new faces } \\
\text { two years later anyway. (A1G212) }\end{array}$ \\
\hline $\begin{array}{l}\text { Self- } \\
\text { Interest }\end{array}$ & $\begin{array}{l}\text { Organizational stakeholders } \\
\text { act in their own self-interest } \\
\text { and the self-interest of their } \\
\text { department (no buy-in to } \\
\text { corporate agenda) }\end{array}$ & $\begin{array}{l}\text { - } \text { "Individual department heads and } \\
\text { individual managers have a task and a } \\
\text { duty to provide the services that they } \\
\text { provide. So at times we might get people } \\
\text { jockeying for position in terms of being } \\
\text { on the hit list in terms of implementation } \\
\text { or application development" (A1G110) } \\
\text { "More self-interest. How is this directly } \\
\text { going to benefit me if there's no direct } \\
\text { benefit, and then I don't believe in it." } \\
\text { (A1G211) } \\
\text { "And to be fair, everyone does, it's in } \\
\text { their nature feel that, they are the most } \\
\text { important need. And you can try putting } \\
\text { your corporate cap, hat on but at the end } \\
\text { of the day. You're the Director }\end{array}$ \\
\hline
\end{tabular}




\begin{tabular}{|l|l|l|}
\hline \multicolumn{1}{|c|}{} & $\begin{array}{l}\text { responsible to the groups that reports to } \\
\text { you." (A1G212) } \\
\text { "(responding to whether corporate-first } \\
\text { decision making or horizontality is part of } \\
\text { the manager's personal performance } \\
\text { wording)...Not really. You don't really } \\
\text { hear them as part of your PFP." (A1G202) }\end{array}$ \\
\hline
\end{tabular}

Table 8 - Sources of Conflict Divergence in City A

\section{CITY B - ANALYSIS OF DIVERGENCE}

The overarching IT governance system is relatively immature within City B; however significant strides have been made in recent years to provide structure and processes around how the organization manages IT investment decisions. Based on the recommendations of the council approved Corporate Technology Strategic Plan (CTSP), a planning, prioritization and selection approach was established in in 2012 , and has currently been used by the City for two rounds of annual planning. Although each progressive year, minor changes are made to the routine, the core mechanisms (committees and artefacts) have remained relatively stable. At the time of the data collection by the primary investigator, the third planning cycle was just beginning, and as such, work was underway to strengthen the IT governance process as well as prepare content for proposed business plans.

In support of the central argument of this paper, when asked directly, most stakeholders within the City felt that the ITPPS process was working well within the organization. When pressed to answer why they felt that way, the majority of respondents were unable to provide a reason for their positive view, or simply referred to the existence of the individual mechanisms of the routine as evidence that it is working. Given that a 
formalized IT governance system did not exist prior to 2012, respondents viewed success from the lens of implementing formal structures of a routine, rather than from the perspective of whether the "right" IT decisions were being made. Interview questions related to assessing the "outcome" of the ITPPS process were often more difficult to answer, and required many interviewees to pause and contemplate their answer.

Not surprisingly, on the surface, stakeholders within the City felt that the IT planning, prioritization selection process was working properly, that the overall routine was well understood, and that in general, enactors were adhering to their role as defined by the formal mechanisms of the routine. Throughout the interviews and with the support of the document review process, clear examples of divergence emerged which contradicted this "first impression" by many respondents. Expectations were in fact not clear, mechanisms were misaligned, behaviour deviated from that desired by governance owners, interpretation of artefacts differed across stakeholders, and overall considerable confusion existed with understanding the roles and responsibilities of all parties involved in the routine.

\section{Council Expectations}

As a foundation to understanding where and why divergence occurs within City B, we first must understand the overall expectation of the ITPPS routine from the perspective of the leaders of the organization. At the top of the organization is the city council. City council sets the priorities and direction of the city staff within the four-year strategic 
plan. Although a number of organizational routines within the city are somewhat immune to changes between terms of council, the ITPPS routine is not one of them. The demands and expectations of council directly influence the type of projects that should be invested in, as well as the mechanisms used to solicit and determine the project proposals that are brought before council for approval. In other words, if council declares that it is no longer interested in investing in new client-service oriented projects in lieu of focusing all non-operational funding on environment-oriented projects, this would cause a change to both 1) the actual list of projects that staff work on, and 2) the decision-processes and artefacts used to capture project proposals as well as prioritize and select potential projects.

Although council provides a number of outward facing objectives in the City's 4-Year Strategic Plan (improve quality of life, ensure positive government engagement, environmental friendly, encourage diversity, planned development, revitalize the downtown core), the internal focus of the current city council is austerity. The current council prides itself on maintaining the lowest annual tax rate increases of any neighbouring municipality. To support this objective, council expects all project-based funding to go towards initiatives that provide direct cost savings, or indirect cost avoidance for the City. As a central component to almost all of the City's transformational projects, IT-enabled projects must be prioritized and selected based on an efficiency-based value proposition. The expectation of council of the ITPPS routine is clearly to produce a list of IT projects for the organization that show a clear cost-saving benefit for the City. 
"Council expects efficiencies, we had talked about customer services and we've told them there will be no reduction in staff at this point in time... But at the end of the day they'll be looking for if have we saved any money? Are there any efficiencies?" A2G106

"I hear from councillors that they see IT that it has got something cliché but they do believe that IT can be an enabler of change in their organization, right, in terms of really building efficiency and reducing staff costs over time makes it the only way that will happen" A2G108

"I think that's an operating consideration for this council, fiscal prudence is a term that I hear so many times. It's a populist council and fiscal responsibility is a big consideration for them" A2G108

"The interesting thing about (City B) is that, and I go back to the different influences of governance, Council is very frugal, so they are very driven by keeping annual tax increases among the lowest of any comparative municipality in this area." A2G208

\section{Governance Owner Expectations}

Below the council, senior IT governance owners also have an overall expectation of the ITPPS routine. These expectations are drawn from the $\mathrm{G} 1$ interview group overall, with specific emphasis placed on members of the CLT and the CIO. The CTSP, which represents the city's senior management perspective on the IT transformation agenda, also provides a top-level set of expectations for the IT governance routines (Given that this document was commissioned and approved by council it is deemed to represent the true expectations of these stakeholders). 
Through the interview process, it was identified that the ultimate outcome of the ITPPS routine at City B is a set of defined and approved IT-enabled projects that are:

1. Prioritized and approved by the business stakeholders of the organization and not the IT group

2. Prioritized and approved based on their benefit to the organization as a whole and not just their benefit to individual business unit needs (horizontality of investments)

3. Aligned to, and directly support the City's direction and objectives

4. Leverage and reuse existing core enterprise systems whenever possible

5. Provide direct and clear value to the citizens and the organization

6. Recognize the need to balance between strategic and tactical investments Appendix $\mathrm{N}$ provides a detailed breakdown of the interviewees and their respective statements that were used to derive this list. The combination of these objectives, along with the austerity objective of council identifies the overall desired behaviour of the ITPPS governance routine. The physical outcome of the routine is a list of projects that represent the "work order" for the IT group. The value of the routine, however, is not simply the existence of a list, but rather the extent to which the list represents the aggregated set of desired behaviours outlined by the IT governance stakeholders. 


\section{Substantive Divergence}

Currently City stakeholders have no way to answer the question as to whether the list of approved IT-enabled projects is the "right" list. The IT governance owners and decisionmaking bodies do not actively assess the list of projects against any given criteria. In other words, stakeholders are not able to judge whether substantive divergence exists within their ITPPS routine or not. The most senior staff board within the City, the Corporate Leadership Team (CLT) has no way of knowing if the expected behaviours of the routine are being met, at least at a holistic level. Their assessment, if actually undertaken, would rest in looking at the checks and balances of the individual artefacts and committees within the routine as a means for measuring whether the final output meets expectations. This recognition directly supports the proposed framework of this paper: That substantive divergence is a function of the underlying representational, translational and performative divergence. It is the minimization of the underlying negative divergence that ultimately reduces the total amount of divergence between desired and actual behaviours.

From a research perspective, the desired behaviours and expected outcome of the ITPPS routine do not appear to be met which suggests that substantive divergence exists. Like the organizational stakeholders, the evidence of this divergence rests in the existence of divergence within the individual mechanisms of the routine. The output of the routine cannot possible be directly aligned to the desired behaviours of the routine because a narrative overview reveals significant areas of divergence throughout the 
structure and performance of the routine. Central to this narrative is the first objective outlined above: ensuring that IT investment decisions are made by the business and not by the IT group.

Traditionally, the decision of which projects were undertaken and when was owned by the IT group. This was a difficult situation because it placed IT managers in the center of choosing between competing priorities within various business lines and also resulted in decisions that were based on capacity or technology considerations rather than business value or business alignment decision (contradicting objective 2, 3 and 5 above). It is for this reason that one of the major recommendations of the CTSP is "Implement a technology governance framework comprising a steering committee with representatives from the departments and the IT Division...to ensure that priorities and decision-making along with corporate goals and objectives" (p. 5). Accordingly, as expressed by one member of the CLT, the general belief is that this transition is complete:

"And the key for me there is that the decision making focus has always been formalized. It has clearly been shifted from IT, right, that they see now is facilitating a corporate CLT decision making process as opposed to being the ones to vet and make decisions themselves or even how allocate resources. I think like others may not have stated that but I think there has been a fundamental shift in terms of where people see that decision being made and they no longer see that decision as being made in IT" (A2G108)

According to the Governance Master Document, the formal prioritization decision for IT investments is to be made by CLT as recommended by IT-PEC. The desired behaviour of 
this particular mechanism, as defined by the responsibility and mandate of CLT is to "review new project requests and project change request to see if they can be accommodated as requested with respect to the suggested timelines" (p. 11) and "evaluate project and its merits and recommended priority, ranking, resourcing and budget" (p.13). Similarly, IT-PEC has the responsibility to "make recommendations with respect to IT Governance (CLT) with respect to new projects or projects or project change requests" (P. 18). Since these two governance committees are comprised primarily of business line representatives, this structure supports the desired behaviour that IT investment decisions are made (and thus owned) by the corporation as a whole and not just the IT group.

A holistic (narrative) analysis of the empirical data however, shows that despite what is written in the core governance documentation, and in contrast to what is believed to be true by many of the IT governance owners of the organization, the responsibility for the prioritization and selection of projects continue to rest solely with the IT group. As presented in the background section for City B, both the CLT and IT-PEC committees are currently struggling to understand their role in the IT governance system. CLT has delegated their decision authority to IT-PEC in favour of focusing on direction setting.

"I see the changing world. First of all, that initially when the governance process was developed it (CLT) was focused on approvals of projects into the queue... and I think the realization came very quickly that many of those decisions can actually be made level lower (IT-PEC) ... It's more about really setting an agenda and driving forward improvements to customer service that sort of thing." (A1G108, CLT member) 
IT-PEC, in turn is currently not providing any prioritization of project either.

"We might not have the right people at the table, the people there are struggling with their role in terms of prioritizing and there is some difficulty to have them think corporately as opposed to just try to get their stuff through" (A2G101)

"It's almost like a rubberstamp. You get these proposals and there hasn't been a lot on dialogue so you just kind of go, "yeah, sure, add that one to the list. We're good to go with it". There hasn't been a lot of meaningful dialogue at those meetings with the group around the table. I think it's almost like it's a rubberstamp level at that point without the discussion." (A2G102, IT-PEC Member)

"Well, basically we get presented with this is a priority, do you approve it or not? And basically we have already decided before we get in the room, this is what happening...So we can actually say that we are governing the IT area because we are not." (A2G106, IT-PEC Member)

"I wouldn't call it a decision making group more of a collaboration and consultation forum." (A2G208)

Despite the mandates of CLT and IT-PEC, the "real" prioritization and selection of IT projects is happening in the IT group where BSPMs draft project proposals on behalf of the business clients and present them to the IT Management group for review and approval. As part of the project scoping exercise the BSPM is responsible for working with the clients to suggest a ranking for each project. The IT Management Committee then probes and questions each project proposal based on requirements, capacity to 
deliver and technological considerations. From this discussion, projects are assigned an urgency/importance score and ranked against other projects in terms of priority.

"And after everything is scoped and all this knowledge is documented, this request is taken to the IT managers to do an assessment and that assessment would also tie to other projects that are already running or that might be in scope to the future...The BSPM suggests and the management assesses and approve, so there is a suggestion rank and the approved rank." (A2G103)

This list is then brought up to IT-PEC for approval, however, IT-PEC members admit that they have never changed or challenged a ranking that IT has suggested.

"And then our evaluation committee will basically give it a go or no go and for the most part we haven't had a lot of controversy, most of the projects have come forward" (A2G107)

"I have not seen them turn down a project, but because there is representation from that steering committee on IT PEC there is discussion about and justification and I mean usually they're coming forward with something that's fairly well thought out right" (A2G210)

"And so for instance the business project manager from IT sits down with a business line and they go through a whole bunch of work, they take that information go to IT management, they go through a whole bunch of work and then it comes to IT-PEC and I have to admit I sit there and say okay if everybody along the way has determined that this is a high priority or high need and that you can do it then what's my role? Like why would I say no, so we are rubber stamp committee" (A2G203) 
Therefore, when we piece together the various elements of the overall narrative of this routine (found within Appendices $\mathrm{O}, \mathrm{P}$ and $\mathrm{Q}$ ), it becomes evident, that despite the expected behaviours and overarching government direction, that the real prioritization of IT investments does not take place within CLT or IT-PEC. In terms of the ITPPS governance routine, both of these committees are ceremonial in nature and do not support the desired behaviour to ensure that the list of approved IT investments are prioritized by the business stakeholders of the corporation. The IT group clearly maintains the burden of selecting the group of projects on which they will focus their efforts.

"I don't see that we really do that (IT PEC Prioritization), so it tends to then fall back into our (IT group) hands where we have got to say okay well all things being equal what order are we going to work on things and then you know what happens after that is that we maybe don't pick that the right choice or you got people unhappy with you because they were expecting it to be done right away and it's not being worked on right away." (A2G101)

Furthermore, as captured in the interviews with the IT management team, the manner in which the IT group assigns rankings to project proposals is less about prioritizing and choosing between competing business objectives and value propositions, but is rather focused on determining how to schedule projects against IT resource availability. In this approach, projects aren't actually approved or rejected based on alignment with corporate goals or ability to provide a defensible cost-benefit justification, but are simply placed into a queue considering their urgency/importance score and the demands on particular IT resources that are required to deliver on the project. 
"Right now we fit in what we need to what makes sense, but we are still kind of making those decisions where we will be better to have that clear list. And at this point really what we have is a list of approved projects and not necessarily a list of prioritized. We have a ranking system, but it's not clear which one is above which. We are still trying to manage this list of projects by these end dates versus here is the next priority." (A2G107)

Therefore, overall for City B, the prioritization and selection decisions are not being made from a corporate perspective, they continue to be made by the IT group despite the identification of two business-oriented IT decision-making bodies. Additionally, the IT group does not feel it has a mandate to filter projects based on business priority and as such simply places all project requests into a queue based on resource and capacity availability. This leads to a situation where all proposals are accepted by the IT group, and it is up to the IT group to do their best to deliver on these asks - exactly the situation which existed before the implementation of the formal ITPPS governance routine. Clearly, despite the implementation of formal structures, the actual enactment of the ITPPS routine continues to operate as it did before the new governance structures were put in place. In the current environment, therefore, substantive divergence clearly exists and is evident in the fact that the list of IT investments is not prioritized by the business units (desired behaviour \#1) and as such cannot be assured to be aligned to corporate objectives $(\# 2,4)$, nor provide value to the business or clients (\#3). Additional support that substantive divergence exists is apparent in the specific analysis of representational, translational and performative divergence that occurs within this routine in City $\mathrm{A}$. 


\section{Representational Divergence}

As per the proposed framework, representational divergence exists when the physical mechanisms put in place by the IT governance owners purposefully or non-purposefully prevent IT governance actors from meeting the desired behaviours or expectations of the same governance owners. The amount of divergence within this domain directly refers to how aligned the governance artefacts, committees and decision frameworks are aligned to the overall expectations of the governance owners. In the case of City B, this represents whether the mechanisms listed in the Overview of City B section, if followed exactly, would result in the desired behaviours of council and our A2G1 executive group.

\section{Purposeful Representational Divergence}

Based on the City's Corporate Planning Framework, the City's Strategic Plan identifies the goals and priorities of a particular council's four-year term. The document is based on community consultations and is meant to provide constituents with a set of externally facing (and politically motivated) commitments and promises. Internally, city staff participates in an annual planning process to ensure that the focus of individual programs and projects are aligned to the achievement of council objectives. The output of the effort is a rolling four-year Corporate Business Plan (CBP) that clearly defines the activities related to the core services and business projects being undertaken by the city in any particular year. The current CBP identifies 47 core service program areas and 120 business projects that are actively being delivered within the city. 
The business planning process is overseen by the Manager of Strategy and Business Planning. The process begins with individual departments and divisions brainstorming the activities that they wish to undertake within the following fiscal year. The objectives of business units are linked to the City's strategic objectives, and potential work activities are prioritized and planned accordingly. As a next step, all business unit leads come together in a half-day workshop and outline the activities that they have planned to undertake. Supporting organizations, such as HR, IT, facilities, and procurement are then asked to provide an assessment of which proposed projects they can support and by when. Prioritization of corporate activities is thus not based on the importance of each activity (CLT trusts the each department knows their own priorities), but rather by the ability of internal service organizations to support these activities. In the previous fiscal year enactment of this process, IT was allowed two days to provide input into the overall corporate planning process (A2G107). As a result, in the current fiscal year enactment, business units have been "advised" to consult with the IT group prior to attending the City-wide corporate planning workshop. After the workshop is completed, business plans are rolled up to an executive level and are approved by the CLT.

Above and beyond the planning of the operational activities within each department or division, the annual planning process also provides business units with the opportunity to submit corporate project proposals to council for approval. Corporate projects are activities that touch more than one organization or are considered to be exceptionally big or complex (although a definitive definition of corporate projects was not able to be 
provided to the primary researcher when asked to multiple stakeholders). Corporate projects require the completion of a business case and a council issue paper to support the investment decision. In the issue paper, projects are ranked based on urgency and importance, very similar to the ITPPS routine. If approved, council provides the sponsoring business unit with the authority to draw on their own financial reserves to proceed with the work effort (council does not have reserve of its own for investment projects).

Purposeful divergence appears in two places in this scenario:

1. The formal approach of business planning, by design, forces IT-enabled investments to be prioritized and ranked by the IT group rather than the business decision makers. As part of the Corporate Planning Workshop, work activities of the business lines are all accepted at face-value pending the ability of the internal services to support the delivery of these projects. In a pure business-led prioritization, competing priorities would be ranked based on their value to the organization or constituents and a "water-line" would be drawn across the list to represent the IT group's ability to deliver on these commitments. This is opposite of the current approach, where IT is asked to pick and choose which activities they are able to support given their resource and scheduling constraints. In fiscal year 2012, this led the ClO to simply "approve" the support of all projects, and accept that throughout the year, some of these priorities may fall off the map (FN A2 Sponsor). 
2. If the corporate business planning process is responsible for approving the operational requirements of business units, as well as larger scale transformative corporate projects within any given year, then the obvious question becomes what is the purpose of the entire ITPPS process? If business units are coming to the IT investment governance process with pre-approval to proceed with a project, then what is the role of the decision-making bodies within that routine? It was already established that CLT and IT-PEC do not prioritize and rank IT investments, and given the corporate business planning process, they also do not have the authority to approve/reject IT-enabled projects.

Both of these represent purposeful representational divergence because they are acknowledged to exist by the corporate stakeholders in the organization. By knowing that the decision-making authority of the IT-PEC is overruled by the decisions made within the business planning process, then it would further appear that the existence of the former is simply for ceremonial or legitimizing purposes (A viewpoint compounded by the fact that the "formal" Governance Master Document remains in draft format and has never been officially approved by the City's leadership team). What authority would IT-PEC have to overturn or go against CLT-approved business plans? The true approval of IT projects happens during the corporate business planning process, and the true "prioritization" of the projects in this process is made by the IT group under significant time constraints (FN A2 Sponsor). 


\section{Non-Purposeful Representation Divergence}

Overall, there is significant non-purposeful divergence that is observed within City B. At a holistic level, the IT governance mechanisms do not align to the overall expectations of the ITPPS routine as defined by the city council and IT governance owners. Identified artefacts put in place by IT governance owners provide little connection to the overall expectations of the routine, and the terms of reference for the decision-making governance bodies are unclear and misaligned. As the most blatant example of nonpurposeful divergence, there is an obvious disconnect between the expectations of city council and the expectation of the IT governance owners that were presented in the section above. City council has a clear expectation that projects that provide direct cost savings to the city should be prioritized and selected above projects that are unable to show a similar value proposition (with the exception of legislative changes). The concept of cost saving was noticeably absent from any of the interviews with the IT governance ownership group, or in the overarching IT governance artefacts. This structural disconnect clearly impacts the ability of IT governance owners to transcribe desired behaviours onto a set of artefacts, when there is a mismatch between what these expected behaviour and outcomes should be within the various "ownership" group.

To further highlight the existence of non-purposeful divergence, individual artefacts are assessed in terms of their ability to represent the desired behaviours of the IT governance owners. To account for the structural disconnect between the two levels of 
IT governance owners, we add the notion of cost savings to the list of expectations identified by IT governance owners. Table 9 provides a summary of this mapping exercise.

\begin{tabular}{|c|c|c|c|c|c|c|c|}
\hline $\begin{array}{l}\text { IT Governance Artefact or } \\
\text { Committee }\end{array}$ & 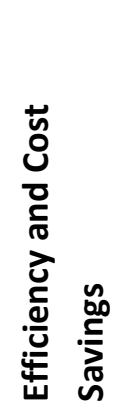 & 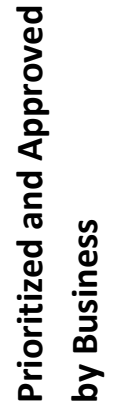 & 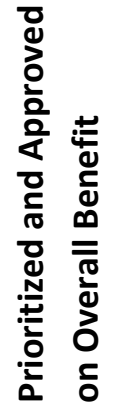 & 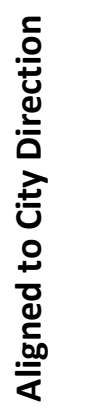 & 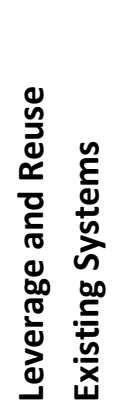 & 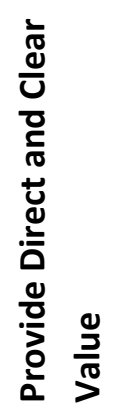 & 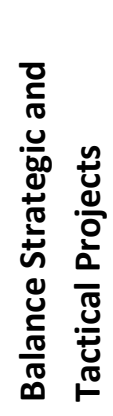 \\
\hline Project Scope Template & No & No & No & No & No & No & No \\
\hline Project Charter Template & No & No & No & No & No & No & No \\
\hline $\begin{array}{l}\text { Prioritization Matrix and } \\
\text { Decision Framework }\end{array}$ & No & No & No & No & No & No & No \\
\hline $\begin{array}{l}\text { Corporate Project } \\
\text { Information Sheet }\end{array}$ & No & Yes & No & Yes & No & No & No \\
\hline $\begin{array}{l}\text { Governance Master } \\
\text { Framework }\end{array}$ & Yes & Yes & No & No & Yes & No & No \\
\hline CLT Terms of Reference & No & Yes & No & No & No & No & No \\
\hline IT-PEC Terms of Reference & No & Yes & No & No & $\begin{array}{l}\text { Yes - } \\
\text { ITSC }\end{array}$ & No & No \\
\hline $\begin{array}{l}\text { IT Steering Committee } \\
\text { Terms of Reference }\end{array}$ & No & Yes & No & No & Yes & No & No \\
\hline $\begin{array}{l}\text { IT Management Terms of } \\
\text { Reference }\end{array}$ & No & Yes & No & No & No & No & No \\
\hline
\end{tabular}

Table 9 - Mapping of Governance Artefacts against IT Ownership Expectations

The second column provides the most dramatic example of non-purposeful divergence within the ITPPS routine within City B. When taken in aggregate, none of the existing artefacts, or the terms of references of any of the IT governance decision bodies 
privilege projects that provide cost savings / efficiencies. In fact, the majority of mechanisms do not require the identification (or subsequent decision-making) of any project benefits whatsoever (see column 4). The basis of prioritization and selection of IT-enabled projects rests in the information gathered through two forms: 1) Project Scoping Request, and 2) Project Charter. Neither of these documents requires business sponsors to identify any potential cost savings that their projects may provide to the organization. Additionally the project information form used by the corporate planning process, also does not require this type of information. Within the Governance Master Document, the proposed Project Proposal Form does include a section for cost-benefit analysis, however in practice this artefact was never released and was replaced by the much less detailed Project Scoping Request Template.

Within the project prioritization matrix, the Importance Scale Scoring Criteria does identify cost saving as one of many considerations when considering a total project ranking. Projects can receive an importance score of $4 / 5$ if the project "can greatly reduce cost(s)" or a score of $3 / 5$ if the project "is likely to reduce cost(s)" or "avoids future cost(s)" (GMD pp. 65-66). The issue exists that these statements are one of many statements that can allow a project to be assigned a similar score. A score of 3 can also be assigned for a project that "mitigates increase in the number of union grievances" or "mitigates complaints elevated to CAO/City Council" (GMD pp. 66). The commentary here isn't that those other objectives aren't equally important, but the fact that they are viewed within the prioritization matrix as the equivalent of a cost-saving benefit 
highlights that the overall ranking process does not privilege cost-saving above other benefits. This is in direct contrast to the desired behaviour as expressed by the council.

Beyond the primary expectation of city council, the artefacts and committee mandates within the ITPPS routine are not aligned with to the overall expectations of the IT governance ownership group. In general, the artefacts are not "misaligned" in the sense that they would lead to behaviours that were contrary to those desired, but rather that they have no alignment at all. If followed exactly, the mechanisms put in place by the IT governance owners would absolutely not lead to the type of behaviour that they are expecting. A large part of this is due to the maturity level of the discipline within the city, but given the degree to which the artefacts do not align to expected behaviours; it also must be, at least in in part, interpreted as a statement on the value placed on ensuring that these artefacts lead to certain behaviour. Although this issue is revealed within the context of non-purposeful divergence, it provides a further suggestion of the purposeful "ceremonial" nature of the governance structure - artefacts are put in place, but with little chance of actually supported a performance that minimized negative divergence within the routine.

When considering the remaining IT governance expectations, the overall design of the ITPPS routine supports the fact that the business is responsible for making IT investment decisions. The Governance Master Document and the CLT and IT-PEC memberships by definition support this expectation. A minor divergence does occur in the fact that the GMD prescribes the Project Scoping Request and the Project Charter document to be 
completed by the IT Business Process Project Manager. As a specific nuance, this direction undermines the IT group's desire to have the business sponsor recognize that they own their projects (and not IT), but this still does not affect the fact that business representatives are sitting on the committees responsible for making IT investment decisions.

"We are trying to shift that to make sure that they (the investment projects) are owned by the business area... So in doing that you are adding work to their plate but you are also creating ownership of the project with them." (A1G107)

Non-purposeful representational divergence exists when considering the terms of reference for both CLT and IT PEC, which state that the primary objective of the two bodies is to "Review New Project Requests and Project Change Requests to see if they can be accommodated as requested with respect to the suggested timelines" (GMD pp $11 \mathrm{CLT}$ and pp 15 IT PEC). Although the expectation of the IT governance stakeholders is for these business-oriented committees to approve and prioritize IT investments against a set of desired criteria, the wording in GMD and their respective ToRs does not include the word "approve" and only mentions a review of projects in terms of resource capacity and scheduling.

The desire to leverage and reuse existing systems is also supported by the overall design of the governance routine. According to the GMD, the IT steering committees have a mandate to "champion their respective Enterprise Application throughout the organization" and (GMD, p. 22) although the document falls short of clearly identifying 
that this committee is responsible for ensuring that their particular core system is considered for all relevant business problems. This connection, however, is put in place by identifying the chair of each steering committee as being a member of IT PEC. From a representational perspective, this expected behaviour can be achieved through this involvement.

In consideration of the remaining desired behaviour, the project scope request, project charter and prioritization matrix represent the sum-total of project proposal information that is considered by the governance committees to approve, rank and prioritize all projects. From this position, both the project scope template and the project charter template do not require business sponsors to identify: the horizontality of their project, a link to city priority, a clear and direct value to citizens or the organization (the project charter mentions cost/benefit "if required"), or an identification of whether this is a tactical or strategic undertaking. As such, it is impossible for these artefacts to ensure that the final approved project selection and prioritization considers any of these items. Furthermore, the project prioritization matrix used by the governance committees also does not account for the alignment to any of these objectives. The corporate project template does include a field that maps the project to a specific set of corporate objectives; however this form is only used for 26 projects across the entire organization (A2G109).

Overall, the evidence of representational divergence is apparent in the City B's ITPPS routine. If the mechanisms put in place by the IT governance owners were followed 
absolutely, the resulting behaviour would not be aligned to the desired by the organization. The positioning of the artefacts used within the routine appears to be built on the assumption that the project will already be going forward. Information is not gathered to support the decision on whether or not to proceed, but rather when and how to proceed. The prioritization is based on scheduling of resources and timelines rather than on the strategic value or alignment of the project and driven primary by the recommendations provided by the IT management committee who are ultimately providing the ranking of each of the projects.

\section{Translational Divergence}

The compliment to representational divergence is translational divergence. IT governance mechanisms are designed and instantiated as a means for ensuring that the actual behaviour from individual performances of the routine is aligned to behaviour desired by the IT governance owners. Translational divergence occurs when the interpretation of an artefact is different than that desired by the governance owner who created the artefact. To understand where translational divergence occurs within City B, we need to continue our analysis above to contrast the desired behaviours associated with each of the core artefacts (both templates and ToRs) along with the interpretation of these artefacts by actors within the routine.

The most obvious example of translational divergence within City B relates to how CLT and IT PEC members have interpreted their role within the ITPPS routine as defined by the GMD and their individual committee Terms of Reference. Although the Terms of 
Reference do not go as far as dictating that these committees are responsible for ultimately "approving" which IT investments are to proceed and in what order, the representation of the IT governance owners' desired behaviour is fairly consistent within the manner in which the IT governance approval process was designed. A disconnect, however, occurs in the manner in which members of these committees interpret their mandate and accountabilities within this framework. For the majority of the members within each committee, neither set of committee group seemed to understand that it was their responsibility to prioritize and select projects.

According to one senior member of the IT PEC committee, the group doesn't do any prioritization:

"Well, basically we get presented with this is a priority, do you approve it or not? And basically we have already decided before we get in the room, this is what happening." (A2G106)

The member goes on to describe that in her understanding, the purpose of the committee is not to make individual investment decisions but rather to set and enforce a global direction for IT investments on behalf of the organization:

"And absolutely I'm not well used to it, it's not a decision, it is not governance. Much more setting the direction, we are not setting the direction for where we need to be in my mind in IT and it should be what the business needs are and it should always be a joint effort, it is not an IT effort." (A2G106) 
When describing the results of one of the first governance meetings of $\mathrm{CLT}$, the $\mathrm{CIO}$ revealed that this committee also did not interpret its role in the routine as being the approver of projects:

"They have made it known that they weren't interested in the detailed level so they've really requested that we bring strategic updates to them that we bring any issues that need to be followed up from the prioritization process. So we more or less, I don't want to say we inform them. They are still at the top level approval body and if there was a contentious issue it would go to them in terms, so they are kind of the rubber stamp to the information that's being provided." (A2G107)

A member of the CLT echoed this sentiment:

"And I think the realization came very quickly that many of those decisions can actually be made level lower and that CLT increasingly has an interest in focusing on these strategic projects like customer service of any service like implementing mobile technology, internal collaboration and the ERP agenda that it's less about approving five timeline extensions that no one really cares about on a helpdesk, backup system upgrade. It's more about really setting an agenda and driving forward improvements to customer service that sort of thing." (A2G108)

The result of this translational divergence is that despite their mandate as framed within the Governance Master Document, both committees have interpreted their formal mandate as to being one of strategic advisors rather than decision-makers. Not only have both committees misinterpreted their role within the routine, they have also both landed on providing the same "strategic advisor" contribution. Prioritization and 
selection of IT investments thus falls to the next highest governance body, namely the IT Management Committee who have informally taken on this accountability somewhat by default. This is a remarkable example of translational divergence, because despite the strong representational alignment for the expectation that business stakeholders own the IT investment decisions, the misinterpretation (or outright rejection, which would be a performative divergence) of published committee mandates and terms of reference has led to a set of behaviours that are in direct conflict with those desired by the IT governance owners. The upshot is that the IT leaders continue to bear the burden of IT project prioritization and selection despite this being one of the major findings and recommendations of the council-driven Corporate Technology Strategic Plan and a prominent desired behaviour of IT governance owners. For all the effort to establish a business-led IT governance system, IT investment decisions, in reality, are still being made by the IT group.

More specific examples of translational divergence can be found when we compare the expectations of the major IT governance artefacts and their respective interpretation by those that contribute to the ITPPS performances. Table 10 provides the IT governance view of the desired behaviour of the Project Scoping Request and Project Charter Template. The desired or expected interpretation of each of these artefacts is drawn from the GMD, and members of the IT governance ownership group.

\begin{tabular}{|l|l|}
\hline IT Governance & \\
Artefact or & Desired Interpretation Statements \\
Committee & \\
\hline
\end{tabular}




\begin{tabular}{|c|c|}
\hline $\begin{array}{l}\text { Project Scoping } \\
\text { Request }\end{array}$ & $\begin{array}{l}\text { - "The proposal describes what the project will do, sets its } \\
\text { priority, and provides cost and resource estimates and a } \\
\text { cost/benefit analysis. Large projects may require a business } \\
\text { case be developed before the proposal" (GMD) } \\
\text { - "An initiating document that is used by the IT governance } \\
\text { committees to review the merits of projects and set project } \\
\text { priorities." (GMD) } \\
\text { "A good scoping document should really tell us what it is } \\
\text { that we are ultimately trying to achieve and why they are } \\
\text { doing it, what business problem they are trying to solve and } \\
\text { ideally it shouldn't be getting into solutions at all." (A2G107) } \\
\text { "You want to see the problem defined and how they can see } \\
\text { the future state being, how it can be different and beyond } \\
\text { that you don't want them going much further than that in } \\
\text { that initial scoping request." (A2G107) } \\
\text { "They will format the scope of the project, their resources } \\
\text { required, the duration, costing and then from there they can } \\
\text { build a project charter." (A2G105) } \\
\text { "That includes people from the business as well as IT, any } \\
\text { stakeholder group really that needs to be involved but largely } \\
\text { the business that is requesting it and the IT groups that will } \\
\text { need to develop it or support it and then they build a project } \\
\text { charter" (A2G105) }\end{array}$ \\
\hline $\begin{array}{l}\text { Project Charter } \\
\text { Template }\end{array}$ & $\begin{array}{l}\text { - "A key project management document that describes the } \\
\text { project and authorizes the project manager to manage the } \\
\text { project. Key sections include project description, scope } \\
\text { definition, funding approval and team organization." (GMD) } \\
\text { - "For project charter we want to clearly to know what the } \\
\text { direction is in terms, well I should be careful on that; } \\
\text { depending on the sizes of the project, some scoping exercises } \\
\text { may actually be a project charter to themselves" (A2G107) } \\
\text { - "We should at that point; all the resource managers should } \\
\text { have been able to speak to what their involvement will be } \\
\text { and what the resource requirements are. So we should have } \\
\text { that clarity, we should know that there is budget and what } \\
\text { the dollars are. We should have identified any risks and we } \\
\text { should definitely have that commitment from the sign off, } \\
\text { from the area that they are in support of the work and they } \\
\text { are going to be there through it to move it forward." } \\
\text { (A2G107) } \\
\text { "The Purpose of the charter is to stop stupid projects" (Field } \\
\text { notes from CIO sponsor meeting) }\end{array}$ \\
\hline
\end{tabular}

Table 10 - Desired Behaviour of Select Governance Artefacts 
To summarize the statements in Table 10, the Project Scoping Request is to be used by the business to define their business needs at a very high-level. The focus is to be on the business problem and not prescribe a particular solution. The template is to be used by the business sponsor to justify the rationale for taking on this particular investment. As an extension to the initial Scoping Request, the Project Charter then is used to solidify the resource commitments of both the business and the IT group, refine the project scope based on IT Management feedback and present a milestone-based project schedule for approval. The two documents together form the project summary used by the governance committees to determine a ranking and prioritization of each investment ask.

Translational divergence occurs in multiple areas with these two forms. Although the desired behaviour is that the Project Scoping Request is business-driven and business focused, the IT group has designated the IT Business Systems Project Managers responsible for completing the template on behalf of their clients. Furthermore, when the project proposal is discussed within the IT Management group, it is the BSPMs that present and defend the project, not the business sponsor. The expectation that business sponsors own their own IT-enabled projects and are responsible for providing project scoping documentation from a business-perspective is completely undermined by an internal IT decision to have BSPMs represent all projects, as evidenced by these two references to the role that BSPMs play in the governance committees.

"I think the BSPM, Project Managers in IT, they sit around the table too typically and they would be the ones to bring- If it's a new project, like if I 
had an accounting project, I would take it through my guy and he would bring it to that committee. I wouldn't bring it myself if it were a new proposal." (A2G102)

"So the BSPMs participate when they have any project to submit or scoping request to submit or any other discussion that they would like to bring up to table." (A2G103)

The result of this nuance to the governance routine is that the project scoping document and the project charter are very heavily influenced by an IT perspective and as such are often times written more as an IT planning document then a business value investment justification. When asked what feedback the IT management group may provide in response to a scoping or charter document, a BSPM suggests:

"There may be things they ask clarity on like what are the resources that are required to support it and to go back and make sure we have that documented or right now infrastructural costs the way we assign costs to servers there is not a formal process." (A2G105)

From this perspective, these documents are not being interpreted by even the IT governance owners as providing the source justification for the approval of businessoriented projects, but rather as an IT project intake form designed to ensure that the IT group is able to provide appropriate resourcing to the project. The root of this misinterpretation has already been discussed: prioritization and selection is not happening within the routine because the senior business governance committees do 
not see this as their role. As such, the "prioritization" performed by the IT group is focused solely on resource scheduling.

When the business sponsor is involved in writing the Project Scoping Request, the expectation that their IT investment request must be driven by a substantive business need also represents an area of translational divergence within City B's IT governance routine. In general, the IT group continues to struggle with business clients that bring forth solution-oriented requests based on something that they have seen in a conference or another municipal government.

"The challenge is again getting them to step back from that shiny object and look at other solutions that could work either within an existing system or something very simple they could even be doing in the business process that achieve the same thing." (A2G107)

"That will be a struggle all the time because I think the art of the possible is often driven from what they do see at the conference. So it's kind of going to be that's where they get the ideas, how things could be different so it is a matter of working with them and getting them to step back and figure out how you can implement that idea in our environment most effectively" (A2G107)

\section{Performative Divergence}

The ability to observe and identify performative divergence within City B was greatly hampered by the existence of significant representational and translational divergence within this routine. In general the IT artefacts that were put in place by the IT 
governance owners as a means to drive and guide a set of desired behaviours were unfinished, unclear, poorly positioned and at times, confusing. To fully investigate the sources of performative divergence requires that IT governance actants have at least a partial understanding of what is expected of them, which in turn can be used by researchers as a baseline for observing why their actual behaviours might diverge from this desired behaviour. Unfortunately, in the case of City B numerous stakeholders were generally unaware of their expected behaviour when participating in a performance of the ITPPS routine and as such, examples of this type of divergence were difficult to suss out during the coding and analysis of the case information. A few sources of performative divergence are highlighted below.

\section{Corrective}

The IT management group presents two examples of divergence that attempt to counteract the representational and translational shortcoming discussed above as a means to better align the actual behaviours of the routine with those expected by the IT governance owners. The first example follows from the misinterpretation of their role by CLT and IT PEC with respect to the prioritization and selection of IT investment proposals. As identified in the previous section related to translational divergence these committees have decided, against the expected behaviours of the governance designers, that they are not responsible for ranking or approving potential projects. Since prioritization needs be undertaken somewhere within the execution of the routine, the IT management group has informally taken on this responsibility. 
'We (the IT management committee) give them (IT PEC) a proposed ranking, but I don't think that, we don't have that process in place now to go - 'Do you approve this ranking?'”' (A2G105).

"The BSPM suggests and the management (IT management committee) assesses and approve, so there is a suggestion rank and the approved rank." (A2G103).

This issue with this approach, however, is despite the IT management group's attempt to fill the prioritization gap within the routine, they are not in a position to provide any level of commentary on alignment to business objectives, business importance, etc. The resulting behaviour therefore is not a prioritization based on strategic value or return on investment, but rather a prioritization based on capacity and scheduling. The decision of "if" a project should be selected is substituted with "when" a project could be initiated. Therefore despite the obvious corrective behaviour by the IT management group, their relative position within the organization prevents them from completely closing the gap caused by existing representational and translational divergence. According to the $\mathrm{ClO}$, "we have a ranking system, but it's not clear which one is above which. We are still trying to manage this list of projects by these end dates versus here is the next priority." (A2G107)

The $\mathrm{ClO}$ continues to outline that rankings and prioritization are based on capacity:

"It's being able to identify within those rankings which ones are going to be the most critical and there is always a resource aspect in there too because some projects will lean more towards one group than another so it relies 
heavily on the network or the database group, do they have resource availability. So you may be able to have a few priorities for different groups depending on what your resource capacity is." (A2G107)

A sentiment echoed by a BSPM:

"So that's part of the prioritization before because the management team or the management committee they are head of the all the IT employees... So there is one specific manager that is head of the developers, one of them is the head of database administrators and one of them is the GIS perspective so they should know which one is available and when could they make them available to a specific project, so that will be the manager responsibility. (A2G103)

The second corrective behaviour by the IT management group does narrow the gap between expected behaviours and actual behaviours by ensuring that system reuse and horizontality of benefits are considered when selecting potential IT investments.

Although the group falls short of prioritizing based on these components (the true desired behaviour of the routine), the committee, along with the BSPMs provide informal feedback and guidance during the project scoping activities to ensure that all project proposals have considered these two expected criteria. By leveraging the fact that they are the domain experts on IT systems and that they have visibility of project proposals across all business lines, the IT management group is in a unique position to be able to influence business stakeholders and the positioning of their respective project proposals. As an example of this type of behaviour, a BSPM recounts a time 
when he connected a number of disparate project proposals as a means for adopting a horizontal approach to meeting the demands of a variety of stakeholders.

"This whole initiative started with one department and once I brought to the measuring team he said, 'Okay, but there were other departments that could also be kept as benefits. So why don't you talk to them so I talked to them?' And they were added and now there are five. Someone else was added to this, so now I have one solution that would fit six departments." (A2G103)

One additional example of corrective divergence emerged during an interview with one of the senior IT governance owners. In response to the threat that business line sponsors were circumventing the ITPPS process by purchasing IT solutions outside the purview of the IT group, the procurement team, informally and organically, began to notify the IT management group any time a large IT purchase request came through their office that did not include an IT endorsement. The interesting part of this arrangement is that it is strictly informal, and arose from a common desire to "do the right thing" and ensure that all IT investment decisions are governed by the corporate IT governance system (A2G110).

\section{Repudiation}

Examples of performative behaviours by actants to knowingly reject the governance mechanisms associated with ITPPS routine were prominent in the stakeholder discourse. In these cases, the expected behaviour was known by the stakeholder, but was overtly ignored in favour of privileging an alternative route to satisfy their IT investment needs and requirements. As one of the most interesting examples of 
repudiation divergence, a business line director points to the fact that their organization is not funded by the tax bases, and as such have the "right" to make IT investment and purchase decisions on their own. From this perspective, because funding is readily available for their projects, the respondent doesn't see the purpose on subjecting their IT investment needs to the City's process, thereby rejecting the formal mechanisms based on the fact that they "would hurt my productivity and my effectiveness." (A2G201) This avoidance is justified by the business sponsor based on the inefficiency of the formal governance system:

"I am also going to say that if I can avoid the IT governance I will as I have outlined earlier but if I have to then I will so if it is a major project then I will but if I can avoid it I am definitely going to avoid to save time and money it is about being effective and efficient." (A2G201).

At the core of this business sponsor's belief is an interpretation of the ITPPS process solely as a funding prioritization mechanism: if you need funding then you must subject yourself to the process, but if you have your own funding there is no need. Although this position also represents a lack of understanding of the purpose and rationale of the routine (avoidance - lack of understanding), the primary motivation for this position is a rejection of control: "it is also a control thing... don't be telling (the CIO) that" (A2G201).

The loss of control argument is echoed by other business-line stakeholders.

"That's where overtime resentment builds up and people become disenfranchised from IT, they don't see IT as customer based. Even the concept of talking about IT governance for me places that barrier between IT 
and their stakeholders. As soon as you hear the word governance you start to think like somebody is making decisions, and it puts a wall up. (A2G209)

"Yeah it's difficult in the sense that if we were private industry and we need IT resources we go and get IT resources" (A2G203)

"We are handcuffed in the situation. Like we talk to our customers, we find what our customers need and what they want. We try to implement what our customer's need from the staffing level; we are trying to mobilize our workforce. In order to do that you need to have the hardware, the software and the system that have been placed so that we can gain efficiencies in our business and rely less on manual processes and that to me, is very important." (A2G205)

A second example of the repudiation divergence appears when actants agree to participate within the corporate ITPPS process, but choose to remove themselves if the output of the routine is not to their liking. When informal discussions with the IT group (through the scoping process and a BSPM) suggested that perhaps the request for an application to monitor the hours of services of field employees perhaps could be repositioned, the manager made the decision to go forward anyway and purchase a solution from a vendor without IT involvement and thereby bypassing the entire IT investment routine.

"They had nothing to do with it the only thing they did for it was install the terminals around this building when we moved in here" (A2G204).

Similarly, citing that the ITPPS process was not a true prioritization based on needs, but rather a capacity assessment of whether the internal IT group has the correct expertise, PhD Thesis - Allen E Brown 
a Director responsible for overseeing the upcoming municipal election was forced to go outside of the routine to meet her business needs when her request for an electronic voting attendance application was questioned by the IT management committee.

"They talked about it and then decided no, which is a huge problem for me. Because we are now in the middle of July, everything that we have planned with respect to workers, logistics, processes are completely tied up at the use of laptops and scanners. To be told no at this stage of the game is pretty significant. The other part of it that was very troublesome for me is that I was not part of the conversation as the key stakeholder with this IT governance." (A2G209)

\section{Avoidance Divergence}

Although the observation of performative divergence proved more difficult than anticipated within the analysis of City B, a new source of performative divergence was readily observed and as such is presented as an additional second-order construct for IT governance divergence. Arising from the interviews with the IT governance actors within City B, was a significant amount of divergence based on avoiding the ITPPS routine altogether when pursuing IT investment projects. Separate from a conscious dismissal of the governance routine driven by a perceived sense of power and control, avoidance divergence appeared to arise from two sources: 1) lack of awareness and 2) self-suppression of demand.

As the first source of avoidance divergence, a number of actants avoided submitting their IT investment needs through the ITPPS routine simply because they did not know 
that they were supposed to. As an example of this type of behaviour, a business line manager who was looking to purchase, install and configure a particular COTS solution simply called the IT helpdesk to move forward on this investment decision. The helpdesk clerk, also unaware of the formal governance mechanism moved forward on the request by assigning resources and approving the purchase request without directing the business sponsor back to the formal intake channel (i.e. complete a Project Scoping Request).

"I used the helpdesk, I sent the ticket to the help desk saying we have done testing; this is the program we want, we want then installed to these devices." (A2G202)

When asked by the interviewer if he was aware of the formal governance processes he responded that he felt this was a suitable approach and that he wasn't aware of how else he was supposed to have proceeded with this IT investment request.

"It would be the path I would use because that is the only path I am really aware of, I know some of the other managers deal with more of our mandate in creating systems and stuff like that, they are doing these scoping documents and thing like that but I am not involved with that end of it very much so this was a one off for me." (A2G202)

A communications manager, equally unaware of the formal governance process looked to internal IT colleagues to support the purchase and implementation of a social media tool. In this case, the manager informally approached a member of the IT team with her requirement for a mobile-based communications application and was informed that the 
web management team within IT had already moved forward with the purchased the application.

"It just kind of hey we are purchasing an app it was... so here it is..." (A2G206)

The manager was obviously confused by this chain of events and admitted that she was unsure of how she was supposed to raise her requirements for IT investments to the IT group. She was unaware of the BSPM role and when asked if there was a formal process to follow or a template to complete, the manager responded:

"No there is no form. A lot of what happens a lot of decisions that happen is through the (corporate) leadership team" (A2G206).

The second form of avoidance divergence identified was related to business line owners consciously choosing not to participate in the governance process by self-supressing their own IT investment demand. Self-suppression represents an extremely interesting by-product of the City B's instantiation of an ITPPS routine. Prior to formal implementation of an IT governance system, a mechanism for filtering and prioritizing the demands of individual business units for IT services did not exist. As such, individual business sponsors were motivated to secure as much IT capacity as was possible to deliver on their various IT-enabled projects by submitting as many requests for services as possible. For a business stakeholder, it was in their best interest to have the entire IT group focused on their personal program objectives, even at the expense of another group's more pressing demand. This behaviour led to a proliferation of IT project 
requests that needed to be understood and actioned by the IT group. Prior to the publishing of the ITSP, the IT group was tracking (but not delivering on) hundreds upon hundreds of client projects. With reference to the progress that has been made, one governance owner stated:

"We look at all the projects on the go at any given time and I think we're down to a much more reasonable number, maybe 40 or 50 projects rather than 200 or 300 -and as new projects come aboard, we discuss them." (A2G102)

This volume to projects was reiterated by this IT PEC member:

"...we've managed to get to the point now where we're really starting to we're seeing a lot of projects being closed and new ones coming onboard. First was really just filtering out 300 or 400 that we have on the go any given time or whatever that was." (A2G207)

That the City was able to close and cancel a significant portion of historical IT project requests was a considerable achievement. More interesting, however, is the recognition that in the current environment, the demand for IT investments does not appear to outstrip the organization's ability to supply these investments. This is no more evident in the fact that in the current routine, there are few if any examples of an IT investment proposal ever having been rejected. Projects may be given a low ranking and may be scheduled far into the future, but in the current routine, any request by a business sponsor is generally "accepted" by the decision-makers of the ITPPS routine. When discussing why demand was so low, one IT governance owner points out that a 
particular client was reluctant to go through the process and as such withheld a project request:

"There was a comment made last week... project volume has gone down and whether that's a result of the process or business units. I think somebody made the comment not wanting to go through the process." (A2G104)

A business sponsor, acknowledging that they have been turned away in the past, suggests that at times they don't bother coming forward with a new request because they have been turned away in the past for ideas that were not in line with the direction of IT:

"I guess to answer your question yes there are times when were got turned away or I think there is a lot of opportunities from what we are hosting the we just know they are too busy so even if we want to ask" (A2G204)

For this IT governance owner, the suppression of demand appears to be the result of a more critical assessment of the priorities and business needs through a road mapping exercise being undertaken by most client areas.

"Yeah, actually that reminds me there is also; this year there has been something of a process for business units including IT to develop project road maps which I think for us and maybe for the business units is kind of highlighting the project volume and workloads and also maybe challenging the necessity for some of the work." (A2G104)

Finally, this business director agrees that demand has been suppressed suggesting that the business line managers are doing a good job of filtering what is brought up through 
their teams to be submitted to the formal governance process and are recognizing that low priority asks will not be actioned in a timely manner.

"I think on a positive perspective I think that in some cases the managers and supervisors are doing, if something comes up that can't move forward or can't move forward at a pace that staff wanted to, I think the managers and directors are doing a fairly good job in terms of managing those expectations to say, 'you know what I get it, but it's just we're not in the queue yet or it's not going to happen fast" (A2G207)

Therefore, in response to the establishment of mechanisms to support IT investment decision making, a number of business clients have chosen to filter their requests to IT and put forward only those project proposals that are the most critical and impactful to their organizations. This avoidance represents a recognition that in the current environment, superfluous investment asks will not be accepted and as such are not worth putting forward.

\section{Capabilities}

Underlying City B's ITPPS routine is an expectation that business line sponsors are able to adequately assess their IT investment needs, and in turn, that those needs can be captured within the Project Scoping Request and the Project Charter in a manner that can facilitate governance prioritization and scheduling. Acknowledging that a significant amount of representational divergence already undermines the ability of these artefacts to provide this information, there was a sense amongst a number of interviewees that both the business sponsors and the IT group were not well versed in preparing project 
proposals. The capabilities disconnect manifested in two ways: 1 ) businesses not being able to identify and scope their needs correctly:

"I don't even think we do a good job with identifying when our needs are, like what our projects should be. What do we need to make business look good or be functioning? I don't think we're that even well-educated on business planning to know what we need to do." (A2G102)

"I think things go ahead and-I think because business doesn't do a good job with planning, they don't really know. I think we're just always, what do you say, behind the eight ball. We just don't even know. Like to be honest, there are some things we're all doing that are into 2014 that I really don't know what that looks like yet and what I'm going to need IT for, or other areas, we're just not that evolved." (A2G102)

"Sometimes I think the scoping is not precise... I feel strongly it is not precise." (A2G106)

"It's still a challenge to draw that information from the business areas" (A1G107)

And 2) the project stakeholders (IT and business) not being able to adequately assess the amount of work required for a project:

"I think that the big problem is, is that like the whole idea of project management actually knowing how long it does take to do something is fairly new and you can schedule people all you want, but if it takes three times a month to do something the whole schedule is falling apart and we also don't have a project management tool right where we are looking at resources across the board and seeing where they are allocated." (A2G210) 
"And sometimes I question, why on earth would you take this long to do this silly weird thing I don't know? (A2G106)

The result of this capabilities divergence within City B is a set of project proposals that may be poorly scoped and/or poorly planned in terms of resource requirements and timelines. This leads to projects being "approved" based on erroneous information that the IT shop then has to deliver against. This has led to the advent (or the reinforcement) of an IT hero model within the organization that is not sustainable over time.

"what ends up happening is you are trying to do something for everybody you are trying to give everybody a little piece of you and in the end what happens is that either it drags on and on and you go way past the initial deadlines that were set and the other part is that you do something and you don't understand it completely or you rush through it and there is free work involved because it is not right." (A2G102)

\section{Conflict}

In City B, a number of competing institutions and motivations interact to affect the manner in which actors behave during the performance of the ITPPS routine. Table 11 provides a summary of the conflict-based sources of divergence (along with their manifest behaviour and substantiation) that were identified within City B.

\begin{tabular}{|l|c|c|}
\hline $\begin{array}{c}\text { Motivation } \\
\text { / Driver }\end{array}$ & $\begin{array}{c}\text { Description of Conflict } \\
\text { Behaviour }\end{array}$ & Interview Substantiation \\
\hline Informal & Preference given to interacting & $\begin{array}{c}\text { "I think that's where sometimes these } \\
\text { systems, the IT governance system }\end{array}$ \\
\hline
\end{tabular}




\begin{tabular}{|c|c|c|}
\hline Norms & $\begin{array}{l}\text { through informal relationship- } \\
\text { based channels rather than the } \\
\text { formal governance mechanisms. }\end{array}$ & $\begin{array}{l}\text { break down is that I think this process } \\
\text { that is also relationship in } \\
\text { governance. I think where we get in } \\
\text { trouble is we rely on relationships to } \\
\text { do process and we rely on process to } \\
\text { do relationships." (A2G110) } \\
\text { "I think the stakeholders should } \\
\text { definitely have a channel or channels } \\
\text { to say something or to discuss with IT } \\
\text { management what is going on I mean } \\
\text { that is a healthy relationship, it is } \\
\text { healthy if they can say those should } \\
\text { be your first priority guys not like this } \\
\text { is important to the corporation not } \\
\text { what you are doing" (A2G110) }\end{array}$ \\
\hline Self-Interest & $\begin{array}{l}\text { "Gaming of the System" by } \\
\text { presenting projects in a manner } \\
\text { that will ensure they are } \\
\text { approved and provided a high } \\
\text { prioritization. }\end{array}$ & $\begin{array}{l}\text { - "We certainly need to tell a cost } \\
\text { benefits story, so there needs to be a } \\
\text { compliance with the law story or a } \\
\text { service enhancement story, we have } \\
\text { got some support for mobile devices } \\
\text { solution in the last budget but I was } \\
\text { not able to successfully champion any } \\
\text { investment in (an internal system) in } \\
\text { the last budget" (A2G208) } \\
\text { "Now from what I have seen you can } \\
\text { loosely tie almost any project to any } \\
\text { of those objectives because many of } \\
\text { the strategic objectives are fairly } \\
\text { broad, so "health and safety" well } \\
\text { everything I do could be tied to } \\
\text { "health and safety" right?" [Laughs] } \\
\text { (A2G210) }\end{array}$ \\
\hline Self-Interest & $\begin{array}{l}\text { Pressure to deliver on own } \\
\text { business commitments leading } \\
\text { committee decision-makers to } \\
\text { privilege their own projects over } \\
\text { other corporate projects. }\end{array}$ & $\begin{array}{l}\text { " we might not have the right people } \\
\text { at the table, the people there (IT PEC) } \\
\text { are struggling with their role in terms } \\
\text { of prioritizing and there is some } \\
\text { difficulty to have them think } \\
\text { corporately as opposed to just trying } \\
\text { to get their stuff through." (A2G101) }\end{array}$ \\
\hline $\begin{array}{l}\text { Cultural } \\
\text { Norm }\end{array}$ & $\begin{array}{l}\text { Adherence to how things have } \\
\text { been done in the past resulting in } \\
\text { a reluctance to consider business } \\
\text { transformation activities as part } \\
\text { of an IT-enabled project }\end{array}$ & $\begin{array}{l}\text { "Without a new system and in } \\
\text { municipal environment is not really } \\
\text { proactive in terms of changing forms } \\
\text { and changing the process has been } \\
\text { there. It has always been there and } \\
\text { people don't like to break away from }\end{array}$ \\
\hline
\end{tabular}




\begin{tabular}{|c|c|c|}
\hline & definition. & $\begin{array}{l}\text { that. So I think that creates an } \\
\text { interesting reality when we go into } \\
\text { departments that why you are doing } \\
\text { it that way or we have to do it this } \\
\text { way or why did you have to do it that } \\
\text { way while we have always done it this } \\
\text { way." (A2G107) }\end{array}$ \\
\hline $\begin{array}{l}\text { Power and } \\
\text { Clout }\end{array}$ & $\begin{array}{l}\text { Perception that prioritization and } \\
\text { selection is based on the political } \\
\text { standing of the requesting actor } \\
\text { (power and clout of business } \\
\text { sponsor). }\end{array}$ & $\begin{array}{l}\text { "Some projects went through and } \\
\text { some did not. I think to me the } \\
\text { decision it depends on the person } \\
\text { who is pushing the projects (A2G204) } \\
\text { "Utilities has a high amount of clout } \\
\text { because it is always mandatory and } \\
\text { they have got the money and the } \\
\text { demand" (A2G106) }\end{array}$ \\
\hline $\begin{array}{l}\text { Power and } \\
\text { Clout }\end{array}$ & $\begin{array}{l}\text { Use of council-approved business } \\
\text { plans, as well as the gap between } \\
\text { the business planning routine } \\
\text { and the IT governance routine, as } \\
\text { evidence for not requiring IT } \\
\text { governance approval. }\end{array}$ & $\begin{array}{l}\text { - "I think the big thing is that it needs to } \\
\text { always be related back to budget and } \\
\text { business planning." (A2G101) } \\
\text { - A2G106 didn’t go through the formal } \\
\text { governance process, because they } \\
\text { received } \$ 20 \text { million in council } \\
\text { funding. }\end{array}$ \\
\hline
\end{tabular}

Table 11 - Sources of Conflict Divergence in City B

This chapter has provided an in-depth analysis of the sources of divergence found within each of the two case studies. The following chapter presents a cross-case analysis of sources of divergence and proposes a theoretical model for identifying and understanding IT governance divergence. 


\section{CHAPTER 7 - DISCUSSION}

\section{CROSS CASE ANALYSIS AND FINDINGS}

\section{Common Contextual Environment}

Overall, the contextual environments of both City A and City B are very similar. Despite City B having had a two year head start on their IT governance undertaking, both organizations are at the same relative level of maturity: they both have established business-led governance bodies dedicated to IT investment decision-making, they both have created and implemented a number of IT project intake and assessment artefacts, and they both have undertaken two full years of performances with their current ITPPS routines. Furthermore, the impetus for establishing an IT governance system in both cities was driven by the same mandate to ensure that the organization as a whole was responsible for key IT decisions and to ensure apparent rigor was established to address the historically "wild west" environments where individual business units jostled independently for access to scarce IT resources.

An interesting similarity between the two organizations also exists in the fact that the core governance documents for each city (the IT Governance Framework in City A and the Governance Master Document in City B) remained unfinished and unapproved as of the time of this study. Both organizations identified the ITPPS routine as the most critical element of their overarching governance systems, and as such, both moved to implement the mechanisms for this routine before even completing and instantiating the broader governance framework. Pressure to demonstrate practical and tangible 
progress to city council in both cities drove IT governance owners to look for opportunities where an investment of effort could yield the most positive benefit. The ITPPS routine provided both sets of IT governance owners with an impactful and visible place to start. This approach of building IT governance mechanisms in a phased roll-out is a common implementation strategy adopted by most organizations facing a greenfield environment for their IT governance systems (Weill and Woodham 2002).

Another similarity between the two organizations is that neither organization has an approved and published IT Strategy. As such, the ITPPS routine in both organizations has been introduced without any overarching vision or direction for IT service delivery within the city. Without a formal IT Strategy (and accompanying architectural standards), the prioritization criteria used in ranking potential IT investments is left to be unique to the ITPPS routine and ultimately lacks the legitimacy (and the perceived authority) that a holistic strategic direction could provide. Without a council-approved IT strategy, both organizations struggled with the perception that the ITPPS routine is strictly an IT activity, rather than an organizational-wide activity.

A comparison of the expected behaviours of the ITPPS routines in both cities also shows a level of similarity between the two organizations. As demonstrated in Table 12, all of the respective expectations from each city can be mapped against each other, except for City $A^{\prime}$ 's focus on integration with the larger planning process (which was implicit in City B, but not overtly stated) and City B's focus on investments that specifically ensure and demonstrate quantifiable cost savings or cost avoidance. 


\begin{tabular}{|l|l|}
\hline City A Expectations & City B Expectations \\
\hline $\begin{array}{l}\text { IT investments directly and overtly } \\
\text { aligned to city priorities and strategic } \\
\text { direction }\end{array}$ & IT investments aligned to city direction \\
\hline $\begin{array}{l}\text { IT investments based on clearly } \\
\text { articulated business value } \\
\text { propositions }\end{array}$ & $\begin{array}{l}\text { IT investments prioritized and approved } \\
\text { based on overall benefit }\end{array}$ \\
\cline { 2 - 2 } & $\begin{array}{l}\text { IT investments that provide direct and } \\
\text { clear value }\end{array}$ \\
\hline $\begin{array}{l}\text { IT investments that reflect the need to } \\
\text { balance between corporate-wide and } \\
\text { business-specific benefits }\end{array}$ & $\begin{array}{l}\text { IT investments that balance strategic } \\
\text { and tactical projects }\end{array}$ \\
\hline $\begin{array}{l}\text { IT investment decisions favourable to } \\
\text { projects that promote horizontal } \\
\text { alignment and existing system reuse }\end{array}$ & $\begin{array}{l}\text { IT investments that leverage and reuse } \\
\text { existing systems }\end{array}$ \\
\hline $\begin{array}{l}\text { IT investments prioritized by the } \\
\text { business, for the business and based } \\
\text { on business needs }\end{array}$ & IT investments prioritized and approved \\
\hline $\begin{array}{l}\text { IT investment decision-making } \\
\text { established as part of the bi-annual } \\
\text { corporate planning process }\end{array}$ & No match \\
\hline $\begin{array}{l}\text { No match } \\
\text { bo }\end{array}$ & $\begin{array}{l}\text { IT investments that drive efficiency and } \\
\text { cost savings }\end{array}$ \\
\hline
\end{tabular}

Table 12 - Mapping of ITPPS Expectations in both Cities

The focus of initial efforts by both sets of IT governance owners was clearly to ensure that the ITPPS decisions were owned by the business units and that all IT investments could demonstrate a traceable alignment to the strategic direction of city council. The identification of senior business-led committees as the final IT investment decision authorities in both organizations along with the adoption of artefacts that guide business sponsors to articulate a tie to a larger city objective as part of the investment proposals are evidence of this focus. The initial push to institute formal controls to ensure business ownership of IT investment decisions is not surprising given that this 
was the core mandate of the newly arrived $\mathrm{ClO}$ in City $\mathrm{A}$ as well as the core message in the council-sponsored Corporate IT Strategic Plan in City B.

Although the alignment to strategic direction through the use of formalized templates was generally successful, both cities struggled considerably with the implementation and operationalization of a committee structure that ensured that non-IT managers and directors were making prioritization and selection decisions for IT investments. Both the ITAB committee in City A and the IT PEC committee in City B were observed to be generally ineffective at fulfilling this mandate. Members of the committees, for the most part, were confused and frustrated with their position in the overall ITPPS routine. To further complicate the issue, the top-level governance committees of both organizations (ITSC/CMT and CLT respectively) overtly divested themselves from any decision-making authority - citing that their roles were more directional in nature and that they were not interested in being an operational approval body. The net result in both cities is that despite a clear expectation to have business units own and execute IT investment decisions, in reality, the IT group continued to be responsible for prioritizing and scheduling IT project activities on behalf of their respective organizations.

As for the rest of the expected behaviours, neither city placed a focus on establishing an approach for the quantitative valuation of IT-enabled projects (despite City B's council objective of austerity), or any mechanisms for ensuring that cross-organizational solutions or solutions that reuse existing technology receive favourable prioritization and ranking scores. The notion of horizontality and reuse were discussed by 
interviewees from the two cities mostly in terms of a utopian end-state rather than a practical and obtainable objective of the ITPPS. An obvious question arises as to whether these two ideals should even be considered as part of the prioritization and selection criteria, given the push in both cities that IT investment decisions be made based on the business value of the individual proposal and not on a particular deployment strategy. Multi-stakeholder support and the leveraging of common systems could be argued to be a design and implementation consideration - one that is made after an investment decision has been made. In both cities, the role of identifying crossorganizational solutions or reuse possibilities falls squarely on the shoulders of the IT group given that they are in the position to see the entire portfolio of IT investment requests.

When asked about the effectiveness of their respective ITPPS routines, both IT governance ownership groups felt that the mechanisms that they had put in place were performing well and that the overall performance of the routine within their city was generally positive. When pressed to define why they felt this was the case, respondents from both cities either pointed to the fact that formal mechanisms had been implemented and were operational (such as templates, decision frameworks or committees) or to the fact that the IT group had a defined work plan of activities as evidence that the routine was working.

"I think it is developing in the right direction. Yes. In the past 18-24 months I have seen significant improvement not only in communication and defining 
of the processes around how we do things but in the inputs from the business clients. I would really say it is coming along nicely" (A1G102)

"Yeah, I think for the organization we are set up well. I think we are just missing the ability to leverage it as well as we could." (A2G107)

"I think it is working better than it ever has... So we have come a long way, I don't know if you have talked about the project numbers... When we started how many projects were funded and we are now down to dozens, right. And so that is a testimony in itself to how we have been able to get our arms around the portfolio" (A2G108)

Not surprisingly, and confirming one of the central arguments of this study, the view that the efficacy of their ITPPS routines could be measured in terms of the alignment of expected and actual behaviours was not evident in the discussions with either organization's IT governance ownership groups. For both cities, the fact that templates and tools existed, governance bodies were meeting and that the IT group had a list of projects on which to work was sufficient evidence that the governance mechanisms are effective and appropriately supporting the IT investment decision process. Neither city had a means or an approach to track the performance of their ITPPS routine and therefore had no real ability beyond anecdotal speculation to assess whether or not the "right" IT investment decisions were being undertaken, or whether the IT investments that were approved were generating their promised benefits.

"Did we actually achieve the outcomes we expected in terms of improved customer satisfaction or efficiencies or whatever, we don't do that, we haven't done that to this point in time other than serve in an anecdotal 
sense. There has been a natural weakness but I know, that I think that our executive has recognized and we've actually started having some discussions around that and what do what we need to do..." (A1G101)

(When asked if benefits are assessed after a project has been approved) "No. We know that we need to do that." (A1G105)

"I don't know if there has ever been an opportunity or a requirement for us to go back and say okay here is how we've realized our investment. I don't even know if that would be desirable as you've already mentioned it's kind of hard sometimes to even quantify it." (A2G209)

The majority of detailed discussion on the efficacy of the ITPPS routine cited in both sets of interviews was related to the specific role and functioning of governance committees or the tweaking of individual artefacts. Efficacy was generally measured in terms of the performance of individual governance mechanisms and not the performance of the ITPPS routine as a whole. In fact, the notion of considering whether the holistic governance routine was effective or not, appeared to be a conceptualization not widely considered by the majority of interview subjects. When asked "what does good look like" for their ITPPS routine, many governance owners struggled to find an answer. The nuance of this observation cannot be overstated: IT governance owners were generally positive about the performance of their ITPPS routines, but at the same time could not easily articulate the expected behaviour of the routine. In both cases, effectiveness was measured anecdotally. 
As a last point on effectiveness, there appeared to be little acknowledgement among the IT governance ownership groups in the two cities to the fact that the performance of their ITPPS routines was directly affected by the inherent disconnect between IT investment decision-making and the broader budget planning processes within their organizations. The disconnect was known within both cities, but the fact that in many cases the assignment of funding from other avenues rendered the decisions of the IT investment committees as moot was not considered by either city's set of IT governance owners as a threat or inhibitor to the efficacy of their ITPPS routine. For most interviewees, the ITPPS routine functioned well even if it remained detached from the wider organizational planning and budgeting processes.

Overall, the contextual environments of the two case studies were remarkably similar. Despite the view of the respective IT governance ownership groups that their ITPPS routines were effective and mature, the within-case and cross-case empirical analysis revealed that considerable substantive divergence exists within the both cities.

\section{Common Sources of Divergence}

As a starting point for a cross-case comparison, word summaries were generated within NVivo against the transcripts of each case study to identify prominent word patterns found within the two sets of interviews. Figure 13 provides a frequency count word cloud for both case interview samples. Each word cloud was filtered to remove highuse, common and connector words and grouped families of words based on a common stem (i.e. organize = organizing, organized, organizational). As such, the clouds provide 
a pictorial view of the dominant and prominent terms discussed during the case interviews. The alignment of high-frequency words to the interview protocol (i.e. project, process, system, plans, prioritizing, and opportunity within the top 10 most frequent words in Case A, and project, business, process, plans, system, and committee within the top 10 words in Case B) provides anecdotal validation that interviews were internally consistent and that the primary researcher was successful at ensuring that each discussion stayed on target. The congruency of high-frequency words between the two clouds provides anecdotal validation that the set of interviews were also consistent across both organizations, thus strengthening the overall validity of the research approach. 

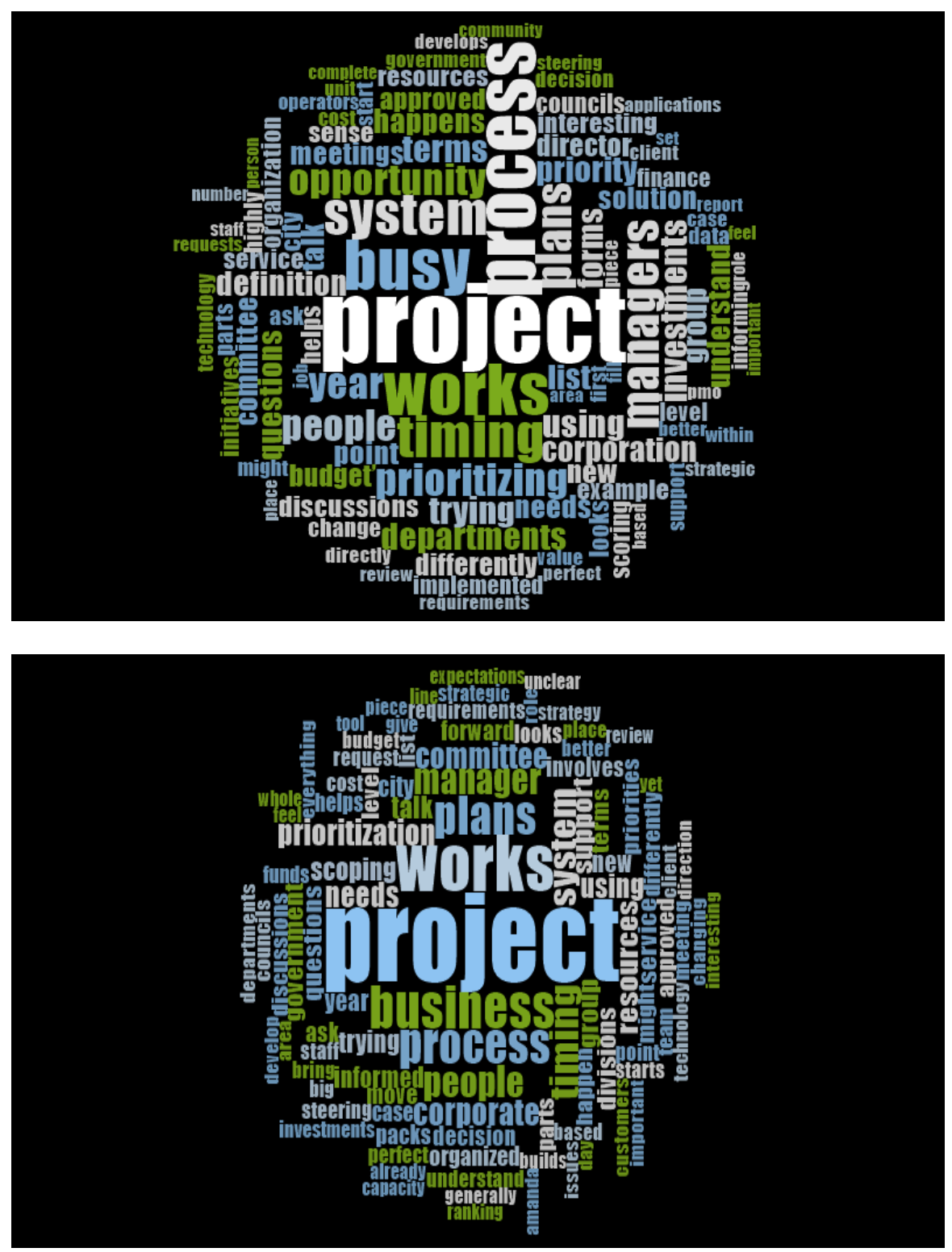

Figure 13 - Word Frequency Clouds for Case A1 and A2

In terms of cross-case analysis of divergence, both cases demonstrated significant examples of divergence across the three first-order constructs of the IT governance divergence framework. Through inductive and recursive pattern matching (Campbell 1975, Bourgeois and Eisenhardt 1988; Pare 2004; Gibbert, Ruigrok, and Wicki 2008) of empirical observations identified within the two "in-case" coding schemas, a number of 
common sources and institutions driving divergence across the two cases were identified and extrapolated. The final pass of within-case coding of divergence for each case study can be found in Appendix R and Appendix S, while Table 13 presents the results of the between-case analysis.

\begin{tabular}{|c|c|c|c|}
\hline $\begin{array}{c}1^{\text {st }} \text { Order } \\
\text { Divergence }\end{array}$ & $\begin{array}{l}2^{\text {nd }} \text { Order } \\
\text { Divergence }\end{array}$ & $\begin{array}{l}\text { City A Divergence } \\
\text { Examples }\end{array}$ & $\begin{array}{l}\text { City B Divergence } \\
\text { Examples }\end{array}$ \\
\hline \multirow[t]{5}{*}{ Representational } & Purposeful & $\begin{array}{l}\text { Council approval vs. IT } \\
\text { approval }\end{array}$ & $\begin{array}{l}\text { Council approval vs. IT } \\
\text { approval }\end{array}$ \\
\hline & Purposeful & $\begin{array}{l}\text { Council trumps } \\
\text { prioritization }\end{array}$ & Budget sets prioritization \\
\hline & Non-Purposeful & $\begin{array}{l}\text { Artefact disconnect of } \\
\text { expectations }\end{array}$ & $\begin{array}{l}\text { No artefacts support cost } \\
\text { saving }\end{array}$ \\
\hline & Non-Purposeful & ITAB role in prioritization & $\begin{array}{l}\text { Business don't approve } \\
\text { projects }\end{array}$ \\
\hline & Non-Purposeful & $\begin{array}{l}\text { Business ownership } \\
\text { mandate }\end{array}$ & \\
\hline \multirow[t]{3}{*}{ Translational } & Translational & $\begin{array}{l}\text { Prioritization not done by } \\
\text { ITAB/ITSC }\end{array}$ & $\begin{array}{l}\text { IT PEC and CLT } \\
\text { rubberstamp }\end{array}$ \\
\hline & Translational & $\begin{array}{l}\text { Interpretation of scoping } \\
\text { forms }\end{array}$ & $\begin{array}{l}\text { Scoping document } \\
\text { completion }\end{array}$ \\
\hline & Translational & Prioritization done by IT & $\begin{array}{l}\text { Prioritization based on } \\
\text { capacity }\end{array}$ \\
\hline \multirow[t]{8}{*}{ Performative } & $\begin{array}{l}\text { Corrective / } \\
\text { Efficiency }\end{array}$ & Horizontality as objective & Horizontality as objective \\
\hline & $\begin{array}{l}\text { Corrective / } \\
\text { Efficiency }\end{array}$ & Start without approval & Prioritization done by IT \\
\hline & Repudiation & $\begin{array}{l}\text { Funding prioritization } \\
\text { mechanism }\end{array}$ & $\begin{array}{l}\text { Funding prioritization } \\
\text { mechanism }\end{array}$ \\
\hline & Repudiation & Process is burdensome & Loss of Control \\
\hline & Repudiation & Reject the response & $\begin{array}{l}\text { Business don't accept } \\
\text { decisions }\end{array}$ \\
\hline & Avoidance & Lack of awareness & Lack of awareness \\
\hline & Avoidance & $\begin{array}{l}\text { Don't understand when to } \\
\text { engage }\end{array}$ & Suppression of demand \\
\hline & Capabilities & Poor business planning & $\begin{array}{l}\text { Business can't scope } \\
\text { needs }\end{array}$ \\
\hline
\end{tabular}




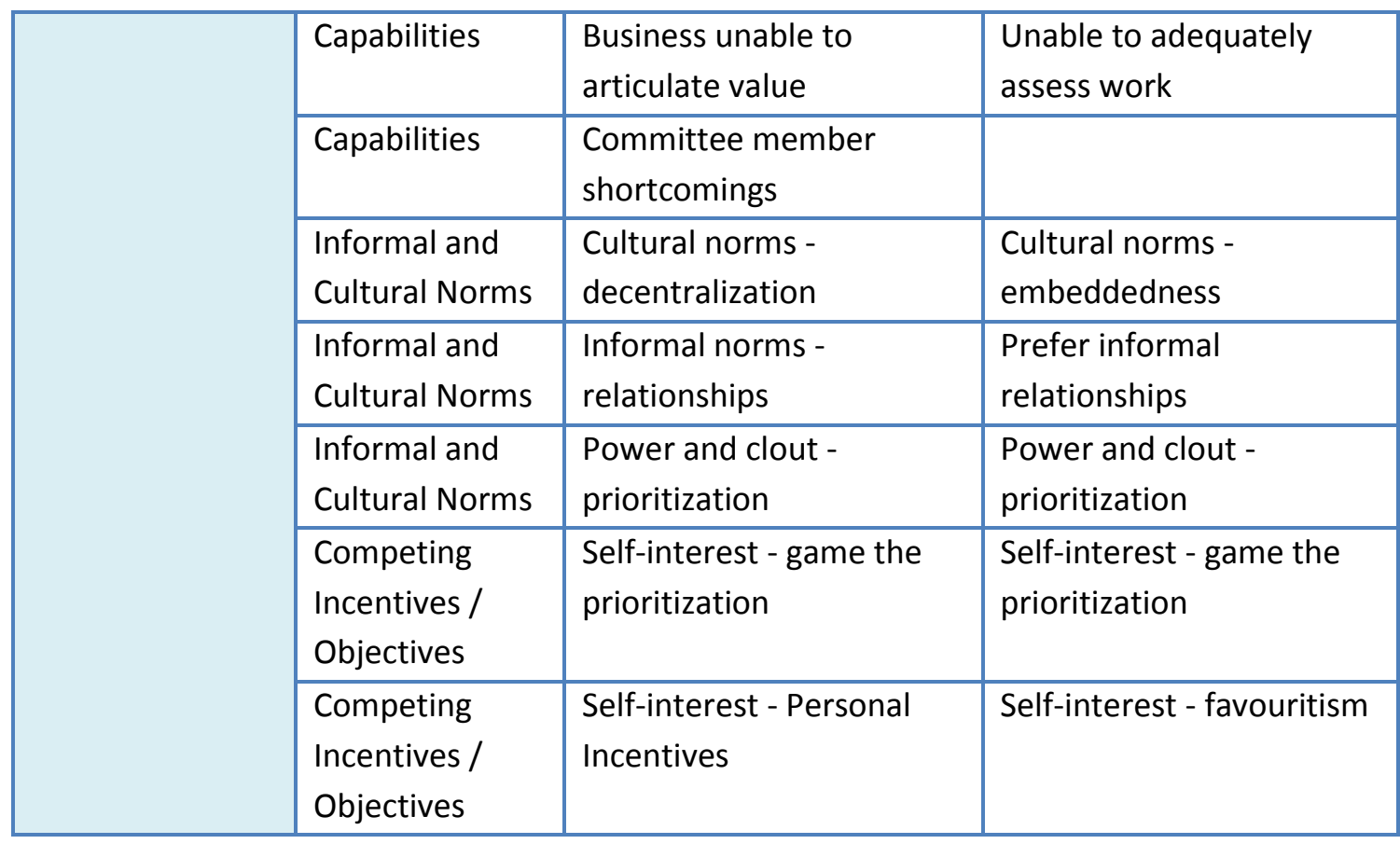

Table 13 - Comparison of Divergence Coding between Cities

Overall, both cities exhibited examples of substantive divergence within their ITPPS routines as evidenced by the fact that the resulting list of IT investments did not (and could not) meet all of the expectations according to the IT governance ownership group in each city. By providing examples of divergence from each city side-by-side, we are able to see a general level of congruence amongst the sources of divergence within each organization. In general, the high-level first-order sources of divergence outlined by the divergence framework held true based on observations from both cities. No empirical examples of divergence were identified in either city that could not be considered a component of representational, translational or performative divergence. The identification and comparison of second-order sources of divergence provides the basis for the establishment of a set of theoretical constructs and relational propositions. 


\section{A THEORETICAL MODEL FOR IT GOVERNANCE DIVERGENCE}

Based on our empirical analysis and inductive identification of common sources of divergence within the two case studies, Figure 14 provides our proposed theoretical model for IT governance routine divergence. The model, derived from observation, supports a preliminary understanding of IT governance effectiveness by identifying the first-order and second-order sources of divergence that occur within individual IT governance routines. Given the uniqueness of the municipal government environment (small public sector organizations driven by political, rather than profit-maximizing behaviour), the applicability of our proposed theory is bound (Whetten 2002; Rivard 2014) to IT governance mechanisms in other small-budget government entities. Given the exploratory nature of our research and the dearth of existing studies within the domain of IT governance effectiveness, a context-specific theoretical contribution is deemed an acceptable objective for scholarly work (Eisenhardt 1989; Gregor 2006).

The following sections will provide an overview of the findings outlined in Chapter 6 against the proposed model. Specific attention is given to summarizing a response to the individual research questions underlying this study. 


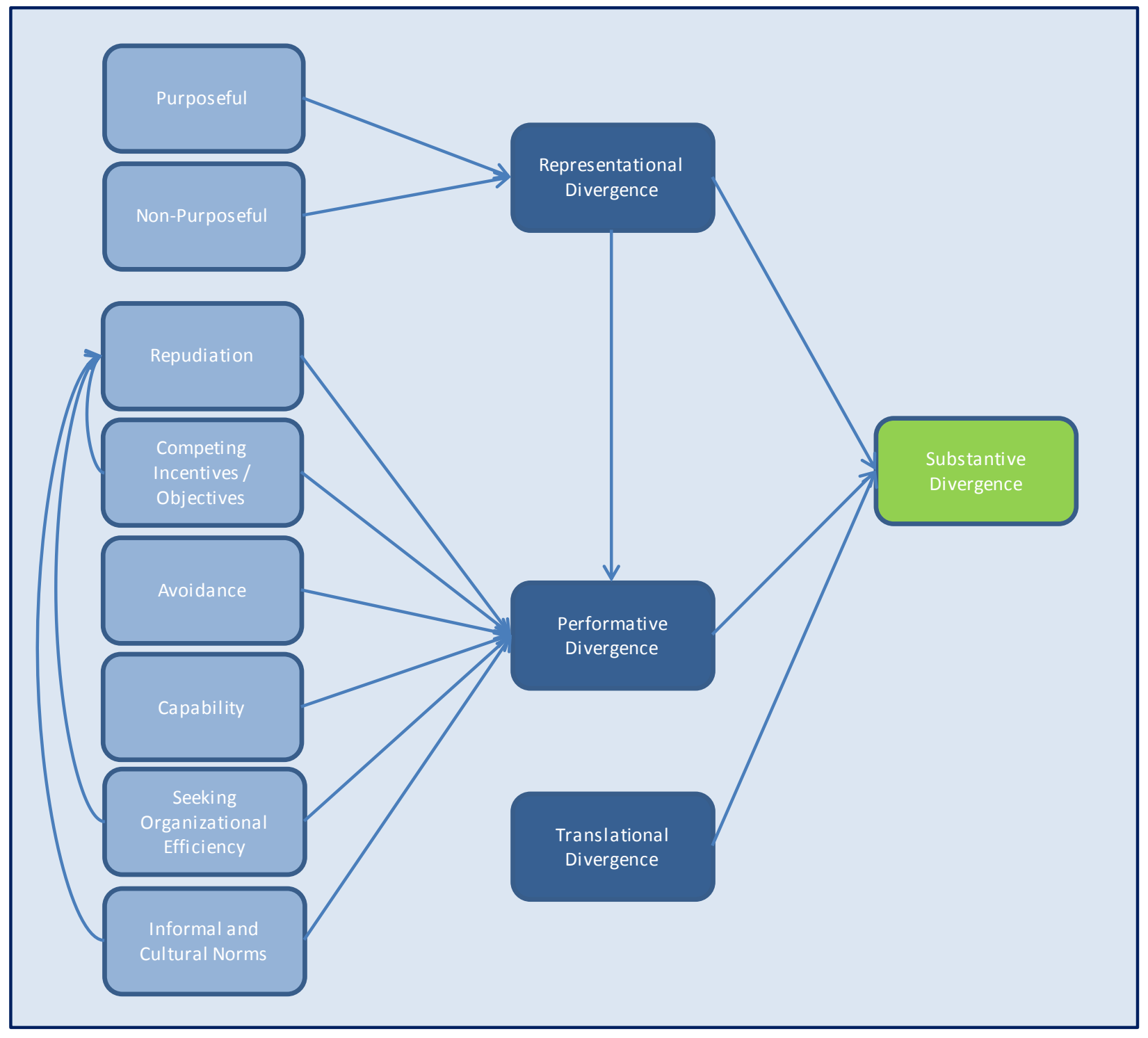

Figure 14 - Theoretical Model for IT Governance Routine Divergence

\section{Primary Research Question - Factors influencing Divergence}

What factors influence the ability of IT governance structures to consistently ensure behaviours and outcomes are aligned with those envisioned and intended by an organization's governance owners and decision-makers? 
Based on the analysis of empirical data from the two case studies, all examples of observed divergence could be categorized as either representational divergence, translational divergence or performative divergence. Grounded in the Divergence Framework for IT Governance routines outlined in Chapter 3, and as evidenced in the divergence coding table in Table 13, we did not encounter any sources of substantive divergence in either case study that could not be fully explained by these three firstorder constructs. Given the amount of avoidance divergence that was observed in both organizations, we considered the possibility as to whether to model this source as a fourth first-order construct; however given that this was a type of behaviour, it was ultimately, and more accurately, categorized as a second-order performative source. P01: The substantive divergence of an IT governance mechanistic routine can be fully explained by the combination of representational, translational and performative divergence.

Within both cities, the net level of divergence between desired expectations of the ITPPS routine and the actual behaviours associated with the routine (substantive divergence) could be fully explained by the misalignment of mechanisms, misinterpretation of these mechanisms and the willful or unconscious decision by actors to deviate from the intended behaviours. In the proposed model, the degree to which each of the first-order construct affects substantive divergence is dependent on the strength and cardinality of underlying second-order constructs. As such, significant positive and negative divergence between competing sources within the same first- 
order construct could result in a minimal impact on the overall substantive divergence arising in a particular performance of a routine. For example, in city A, translational divergence was observed within the ITAB committee's misinterpretation of their responsibility in the prioritization routine, but this was "cancelled out" by an equal misinterpretation by PSC who felt that the act of prioritization was part of their core mandate. The net result is tempered: prioritization of IT investments is done, but substantive divergence still exists in the fact that the prioritization was not performed by business stakeholders.

The relationship between these first-order constructs and the resulting substantive divergence is not linear as evidenced in both case studies. In City A, despite the lack of a formal governance mechanism designed to ensure the reuse of existing applications as a driving factor for a higher prioritized investment, the SPC, as part of their review of project proposals, took it upon themselves to identify opportunities to leverage previous investments. The former represents a clear example of representational divergence but the net effect of this divergence is offset by the performative divergence of a committee working outside of its formal mandate (as defined by the organizational IT Governance Framework). Likewise in City B, one source of performative divergence due to a business sponsor's inability to adequately and appropriately complete a project scope document is counteracted by a BSPM stepping outside of their defined role to complete the artefact on behalf of the business client. 
P02: The degree and direction of representational, translational and performative

divergence is dependent on the degree and direction of the individual underlying sources of divergence.

When contrasting the two case studies, although the sources of divergence were generally congruent between the two cities, what differed in the empirical evidence was the relative distribution of divergence across the respective ITPPS routines. As the result of having a more refined set of governance artefacts (including the PSP, a framework dedicated to designing the ITPPS routine), significantly fewer examples of representational divergence were observed within City A when compared to City B. In contrast to this observation, however, City $\mathrm{A}$ also demonstrated a significant increase in performative divergence, specifically with respect to avoidance behaviour when compared to City B. When investigated further, this observation becomes less surprising.

City A's lower level of representational divergence was due to the establishment of a number of well-defined artefacts designed to drive expected behaviour, the best examples being the Opportunity Definition Form, the Project Scoring Matrix and the Project Dashboard Selector. By implementing strongly aligned artefacts in support of the ranking and prioritization of project requests, business stakeholders were provided with very little "wiggle room" to control the ultimate ranking and prioritization of their investment proposals. When combined, these mechanisms greatly limited the actors of the ITPPS from behaving in a manner contrary to that desired by the IT governance 
owners without demonstrating a form of performative divergence. In other words, the greater alignment of artefacts in City A results in a lower level of potential agency by routine participants. This feeling of loss of agency in turn results in actors choosing to avoid the ITPPS routine altogether, a phenomenon also observed by Burns and Scapens (2000), Howard-Grenville (2005) and Lazaric (2011). Given that the ultimate objective of a formal IT governance mechanism is to guide the behaviours of routine actors towards a set of expected or desired behaviours, it holds that a relationship exists between the amounts of control exerted by IT governance artefacts through tightly aligned artefacts and the behavioural response to those controls by the actors of the routine.

\section{P03: The lower the representational divergence, the greater chance that repudiation} performative divergence will occur within the performance of a routine.

The opposite also holds true for the relationship between representational and performative divergence. In City B, the artefacts were much less defined than in City A. The project scope document was very lean and open-ended which led to poorly scoped project submissions, and the prioritization matrix was open to considerable "gaming' based on the fact that it included numerous confounding measures as a means of determining a priority ranking. Stakeholders did not feel that their agency was being limited, and as such, did not feel they needed to resort to divergent behaviour. Most performative pressures could be addressed within the context of the formal routine, because the routine was so loosely defined. This was best seen in one example where an A2G2 business sponsor ceremoniously submitted a project scope document that they 
knew should be rejected based on a lack of alignment to strategic direction, but felt it wasn't necessary to avoid the routine as they felt it would be accepted anyway.

P04: The higher the representational divergence, the lower chance that repudiation performative divergence will occur within the performance of a routine.

\section{Sub-Research Question 1 - Impact of Artefacts}

What is the role and impact of formal mechanisms on IT governance routine divergence?

A disconnect between the expected behaviours of the IT governance owners and the implemented formal structures of the routine was evident in multiple examples within both City A and City B. The result of misaligned or missing artefacts directly impacted the ability of actors performing the routine to align to the expectations of the governance owners, and as such, led to increased substantive divergence. Examples of representational divergence were observed in the two case studies to occur in two ways: purposeful (with knowledge of IT governance owners) and non-purposeful (without knowledge of IT governance owners).

Purposeful representation divergence was identified within both cities in the manner in which the ITPPS routine was positioned with respect to the overall planning and budgeting practices of the respective organizations. In both cities, budgeting for projects and programs are done separately from the IT investment routine. This disconnect fully removes the authority for selection and partially removes the authority for prioritization by the ITPPS governance bodies. What is left over is a governance 
routine focused on resource-based prioritization and scheduling of work activities for the IT group. For City A, the core governance document for the ITPPS routine, the PSP even uses this wording indicating that the $\mathrm{ClO}$ is accountable to "assess resource requirements and develop preliminary IS\&T workplan" and that the ITSC (CMT) is accountable to "approve IS\&T Workplan (projects and priorities)" (PSP, p. 17). In both cities, the idea of a business-led IT investment decision-making routine based on business value assessments has been replaced, in actuality, by an IT group-led scheduling and resource allocation process.

From this perspective, the question has to be asked of each organization if the ITPPS is simply ceremonial in nature. Mechanisms are put in place by the IT governance owners, but the authority of the decision makers within the routine is trumped by the corporate budgeting process, and in fact, the entire structure of the routine is trumped if either city council wants a particular IT-enabled project to be undertaken. Stakeholders in both organizations were clear that council requests or mayoral taskforce activities take precedent over any other type of investment and do not need to be part of the overall prioritization and selection queue.

"You may have all kinds of different business needs, but then you have the mayoral task force. That upsets the whole hand... That pushes everything else down, and, you know for good reason, perhaps." (A1G212)

"An example would be the mayoral task force, which kind of made it a, made a priority of anything that came out of the recommendations of that task force. This includes IT investment in that system..." (A1G208) 
"I think that there are sort of three concentric arenas of decision making one is the council and they approve operating and capital budgets" (A2G208)

What is of particular interest is that it doesn't appear that either set of interviewees in each organization want to acknowledge that this situation is occurring. The traditional argument of ceremony (in the context of institutions, but transferable to organizational routines) rests in the creation of structural "facades" as a means for providing the appearance of legitimacy in response to isomorphic pressures (Meyer and Rowan 1977). In City A and City B, although external pressures for legitimacy are not apparent, IT governance owners are driven to meet the mandates of the $\mathrm{ClO}$ organization and the ITSP respectively. Both organizations are driven by the desire to establish some sort of order to a historically chaotic business process and thus the pressure to establish an orderly and professional structure at times may outweigh the governance owners' desire to ensure that the "correct" IT investment decisions are made.

P05: The greater the isomorphic pressure for legitimacy, the higher the purposeful representational divergence within a governance routine.

Non-purposeful representational divergence in both cities primarily manifested itself in missing or misaligned mechanisms to support the expected or desired behaviours of routine actants as envisioned by the IT governance owners. Specific to the respective ITPPS routines, non-purposeful representational divergence is found within the project proposal and assessment templates (for example the Project Scoring Matrix for City A providing a lower rank for projects that cross multiple business units, and cost-savings 
being blended with other benefits in the Prioritization and Decision Framework of City B) and the unclear position of IT governance bodies with respect to their role in the prioritization process. In both cities, the IT group provides a first cut of prioritization and ranking that is rarely changed or challenged by any of the more senior committees (ITAB and ITSC in City A, IT PEC and CLT in City B). In City A, this divergent behaviour is not only tolerated, it is supported by the committee terms of reference that outlines that the SPC "reviews and approves proposals and business cases for information and technology investment decisions" (ITGF, p. 23) and that ITAB members aren't required to challenge each other's projects or proposed prioritization (A1G101). In this case, despite the IT governance ownership's expectations that prioritization and selection decisions would be made by business members, the committee ToRs directly contract this desire and as such limits the ability of the routine to support owner expectations.

This type of divergence is also observed in the manner in which IT-enabled projects are shepherded through each city's IT investment governance routine. In City A, the IT managers present and defend the project proposals on behalf of client sponsors throughout the performance of the routine, and in City B the same activities are performed by the BSPMs. In both cases, having IT resources formally represent project proposals completely contradicts the IT governance owner's expectation that IT investments are "owned" by the sponsoring business lines and not the IT group. The IT group members are expected to be service delivery agents for IT-enabled projects, but not the project champion for business-sponsored initiatives. 
P06: The greater the intended or unintended misalignment of artefacts with expected behaviour, the greater the overall representational divergence within a routine.

In addition to substantive divergence being driven by the misalignment of routine artefacts and expected behaviours, divergence was also observed within the two case studies in the manner in which artefacts and mechanisms are interpreted by organizational actors. The sources of this translational divergence found within the two cities were essentially identical. In both cases, 1) the ITPPS committees did not understand their role and as such interpreted their mandates as they saw fit, 2) the scoping documents were used to suggest IT solutions rather than quantify business plan points, and 3) the IT group (based on their vantage point in the organization) prioritized projects based on IT capacity rather than business value.

At the core of this divergence within both cities is the lack of a clear written mandate for the ITAB and IT PEC committees. In both cities, a stand-alone set of ToRs (separate from reference within governance documentation) could not be provided for any of the ITPPS governance bodies by either set of IT governance owners.

"Yeah, I know we talked about (having a terms of reference). I think we actually did get the one, but it was pretty well soon after we have developed it, we kind of evolved to the model of (ITAB) being just the whole Directors Group. You know, I don't think that they ever get to formally, formally ever approve anything, to the Directors Group." (A1G212) 
(In response to whether there is a terms of reference for IT PEC) "They've tried to define a few times what that group is about, but I mean and the reason that I struggle is I have asked the question a few times." (A2G203)

Committee mandates and roles and responsibilities were derived from the overarching governance frameworks and documentation (ITGF for City A and GMD for City B), and from discussions that took place during the preliminary meetings with each of these committees. In the absence of clear ToRs both groups interpreted their roles how they wanted to. For ITAB this means setting overall direction on IT investments while reviewing project progress, and for IT PEC it means "rubber-stamping" prioritization that is provided to them by the IT group. In both cities, translational divergence was directly related to the existence of ill-defined and incomplete committee-related artefacts.

P07: The less specified a formal artefact, the greater the level of interpretation required by actors, and the greater the divergence between performance and desired behaviours.

An interesting contrast between the two organizations is found in the IT group's interpretation of their respective roles as defined by the core governance artefacts. In City A, the IT group performs the ranking and prioritization of IT investment proposals because that is what they interpret their role to be within the routine. A portion of this divergence has to be attributable to the representational divergence resulting from the ambiguous mandate of the committee as defined in the ITGF (as discussed above), but it must also be attributed to translational divergence since the IT group has misinterpreted the direction that investments are to be prioritized and selected by the business units. Despite the fact that it is in their best interest to leave the justification 
of project ranking scores and the ultimate prioritization of IT investments to the business-led decision bodies (in the sense that this absolves the IT group of the responsibility to "tie-break" competing business priorities), the IT group believes that they must perform these activities as part of their contribution to the routine performance.

In City B, a similar situation occurs: The IT group performs the ranking and prioritization of IT investments due to the fact that the IT PEC and CLT committees have interpreted their roles as being strictly strategic and, as such, members of these committees do not feel that they are responsible for operational-level project selection. The difference between the two cases, however, lies in the underlying motivation for this divergence. In City A, the IT group truly believes that they should be performing the prioritization of IT investment proposals on behalf of the organization. But in City B, the IT group does not believe this. They do not want to perform this role, don't feel that they should perform this role, and only do so by default to ensure that the activity is actually undertaken somewhere within the city. For City A this is a clear example of translational divergence: The IT group has misinterpreted its role with respect to the expectations and artefacts of the IT governance owners. For City B this is an example of performative (corrective) divergence, because the IT group is going against its correct understanding of its mandate and role. The resulting behaviour is the same in the two cities, but the motivation for divergence is considerably different. 
P08: The greater the level of representational and translational divergence, the greater the opportunity for increased corrective performative divergence.

The last common example of translational divergence involves business sponsors misinterpreting the purpose of the respective project scoping documents within each city. In both cases the objective of these scoping documents is to allow for a decision to be made based on the business value and business alignment of the investment opportunities. The fact that a number of business sponsors use these forms to submit unsubstantiated IT solution requests represents an overall misunderstanding of the purpose of the ITPPS routine and a lack of buy-in that IT-enabled projects are business projects first and IT projects second. Business units in both cities continue to see IT investments as a panacea for all business problems or as a way to bring in new shiny functionality, rather than a means to support a business-focused reengineering effort to address business inefficiencies or pain points. In both cases the purpose and approach of each of the project scoping documents are fairly well defined but a misinterpretation of these documents by business sponsors leads to IT investment proposals that lack the information required by the downstream prioritization mechanism. Proper and quantifiable business value-based prioritization cannot be performed when this information is not captured as part of the planning phase of the ITPPS routine.

\section{Sub-Research Question 2 - Behavioural-Based Sources}

What factors influence the manner in which individual actors adhere to the formal expectations and structure of an IT governance routine? 
Second-order performative sources of divergence were more difficult to observe and identify in comparison to representational and translational sources. This was especially apparent in City B, where a high level of representational divergence resulted in a number of actors being unclear of their roles or the expected behaviours associated with the mechanisms of the ITPPS routine. Overall, behaviour influences encompass the social, cultural and environmental factors that combine to affect the actions taken by actors during the performance of a routine (Becker et al. 2005). As such, although the existence of performative divergence may be easy to observe and recognise (Dougherty 1992; Adler et al. 1999; Feldman 2000; Becker, Salvatore and Zirpoli 2005; HowardGrenville 2005), gaining an in-depth understanding of the underlying motivation for this divergence can prove to be much more difficult (Pentland and Feldman 2008).

Based on our empirical analysis, there are five latent motivations or influences that drive performative divergence within the two cities: a desire to improve the efficiency of the routine, competing incentives or objectives, informal and cultural norms, insufficient capability to perform appropriately or as required, and a general lack of awareness of expected behaviours. Repudiation was recognized as both an underlying source of performative divergence but also as a manifest behaviour exhibited in response to the other influences.

\section{Corrective / Efficiency}

As discussed in the previous sections, the SPC and IT Management committees in both organizations provide the most prominent examples of performative divergence based 
on a desire to improve the efficiency (and efficacy) of their ITPPS routines. In response to that fact that neither city has implemented any formal mechanisms to satisfy the expectations that IT investments strive to provide cross-business unit benefits (horizontality) and reuse existing assets, these two committees sought to address and rectify this clear example of representational divergence. In response to this structural oversight, these committees leveraged their privileged position as stewards of the various IT systems and the collectors of all investment proposals to informally promote these expected behaviours. In City B, this behaviour is emulated by the BSPMs who also draw on their relationship with the larger IT group to identify potential areas of overlap with other business unit IT projects and technology reuse opportunities.

More holistically, the fact that both of these committees undertake any form of prioritization of project proposals is in itself a corrective behaviour (although as discussed, in the case of the SPC in City A this is in part a case of translational divergence) accounting for gaps left in the routine by the more senior decision-making bodies. A similar inefficiency gap is addressed in City A through the creation of an informal "fast-track" process that allows highly-ranked projects to begin execution prior to receiving formal endorsement from the ITAB or ITSC. The execution of this informal process would be observed as repudiation behaviour since it is an outright rejection of adhering to the formal ITPPS routine. The underlying motivation of this behaviour, however, is the recognition that the bi-annual schedule of ITAB does not facilitate investment opportunities that arise outside of the formal planning window. Although some of these "in-year" requests are a result of poor planning on behalf of the 
organizational sponsors, a number are driven by legislative or citizen-driven priorities that couldn't have been foreseen or predicted. In this example, resistance to following the formalized mechanisms related to IT investment decision-making is driven not by an outright rejection of the system, but by a desire to increase the overall efficiency of the routine.

P09: The amount of corrective divergence within a routine is directly related to the perceived level of formalized inefficiency embedded within an IT governance mechanism. The common motivation underlying all of these examples of performative divergence is that actors within the routine have recognized inefficiency in the formal structure of the routine and are adjusting their behaviour in order to overcome or circumvent that inefficiency. The divergence exhibited is a conscious and proactive response to addressing a gap in the manner in which the ITPPS routine is designed or executed. In terms of cardinality this type of corrective divergence should be considered as positive, yet it would typically be sought to be eliminated by a typical command and controlbased governance environment (Wolf 2007; Weichbrodt and Grote 2010). The decisions to diverge from the behaviour outlined by the formal ITPPS mechanisms demonstrated an adherence to the "spirit" of the governance routine rather than a strict adherence to the structure of the routine, and moved actual behaviours back in line with those envisioned by the IT governance owners (Pentland and Feldman 2005; Lazaric and Denis 2005; Wolf 2007; Weichbrodt and Grote 2010). 
P10: The desire to seek efficiencies by routine actors may result in an increased manifestation of repudiation divergence.

\section{Competing Incentives / Objectives}

A palpable tension existed within the IT governance actor groups of both cities in terms of their desire to adhere to the ITPPS routine framework and the desire to deliver on their own program mandates. In both cities, individual business units annually plan and forecast a set of program activities that will be completed over the course of the following year. This planning process not only helps solidify the operating and capital budgets of the city, but also allows each department to articulate a set of program objectives and performance targets. Business sponsors are responsible for delivering against their individual performance objectives and the "effectiveness" of management is measured by the ability to accurately plan and execute on program commitments.

When a work activity in either city involves an IT investment, and as such, requires the support of the IT group, business sponsors are directed to participate in their city's respective ITPPS routines. At this point, the ability to control the progress and schedule of the program activity is relinquished to an organization-wide governance structure in which the individual stakeholder has little direct ability to influence. Furthermore, the expected behaviour of ITPPS is one of horizontal solutions, reuse of existing systems, alignment to broad corporate goals and collective prioritization of all competing organizational needs. For the business sponsor, all of these objectives are in complete 
conflict with moving forward with their locally-focused, specific program activity and meeting their council-approved performance targets.

"As soon as I hear governance I'm thinking policies and procedures and forms and somebody gets to make a decision and where am I in all that?" (A2G209)

"Because at the end of the day, each area's got their own mandate, has their own deliverables, has their own priorities, and at the end of the day, that's what they're going to go with, because to do something in an enterprise fashion takes a little give and take and it takes patience and maybe it's not right for the City, given the size, the organization. Maybe (horizontality is) an unrealistic, maybe it unattainable goal, right." (A1G209)

Participation in the ITPPS routine in both cities threatens the ability of business stakeholders to meet their program objectives, because the drivers of the ITPPS are not aligned to the drivers motivating individual business stakeholders. For some business units, such as the utilities organization in City $A$ and the building permit organization in City $B$, this is overtly evident. For these organizations, revenue and client servicerelated pressures faced far outweighs their interest in ensuring that they conform to a corporate process. This results in the ITPPS routine as being viewed as a hindrance rather than an enabler to achieving business objectives.

"We are a separate business identity on our own, that has unique characteristics that require unique skill sets and require unique IT solutions. We are basically one division of many with (City B), which makes it difficult for us to attain our goals and objectives with our customers... if there are 
other needs that supersede our needs based on (IT PEC) or council direction then we fall after them, we are going to have to wait for others" (A2G205)

"I am more accountable to customers than the tax base so therefore I am frugal so I want to make sure if I can save a buck and I want to save a buck... I need to look at things so they can be implemented as efficiently and effectively as possible and that usually saves money... (The conformance to the ITPPS) would hurt my productivity and my effectiveness" (A2G201)

"There's process for (the utilities organization) and then there's processes for everybody else so they haven't quite bought into the centralized view" (A1G102)

In City A, not only is there reputational pressure (or in the case of the utilities organization, market pressure) to meet departmental work plan targets, the management team also receives incentive pay based on their individual performance against locally-defined targets. In this situation, a low prioritization of an IT investment proposal not only threatens a business unit's ability to meet its established objectives, it can also result in the sponsoring management team losing out on potential compensation bonuses.

In the two cities, a misalignment of business and personal incentives with the expected behaviours of the ITPPS routine was observed to manifest itself in a number of behaviours including: individuals attempting to "game" the prioritization process to ensure a higher ranking for their project, committee members favoring their own organization's investment proposals over others, and business sponsors avoiding or 
outright refusing to participate in the ITTPS routine by going directly to external vendors for IT services. These observations are consistent with Howard-Grenville (2005) who also found that individual actors interact within a routine in a manner that tries to advance both their personal and the broader organizational goals.

P11: The greater the misalignment between IT governance mechanisms and individual incentives, the greater the negative performative divergence and greater the amount of overall substantive divergence.

\section{Informal and Cultural norms}

Although interview respondents in both cities alluded directly or indirectly to a number of institutional norms that impacted their behaviour during the enactment of the ITPPS routine, three common sources of divergence emerged most prominently from these discussions. As the first source, the influence of a longstanding culture of decentralization was identified in both cities as major factor contributing to the performative divergence of routine actors.

"maybe I am speaking out of turn, but I think in the past, especially you may find in the interviews, we were very decentralized if you will, and we have enabled as a corporation different business units to do their own things and maybe come back after the fact and ask for forgiveness afterwards, so that a bit of that culture may play into (why people diverge from expected behaviours)" (A1G201)

"I think it's part and parcel of what a municipality is, so it's a group of, to a large degree, independent businesses, as opposed to one, you know, 
company that is in one line of business... work planning and things like that are all kind of done within those silos. And so, I think it's probably a challenge culturally to break that down" (A1G109)

The embedded cultural approach of managing program deliverables in isolated siloes directly contradicts the corporate-wide focus of the ITPPS routines in each city, a similar situation as was identified with individual incentives. The difference however lies in the fact that individual incentives appeared to drive conscious divergence behaviour (in the form of repudiation or avoidance), where the embedded culture of decentralization was more subtle and indirect. This is observed in the fact that multiple organizations implementing point of sales systems in City A didn't even consider the possibility that other organizations might want to leverage the same solution (A1G109) or the lack of consideration given to leveraging the central ERP system by multiple organizations proposing HR-related solutions in City B (A2G108).

The second informal influence on performative behaviour in both cities was a desire or preference to leverage personal relationships as opposed following the formal mechanisms of the ITPPS routine. As a prime example of this, a business sponsor in City B opted to have a "coffee chat" with key decision makers rather than submit a formal project scoping request for approval for a particular low-dollar investment request (A2G201). This approach, which represented a clear example of repudiation behaviour, was driven by the sponsor's belief that informal relationships drove project prioritization and selection decisions rather than the formal ITPPS mechanisms. Likewise a sponsor in City A pointed out that she often leverages friends within the IT 
shop to get small pieces of IT-related work done without having to be subjected to the overhead of the formal project scoping process and then having to wait for the results of the prioritization and selection mechanisms (A1G203).

\section{P12: Divergence due to cultural and institutional norms can increase performative} divergence directly or through the manifestation of repudiation and avoidance behaviours.

The final influence was discussed in an anecdotal manner within both organizations. However, instances of this behaviour were not able to be identified by the research team through direct observation or through the development of individual city routine narratives. In both cities, a number of stakeholders strongly believed that the prioritization and selection of IT investment proposals was based primarily on the relative organizational power held by the sponsoring business unit. Although most interviewees could not provide examples of when this may have occurred, the perception existed that certain business units (specifically the utilities groups in both cities, and the transportation group in City A) were better accommodated by the ITPPS routine than other business units. If substantiated, this behaviour would represent a significant source of performative divergence on behalf of the governing bodies associated with the ITPPS routine.

\section{Capabilities}

The efficacy of the ITPPS routines in both cities is dependent, among other things, on the ability of business sponsors to adequately forecast, articulate and quantify their IT 
investment requirements in a timely and consistent manner. In order to rank, prioritize and select projects based on their business value and alignment to organizational objectives, these criteria must be adequately completed as part of the overall project scoping portion of the routine. As identified in Chapter 5, both cities experience difficulty related to planning in general, as well as the ability to draft sound investment proposal documentation.

"I don't even think we do a good job with identifying when our needs are, like what our projects should be. What do we need to make business look good or be functioning? I don't think we're that even well-educated on business planning to know what we need to do." (A2G102)

"Oh, funny you should say that, because I did raise that issue with (the IT group). So it all depends on what kind of stories Directors tell, the way that (the project proposal) is set up. They will try to advance a project on these, you know, wild... guesses" (A1G212)

Although some of this difficulty may be attributable to translational divergence (i.e. a misunderstanding as to what is expected in a scoping document), it was mentioned in both organizations that oftentimes business stakeholders did not have a sufficient ability to create a sound investment business case based on the expectations of the routine, and even if they could, that the governance bodies that were charged with reviewing the business cases did not have sufficient ability to appropriately analyse and compare these cases. In City A, the general observation was that business sponsors did a poor job of articulating the business value of the proposal, while in City B business sponsors were unable to sufficiently quantify cost savings - an interesting dichotomy 
that clearly shows the difference in council expectations between the two organizations (value vs. cost savings). In either case, the expectation that IT investment decisions are made on clearly articulated, business-driven, defensible proposal templates was typically not met in either organization due to a perceived immaturity of project and investment management acuity amongst the routine actors. Overall the feeling in both cities was that there was a significant lack of skill amongst staff to create and present quantitative investment business cases. The immaturity of project-related capabilities is a problem facing many organizations (Rodriguez and Juiz 2014).

P13: The more specific the skillset required to enact a routine, the greater the chance of divergence between expected and actual behaviour.

\section{Avoidance}

As the final stand-alone second-order construct, avoidance divergence was the most prominently coded source of divergence within the two cities. As opposed to repudiation divergence which represents a conscious rejection of the routine structure, avoidance divergence describes the behaviour of actors that work around the formal ITPPS structure solely due to the fact that they were unaware that they should be submitting formal IT investment requests through this routine. At the root of this type of divergence behaviour is a lack of communication of the formal process in both cities. Although IT governance owners generally felt that the ITPPS routine was well understood by their organizations, interviews with the IT governance actors group 
revealed that many organizational stakeholders were either not aware of the routine, or had a very rudimentary understanding of their role within the routine.

"No, I would submit that (the ITPPS routine) is not fully understood. There are probably some managers or directors that have a strong grasp of it and others probably a fairly weak understanding which takes us to the next level - what sort of understanding do operational staff need to have? I think at that level it is almost non-existent...I would think we need to promote it more- get it out there" (A1G102)

"I don't believe most businesses understand (the ITPPS routine) at all" (A2G105)

"I think from a process perspective, I think that we as a corporation could do a bit better in terms of raising awareness across the corporation with what the (ITPPS routine) is" (A2G207)

"That is the only path I am really aware of. I know some of the other managers deal with more of our mandate in creating systems and stuff like that, they are doing these scoping documents and this like that but I am not involved with the end of it very much, so this (the path) for me" (A2G202)

The last quote was from an individual business sponsor in City B that went through the helpdesk to procure a particular software solution. In this example, neither the business sponsor, nor the help desk agent was aware that any significant IT investment request requiring any type of IT involvement (in this case customization and integration with other systems was necessary) should go through the ITPPS routine for prioritization and ranking. The end result was that the helpdesk agent worked with their IT contacts to 
secure the purchase and installation of the vendor software completely outside the purview and oversight of the IT governance system.

P14: The less awareness and communication of a routine within an organization, the greater the avoidance divergence.

\section{Repudiation}

In contrast to avoidance divergence, repudiation divergence is motivated by a conscious and overt circumvention of the formal structures of a routine. As discussed at great length in Chapter 5, this behaviour was observed in both cities in terms of an outright or delayed rejection of the ITPPS routine primarily based on a loss of agency or the belief that the mechanisms were only necessary if funding wasn't available. In the discussion of the performative sources of divergence above, we also identified that repudiation behaviour existed due to a desire to improve operational efficiencies (the $\mathrm{ClO}$ fast-track process in City A), to privilege personal incentives over the desired behaviours of the ITPPS routine (direct to vendor for IT services) and the use of informal relationships to bypass formal mechanism (coffee-talk with IT executives). As such, repudiation is modelled as both a second-order construct influencing performative divergence but also as a manifest behaviour driven by an underlying source of divergence motivation.

P15: The greater the level of incentive, informal and cultural, and corrective divergence, the greater the level of repudiation divergence.

Table 14 provides a summation of the proposition statements proposed in this chapter. 


\begin{tabular}{|c|c|}
\hline $\begin{array}{l}\text { First-order } \\
\text { Construct }\end{array}$ & Proposition Statements \\
\hline \multirow[t]{4}{*}{$\begin{array}{l}\text { Substantive } \\
\text { Divergence }\end{array}$} & $\begin{array}{l}\text { P01: The substantive divergence of an IT governance mechanistic } \\
\text { routine can be fully explained by the combination of representational, } \\
\text { translational and performative divergence. }\end{array}$ \\
\hline & $\begin{array}{l}\text { P02: The degree and direction of representational, translational and } \\
\text { performative divergence is dependent on the degree and direction of } \\
\text { the individual underlying sources of divergence. }\end{array}$ \\
\hline & $\begin{array}{l}\text { P03: The lower the representational divergence, the greater chance } \\
\text { that repudiation performative divergence will occur within the } \\
\text { performance of a routine. }\end{array}$ \\
\hline & $\begin{array}{l}\text { P04: The higher the representational divergence, the lower chance that } \\
\text { repudiation performative divergence will occur within the performance } \\
\text { of a routine. }\end{array}$ \\
\hline \multirow{4}{*}{$\begin{array}{l}\text { Representational } \\
\text { / Translational } \\
\text { Divergence }\end{array}$} & $\begin{array}{l}\text { P05: The greater the isomorphic pressure for legitimacy, the higher the } \\
\text { purposeful representational divergence within a governance routine. }\end{array}$ \\
\hline & $\begin{array}{l}\text { P06: The greater the intended or unintended misalignment of artefacts } \\
\text { with expected behaviour, the greater the overall representational } \\
\text { divergence within a routine. }\end{array}$ \\
\hline & $\begin{array}{l}\text { P07: The less specified a formal artefact, the greater the level of } \\
\text { interpretation required by actors, and the greater the divergence } \\
\text { between performance and desired behaviours. }\end{array}$ \\
\hline & $\begin{array}{l}\text { P08: The greater the level of representational and translational } \\
\text { divergence the greater the opportunity for increased corrective } \\
\text { performative divergence. }\end{array}$ \\
\hline \multirow[t]{5}{*}{$\begin{array}{l}\text { Performative } \\
\text { Divergence }\end{array}$} & $\begin{array}{l}\text { P09: The amount of corrective divergence within a routine is directly } \\
\text { related to the perceived level of formalized inefficiency embedded } \\
\text { within an IT governance mechanism. }\end{array}$ \\
\hline & $\begin{array}{l}\text { P10: The desire to seek efficiencies by routine actors may result in an } \\
\text { increased manifestation of repudiation divergence. }\end{array}$ \\
\hline & $\begin{array}{l}\text { P11: The greater the misalignment between IT governance } \\
\text { mechanisms and individual incentives, the greater the negative } \\
\text { performative divergence and greater the amount of overall substantive } \\
\text { divergence. }\end{array}$ \\
\hline & $\begin{array}{l}\text { P12: Divergence due to cultural and institutional norms can increase } \\
\text { performative divergence directly or through the manifestation of } \\
\text { repudiation and avoidance behaviours. }\end{array}$ \\
\hline & $\begin{array}{l}\text { P13: The more specific the skillset required to enact a routine, the } \\
\text { greater the chance of divergence between expected and actual } \\
\text { behaviour. }\end{array}$ \\
\hline
\end{tabular}




\begin{tabular}{|l|l|}
\hline & $\begin{array}{l}\text { P14: The less awareness and communication of a routine within an } \\
\text { organization, the greater the avoidance divergence. }\end{array}$ \\
\hline $\begin{array}{l}\text { P15: The greater the level of incentive, informal and cultural, and } \\
\text { corrective divergence, the greater the level of repudiation divergence. }\end{array}$ \\
\hline
\end{tabular}

\section{Table 14 - Proposition Statements}

\section{Implications for the Design of IT Governance Routines}

Our theoretical model and the proposition that IT governance effectiveness is measured by the level of divergence between expected behaviours and actual behaviours represents a fundamental shift in the manner in which IT governance mechanisms should be viewed by IT governance owners. As City A and City B demonstrate, IT governance routines are not static systems that can be implemented once and left to run within an organization, as emerging sources of divergence will inherently emerge and limit the efficacy of the ongoing performances of the routine. To account for the behavioural aspect of routine performance, governance systems must be treated as dynamic objectives, requiring constant tinkering and tweaking. Positive divergence must be continually recognized and assessed in terms of their implications on the existing structural mechanisms of the routine while negative divergence must be controlled or limited as much as possible. Designing IT governance as a cybernetic system privileges the need for feedback loops and constant refinement of the system based on system performance and reinforces the flexible and adaptive nature of behavioural-based social structures.

Drawing from observations from both cases, the following recommendations are made to IT Governance Owners to ensure the maximal efficacy of the IT governance routines. 
- Clearly define and document the expected behaviours of an IT governance mechanism prior to designing and implementing routine artefacts. Without a strong understanding of the rationale for implementing a particular routine there is no way to assess whether the particular mechanisms are effective or not, and no way to ensure that implemented mechanisms align to the expected behaviours.

- Ensure that all formal mechanisms implemented within the organization directly support the expected behaviour of the routine. Misalignment of governance artefacts ensures that even when performative divergence is low, the organization will still experience significant substantive divergence. Expected behaviours that are not supported by formal mechanisms will not be realized within any IT governance system.

- Accept that divergence will occur in any behavioural-based system such as an IT governance routine. Recognize and record examples of the corrective and efficiency-driven behaviours that occur during a performance of the governance routine as a means for identifying areas where the routine can be adjusted and improved. Standard, top-down command and control governance structures (as conceptualized by the normative position) are not able to recognize the efficiencybased behaviours of the individuals that are actually involved in the day-to-day performance of the routine.

- Align personal incentive models to the expected behaviours of IT governance mechanism. If horizontality is important enough to an organization to be a 
fundamental requirement of their IT investment routine, then individual incentives and bonus structures must also recognize (or at the very least not directly contradict) this desired behaviour. Design of artefacts should recognize and account for competing priorities facing the core actants of a particular governance routine. Competing pressures cannot all be addressed, but by recognizing the major sources of divergence, mechanisms can be adjusted accordingly or expected behaviours of the routine can be revised and repositioned.

- Desired behaviours from IT governance routines must account for other institutional pressures faced by organizational stakeholders. Cultural or informal norms should be accounted for as best as possible in both the physical artefacts of the routine and the level of divergence tolerated by IT governance owners.

- Seek to understand repudiation behaviours. Understand why people avoid the governance routine, not as a means to implement stronger controls to address this behaviour but as a means for adjusting downstream governance activities that may be legitimately motivating the repudiation divergence. Repudiation divergence, as shown in City A and City B, may be motived by efficiency-seeking behaviour and, as such, provide IT governance owners with clear examples of where routine efficiencies can be gained. Mechanisms must balance and respect the importance of agency on behalf of stakeholders that interact with the routine. Mechanisms that are too restrictive will result in repudiation divergence, while mechanisms that are 
too flexible may not sufficiently guide expected or desired behaviour. Governance routines are about behaviour, not control.

- Develop a communication strategy in support of your IT governance routines. When all members of the organization are aware of and understand the purpose of a particular governance routine, the likelihood of avoidance-based divergence is minimized. Provide routine actants with an explanation of why each artefact exists along with the expected behaviour of each to help reduce the likelihood of translational divergence.

- Ensure governance bodies have published and approved terms of reference that clearly identify the expected behaviour of each committee. As shown in both cities, the absence of this allows governance decision-makers to define their own role within the routine and significantly reduces the efficacy of the overall governance routine.

- Schedule formalized reviews of IT governance routine effectiveness. Establish criteria for evaluating the effectiveness of the routine as a whole, as well as the effectiveness of the underlying governance mechanisms. Accept that the implementation of an IT governance mechanism is an ongoing investment, not a one-time implementation. The return-on-investment for IT governance lies in its ability to ensure that actual behaviours continue to be aligned with those desired by the organization. 
- Recognize and limit investment in ceremonial governance structures. If legitimizing mechanisms are required in response to isomorphic pressures, ensure that organization staff does not dedicate significant time or effort the performance of these "façade" routines. Time spent navigating a ceremonial governance structure represents time away from efficiency-driven activities. 


\section{CHAPTER 8 - CONCLUSION}

\section{CONTRIBUTIONS}

The objective of this study is to develop a theoretic base and preliminary understanding of the sources of divergence that occur within the enactment of individual IT governance mechanisms as a means for defining and understanding IT governance effectiveness. Our study represents an important and significant contribution to the IT governance discussion. Based on Tiwana, Konsynski and Venkatraman (2013), this work directly addresses an important and understudied domain within the IT Governance Cube: the decision dynamics associated with firm-level governance of stakeholders. Our study proposes a conceptualization of effectiveness that is currently missing from the research domain and addresses the ongoing theoretical pitfalls of seeking a causal association of IT governance constructs and macro-organizational consequences. The absence of a dependent variable within the domain is severely hampering the ability of researchers to understand how IT governance is enacted in practice. In the majority of academic research, the effectiveness of IT governance is assumed; this is in contrast to the reality of organizations implementing and managing IT governance systems. This research-practitioner disconnect undermines the potential contribution of academia to support improved IT decision making and control/influence within real organizations. This disconnect endures due in part to the proliferation of structural-based analysis of IT governance performance. Our study extends the current research on the microdynamics of IT governance in action and provides an initial behavioural-based 
theoretical frame for understanding how organizational actors interact with implemented IT governance systems.

By associating behavioural divergence with effectiveness, we argue that the divergence that occurs at the various levels of an organizational routine provides an explanation as to why IT governance systems do not always produce desired behaviours and outcomes. By defining IT governance as a set of organizational routines, we introduce an alternative conceptualization, as well as novel unit of analysis to the larger IT governance domain that encompasses the various structural and behavioural aspects of IT governance mechanisms. To support the establishment of a preliminary set of firstorder constructs, as well as a manner by which to code and classify empirical data, an a priori conceptual framework is proposed through an extensive review of the existing IT governance and organizational routines literature. Although the notion of divergence is sparsely addressed within the IT governance domain, the framework serves to aggregate and synthesise a number of disparate empirical investigations related to organizational routines. Through the execution of in-depth exploratory investigation of two common IT governance routines within two separate cases, a refined theoretical model is established and a set of valid and consistent second-order constructs and relationships are proposed. As a theory building exercise, the output of the research study supports a further investigation into the drivers of divergence and as such provides both practitioners and academics with a renewed perspective on how best to design IT governance systems. The methodology and findings of this study provide a number of unique contributions to both the practitioner and academic communities. 


\section{Practitioner Contribution}

From a practitioner perspective, the conceptualization of IT mechanisms in terms of organizational routines privileges the notion that IT governance is first and foremost about supporting and guiding collective action and not simply about designing and implementing formal IT governance artefacts (Becker, Salvatore and Zirpoli 2005; Pentland and Feldman 2008). As an alternative to the traditional structural and normative perspective of IT governance, an institutional perspective allows IT governance designers and authorities to recognize and account for the notion of agency within the enactment of IT decisions (Jacobson 2009). Therefore, we argue here, that rather than implementing IT governance structures as a means to control and drive particular behaviours, designers need to embrace the notion that divergence will exist and design IT governance mechanisms that are responsive and attuned to the various sources of substantive divergence. Design, therefore, is about action, not structure and overestimating the importance of formal artefacts "leads managers to underestimate the importance of the adjustments and improvisations that people undertake to make the routine work" (Feldman and Pentland 2003). A number of considerations for designing effective IT governance structures are provided in the discussion section.

Underlying this shift in design motivation is an overt realization that divergence is not a singularly negative ideal, and should not be ignored or discouraged by governance authorities (Pentland 2003; Pentland and Feldman 2005). Divergence in IT governance routines should not be viewed as something that needs to be eliminated, as is the case 
in current "control-based" conceptualization of IT governance, but rather something that needs to be understood and accounted for in design. As proposed in our conceptual framework, corrective divergence clearly represents a set of positive activities undertaken by organizational actors, that although appear to be divergent form formal structures, are actually motivated by a desire to improve the efficiency or alignment of a particular routine. Tight and authoritarian governance control, therefore, not only increases the amount of purposeful divergence within the system by alienating individual actants, it also stifles the willingness and desire for those that "live" the routine to seek ongoing and perpetual improvements of the routine. Governance designed in a more flexible manner (Howard-Grenville 2005) can actually lead to a decreased amount of negative divergence and an increased amount of positive divergence, which in turn can increase the effectiveness of the IT governance mechanism.

Lastly, by applying an organizational routines lens to IT governance raises awareness for practitioners that although formal artefacts have been shown to have limited impact on organizational routines performance (Becker 2004; Becker et al. 2005; Hales and Tidd 2009), most practitioner-based literature is related to the structural, process and relational mechanisms required to adequately control and guide organizational IT decisions and actions. Practitioners, faced with the desire to do something to improve the success rate of their IT investments, are surrounded by a sea of frameworks and prescriptive anecdotes, all promising a panacea for designing and implementing world class IT governance. At the core of the majority of these articles is a set of "must-have" 
organizational structures and processes. As such, it should not be surprising that organizations continue to implement artefact-centric governance structures that have proven ineffective at driving desired behaviours and which have been shown to have little causal relationship with the overall performance of the organization. By providing a definition of IT governance effectiveness in terms of divergence, the study directs designers towards the true objective of an IT governance system: to align actual behaviours with desired behaviours. By making this the central focus of IT governance, the generally unsubstantiated and cloudy connection with organizational performance is removed from the equation, allowing designers to focus their efforts on what matters most within the realm of IT governance. The connection with organizational outcomes remains important, but the focus shifts to understanding what behaviours are most necessary for positive organizational performance, but only once we have achieved a better understanding of how to align desired and actual behaviours within an IT governance system.

\section{Academic Contribution}

From an academic perspective, this study offers a number of novel and unique considerations with respect to the investigation and conceptualization of IT governance. Firstly, the positioning of IT governance mechanisms in terms of a specific type of organizational routine directly connects two literature bases that had previously remained distinct and disconnected, save for the occasional reference to governance in relation to the formal aspect of routines. The establishment of the concept of IT 
governance routines represents a unique level of analysis within the IT governance literature and opens the door for the inclusion of agency and individual behaviour within the IT governance conceptualization. Responding to calls for a non-structural conceptualization of IT governance (Jacobson 2009), the appropriation of organizational routines allows for the adoption of an institutional-aligned theoretical perspective as well as a means for highlighting and exposing the various layers of divergence that occur within the enactment of an IT governance routine. By taking an organizational routines perspective, we can take what we know about effectiveness and divergence of routines within an organization and apply it to the domain of IT governance

Following on this, the second contribution of this study relates to the development and proposal of a theoretical model that allows for a holistic understanding of divergence within IT governance routines. Answering calls from the organizational literature as well as the IT governance literature (Becker, Salvatore and Zirpoli 2005; Pentland and Feldman 2005; Feldman and Pentland 2008; Hales and Tidd 2009; Weichbrodt and Grote 2010), this conceptualization provides researchers with an integrated and connected theoretical platform from which to launch further research. With the objective of developing a theory of explaining, where the end product of investigation is the theory itself, the conceptual model provides a novel and explanatory rationale to a domain that was previously poorly understood (Gregor 2006). In this sense, aside from providing a consolidated viewpoint for future research, the model also serves to consolidate and rationalize the various disconnected and non-cumulative works related to organizational routines divergence. 
As part of our conceptual model, we also provide a contribution to the organizational routine literature, by highlighting the need to decouple the two dimensions of the ostensive aspect. Building on Pentland and Feldman's (2005; 2008) pluralistic conceptualization of organizational routines, the proposed conceptual model highlights that the ostensive understanding of an artefact is a function of both the actor's ability to translate and decipher the desired actions embedded within a physical artefact, but also in the ability of governance designers to adequately inscribe their wishes within an artefact. Although somewhat implied in many organizational routines works, this delineation has not been previously raised in an explicit manner.

Fourthly, as also mentioned as a benefit for practitioners, the study suggests a definitive and measureable dependent variable for IT governance effectiveness. Traditionally glossed-over or implicitly assumed, definitions of "effective" IT governance have remained elusive. The underlying assumption in most IT governance research is that an organization needs to strive towards having effective IT governance, because after all, IT governance is good. Defining IT governance effectiveness as the minimization of negative divergence between desired behaviours and actual behaviours provides researchers with a measurable and observable construct that negates the need to enter into the muddy and factor-confounding waters of IT governance and organizational performance.

As a final contribution, by drilling down into the individual factors driving performance divergence within routines, the study addresses a growing number of articles calling for 
the inclusion of the factors of individual agency within the organizational routines conceptualization (Bevir and Rhodes 2001; Felin and Foss 2004; Howard-Grenville 2005; Abell, Felin and Foss 2008). While the behavioural view of organizational routines denounces the black-box perspective of routines-as-rules, it could be argued that without including the behavioural drivers of the individual actors within an enactment of a routine, we are creating a similar black box effect - where this time little consideration is given to the conflicting factors that shape organizational actors' decisions and actions when inside the enactment of a particular routine. Without understanding the motivations and influences of the individuals within the system, the development of an explanatory or prediction theory (Gregor 2006) will remain elusive.

\section{LIMITATIONS AND FUTURE RESEARCH}

Through the research design of this study, every effort was made to address methodological reliability, construct validity, internal validity and external validity, as a means for ensuring findings and conclusions were valid and consistent. Beyond the pure execution of the research, however, a number of other limitations are identified and discussed. Firstly, the conceptualization of IT governance mechanisms in terms of organizational routines, although effective for identifying and highlighting sources of divergence, also suffers from many of the traditional concerns related to employing organizational routines as a level of analysis. Given their contextual dependency, organizational routines may not result in generalizable findings (Becker, Salvatore and Zirpoli 2005), despite our efforts to obtain external validity. Operationalization of organizational routines has also proven difficult, and scepticism rests in a researcher's 
ability to untangle the technological and social aspects of organizational routines as a means for truly understanding the latent dynamics at play (Cohen and Bacdayan 1994; Cohen et al. 1996, Williamson 1999; Pentland and Feldman 2003, Felin and Foss 2004; Becker et al. 2005; Feldman and Pentland 2008;). The definition of IT governance routines and the establishment of multi-phased data collection process in order to capture the varied levels of organizational routines was the chosen method for addressing these concerns. Other options, such as identifying routines as grammars or reproducing the performance of mechanisms in a lab setting, could also have been employed to address the difficulties in operationalizing organizational routines.

Secondly, cross-population and theoretical generalizability have been marginalized in favour of a research design that privileges contextual richness over theoretical saturation. Although a valid research approach, the definition of the number of cases in advance of beginning study may not allow for the development of a theoretical base that is applicable across a wide variety of contexts (Eisenhardt 1989; Pare 2004). The selection of cases within the same industry sector limits the ability to establish crosspopulation generalizability. Although generalizability was not a specific objective of this study, we acknowledge that the proposed theoretical model, as the ultimate contribution of our research effort was developed within a contextual environment specific to municipal governments.

As public organizations, municipal governments are not subject to the same profitmaximizing behaviour as similar sized private organizations and as such the identified 
sources of divergence may be more heavily skewed towards political, rather than economic forces. Even within the public sector, municipal governments are forced to be more transparent in their decision-making when compared to other levels of government given their smaller size and smaller operating budgets. IT governance decisions that are viewed as "large" within a municipal environment, may be "small" within a federal government organization and as such not require the same level of governance oversight and control, which may in turn, influence the behavioural responses (and divergence) observed during the enactment of a particular ITPPS routine.

Given the theory-building nature of our study, we accept that our findings may not be transferable beyond the municipal government domain and as such, recognize that our proposed theory could be strengthened through further empirical testing across a wide variety of organizational industries and sizes. Testing across different IT governance routines would also be valuable to further validate and our model, however at this stage, we believe that the choice of routine was less influential on the findings than the choice of industry type. It should also be noted that our proposed model may not be unique to IT governance and may hold true for a more broad view of governance. Would the dynamics of a routine responsible for the planning, prioritization and selection of real property investment opportunities differ from those related to the ITPPS routines in our study? In our opinion, IT governance is unique from the larger domain of corporate governance and decision-making given the inherent embeddedness of IT within the everyday routines of an organization. IT decisions are 
critical to the overall operations of an organization and as such could be considered to drive more profound (and hypothetically more divergent) behaviours than traditional governance systems. Further investigation would be required to substantiate whether our proposed model would hold true within a broader decision-making environment beyond that of IT governance.

As a final limitation, the analysis and theoretical output of the study were widely focused on an institutional-based theoretical perspective. Although organizational routines as a level of analysis are connected to the institutional perspective, they are not inherently one and the same. As such alternative institutional perspectives (for example, Ostrom's Institutional Analysis and Design Framework) could also be applied to the same empirical data to derive an alternative understanding and explanation of the sources of observed divergence and as a means for establishing a stronger resulting theory through an approach that favours theoretical triangulation.

For future research, we propose that our model be tested beyond the municipal government environment. By assessing the appropriateness of the model across a wide range of industry types would strengthen its external validity and add to its usefulness as theory. Hypotheses based on the constructs identified within our study could be established and validated through a cross-sectional survey. Lastly, measurement models for each of the second order constructs could be developed to extend our understanding of the underlying factors driving divergence within IT governance systems. 


\section{REFERENCES}

Abell, P., Felin, T., \& Foss, N. (2008) "Building Micro-foundations for the Routines, Capabilities, and Performance Links", Managerial and Decision Economics (29), pp. 489502.

Adler, P.S., Goldoftas B. \& Levine D.I. (1999) “Flexibility versus efficiency: A case study of model changeovers in the Toyota production system", Organizational Science (10), pp. 43-68.

Alavi, M. \& Carlson, P. (1992) "A review of MIS research and disciplinary development", Journal of Management Information Systems (8)4, pp. 45-62.

Ali, S., \& Green, P. (2006) "Effective Information Technology Governance Mechanisms in Public Sectors: An Australian Case", PACIS 2006 Proceedings, pp. 1070-1089.

AT Kearney (2009) "The 7 Habits of Highly Effective IT Governance: Powerful lessons in transforming business and information technology" Retrieved from Internet February 2013.

Avgerou C. (2000) "IT and Organizational Change: an Institutionalist Perspective," Information Technology \& People (13:4), pp. 234-262.

BBC News (2007) "Demand hampers Olympic Ticketing", October 30, Retrieved March 2013

BBC News (2012) "RBS chief apologises for NatWest banking problems", June 23, Retrieved March 2013.

Beck, N. (2004) "Rationality and Institutionalized Expectations: The Development of an Organizational Set of Rules", Retrieved from Internet November 2012.

Becker, M.C. (2001) "Empirical Research on Routines the State of the Art and Its Integration into the Routines Debate", Nelson and Winter Conference.

Becker, M.C. (2002) "The concept of routines twenty years after Nelson and Winter (1982): A review of the literature", DRUID Working Paper No 03-06.

Becker, M.C. (2004) “Organizational Routines: A Review of the Literature”, Industrial and Corporate Change (13)4, pp. 643-677.

Becker, M.C. (2005) “A Framework for Applying Organizational Routines in Empirical Research: Linking Antecedents, Characteristics and Performance Outcomes of Recurrent Interaction Patterns", Industrial and Corporate Change (14)5, pp. 817-846. 
Becker, M.C \& Knudsen, T. (2004) "The Role of Routines in Reducing Pervasive Uncertainty", Journal of Business Research (58), pp. 746-757.

Becker, M.C., Lazaric, N., Nelson, R. R., \& Winter, S. G. (2005) “Applying Organizational Routines in Understanding Organizational Change", Industrial and Corporate Change (14)5, pp. 775-791.

Becker, M.C., Salvatore P. \& Zirpoli F. (2005) “Appling Organizational Routines in Analyzing Organizations: Methodological Issues and Analytical Contributions", Working Paper, Retrieved from Internet November 2012.

Becker, M.C., \& Zirpoli, F. (2008) "Applying Organizational Routines in Analyzing the Behavior of Organizations", Journal of Economic Behavior \& Organization (66), pp. 128148.

Benbasat I., Goldstein, D.K. \& Mead, M. (1987) "The Case Research Strategy in Studies of Information Systems", MIS Quarterly (11)3, pp. 369-386.

Ben Boubaker, K. \& Nyrhinen, M. (2008) “Explaining the choice of IT governance modes made by organizations from the institutional perspective: A theoretical framework development", Working Paper - retrieved from Internet July 2011.

Bevir, M., \& Rhodes, R. W. (2001) "A Decentered Theory of Governance: Rational Choice, Institutionalism, and Interpretation", Working Papers, pp. 1-49.

Bharadwaj A., Keil M. \& Mahring M. (2009) "Effects of information technology failures on the market value of firms", Journal of Strategic Information Systems (18), pp. 66-79.

Borgman, H. P., \& Heier, H. (2010) "Ricochet of the Magic Bullet: Revisiting the Role of Change Management Initiatives in IT Governance", Proceedings of the 43rd Hawaii International Conference on System Sciences, pp. 1-11.

Boritz, E., \& Lim, J.H. (2007) “Impact of Top Management's IT Knowledge and IT Governance Mechanisms on Financial Performance”, ICIS 2007 Proceedings, Paper 88.

Bouraad, F. (2010) "IT project portfolio governance: The emerging operation manager", Project Management Journal (41)5, pp. 74-86.

Bourgeois, L. J., \& Eisenhardt, K. M. (1988) "Strategic Decision Process in High Velocity Environments: Four Cases in the Microcomputer Industry", Management Science (34)7, pp. 816-835.

Bowen, P. L., Cheung, M.Y. D., \& Rohde, F. H. (2007) “Enhancing IT Governance Practices: A Model and Case Study of an Organization's Efforts", International Journal of Accounting Information Systems (8), pp. 191-221. 
Braverman H. (1974) Labor and Monopoly Capital: The Degradation of Work in the Twentieth Century. New York: Monthly Review Press.

Brewer, J \& Hunter, A (1989), Multimethod research: A syntheses of styles, Newbury Park: Sage, Sage Library of Social Research Series, (175).

Brickley, J. A., \& Zimmerman, J. L. (2010) "Corporate Governance Myths: Comments on Armstrong, Guay, and Weber", Journal of Accounting and Economics (50), pp. 235-245.

Broadbent, M. (2005) "Why Governance Matters", ClO Insight (60), pp. 29-30.

Broadbent, M. \& Weill, P. (1993) "Improving business and information strategy alignment: Learning from the banking industry", IBM Systems Journal (32)1, pp. 162179.

Broadbent, M. \& Kitzis, E. (2004) The New ClO Leader: Setting the Agenda and Delivering Results, Boston MA: Harvard Business School Press.

Brown, A. E., \& Grant, G. G. (2005) "Framing the Frameworks: A Review of IT Governance Research", Communications of the Association for Information Systems (50), pp. 696-712.

Brown, W.C. (1997) "Examining the Emergence of Hybrid IS Governance Solutions: Evidence from a Single Case Site", Information Systems Research (8)1, pp. 69-95.

Brown, W. C. (2006) "IT Governance, Architectural Competency, and the Vasa", Information Management \& Computer Security (14)2, pp. 140-154.

Brynjolfsson E. (1993) "The Productivity Paradox of Information Technology", Communications of the ACM (36)12, pp. 67-77.

Buchwald A, Urbach N. \& Ahlemann, F. (2014) "Business value through controlled IT: toward an integrated model of IT governance success and its impact", Journal of Information Technology (29), pp. 128-147.

Burawoy M. (1979) Manufacturing Consent: Changes in the Labor Process under Monopoly Capital, Chicago: University of Chicago Press.

Burns, J., \& Scapens, R. W. (2000) “Conceptualizing Management Accounting Change: An Institutional Framework", Management Accounting Research (11), pp. 3-25.

Bussen W. \& Myers M. (1997) “Executive information system failure: a New Zealand case study", Journal of Information Technology (12)2, pp. 145-153.

Calder, A. (2014) "The Boardroom View on Cyber Security", Corporate Board (35)208, pp. 11-15. 
Campbell, D.T. (1975) "Degrees of freedom and the case study", Comparative Political Studies (8), pp. 178-193.

Carruthers, B. (1995) "Accounting, ambiguity, and the new institutionalism", Accounting, Organizations and Society (20)4, pp. 313-328.

Chan, Y. E. (2002) "Why Haven't We Mastered Alignment? The Importance of the Informal Organization Structure", MIS Quarterly Executive, (1)2, pp. 97-112.

Chan, Y.E. \& Huff, S.L. (1993) "Investigating Information System Strategic Alignment", Proceedings of the 14th ICIS, Orlando Florida, pp. 345-363.

Chin, P.O., Brown, G.A and Q. Hu (2004) "The Impact of Mergers \& Acquisitions on IT Governance Structures: A Case Study", Journal of Global Information Management (12)4, pp. 50-74.

Chomsky, N. (1980) Rules and Representations, New York: Columbia University Press.

Chong, J.L \& Tan, F.B. (2012) "IT Governance in Collaborative Networks: A SocioTechnical Perspective", Pacific Asia Journal of the Association for Information Systems (4)2, Article 3.

Christopher, J. (2010) “Corporate Governance - A Multi-Theoretical Approach to Recognizing the Wider Influencing Forces Impacting on Organizations", Critical Perspectives on Accounting (21), pp. 683-695.

Cobanoglu C., Ayoun B., Connolly D. \& Nusair, K. (2013) "The Effect of Information Steering Committees on Perceived IT Management Sophistication in Hotels", International Journal of Hospitality and Tourism Administration (14)1, pp. 1-22.

Cohen, M.D. (2007) "Reading Dewey: Reflections on the Study of Routine", Organization Studies (28)5, pp. 773-786.

Cohen, M.D., Burkhart R., Dose G., Egidi M., Marengo L., Warglien M., \& Winter S. (1996) "Routines and other recurring action patterns of organizations: Contemporary research issues", Industrial and Corporate Change (5)3, pp. 653-698.

Cohen, M.D., \& Bacdayan, P. (1994) “Organizational Routines Are Stored as Procedural Memory: Evidence from a Laboratory Study", Organization Science (5)4, pp. 554-568.

Coles, J. W., McWilliams, V. B., \& Sen, N. (2001)"An Examination of the Relationship of Governance Mechanisms to Performance", Journal of Management (21), pp. 23-50.

Cooke, T.D. \& Campbell, D.T. (1979) Quasi-Experimentation: Design and Analysis for Field Settings, Rand McNally: Chicago, Illinois. 
Corbin, J. \& Strauss, A. (2008) Basics of qualitative research ( ${ }^{\text {rd }}$ Ed.) Thousand Oaks: Sage.

Coriat, B. and Dosi G. (1998) “Learning How To Govern and Learning How To Solve Problems : on the Co-Evolution of Competences, Conflicts and Organizational Routines", in A. D. Chandler, Jr., P. Hagström and Ö. Sölvell (Eds.), The Dynamic Firm, Oxford University Press.

Corley, K. G., \& Gioia, D. A. (2011) "Building Theory about Theory Building: What Constitutes A Theoretical Contribution?", Academy of Management Review (36)1, pp. $12-32$.

Cousins, K. C., \& Robey, D. (2005) “Human Agency in a Wireless World: Patterns of Technology use in Nomadic Computing Environments", Information and Organization (15), pp. 151-180.

Croteau, A. M., Bergeron, F. (2001) "An information technology trilogy: Business strategy, technological deployment and organizational performance", Journal of Strategic Information Systems (10)1, pp. 77-99.

Csaszar, F., \& Clemons, E. (2006) "Governance of the IT Function: Valuing Agility and Quality of Training, Cooperation and Communications", Proceedings of the 39th Hawaii International Conference on System Sciences, pp. 1-10.

CTV (2014) Accessed via: http://www.ctvnews.ca/politics/4-5m-sunk-into-failed-courtmodernization-project-in-ontario-1.2015223.

Cyert, R.M \& March, J.G. (1963) A Behavioral Theory of the Firm, Englewood Cliffs, NJ: Prentice-Hall.

D'Adderio, L. (2008)"The Performativity of Routines: Theorizing the Influence of Artifacts and Distributed Agencies on Routines Dynamics", Research Policy (37), pp. 769-789.

D’Adderio, L. (2009) “The influence of artefacts and distributed agencies on routines' dynamics: from representation to performation", Organizational Routines: Advancing Empirical Research, p. 185.

D’Adderio, L. (2011) “Artifacts at the centre of routines: performing the material turn in routines theory", Journal of Institutional Economics (7)2, pp. 197-230.

Dahlberg, T., \& Kivijärvi, H. (2006) "An Integrated Framework for IT Governance and the Development and Validation of an Assessment Instrument", Proceedings of the 39th Hawaii International Conference on System Sciences, pp. 1-10. 
Dalton, D. R., Daily, C. M., Ellstrand, A. E. \& Johnson, J. L. (1998) “Meta-analytic Reviews of Board Composition, Leadership Structure, and Financial Performance", Strategic Management Journal (19)3, pp. 269-290.

Damianides, M. (2005) "Sarbanes-Oxley and it Governance: New Guidance on IT Control and Compliance", Information Systems Management, pp. 77-85.

Daneshvar, M., Dikmen, I. and Birgonul, M. (2012) "Investigation of Organizational Routines in Construction Companies", Proceedings EPOC Conference, Rhenden, Netherlands.

Darke, P., Shanks, G. and Broadbent, M. (1998) "Successfully completing case study research: combining rigor, relevance and pragmatism", Information Systems Journal (8), pp. 273-289.

Davis, G. F., \& Thompson, T. (1994) "A social movement perspective on corporate control”, Administrative Science Quarterly (39), pp. 141-173.

DeBoer, E.A. \& Zandberg T. (2010) “Organizational routines versus individual agency and personality traits", Eurochrie conference 2010, Amsterdam.

Debreceny R.S. (2013) "Research on IT Governance, Risk and Value: Challenges and Opportunities", Journal of Information Systems (27)1, pp. 129-135.

Debreceny R.S. \& Gray, G.L. (2013) "IT Governance and Process Maturity: A Multinational Field Study”, Journal of Information Systems (27)1, pp. 157-188.

De Haes, S., \& Van Grembergen, W. (2005) “IT Governance Structures, Processes and Relational Mechanisms: Achieving IT/Business Alignment in a Major Belgian Financial Group", Proceedings of the 38th Hawaii International Conference on System Sciences, pp. 1-10.

De Haes, S., \& Van Grembergen, W. (2006) "Information Technology Governance Best Practices in Belgian Organizations", Proceedings of the 39th Hawaii International Conference on System Sciences, pp. 1-9.

De Haes, S., \& Van Grembergen, W. (2008) "Analyzing the Relationship Between IT Governance and Business/IT Alignment Maturity", Proceedings of the 41st Hawaii International Conference on System Sciences, pp. 1-10.

De Haes, S., \& Van Grembergen, W. (2009) “An Exploratory Study into IT Governance Implementations and its Impact on Business/IT Alignment", Information Systems Management (26), pp. 123-137.

Deloitte (2005) "Are you sitting comfortably? 2005 IT Governance survey findings", Retrieved from Internet July 2013. 
Denzin, N. (1984) The research act, Englewood Cliffs, NJ: Prentice Hall.

Devos, J., Van Landeghem, H., \& Deschoolmeester, D. (2011) "Rethinking IT Governance for SMEs", Industrial Management \& Data Systems (112)2, pp. 206-223.

DiMaggio, P.J. (1988) "Interest and agency in institutional theory" in Institutional patterns and culture, L. Zucker (ed.), Cambridge, MA: Ballinger Publishing Company: 322.

DiMaggio, P.J., \& Powell, W.W. (1983) "The Iron Cage Revisited: Institutional Isomorphism and Collective Rationality in Organizational Fields", American Sociological Review (48)2, pp. 147-160.

Dosi, G. (1995) "Hierarchies, market and power - some foundational issues on the nature of contemporary economic organizations", Industrial and Corporate Change (4), pp. 1-19.

Dosi, G., Nelson, R.R., \& Winter, S.G. (2000) “The Nature and Dynamics of Organizational Capabilities" in The Nature and Dynamics of Organizational Capabilities, edited by G. Dosi, R. R. Nelson, and S. G. Winter, Oxford University Press: Oxford.

Dougherty D. (1992) “Interpretive barriers to successful product innovation in large firms", Organizational Science (3), pp. 179-202.

Dube, L., \& Paré, G. (2003) "Rigor in Information Systems Positivist Case Research: Current Practices, Trends, and Recommendations", MIS Quarterly (27)4, pp. 597-635.

Dyer, W. G., \& Wilkins, A. L. (1991) "Better Stories, Not Better Constructs, to Generate Better Theory: A Rejoinder to Eisenhardt", Academy of Management Review (16)3, pp. 613-619.

Edmondson, A. C., Bohmer, R. M., \& Pisano, G. P. (2001) “Disrupted routines: Team learning and new technology implementation in hospitals", Administrative Science Quarterly (46)4, p. 685.

Egidi, M. \& Narduzzo, A. (1997) "The emergence of path-dependent behaviors in cooperative contexts," International Journal of Industrial Organization (15)5, pp. 677709.

Eisenhardt, K. M. (1989) "Building Theories from Case Study Research", Academy of Management Review (14)4, pp. 532-550.

Eisenhardt, K. M., \& Graebner, M. E. (2007) “Theory Building from Cases: Opportunities and Challenges", Academy of Management Journal (50)1, pp. 25-32. 
Elsbach, K. and Sutton, R. (1992) "Acquiring Organizational Legitimacy through Illegitimate Actions: A Marriage of Institutional and Impression Management Theories", Academy of Management Journal (35)4, pp. 600-738.

Emirbayer, M., \& Mische, A. (1998) "What Is Agency?”, American Journal of Sociology (103)4, pp. 962-1023.

Feldman, M. S. (2000) “Organizational Routines as a Source of Continuous Change", Organization Science (11)6, pp. 611-629.

Feldman, M. S. (2003) "A Performative Perspective on Stability and Change in Organizational Routines", Industrial and Corporate Change (12)4, pp. 727-752.

Feldman, M.S., \& Pentland, B.T. (2003) "Reconceptualising Organizational Routines as a Source of Flexibility and Change", Administrative Science Quarterly (48), pp. 94-118.

Feldman, M.S. \& Pentland B.T (2008) "Issues in Empirical Field Studies of Organizational Routines" in Handbook for Organizational Routines.

Feldman, M.S., \& Rafaeli, A. (2002) "Organizational Routines as Sources of Connections and Understandings", Journal of Management Studies (39)3, pp. 309-331.

Felin T. \& Foss, N.J. (2004) “Organizational Routines: A Skeptical Look”, DRUID Working Paper No 04-13.

Felin, T. \& Foss, N. J. (2009) “Organizational Routines and Capabilities: Historical Drift and a Course-Correction Toward Micro foundations", Scandinavian Journal of Management (25), pp. 157-167.

Ferguson, C., Green, P., Vaswani, R. \& Wu, G. (2013) “Determinants of Effective Information Technology Governance", International Journal of Auditing (17)1, pp. 75-99.

Flyvbjerg, B. (2006) "Five Misunderstandings About Case-Study Research", Qualitative Inquiry (12)2, pp. 219-245.

Fonstad, N. O., \& Subramani, M. (2009) "Building Enterprise Alignment: A Case Study", MIS Quarterly Executive (8)1, pp. 31-41.

Frey, T., \& Buxmann, P. (2011) "The Importance of Governance Structures in IT Project Portfolio Management", ECIS 2011 Proceedings - Paper 17.

Gartner (2010) “Gartner Perspective: IT Spending 2010”. Retrieved online April 2013.

Gartner (2012) “Gartner IT Key Metrics Data: 2012 IT Enterprise Summary Report”. Retrieved online July 2013. 
Gersick, C.J.G. \& Hackman J.R. (1990) "Habitual routines in task-performing teams", Organizational Behaviour and Human Decision Processes (47), pp. 65-97.

Gheorghe, M. (2010) "Audit Methodology for IT Governance”, Informatica Economica (14)1, pp. 32-42.

Gheorghe, M., Boldeanu, D., Nastase, P., \& Ofelia, A. (2009) "IT Governance in Romania: A Case Study", Global Economy Journal (9)1 - Article 7.

Gibbert, M., Ruigrok, W. \& Wicki, B. (2008) “What Passes as a Rigorous Case Study?”, Strategic Management Journal (29), pp. 1465-1474.

Gigerenzer, G. (2001) “Decision Making: Nonrational Theories," International Encyclopedia of the Social and Behavioral Sciences (5), pp. 3304-3309.

Given, L.M. (Ed.) (2008) The Sage Encyclopedia of Qualitative Research Methods, Sage: Thousand Oaks, CA.

Goldfinch S. (2007) "Pessimism, Computer Failure, and Information Systems Development in the Public Sector", Public Administration Review, September/October, pp. 917-929.

Grant G., Brown A., Uruthirapathy, A. \& McKnight S. (2006) "Institutionalizing IT-SSO Governance: From Concept to Realization", Working Paper, July 6, 36 pages.

Grant, G., Brown, A., Uruthirapathy, A., \& McKnight, S. (2007) "An Extended Model of IT Governance: A Conceptual Proposal", AMCIS 2007 Proceedings, Paper 215, Keystone, Colorado.

Gregor, S. (2006) "The Nature of Theory in Information Systems", MIS Quarterly (30)3, pp. 611-642.

Grote, G. (2004) "Uncertainty management at the core of system design" Annual Reviews in Control (28), pp. 267-274.

Grote, G., Weichbrodt, J., \& Günter, H. (2006) “Coordination in High-Risk Organizations: The Need for Flexible Routines", Third International Conference on Organizational Routines "Empirical Research and Conceptual Foundations", pp. 1-20.

Gu, B., Xue, L., \& Ray, R. (2008) “IT Governance and IT Investment Performance: An Empirical Analysis”, ICIS 2008 Proceedings, Paper 30, Paris, France.

Guba E.G. (1981) "Criteria for assessing the trustworthiness of naturalistic inquiries", Educational Communication and Technology Journal (29), pp. 75-91.

Guba E.G. \& Lincoln, Y.S. (1989) Fourth generation evaluation, Newbury Park: Sage. 
Guldentops, E., Grembergen, W. V. and De Haes, S. (2002) "Control and governance maturity survey: establishing a reference benchmark and a self-assessment tool", Information Systems Control Journal (6), pp. 32-35.

Guney, S., \& Cresswell, A. M. (2010) "IT Governance as Organizing: Playing the Game", Proceedings of the 43rd Hawaii International Conference on System Sciences (HICSS-43), Koloa, Kauai, HI.

Hales, M., \& Tidd, J. (2009) "The Practice of Routines and Representations in Design and Development", Industrial and Corporate Change (18)4, pp. 551-574.

Heart, T., Maoz, H., \& Pliskin, N. (2010) "From Governance to Adaptability: The Mediating Effect of IT Executives' Managerial Capabilities", Information Systems Management (27), pp. 42-60.

Heroux, S. \& Fortin, A. (2014) "IT Dependence and IT Governance", Information Systems Management (31)2, pp. 143-166.

Hicks, M., Pervan, G., \& Perrin, B. (2012) "A Study of the Review and Improvement of IT Governance in Australian Universities", CONF-IRM 2012 Proceedings, Paper 22.

Hirschheim, R., \& Newman, M. (1988) “Information Systems and User Resistance: Theory and Practice", The Computer Journal (31)5, pp. 398-408.

Hodgson, G.M. (2003) "The Mystery of the Routine: The Darwinian Destiny of An Evolutionary Theory of Economic Change", Revue Economique (54)2, pp. 355-384.

Hodgson, G.M. (2004) "The Concept of a Routine", Business School Working Papers, vol. UHBS 2004-2, University of Hertfordshire.

Hodgson, G. M., \& Knudsen, T. (2004) "The Firm as an Interactor: Firms as Vehicles for Habits and Routines", Journal of Evolutionary Economics (14), pp. 281-307.

Hoffman, T. (2004a) "IT Oversight Gets Attention at Board Level," Compuworld, May 17. Hoffman, T. (2004b) "IT Governance is on the Hot Seat," Computerworld, July 12.

Howard-Grenville, J. A. (2005) "The Persistence of Flexible Organizational Routines: The Role of Agency and Organizational Context", Organization Science (16)6, pp. 618-636.

Huang, R., Zmud, R. W., \& Price, R. L. (2010) "Influencing the Effectiveness of IT Governance Practices Through Steering Committees and Communication Policies", European Journal of Information Systems (19), pp. 288-302.

Huber, N. (2004) "IT looks the weak link in compliance", Computer Weekly, July 27, p. 4. 
Hutchins, E. (1991) “Organizing work by adaptation", Organization Science (2)1, pp. 1439.

lannacci, F., \& Hatzaras, K. S. (2012) “Unpacking Ostensive and Performative Aspects of Organisational Routines in the Context of Monitoring Systems: A Critical Realist Approach", Information and Organization (22), pp. 1-22.

Iliescu, F.M. (2010) “Auditing IT Governance”, Informatica Economica (14)1, pp. 93-102. Information Week (2012) "LinkedIn Security Breach Triggers \$5 Million Lawsuit", June 20, Retrieved March 2013.

ISACA (2012) “Governance of Enterprise IT (GEIT) Survey - Global Edition", Retrieved from Internet February 2013.

ITGI (2003) "Board Briefing on IT Governance", IT Governance Institute, 2nd Edition, Rolling Meadows, IL.

ITGI (2006) "Enterprise Value: Governance of IT Investments", IT Governance Institute, Rolling Meadows, IL.

Jacobson, D. D. (2009) "Revisiting IT Governance in the Light of Institutional Theory", Proceedings of the 42nd Hawaii International Conference on System Sciences, pp. 1-9.

Jewer, J. \& McKay, K. (2012) "Antecedents and Consequences of Board IT Governance: Institutional and Strategic Choice Perspectives", Journal of the Association for Information Systems (13)7, pp. 581-617.

Johnson, M. (2004) “IT's New Balance”, Computerworld (38)31, p 14.

Johnstone, D., Huff, S., \& Hope, B. (2006) "IT Projects: Conflict, Governance, and Systems Thinking", Proceedings of the 39th Hawaii International Conference on System Sciences, pp.1-9.

Jordan, E. and Musson, D. (2004) "Corporate Governance and IT Governance: exploring the board's perspective," Working paper. Retrieved, November 2012, from the World Wide Web: http://ssrn.com/abstract=787346

Kamens, M. (2006) "Change management is key to SOX success", Network World (23)36, pp. 39-39.

Keen, P.G.W. (1980) Information Systems and Organizational Change, MIT Libraries.

Keen, P.G.W. (1981) "Information Systems and Organizational Change" Social Impacts of Computing (24)1, pp. 24-33. 
Keyes-Pearce, S.V. (2002) "Rethinking the Importance of IT Governance in the e-world", Proceedings of the 6th Pacific Asia Conference on Information Systems, pp. 256-272.

Kilcourse, B. (2003) "Why IT Governance is Important to Solution Providers", Chain Store Age (79)10, p. 73.

Klein H.K. \& Myers, M.D. (1999) "Evaluating Interpretive Field Studies", MIS Quarterly (23)1, pp. 67-93.

Ko, D., \& Fink, D. (2010) "Information Technology Governance: An Evaluation of the Theory-Practice Gap", Corporate Governance (10)5, pp. 662-674.

Kobelsky, K. (2010) “Discussion of 'A Capabilities-based Approach to Obtaining a Deeper Understanding of Information Technology Governance Effectiveness: Evidence from IT Steering Committees'”, International Journal of Accounting Information Systems (11), pp. 233-235.

Korac-Kakabadse, N., \& Kakabadse, A. (2001) “IS/IT Governance: Need for an Integrated Model", Corporate Governance (1)4, pp. 9-11.

KPMG (2005) "Global IT Project Management Survey", Retrieved from Internet March 2013.

Larsen, M. H., Pedersen, M. K., \& Andersen, K. V. (2006) “IT Governance: Reviewing 17 IT Governance Tools and Analyzing the Case of Novozymes A/S", Proceedings of the 39th Hawaii International Conference on System Sciences, pp. 1-11.

Latour, B. (1986) "The powers of association", in J. Law (ed.), Power, Action and Belief, London: Routledge and Kegan Paul.

Latour, B. (1991) "Technology is society made durable", in John Law (Ed.), A Sociology of Monsters: Essays on Power, Technology and Domination, London: Routledge, pp. 103 131.

Layder, D. (1993) New Strategies in Social Research: An Introduction and Guide, Cambridge, MA: Polity Press.

Layder, D. (1994) Understanding Social Theory, London, England: Sage Publications.

Lazaric, N. (2000) "The Role of Routines, Rules and Habits in Collective Learning: Some Epistemological and Ontological Considerations", European Journal of Economic and Social Systems (14)2, pp. 157-171.

Lazaric, N. (2011) “Organizational Routines and Cognition: Introduction to the Special Issue on Routines", Journal of Institutional Economics (7)2, pp. 147-156. 
Lazaric, N., \& Denis, B. (2005) "Routinization and Memorization of Tasks in a Workshop: The Case of the Introduction of ISO Norms", Industrial and Corporate Change (14)5, pp. 873-896.

Lazaric, N., \& Raybaut, A. (2005) "Knowledge, Hierarchy and the Selection of Routines: An Interpretative Model with Group Interactions", Journal of Evolutionary Economics (15), pp. 393-421.

Leonard-Barton, D. (1990) “A Dual Methodology for Case Studies: Synergistic Use of a Longitudinal Single Site with Replicated Multiple Sites", Organization Science (1)3, pp. 248-265.

Lee, A.S. (1985) "The Scientific Basis for Conducting Case Studies of Organizations", Proceedings of the Academy of Management, San Diego, pp. 320-324.

Lee, A.S. (1989) “A Scientific Methodology for MIS Case Studies”, MIS Quarterly (13)1, pp. 33-50.

Lee, A.S \& Baskerville, R.L (2003) "Generalizing Generalizability in Information Systems Research", Information Systems Research (14)3, pp. 221-243.

LePree J. (2002) “Think Big, Think Governance”, MSI (20)4, pp. 32-35.

Leung, L. (2004) “Instilling IT governance”, Network World (21)16, pp. 43-43.

Levin, D. Z. (2002) “When Do Organizational Routines Work Well? A New Approach to Knowledge Management", Organization Science, pp. 1-33.

Levin, D. Z., \& Barnard, H. (2008) "Technology Management Routines That Matter to Technology Managers", International Journal of Technology Management (41)1, pp. 2237.

Levitt, B. \& March, J.G (1988) “Organizational Learning”, Annual Review of Sociology (14), pp. 319-340.

Lewin, A., Massini S \& Peeters, C. (2011) "Microfoundations of Internal and External Absorptive Capacity Routines", Organization Science (22)1, pp. 81- 98.

Lewins A. \& Silver C. (2007) Using Software in Qualitative Research: A Step-by-Step Guide, Los Angeles: Sage, 283 pages.

Lewis, D. (2004) "Stop the Pendulum", Computerworld (38)2, pp. 37-38.

Lipson, M. (2006) “Organized Hypocrisy and Global Governance: Implications for United Nations Reform", Retrieved from Internet October 2012. 
Lin, Y. M., Arshad, N. H., Haron, H., Wah, Y. B., Yusoff, M., \& Mohamed, A. (2010) “IT Governance Awareness and Practices: an Insight from Malaysian Senior Management Perspective", Journal of Business Systems, Governance and Ethics (5)1, pp. 43-57.

Lincoln (1995) "Emerging criteria for quality in qualitative and interpretive research", Qualitative Inquiry (1), pp. 275-289.

Lincoln Y.S. \& Guba, E. G (1985) Naturalistic inquiry, Beverly Hills: Sage.

Louis, M.R. \& Sutton, R.I. (1991) "Switching cognitive gears: From habits of mind to active Thinking", Human Relations (44), pp. 55-76.

Lukka K. (2007) "Management accounting change and stability: Loosely coupled rules and routines in action", Management Accounting Research (18), pp. 76-101.

Lunardi, G. L., Becker, J. L. \& Macada, A. G. (2009) "The Financial Impact of IT Governance Mechanisms' Adoption: An Empirical Analysis with Brazilian Firms", Proceedings of the 42nd Hawaii International Conference on System Sciences, pp. 1-10.

Lunardi, G.L., Becker, J.L., Macada, A.G. \& Dolci, P.C. (2014) "The impact of adopting IT governance on financial performance: An empirical analysis among Brazilian firms", International Journal of Accounting Information Systems (15)1, pp. 66-81.

Macdonald (2000) "Governance and Oversight of Large Information Technology Projects", Published by the New Zealand Controller and Auditor General.

MacLean, T. \& Behnam M. "The Dangers of Decoupling: The Relationship between Compliance Programs, Legitimacy Perceptions, and Institutionalized Misconduct", Academy of Management Journal (53)6, pp. 1499-1520.

Maimbo, H. \& Pervan, G. (2005) “Designing a case study protocol for application in IS research" in Chau, P. (ed) The Ninth Pacific Conference on Information Systems, pp. 1281-1292.

March, J.G. \& Simon, H.A (1958) Organizations, Cambridge, MA: Blackwell.

March, J.G. \& Olson, J.P. (1989) Rediscovering Institutions, New York: Free Press.

Marchionini, G. \& Teague, J. (1987) “Elementary students' use of electronic information services: an exploratory study", Journal of Research on Computing in Education (20), pp. 139-155.

Markus, M.L. \& Benjamin, R.I. (1997) "The magic bullet theory in IT-enabled Transformation", Sloan Management Review (38), pp. 55-698. 
Markus, M.L. \& Keil, M. (1994) "If we build it, they will come: designing information systems that users want to use", Sloan Management Review (45)4, pp. 11-25.

Markus, L.M. \& Robey, D. (1988) "Information Technology and Organizational Change: Causal Structure in Theory and Research", Management Science (34)5, pp. 583-598.

Marshall, P., \& McKay, J. (2004) "Strategic IT Planning, Evaluation and Benefits Management: The Basis for Effective IT Governance", Australasian Journal of Information Systems (11)2, pp. 14-26.

Mathison, S. (1988) "Why triangulate?", Educational Researcher, 17(2), 13-17.

McKay, J., Marshall, P., and Smith, L. (2003) "Steps Towards Effective IT Governance: Strategic IS Planning, Evaluation and Benefits Management", Proceedings of the 7th Pacific Asia Conference on Information Systems, 10-13 July, Adelaide, South Australia, pp. 956-970.

Meyer, J. and Rowan, B. (1977) "Institutional Organizations: Formal Structure as Myth and Ceremony", American Journal of Sociology (83)2, pp. 340-363.

Miles, M.B. \& Huberman, A.M. (1994) Qualitative Data Analysis: An expanded Sourcebook ( $\left.2^{\text {nd }} E d\right)$, California: Sage.

Moldoveanu M. \& Martin R. (2001) "Agency theory and the design of an efficient governance mechanism", Working Paper, Rotman School of Management, University of Toronto.

NASCIO (2010) "The 2010 state ClO survey: Perspectives and trends from state government IT leaders", Retrieved from Internet February 2013.

Nelson R.R. \& Winter S.G. (1982) An Evolutionary Theory of Economic Change, Cambridge, Massachusetts: The Belknap Press of Harvard University Press.

Newton, Nigel (2010) |The use of semi-structured interviews in qualitative research: strengths and weaknesses", Retrieved online at http://www.academia.edu/1561689/The_use_of_semistructured_interviews_in_qualitative_research_strengths_and_weaknesses, December 2013.

New York Times (2013) "Some Victims of Online Hacking Edge into the Light", February 20, Retrieved March 2013.

Nfuka, E. N., \& Rusu, L. (2010) "Critical Success Factors for Effective IT Governance in the Public Sector Organizations in a Developing Country: The Case of Tanzania", ECIS 2010 Proceedings, Paper 128. 
Nfuka, E. N., \& Rusu, L. (2011) “Critical Success Factors Framework for Implementing Effective IT Governance in Public Sector Organizations in a Developing Country", AMCIS 2011 Proceedings, Paper 365.

North, D.C (1993) "The New Institutional Economics and Development", Economic History, EconWPA.

OAG (2006) "Chapter 3-Large Information Technology Projects", November Report of the Auditor General of Canada, Retrieved online April 2012.

Orlikowski, W.J. (1992) "The duality of technology: Rethinking the concept of technology in organizations", Organization Science (3), pp. 398-427.

Orlikowski, W.J. (2000) "Using Technology and Constituting Structures: A Practice Lens for Studying Technology in Organizations", Organization Science (11)4, pp. 404-428.

Orlikowski, W.J. (2002) "Knowing in Practice: Enacting a Collective Capability in Distributed Organizing", Organization Science (13)4, pp. 249-273.

Orlikowski, W.J., \& Baroudi, J. J. (1991) "Studying Information Technology in Organizations: Research Approaches and Assumptions", Information Systems Research (2)1, pp. 1-28.

Orlikowski W.J. \& Iacono C.S. (2001) "Desperately seeking the "IT" in IT research - a call to theorizing the IT artifact", Information Systems Research (12)2, pp. 121-134.

Ostrom, E. (2005) Understanding Institutional Diversity, Princeton, NJ: Princeton University Press.

Othman, M., Chan, T., Foo, E., Nelson, K. J., \& Timbrell, G. T. (2011) “Barriers to information technology governance adoption: a preliminary empirical investigation", in Proceedings of 15th International Business Information Management Association Conference, pp. 1771-1787.

Ottawa Citizen (2000) "Gun registry is millions over budget", April 20, Retrieved March 2013.

Pang, M-S (2014) "IT governance and business value in the public sector organizations The role of elected representatives in IT governance and its impact on IT value in U.S. state governments", Decision Support Systems (59), pp. 274-285.

Paquette, S. (2010) "Discussion of 'A Capabilities-Based Approach to Obtaining a Deeper Understanding of Information Technology Governance Effectiveness: Evidence from IT Steering Committees'”, International Journal of Accounting Information Systems (11), pp. 236-238. 
Paré, G. (2004) "Investigating Information Systems with Positivist Case Study Research", Communications of the Association for Information Systems (13), pp. 233-264.

Paré, G. \& Elam J. (1997) “ Using case study research to build theories of information technology implementation" in A. S. Lee, J. Liebenau, J. I. DeGross, eds. Information Systems and Qualitative Research, Ghapman \& Hall, New York, 31-68.

Park C.W., Keil, M. \& Kim J.W. (2009) "The Effect of IT Failure and Personal Morality on IT Project Reporting Behaviour", IEEE Transactions on Engineering Management (56)1, pp. 45-60.

Parmigiani, A., \& Howard-Grenville, J. (2011) "Routines Revisited: Exploring the Capabilities and Practice Perspectives", The Academy of Management Annals (5)1, pp. 413-453.

Patel, N. V. (2003) “An Emerging Strategy for e-Business IT Governance” In: W. Van Grembergen (eds.), Strategies for Information Technology Governance, Hershey, PA: Idea Group Publishing

Patton M.Q. (1990) Qualitative Evaluation and Research Methods (2 ${ }^{\text {nd }}$ ed.), Newbury Park, CA, Sage.

Pentland, B.T. (1995) "Grammatical Models of Organizational Processes", Organization Science (6), pp. 541-556.

Pentland, B.T. (2003) "Sequential Variety in Work Processes", Organization Science (14)5, pp. 528-540.

Pentland, B.T., \& Feldman, M.S. (2005) "Organizational Routines as a Unit of Analysis", Industrial and Corporate Change (14)5, pp. 793-815.

Pentland, B.T., \& Feldman, M.S. (2007) “Narrative Networks: Patterns of Technology and Organization", Organization Science (18)5, pp. 781-795.

Pentland, B.T., \& Feldman, M.S. (2008) "Designing Routines: On the Folly of Designing Artifacts, while Hoping for Patterns of Action", Information and Organization (18), pp. 235-250.

Pentland, B. T., \& Rueter, H. H. (1994) "Organizational Routines as Grammars of Action", Administrative Science Quarterly (39), pp. 484-510.

Pentland, B. T., Haerem, T., \& Hillison, D. (2010) "Comparing Organizational Routines as Recurrent Patterns of Action", Organization Studies (31)7, pp. 917-940.

Pentland, B. T., Haerem, T., \& Hillison, D. (2011) "The (N)Ever-Changing World: Stability and Change in Organizational Routines", Organization Science (22)6, pp. 1369-1383. 
Peterson, R. (2001) "Configurations and coordination for global information technology governance: complex designs in a transnational European context", in Proceedings of the 34th Annual Hawaii International Conference on System Sciences.

Peterson, R. (2003) "Information strategies and tactics for information technology governance" in Strategies for information technology governance, W. Van Grembergen (ed.), Idea Group Publishing

Peterson, R. (2004) "Crafting Information Technology Governance", Information Systems Management (21)4, pp. 7-22.

Peterson, R., Parker, M., \& Ribbers, P. (2002) “Information Technology Governance Processes Under Environmental Dynamism: Investigating Competing Theories of Decision Making and Knowledge Sharing", ICIS 2002 Proceedings, Paper 41, pp. 563-572.

Peterson, R., Ribbers, P., \& O'Callaghan, R. (2000) “Information Technology Governance by Design: Investigating Hybrid Configurations and Integration Mechanisms", ICIS 2000 Proceedings, Paper 52, pp. 435-452.

Pettigrew, A. (1988) “Longitudinal field research on change: Theory and practice", Paper presented at the National Science Foundation Conference on Longitudinal Research Methods in Organizations, Austin.

Pfeffer, J. and Salancik, G. R. (1978) The External Control of Organizations: A Resource Dependence Perspective, Harper \& Row, New York.

Posthumus, S., Von Solms, R., \& King, M. (2010) "The Board and IT Governance: The What, Who and How", South African Journal of Business Management (41)3, pp. 23-32.

Powell, W.W. \& DiMaggio P.J. (1991) The New Institutionalism in Organizational Analysis, Chicago: University of Chicago Press.

Powell, W.W. \& Colyvas, J.A. (2008) "Microfoundations of Institutional Theory" in Handbook of Organizational Institutionalism, eds: Royston Grennword, Christine Over, Kerstin Sahlin-Andersson and Roy Suddaby, pp. 276-298.

Prasad, A., Heales, J., \& Green, P. (2010) “A Capabilities-Based Approach to Obtaining a Deeper Understanding of Information Technology Governance Effectiveness: Evidence from IT Steering Committees", International Journal of Accounting Information Systems (11), pp. 214-232.

Rau, K.G. (2004) “Effective Governance of IT: Design Objectives, Roles, and Relationships", Information Systems Management (21)4, pp. 34-42.

Read T.J. (2004) "Discussion of director responsibility for IT governance", International Journal of Accounting Information Systems (5)2, pp. 105-107. 
Rerup, C., \& Feldman, M. (2011) "Routines as a Source of Change in Organizational Schemata: The Role of Trial-And-Error Learning", Academy of Management Journal (54)3, pp. 577-610.

Reynaud, B. (2005) "The Void at the Heart of Rules: Routines in the Context of RuleFollowing. The Case of the Paris Metro Workshop", Industrial and Corporate Change (14)5, pp. 847-871.

Ribbers, P., Peterson, R., \& Parker, M. (2002) “Designing Information Technology Governance Processes: Diagnosing Contemporary Practices and Competing Theories", Proceedings of the 35th Hawaii International Conference on System Sciences, pp. 1-12.

Richards, L. \& Morse, J. (2007) Users guide for qualitative methods ( ${ }^{\text {nd }}$ Ed.), Thousand Oaks, CA: Sage.

Rivard, S. (2014) "The Ions of Theory Construction", MIS Quarterly (38)2, pp. iii-xiii.

Rodriguez M. \& Juiz C. (2014) "Some Ps are Missing in the Governance of Projects, Programs and Portfolios (PPP)" in Proceedings of the European Conference on Information Management and Evaluation, pp. 198-205.

Royal Academy of Engineering (2004) "The Challenges of Complex IT Projects: The report of a working group from the Royal Academy of Engineering and the British Computer Society", Retrieved from Internet March 2013.

Rubino, M. \& Vitolla, F. (2014) “Corporate governance and the information system: how a framework for IT governance supports ERM", Corporate Governance: The International Journal of Effective Board Performance (14)3, pp. 320-338.

Sabherwal, R., \& Robey, D. (1993) "An Empirical Taxonomy of Implementation Processes Based on Sequences of Events in Information System Development", Organization Science (4)4, pp. 548-576.

Saldana, J. (2009). The coding manual for qualitative researchers. Los Angeles, CA: SAGE.

Salvato, C. and C. Rerup (2011) "Beyond collective entities: Multilevel research on organizational routines and capabilities", Journal of Management (54)3, pp. 468-490.

Sambamurthy V. \& Zmud B. (1999) "Arrangements for Information Technology governance: A Theory of Multiple Contingencies", MIS Quarterly (23)2, pp. 261-291.

Scapens, R. W., \& Roberts, J. (1993) "Accounting and control: a case study of resistance to accounting change", Management Accounting Research (4), pp. 1-32.

Schrage, M. (2006) "The Hammer of Consensus", ClO (19)15, pp. 36-38. 
Schwarz, A., \& Hirschheim, R. (2003) “An Extended Platform Logic Perspective of IT Governance: Managing Perceptions and Activities of IT", Journal of Strategic Information Systems (12), pp. 129-166.

Scott D., Holub E. \& Pultz J. (2006) “Organizing for IT infrastructure and Operations: Trends and Best Practices, Gartner Inc., Stamford, CT.

Scott, R.W (1987) "The adolescence of institutional theory", Administrative Science Quarterly (32), pp. 493-511.

Scott, R.W. (1995) Institutions and Organizations, Thousand Oaks, CA: Sage, 1st ed. Scott, R.W. (2001) Institutions and Organizations, Thousand Oaks, CA: Sage, 2nd ed.

Scott, R.W. (2004) "Reflections on a half-century of organizational sociology", Annual Review of Sociology, (30), pp.1-21.

Scott, R.W. (2008) "Approaching adulthood: the maturing of institutional theory", Theory and Society (37)5, pp. 427-442.

Searle, J. (1983) Intentionality: An essay in the philosophy of mind, Cambridge: Cambridge University Press.

Selton, R. (2002) "What is Bounded Rationality" in Bounded Rationality: The Adaptive Toolbox, G. Gigerenzer and R. Selton, eds.

Seo, M.G., \& Creed, W. D. (2002) "Institutional Contradictions, Praxis, and Institutional Change: A Dialectical Perspective", Academy of Management Review (27)2, pp. 222-247.

Sethibe, T., Campbell, J., \& McDonald, C. (2007) “IT Governance in Public and Private Sector Organisations: Examining the Differences and Defining Future Research Directions", ACIS 2007 Proceedings, Paper 118, pp. 833-843.

Sharapov, D. (2012) "Structure and Knowledge Management: Impacts on Routine Attributes, Value and Imitability", Druid Working Paper.

Shenton, A. (2004) "Strategies for ensuring trustworthiness in qualitative research projects", Education for Information (22), pp. 63-75.

Sherer, S. A. (2004) "IS Project Selection: The Role of Strategic Vision and IT Governance", Proceedings of the 37th Hawaii International Conference on System Sciences, pp. 1-8.

Simon, H.A. (1956) "Rational choice and the structure of the environment", Psychological Review (63)2, pp. 129-138. 
Simon, H.A. (1957) "A Behavioral Model of Rational Choice", in Models of Man, Social and Rational: Mathematical Essays on Rational Human Behavior in a Social Setting, New York: Wiley.

Simonsson, M. \& Johnson, P. (2006) “Defining IT Governance - A Consolidation of Literature", EARP Working Paper, ms103.

Simonsson, M. \& Johnson, P. (2008) "The IT organization modeling and assessment tool: Correlating IT governance maturity with the effect of IT", Proceedings of the $41^{\text {st }}$ Hawaii International Conference on System Sciences, pp. 431-431.

Simonsson, M., Johnson, P., \& Ekstedt, M. (2010) "The Effect of IT Governance Maturity on IT Governance Performance", Information Systems Management (27), pp. 10-24.

Smith, A., Bradley, R., Bichescu, B. \& Trebmlay, M. (2013) “IT Governance Characteristics, Electronic Medical Records Sophistication, and Financial Performance in U.S. Hospitals: An Empirical Investigation", Decision Sciences (44)3, pp. 483-.516.

Smith, M. (2005) “A Model for IT Governance”, Intelligent Enterprise (8)12, p. 8.

Soh, C. \& Markus, M.L. (1995) "How IT Creates Business Value: A Process Theory Synthesis", Proceedings of the 1995 ICIS, Paper 4.

Sohal, A.S \& Fitzpatrick, P. (2002) "IT governance and management in large Australian Organisations", International Journal of Production Economics (75)1, pp. 97-112.

Spender, J.C. (2009) "Routines and the Rhetorical Microfoundations of Organization", Retrieved from Internet March 2013.

Spillane J.P, Parise, L.M. \& Sherer, J.Z (2010) "Organizational Routines as Coupling Mechanisms: Policy, School Administration and the Technical Core", Working Paper.

Stake, R. (1995) The art of case research, Newbury Park, CA: Sage Publications.

Stake, R. (2000) "Case studies", In N. K. Denzin \& Y. S. Lincoln (Eds.), Handbook of qualitative research (2nd ed., pp. 435-454), Thousand Oaks, CA: Sage.

Standish Group (2010) “Chaos Summary for 2010” Retrieved from Internet July 2012.

Stene E.O. (1940) "An approach to a science of administration", The American Political Science Review (34)6 pp. 1124-1137.

Suddaby, R. (2010) “Editor's Comments: Construct Clarity in Theories of Management and Organization", Academy of Management Review (35)3, pp. 346-357. 
Sutton, R. I. \& Stew, B. M. (1995) "What Theory is Not", Administrative Science Quarterly (40), 371-384.

Sylvester, D. (2009) "The People Factor in IT Governance", COBIT Focus (2009)1, pp. 1-3.

The Telegraph (2011) "NHS computer face to cost another 2bn", December 8, Retrieved March 2013.

The Economist (2013) “The BBC's High-tech failure", June 10, Retrieved March 2013.

Tiwana, A., Konsynski, B. \& Venkatraman, N. (2013) "Special Issue: Information Technology and Organizational Governance: The IT Governance Cube", Journal of Management Information Systems (30)3, pp. 7-12.

Tolbert, P.S. \& Zucker, L.G. (1983) "Institutional sources of change in the formal structure of organizations: The diffusion of civil service reform, 1880-1935", Administrative Science Quarterly (30), pp. 22-39.

Tolbert, P. S., \& Zucker, L. G. (1995) “Institutional Analyses of Organizations: Legitimate but Not Institutionalized", Institute for Social Science Research (6)5.

Trites, G. (2004) "Director Responsibility for IT governance”, International Journal of Accounting Information Systems 5(2), pp. 89-99.

Tsang, E.W.K \& Williams, J.N. (2012) “Generalization and Induction: Misconceptions, Clarifications, and a Classification of Induction", MIS Quarterly (36)3, pp. 729-748.

Tu, W. (2007) "Identifying Incentive Factors in IT Governance: An Exploratory Study", 2007 International Conference on Convergence Information Technology, pp. 1425-1432

Turel O., \& Bart, C. (2014) "Board-level IT governance and organizational performance", European Journal of Information Systems (23)2, pp. 223-239.

Van Der Steen, M. (2008) "Inertia and Management Accounting Change: The Role of Ambiguity and Contradiction Between Formal Rules and Routines", Accounting, Auditing \& Accountability Journal (22)5, pp. 736-761.

Van Grembergen, W. (2002) "Introduction to the Minitrack: IT Governance and its Mechanisms", Proceedings of the 35th Hawaii International Conference on System Sciences (HICSS), HICSS-35.

Van Grembergen, W., De Haes, S. \& Guldentops, E. (2004) "Structures, processes and relational mechanisms for information technology governance: Theories and practices" in Strategies for information technology governance, W. Van Grembergen (ed), Idea Group Publishing, Hershey (PA), pp. 1-36. 
Van Maanen, J. (1983) "The fact and fiction in organizational ethnography", in Qualitative methodology, J. Van Maanen ed. Beverly Hills: Sage, pp. 37-55.

Vergne, J-P. (2011) "Toward a New Measure of Organizational Legitimacy: Method, Validation, and Illustration", Organizational Research Methods (14)3, pp. 484-502.

Verhoef, C. (2007) "Quantifying the Effects of IT-Governance Rules", Science of Computer Programming (67), pp. 247-277.

Vromen J. (2011), "Routines as multilevel mechanisms", Journal of Institutional Economics (7)2, pp. 175-196.

Wall Street Journal (2012) "Tokyo tackles trading glitch", February 2, Retrieved March 2013.

Walsham, G. (1995) "Interpretive case studies in IS research: Nature and Method", European Journal of Information Systems 4(2) 74-81.

Webb, P., Pollard, C., \& Ridley, G. (2006) “Attempting to Define IT Governance: Wisdom or Folly?", Proceedings of the 39th Hawaii International Conference on System Sciences, pp. 1-10.

Weber, M. (1978) Economy and Society, Berkley, CA: University of California Press.

Weichbrodt J. \& Grote, G. (2010) "Rules and Routines in Organizations: A Review and Extension", Proceedings of the 4th International Conference on Organizational Routines, Nice, France.

Weick, K.E. (1976) "Educational Organizations as Loosely Coupled Systems", Administrative Science Quarterly (21)1, pp. 1-19.

Weill, P. (2004) “Don't Just Lead, Govern: How Top-Performing Firms Govern IT”, MIS Quarterly Executive (3)1, pp. 1-17.

Weill, P. \& Olson, (1989) "An Assessment of the Contingency Theory of Management Information Systems", Journal of Management Information Systems (6)1, pp. 59-85.

Weill, P. \& Ross, J. (2004) IT Governance: How Top Performers Manage IT Decision Rights for Superior Results: Harvard Business Press Books.

Weill P. \& Ross, J. (2005) "A Matrixed Approach to Designing IT Governance", MIT Sloan Management Review (46)2, pp. 26-34.

Weill P. \& Woodham R. (2002) “Don't Just lead, govern: Implementing effective IT governance”, (CISR WP № 326), Cambridge, MA: MIT Sloan School of Management. 
Westphal J.D \& Zajac, E.J. (2001) "Decoupling Policy from Practice: The Case of Stock Repurchase Programs", Administrative Science Quarterly (46)2, pp. 202-228.

Whetten, D. A. (1989) "What Constitutes a Theoretical Contribution?", Academy of Management Review (14)4, pp. 490-495.

Wilkin, C. L., \& Chenhall, R. H. (2010) "A Review of IT Governance: A Taxonomy to Inform Accounting Information Systems", Journal of Information Systems (24)2, pp. 107146.

Wilkin, C. L., \& Riddett, J. (2009) "IT Governance Challenges in a Large Not-for-Profit Healthcare Organization: The Role of Intranets", Electronic Commerce Research (9), pp. 351-374.

Willcocks, L., Feeny, D., \& Olson, N. (2006) “Implementing Core IS Capabilities: FeenyWillcocks IT Governance and Management Framework Revisited", European Management Journal (24)1, pp. 28-37.

Willcocks, L. \& Lester, S. (1997) "Assessing IT Productivity: Any Way Out of the Labyrinth?", in Managing IT as a Strategic Resource, Leslie Willcocks, D.F. Feeny, \& G. Islei Eds, Chapter 4, The McGraw-Hill Company, London, pp. 64-93.

Williams, C. \& Karahanna E. (2013) "Causal Explanations in the Coordinating Process: A Critical Realist Case Study of Federated IT Governance Structures", MIS Quarterly (37)3, pp. 933-973.

Williamson, O.E. (1975) Markets and Hierarchies: Analysis and Antitrust Implications, New York: Free Press.

Williamson, O.E. (1999) "Strategy research: Governance and Competence Perspectives", Strategic Management Journal (20), pp. 1087-1108.

Willson, P., \& Pollard, C. (2009) “Exploring IT Governance in Theory and Practice in a Large Multi-National Organisation in Australia", Information Systems Management (26), pp. 98-109.

Witt U. (2011) "Emergence and functionality of organizational routines: an individualistic approach", Journal of Institutional Economics (7)2, pp. 157-174.

Wittgenstein, L. (1995) Philosophische Untersuchungen, Suhrkamp: Framkfurt/M.

Wolf C. (2007) "How Institutional Influences on Routines Impact Routine Learning Processes", Retrieved from Internet, April 2013. 
Xu, W., Grant, G., Nguyen, H. \& Dai, X. (2008) "Security Breach: The Case of TJX Companies, Inc.", Communications of the Association for Information Systems (23), Article 31.

Xue, L., Zhang, C., Ling, H. \& Zhao, X. (2013) “Risk Mitigation in Supply Chain Digitization: System Modularity and Information Technology Governance", Journal of Management Information Systems (30)1, pp. 325-352.

Xue, Y., Liang, H. \& Boulton, W.R. (2008) "Information Technology Governance in Information Technology Investment Decision Processes: The Impact of Investment Characteristics, External Environment, and Internal Context", MIS Quarterly (32)1, pp. 67-96.

Yin, R.K. (1981) "The Case Study Crisis: Some Answers", Administrative Science Quarterly (26)1, pp. 58-65.

Yin, R.K. (1984) Case study research: Design and methods, Newbury Park, CA: Sage.

Yin, R. K. (1994) Case study research: Design and methods (2nd ed.), Newbury Park, CA: Sage Publications.

Yin, R.K. (2003) Case study research: Design and methods (3rd ed.), Thousand Oaks CA: Sage.

Zenger, T.R, Lazzarini, S.G., Poppo, L. (2001) “Informal and Formal Organization in New Institutional Economics, Retrieved from Internet July 2013.

Zhong, X., Vatanasakdakul, S., \& Aoun, C. (2012) “Does Culture Matter? Cultural Influences and IT Governance Integration Mechanism", AMCIS 2012 Proceedings, Paper 2, pp. 1-8

Zimmerman, M. A., \& Zeitz, G. J. (2002) "Beyond Survival: Achieving New Venture Growth by Building Legitimacy", Academy of Management Review (27)3, pp. 414-431.

Zivkovic, J. (2012) "Strengths and Weaknesses of Business Research Methodologies: Two Disparate Case Studies", Business Studies Journal (4)2, pp. 91-99.

Zollo, M. \& Winter S.G. (2002) "Deliberate learning and the evolution of dynamic capabilities", Organization Science (13), pp. 339-351.

Zucker, L. G. (1977) "The Role of Institutionalization in Cultural Persistence", American Sociological Review (42)5, pp. 726-743. 


\section{APPENDIX A - EMAIL TO POTENTIAL INTERVIEW CANDIDATES}

Hi Mr/Ms. (Candidate Last Name)

My name is Allen Brown, and I am being sponsored by (Name of $\mathrm{ClO}$ ), $\mathrm{ClO}$ to conduct interviews at the City of (City Name) to support my PhD research in IT governance. A couple of months ago, I believe (Name of $\mathrm{CIO}$ ) reached out to you as a potential interview candidate. With your permission, I would like to schedule a one-time discussion as a follow-up to this request.

The interview will run no longer than 60 minutes, and will consist of open-ended questions regarding your role and thoughts around the IT investment prioritization and selection process at the city of Kingston. Your participation and responses will be strictly confidential and you are welcome to terminate the discussion at any point during the interview.

In addition to gathering information to complete my PhD thesis, the (City Name) will be provided an analysis and report on the current state of its IT investment process, as well as recommendations for further improving the performance of its governance mechanisms.

To accommodate your busy schedule and to help manage the scheduling of multiple interviews, I have blocked off a number of potential interview times (see below) for when I'll be in (City). Please let me know which time works best for you and I will respond with a confirmation. Of course, if a time outside of this schedule works best for you, please let me know and I'll try my best to make it work.

Thank you very much for your support!

Allen Brown

PhD Candidate, Sprott School of Business, Carleton University

613-797-4758

\section{$\underline{\text { Potential Interview Times }}$}

Listing of Potential Interview Dates and Times 


\section{APPENDIX B - INFORMATION FOR INTERVIEW PARTICIPANTS}

Exploring IT Governance Effectiveness: Identifying the sources of mechanistic divergence through the adoption of a behavioural-based organizational routines perspective

This research is being conducted by researchers from the Sprott School of Business, Carleton University, Ottawa, Canada as part of a Ph.D. Thesis Report.

Principal Researchers are:

\begin{tabular}{|l|l|}
\hline Allen Brown & Ph.D. Candidate, Sprott School of Business \\
\hline Dr. Gerald Grant & Associate Professor, Sprott School of Business \\
\hline
\end{tabular}

In this research we seek to understand how IT governance is enacted and followed within organizations. By understanding the difference between formal governance structures and the way that work is actually performed, we hope to learn how better to define and implement IT governance in order to improve the success rate and performance of IT investments. The research is expected to have a positive impact on how organizations manage and oversee their IT decisions.

Your participation in this study would involve a face-to-face or telephone interview that will take between 30 to 40 minutes of your time, which would be scheduled at your convenience. The purpose of the interview is to help us better understand the purpose of particular IT governance mechanisms and the reasons for diverging from the formal governance rules.

While there are no anticipated emotional or psychological risks associated with your participation in this interview, the interview questions will require you to reflect deeply on the nature your work and discuss examples of when governance rules are not directly followed. The potential for any social or economic exposure associated with your answers is taken seriously and is mitigated by ensuring the anonymity of your participation and responses. I would like to make it clear that, if you agree to participate, you will not be obligated to answer any question with which you are uncomfortable. Furthermore, you are entirely free to stop the interview at any time and may drop out of the study at any time, before (DATE), without question.

We will maintain the anonymity of your responses by assigning you an identification number that is linked to your name and contact information only on a master list 
accessible solely to the principal researcher. Your answers will not be shared with anyone in your organization. This master list will be destroyed once the findings have been fully reported. With your permission, we would like to digitally record the audio of the interview in order to accurately capture your ideas. You name will not be mentioned on the recording, nor will any identifying information other than your ID number be associated with the recording. The data generated may only be used in the present study and any future studies directly related to this topic, but the interview recording itself will be destroyed once all of the reports from the present study are completed.

Furthermore, your name and personal information will not be divulged in any report of the findings of this study. Statistical results will only be reported in the aggregate so that no individual's responses can be linked to the individual. Any quotes from your interview that are used in reports will be cited in such a way as to maintain your anonymity.

This project has been reviewed and received ethics clearance through the Carleton University Research Ethics Committee. If you have any comments or concerns regarding the ethical administration of this study, please address them to the chair of the Carleton University Ethics Board:

Prof. Andy Adler \& Prof. Louise Heslop, Co-Chairs

Carleton University Research Ethics Board

Tel: 613-520-2517

E-mail: ethics@carleton.ca

Thank you again for you time. We look forward to your participation. 


\title{
APPENDIX C - FIELD PROTOCOL
}

\author{
Before Entering Research Site
}

- Send introductory email (Appendix A), and follow up through email to confirm an interview date, time and location. Provide research overview as part of the email.

- Make contact with individuals prior to arriving at research site to confirm time and location. Ensure that the interview candidate is still available to meet.

- Arrive 15 minutes early to prepare informed consent forms, interview protocols, recording device and ensure that the meeting room is appropriate (for recording). Assign interview candidate an interview code based on location and protocol.

\section{During Interview Period}

- Researcher introduction, confirm that participant is comfortable, confirm that the participant is available for an hour session.

- Sign and date duplicate copies of the Informed Consent form.

- Provide introductory script (overview of the background of the researcher and the project, an outline of how the researchers were sponsored into the organization and an assurance that all responses will remain private and confidential).

- Confirm that the candidate is ok with being recorded, allow for any questions. Highlight that researcher will be taking notes during the session.

- During interview, allow time for interviewee to respond, do not lead the discussion, but rather facilitate (i.e. no leading questions).

- Allow time at the end for any additional discussion (leave recorder on).

- Thank participant. Reconfirm steps taken to ensure anonymity and ask about the potential of a follow-up discussion if needed.

- Ensure all documentation is taken with researcher.

After Interview Period

- Move audio filed to personal laptop. Send for transcription - store securely.

- Write up Field Notes within 24 hours - store securely.

- Schedule any follow up meetings, or follow up on any leads from interview. 


\section{APPENDIX D - INTERVIEW PROTOCOL - FINAL}

\section{Group: Governance Designers and Governance Owners}

Template Version: Formal Interview

\section{Part 1 Interview and Participant Tombstone Information}

\begin{tabular}{|l|l|}
\hline Interview Date and Time & \\
\hline Interview Location & \\
\hline Location ID Code & \\
\hline Participant ID Code & \\
\hline Interview Type & \\
\hline
\end{tabular}

\section{Part 2 Introduction Checklist}

\begin{tabular}{|l|l|}
\hline & Completion of Introductory Script \\
\hline Distribute Participant Information Form \\
\hline Completion of Participant Informed Consent Form \\
\hline & Verification of Recording \\
\hline & Question and Answers \\
\hline
\end{tabular}

\section{Part 3 - General Narrative Questions}

Role $\quad$ Are you familiar with the way in which IT investment planning and prioritization is performed within your organization? (How are IT project ideas, submitted, evaluated and selected among those proposed/required) 


\begin{tabular}{|c|c|}
\hline & $\begin{array}{l}\text { How would you describe your role in the IT investment planning and prioritization } \\
\text { process? (Do you submit projects? Are you involved in prioritizing and selecting } \\
\text { projects? Do you manage or create any documentation related to this process). - IF } \\
\text { more than one role - what is the most common role? }\end{array}$ \\
\hline Description & $\begin{array}{l}\text { Can you please describe the steps that your organization uses to plan and prioritize IT } \\
\text { investments? }\end{array}$ \\
\hline \multirow[t]{3}{*}{ Effectiveness } & $\begin{array}{l}\text { In your view, what are the desired outcomes or desired objective of the investment } \\
\text { planning and prioritization process? (What does good look like?) - What should be } \\
\text { the final result of this process? }\end{array}$ \\
\hline & $\begin{array}{l}\text { Are the outcomes or performance of the investment planning and prioritization } \\
\text { process formally measured or captured? }\end{array}$ \\
\hline & $\begin{array}{l}\text { Overall, in your opinion, do you feel that the current IT investment planning and } \\
\text { prioritization process effective? How do you define effective? How could the system } \\
\text { be improved? }\end{array}$ \\
\hline $\begin{array}{l}\text { Controls and } \\
\text { Mechanisms } \\
\text { (If not } \\
\text { captured in }\end{array}$ & $\begin{array}{l}\text { Following from your description of the investment planning and prioritization process, } \\
\text { what controls are in place to ensure that this outcome is achieved? (Controls can be } \\
\text { defined by Governing bodies, process flow charts, templates, checklists, prioritization } \\
\text { matrices, etc.) }\end{array}$ \\
\hline $\begin{array}{l}\text { General } \\
\text { Divergence }\end{array}$ & $\begin{array}{l}\text { Do you believe all stakeholders generally act in a manner that is directly aligned to } \\
\text { the formal controls of the governance process? Do stakeholder ever work around, } \\
\text { avoid or ignore the formal rules of the IT investment planning and prioritization } \\
\text { process? Can you provide examples? }\end{array}$ \\
\hline
\end{tabular}

\section{Specific Mechanism Questions - 30 Minute Mark}

\section{(Select one specific mechanism from Discussion)}

\begin{tabular}{|l|l|}
\hline Mechanism & $\begin{array}{l}\text { At this stage, I would like to focus more deeply on one item of the IT investment } \\
\text { planning and prioritization process. Are you comfortable discussing X? Can you } \\
\text { suggest a particular decision point or step in the process that you would like to } \\
\text { discuss? }\end{array}$ \\
\hline Mechanism & $\begin{array}{l}\text { If we were to define outcomes of this mechanism in terms of behaviours, how } \\
\text { would you describe the desired behaviours of the activity? What behaviours do } \\
\text { you feel that senior management would want from this structure? }\end{array}$ \\
\hline Artefacts & $\begin{array}{l}\text { Can you describe the detailed controls and tools that are put in place to drive this } \\
\text { type of behaviour (ToR, decision template, submission forms, RoDs, etc.) }\end{array}$ \\
\hline
\end{tabular}




\begin{tabular}{|l|l|}
\hline Divergence & $\begin{array}{l}\text { Do you feel that stakeholders typically follow the behaviours prescribed by this } \\
\text { mechanism? If not, why do you feel that they don't? Can you provide examples? }\end{array}$ \\
\hline Representative & $\begin{array}{l}\text { Do you feel that the formal controls or tools are suitable for producing the desired } \\
\text { behaviours and outcomes? Are they able to drive this behaviour in their current } \\
\text { form? Explain. Are there external pressures that may create particular formal } \\
\text { structures? }\end{array}$ \\
\hline Conclusion & $\begin{array}{l}\text { Overall, are there any other examples of divergence that you may have witnessed } \\
\text { within this or any other governance structure that you would like to discuss? }\end{array}$ \\
\hline
\end{tabular}

\section{Part 4 Conclusion and Thank You}

\begin{tabular}{|l|l|}
\hline & Completion of Interview \\
\hline Thank for Time \\
\hline & Reminder of activities to ensure anonymity \\
\hline & Ask permission for follow-up \\
\hline & Question and Answers \\
\hline
\end{tabular}




\section{Group: Governance Users and Consumers}

\section{Template Version: Formal Interview}

\section{Part 1 Interview and Participant Tombstone Information}

\begin{tabular}{|l|l|}
\hline Interview Date and Time & \\
\hline Interview Location & \\
\hline Location ID Code & \\
\hline Participant ID Code & \\
\hline Interview Type & \\
\hline
\end{tabular}

\section{Part 2 Introduction Checklist}

\begin{tabular}{|l|l|}
\hline & Completion of Introductory Script \\
\hline & Distribute Participant Information Form \\
\hline Completion of Participant Informed Consent Form \\
\hline & Verification of Recording \\
\hline & Question and Answers \\
\hline
\end{tabular}

\section{Part 3 - General Narrative Questions}

\begin{tabular}{|l|l|} 
Role & $\begin{array}{l}\text { Are you familiar with how IT investment planning and prioritization is performed } \\
\text { within your organization? (How are IT projects selected among those } \\
\text { proposed/required) }\end{array}$ \\
\hline How would you describe the role in the IT investment planning and prioritization
\end{tabular}




\begin{tabular}{|l|l|}
\hline Description & process? (Do you submit projects? \\
\hline Effectiveness & $\begin{array}{l}\text { In your view, what are the desired outcomes of the investment planning and } \\
\text { andioritization process? Are the outcomes or performance of the investment planning } \\
\text { and prioritization process formally measured or captured? }\end{array}$ \\
\hline & $\begin{array}{l}\text { Overall, in your opinion, do you feel that the current IT investment planning and } \\
\text { prioritization process effective? How do you define effective? How could the system } \\
\text { be improved? }\end{array}$ \\
\hline $\begin{array}{l}\text { General } \\
\text { Divergence }\end{array}$ & $\begin{array}{l}\text { Do you believe all stakeholders generally act in a manner that is directly aligned to } \\
\text { the formal controls of the governance process? Do stakeholders ever work around, } \\
\text { avoid or ignore the formal rules of the IT investment planning and prioritization } \\
\text { process? Can you provide examples? }\end{array}$ \\
\hline
\end{tabular}

\title{
Specific Mechanism Questions - 30 Minute Mark
}

\section{(Select one specific mechanism from Discussion)}

\begin{tabular}{|l|l|}
\hline $\begin{array}{l}\text { Specific } \\
\text { Example }\end{array}$ & $\begin{array}{l}\text { At this stage, I would like to talk about a specific interaction with the investment } \\
\text { planning process. Can you describe the specific steps you took when you } \\
\text { submitted/championed/supported through the process? }\end{array}$ \\
\hline Mechanism & $\begin{array}{l}\text { Do you feel you understood the rationale behind the various steps in the process? } \\
\text { Did you understand the reasoning behind each decision body? }\end{array}$ \\
\hline Artefacts & $\begin{array}{l}\text { Can you describe the set of tools, templates, governing bodies, decision processes } \\
\text { that you used or interacted with during your interaction with the process? }\end{array}$ \\
\hline Divergence & $\begin{array}{l}\text { Do you feel that stakeholders typically follow the behaviours prescribed by this } \\
\text { mechanism? Did you? Why or why not? }\end{array}$ \\
\hline Conclusion & $\begin{array}{l}\text { Overall, are there any other examples of divergence that you may have witnessed } \\
\text { within this or any other governance structure that you would like to discuss? }\end{array}$ \\
\hline
\end{tabular}

\section{Part 4 Conclusion and Thank You}

\author{
Completion of Interview
}




\begin{tabular}{|l|l|}
\hline & Thank for Time \\
\hline & Reminder of activities to ensure anonymity \\
\hline & Ask permission for follow-up \\
\hline & Question and Answers \\
\hline
\end{tabular}




\section{APPENDIX E - DRAFT INTERVIEW PROTOCOLS - PRE-TEST \\ Group: Governance Designers and Governance Owners \\ Template Version: Beta Pretest v1}

\section{Part 1 Interview and Participant Tombstone Information}

\begin{tabular}{|l|l|}
\hline Interview Date and Time & \\
\hline Interview Location & \\
\hline Location ID Code & \\
\hline Participant ID Code & \\
\hline Interview Type & \\
\hline
\end{tabular}

\section{Part 2 Introduction Checklist}

\begin{tabular}{|l|l|}
\hline & Completion of Introductory Script \\
\hline Distribute Participant Information Form \\
\hline Completion of Participant Informed Consent Form \\
\hline & Verification of Recording \\
\hline & Question and Answers \\
\hline
\end{tabular}

\section{Part 3 - General Narrative Questions}

Role $\quad$ Are you familiar with the investment planning and prioritization process within your organization? (Manner by which IT projects are chosen and prioritized) 


\begin{tabular}{|c|c|}
\hline & What is your role in the establishment and oversight of IT decisions and investments? \\
\hline & $\begin{array}{l}\text { How would you define your last interaction and role with this process (owner, } \\
\text { decision-maker, participant, and stakeholder)? }\end{array}$ \\
\hline & $\begin{array}{l}\text { Do you sit on any decision boards or steering committees? Did you help create any } \\
\text { documentation or rules related to this governance process? }\end{array}$ \\
\hline & $\begin{array}{l}\text { Are you involved in any other IT governance activities within your organization } \\
\text { (planning, creating artefacts, monitoring, reporting)? }\end{array}$ \\
\hline \multirow[t]{5}{*}{ Description } & $\begin{array}{l}\text { Can you please describe the approach that your organization uses to plan and } \\
\text { prioritize IT investments? }\end{array}$ \\
\hline & How long has this system been in place? Is it stable? \\
\hline & $\begin{array}{l}\text { In your view, what is the purpose of the IT planning and prioritization process? What } \\
\text { is the desired outcome of this activity? }\end{array}$ \\
\hline & $\begin{array}{l}\text { How are the outcomes / successes of the governance process measured in your } \\
\text { organization? }\end{array}$ \\
\hline & $\begin{array}{l}\text { How would you define success of this process? What would a perfectly functioning } \\
\text { Planning and Prioritization process work? }\end{array}$ \\
\hline Mechanisms & $\begin{array}{l}\text { What controls are in place to ensure that this outcome is achieved? Governing } \\
\text { bodies, templates, checklists, prioritization matrices, etc.? }\end{array}$ \\
\hline \multirow[t]{4}{*}{ Effectiveness } & Do you feel the current system is effective at ensuring its objectives are met? \\
\hline & What recommendations would you make to improve on the system? \\
\hline & $\begin{array}{l}\text { Do you believe all stakeholders generally act in a manner that is directly aligned to } \\
\text { the spirit of the governance process? If not, can you give examples? }\end{array}$ \\
\hline & $\begin{array}{l}\text { Do you know of any examples where stakeholders may not have conformed directly } \\
\text { to the formal rules of the process either to improve the process or workaround the } \\
\text { formality of the process? }\end{array}$ \\
\hline
\end{tabular}

\section{Construct Questions}




\begin{tabular}{|c|c|}
\hline Behaviour & $\begin{array}{l}\text { If we were to define outcomes in terms of behaviours. How would you describe } \\
\text { the desired behaviours of the activity? What behaviours do you feel that senior } \\
\text { management would want from this governance structure? }\end{array}$ \\
\hline Artefacts & $\begin{array}{l}\text { Can you give examples of the way that the controls put in place for this process } \\
\text { drive particular behaviours? }\end{array}$ \\
\hline Behaviour & Do you feel that the current structure drives these behaviours? Why or why not? \\
\hline Representative & $\begin{array}{l}\text { Do you feel that the formal governance elements are suitable for producing the } \\
\text { desired behaviours and outcomes? Are they able to drive this behaviour in their } \\
\text { current form? Explain }\end{array}$ \\
\hline Divergence & $\begin{array}{l}\text { Where do you think participants tend to diverge from the desired behaviours? } \\
\text { Provide examples and explain. }\end{array}$ \\
\hline Representative & $\begin{array}{l}\text { Why were these formal elements chosen? Are there any external pressures that } \\
\text { would cause the organization to create formal structures that they don't intend to } \\
\text { follow? }\end{array}$ \\
\hline Representative & $\begin{array}{l}\text { In your opinion does the organization adhere to the IT governance mechanisms? } \\
\text { Does the organization as a whole follow its own rules? }\end{array}$ \\
\hline Substantive & $\begin{array}{l}\text { Do you feel this governance mechanism is aligned to the overall direction/strategy } \\
\text { of the organization? }\end{array}$ \\
\hline Conclusion & $\begin{array}{l}\text { Overall, are there any other examples of divergence that you may have witnessed } \\
\text { within this or any other governance structure? }\end{array}$ \\
\hline
\end{tabular}




\section{Group: Governance Designers and Governance Owners \\ Template Version: Beta Pretest v2}

\section{Part 1 Interview and Participant Tombstone Information}

\begin{tabular}{|l|l|}
\hline Interview Date and Time & \\
\hline Interview Location & \\
\hline Location ID Code & \\
\hline Participant ID Code & \\
\hline Interview Type & \\
\hline
\end{tabular}

\section{Part 2 Introduction Checklist}

\begin{tabular}{|l|l|}
\hline & Completion of Introductory Script \\
\hline & Distribute Participant Information Form \\
\hline Completion of Participant Informed Consent Form \\
\hline & Verification of Recording \\
\hline & Question and Answers \\
\hline
\end{tabular}

\section{Part 3 - General Narrative Questions}

\begin{tabular}{|l|l|} 
Role & $\begin{array}{l}\text { Are you familiar with how IT investment planning and prioritization is performed } \\
\text { within your organization? (How are IT projects selected among those } \\
\text { proposed/required) }\end{array}$ \\
\hline How would you describe the role that you typically you play in terms of the IT
\end{tabular}




\begin{tabular}{|c|c|}
\hline & $\begin{array}{l}\text { investment planning and prioritization process? (Do you submit projects? Are you } \\
\text { involved in prioritizing and selecting projects? Do you manage or create any } \\
\text { documentation related to this process) }\end{array}$ \\
\hline Description & $\begin{array}{l}\text { Can you please describe the steps that your organization uses to plan and prioritize IT } \\
\text { investments? }\end{array}$ \\
\hline \multirow[t]{3}{*}{ Effectiveness } & $\begin{array}{l}\text { In your view, what are the desired outcomes of the investment planning and } \\
\text { prioritization process? }\end{array}$ \\
\hline & $\begin{array}{l}\text { Are the outcomes or performance of the investment planning and prioritization } \\
\text { process formally measured or captured? }\end{array}$ \\
\hline & $\begin{array}{l}\text { Overall, in your opinion, do you feel that the current IT investment planning and } \\
\text { prioritization process effective? How do you define effective? How could the system } \\
\text { be improved? }\end{array}$ \\
\hline $\begin{array}{l}\text { Controls and } \\
\text { Mechanisms }\end{array}$ & $\begin{array}{l}\text { Following from your description of the investment planning and prioritization process, } \\
\text { what controls are in place to ensure that this outcome is achieved? (Controls can be } \\
\text { defined by Governing bodies, process flow charts, templates, checklists, prioritization } \\
\text { matrices, etc.) }\end{array}$ \\
\hline $\begin{array}{l}\text { General } \\
\text { Divergence }\end{array}$ & $\begin{array}{l}\text { Do you believe all stakeholders generally act in a manner that is directly aligned to } \\
\text { the formal controls of the governance process? Do stakeholders ever work around, } \\
\text { avoid or ignore the formal rules of the IT investment planning and prioritization } \\
\text { process? Can you provide examples? }\end{array}$ \\
\hline
\end{tabular}

\section{Specific Mechanism Questions - 30 Minute Mark}

\section{(Select one specific mechanism from Discussion)}

\begin{tabular}{|l|l|}
\hline Mechanism & $\begin{array}{l}\text { At this stage, I would like to focus more deeply on one item of the IT investment } \\
\text { planning and prioritization process. Are you comfortable discussing X? Can you } \\
\text { suggest a particular decision point or step in the process that you would like to } \\
\text { discuss? }\end{array}$ \\
\hline Mechanism & $\begin{array}{l}\text { If we were to define outcomes of this mechanism in terms of behaviours, how } \\
\text { would you describe the desired behaviours of the activity? What behaviours do } \\
\text { you feel that senior management would want from this structure? }\end{array}$ \\
\hline Artefacts & $\begin{array}{l}\text { Can you describe the detailed controls and tools that are put in place to drive this } \\
\text { type of behaviour (ToR, decision template, submission forms, RoDs, etc.) }\end{array}$ \\
\hline Divergence & $\begin{array}{l}\text { Do you feel that stakeholders typically follow the behaviours prescribed by this } \\
\text { mechanism? If not, why do you feel that they don't? Can you provide examples? }\end{array}$ \\
\hline
\end{tabular}




\begin{tabular}{|l|l|}
\hline Representative & $\begin{array}{l}\text { Do you feel that the formal controls or tools are suitable for producing the desired } \\
\text { behaviours and outcomes? Are they able to drive this behaviour in their current } \\
\text { form? Explain. Are there external pressures that may create particular formal } \\
\text { structures? }\end{array}$ \\
\hline Conclusion & $\begin{array}{l}\text { Overall, are there any other examples of divergence that you may have witnessed } \\
\text { within this or any other governance structure that you would like to discuss? }\end{array}$ \\
\hline
\end{tabular}

\section{Part 4 Conclusion and Thank You}

\begin{tabular}{|l|l|}
\hline & Completion of Interview \\
\hline Thank for Time \\
\hline & Reminder of activities to ensure anonymity \\
\hline Ask permission for follow-up \\
\hline & Question and Answers \\
\hline
\end{tabular}




\section{Group: Governance Users and Consumers}

\section{Template Version: Beta Pretest v1}

\section{Part 1 Interview and Participant Tombstone Information}

\begin{tabular}{|l|l|}
\hline Interview Date and Time & \\
\hline Interview Location & \\
\hline Location ID Code & \\
\hline Participant ID Code & \\
\hline Interview Type & \\
\hline
\end{tabular}

\section{Part 2 Introduction Checklist}

\begin{tabular}{|l|l|}
\hline & Completion of Introductory Script \\
\hline & Distribute Participant Information Form \\
\hline Completion of Participant Informed Consent Form \\
\hline & Verification of Recording \\
\hline & Question and Answers \\
\hline
\end{tabular}

\section{Part 3 - General Narrative Questions}

\begin{tabular}{|l|l|l|l} 
Role & $\begin{array}{l}\text { Are you familiar with the investment planning and prioritization process within your } \\
\text { organization? (Manner by which IT projects are chosen and prioritized) }\end{array}$ \\
What is your role in the establishment and oversight of IT decisions and investments?
\end{tabular}




\begin{tabular}{|c|c|}
\hline & $\begin{array}{l}\text { How would you define your last interaction and role with this process (owner, } \\
\text { decision-maker, participant, and stakeholder)? }\end{array}$ \\
\hline & $\begin{array}{l}\text { Do you sit on any decision boards or steering committees? Did you help create any } \\
\text { documentation or rules related to this governance process? }\end{array}$ \\
\hline & $\begin{array}{l}\text { Are you involved in any other IT governance activities within your organization } \\
\text { (planning, creating artefacts, monitoring, reporting)? }\end{array}$ \\
\hline \multirow[t]{5}{*}{ Description } & $\begin{array}{l}\text { Can you please describe the approach that your organization uses to plan and } \\
\text { prioritize IT investments? }\end{array}$ \\
\hline & How long has this system been in place? Is it stable? \\
\hline & $\begin{array}{l}\text { In your view, what is the purpose of the IT planning and prioritization process? What } \\
\text { is the desired outcome of this activity? }\end{array}$ \\
\hline & $\begin{array}{l}\text { How are the outcomes / successes of the governance process measured in your } \\
\text { organization? }\end{array}$ \\
\hline & $\begin{array}{l}\text { How would you define success of this process? What would a perfectly functioning } \\
\text { Planning and Prioritization process work? }\end{array}$ \\
\hline Mechanisms & $\begin{array}{l}\text { What controls are in place to ensure that this outcome is achieved? Governing } \\
\text { bodies, templates, checklists, prioritization matrices, etc.? }\end{array}$ \\
\hline \multirow[t]{4}{*}{ Effectiveness } & Do you feel the current system is effective at ensuring its objectives are met? \\
\hline & What recommendations would you make to improve on the system? \\
\hline & $\begin{array}{l}\text { Do you believe all stakeholders generally act in a manner that is directly aligned to } \\
\text { the spirit of the governance process? If not, can you give examples? }\end{array}$ \\
\hline & $\begin{array}{l}\text { Do you know of any examples where stakeholders may not have conformed directly } \\
\text { to the formal rules of the process either to improve the process or workaround the } \\
\text { formality of the process? }\end{array}$ \\
\hline
\end{tabular}

\section{Construct Questions}

Behaviour

If we were to define outcomes in terms of behaviours. How would you describe the desired behaviours of the activity? What behaviours do you feel that senior management would want from this governance structure? 


\begin{tabular}{|c|c|}
\hline Artefacts & $\begin{array}{l}\text { Can you give examples of the way that the controls put in place for this process } \\
\text { drive particular behaviours? }\end{array}$ \\
\hline Behaviour & Do you feel that the current structure drives these behaviours? Why or why not? \\
\hline Representative & $\begin{array}{l}\text { Do you feel that the formal governance elements are suitable for producing the } \\
\text { desired behaviours and outcomes? Are they able to drive this behaviour in their } \\
\text { current form? Explain }\end{array}$ \\
\hline Divergence & $\begin{array}{l}\text { Where do you think participants tend to diverge from the desired behaviours? } \\
\text { Provide examples and explain. }\end{array}$ \\
\hline Representative & $\begin{array}{l}\text { Why were these formal elements chosen? Are there any external pressures that } \\
\text { would cause the organization to create formal structures that they don't intend to } \\
\text { follow? }\end{array}$ \\
\hline Representative & $\begin{array}{l}\text { In your opinion does the organization adhere to the IT governance mechanisms? } \\
\text { Does the organization as a whole follow its own rules? }\end{array}$ \\
\hline Substantive & $\begin{array}{l}\text { Do you feel this governance mechanism is aligned to the overall direction/strategy } \\
\text { of the organization? }\end{array}$ \\
\hline Conclusion & $\begin{array}{l}\text { Overall, are there any other examples of divergence that you may have witnessed } \\
\text { within this or any other governance structure? }\end{array}$ \\
\hline
\end{tabular}




\section{Group: Governance Users and Consumers}

\section{Template Version: Beta Pretest v2}

\section{Part 1 Interview and Participant Tombstone Information}

\begin{tabular}{|l|l|}
\hline Interview Date and Time & \\
\hline Interview Location & \\
\hline Location ID Code & \\
\hline Participant ID Code & \\
\hline Interview Type & \\
\hline
\end{tabular}

\section{Part 2 Introduction Checklist}

\begin{tabular}{|l|l|}
\hline & Completion of Introductory Script \\
\hline & Distribute Participant Information Form \\
\hline Completion of Participant Informed Consent Form \\
\hline & Verification of Recording \\
\hline & Question and Answers \\
\hline
\end{tabular}

\section{Part 3 - General Narrative Questions}

\begin{tabular}{|l|l|} 
Role & $\begin{array}{l}\text { Are you familiar with how IT investment planning and prioritization is performed } \\
\text { within your organization? (How are IT projects selected among those } \\
\text { proposed/required) }\end{array}$ \\
\hline How would you describe the role that you typically you play in terms of the IT
\end{tabular}




\begin{tabular}{|l|l|}
\hline Description & $\begin{array}{l}\text { investment planning and prioritization process? (Do you submit projects? Are you } \\
\text { involved in prioritizing and selecting projects? Do you manage or create any } \\
\text { documentation related to this process) }\end{array}$ \\
\hline Effectiveness & $\begin{array}{l}\text { Can you please describe the high-level steps that your organization uses to plan and } \\
\text { prioritize IT investments? }\end{array}$ \\
\hline $\begin{array}{l}\text { In your view, what are the desired outcomes of the investment planning and } \\
\text { and prioritization process formally measured or captured? }\end{array}$ \\
\hline $\begin{array}{l}\text { averall, in your opinion, do you feel that the current IT investment planning and } \\
\text { prioritization process effective? How do you define effective? How could the system } \\
\text { be improved? }\end{array}$ \\
\hline Divergence & $\begin{array}{l}\text { Do you believe all stakeholders generally act in a manner that is directly aligned to } \\
\text { the formal controls of the governance process? Do stakeholder ever work around, } \\
\text { avoid or ignore the formal rules of the IT investment planning and prioritization } \\
\text { process? Can you provide examples? }\end{array}$ \\
\hline
\end{tabular}

\section{Specific Mechanism Questions - 30 Minute Mark}

\section{(Select one specific mechanism from Discussion)}

\begin{tabular}{|l|l|}
\hline $\begin{array}{l}\text { Specific } \\
\text { Example }\end{array}$ & $\begin{array}{l}\text { At this stage, I would like to talk about a specific interaction with the investment } \\
\text { planning process. Can you describe the specific steps you took when you } \\
\text { submitted/championed/supported through the process? }\end{array}$ \\
\hline Mechanism & $\begin{array}{l}\text { Do you feel you understood the overall investment planning and prioritization } \\
\text { process? Did you understand the reasoning behind each decision body? }\end{array}$ \\
\hline Artefacts & $\begin{array}{l}\text { Can you describe the set of tools, templates, governing bodies, decision processes } \\
\text { that you used during your interaction with the process? }\end{array}$ \\
\hline Divergence & $\begin{array}{l}\text { Do you feel that stakeholders typically follow the behaviours prescribed by this } \\
\text { mechanism? Did you? Why or why not? }\end{array}$ \\
\hline Conclusion & $\begin{array}{l}\text { Overall, are there any other examples of divergence that you may have witnessed } \\
\text { within this or any other governance structure that you would like to discuss? }\end{array}$ \\
\hline
\end{tabular}

\section{Part 4 Conclusion and Thank You}




\begin{tabular}{|l|l|}
\hline & Thank for Time \\
\hline & Reminder of activities to ensure anonymity \\
\hline & Ask permission for follow-up \\
\hline & Question and Answers \\
\hline
\end{tabular}




\section{APPENDIX F - INFORMED CONSENT DOCUMENT}

Thank you for agreeing to participate in this study. I expect the interview to take between 30 to 40 minutes of your time.

The purpose of the interview is to better understand how IT governance is enacted and followed within your organization. By understanding the difference between formal governance structures and the way that work is actually performed, we hope to learn how better to define and implement IT governance.

While there are no anticipated emotional or psychological risks associated with your participation in this interview, the interview questions will require you to reflect deeply on the nature your work and discuss examples of when governance rules are not directly followed. The potential for any social or economic exposure associated with your answers is taken seriously and is mitigated by ensuring the anonymity of your participation and responses. I would like to make it clear that, if you agree to participate, you will not be obligated to answer any questions with which you are uncomfortable. Furthermore, you are entirely free to drop out of the study at any time, without question, should you become uncomfortable with your participation in the study.

We will maintain the anonymity of your responses by assigning you an identification number that is linked to your name and contact information only on a master list accessible solely to the principal researcher. This master list will be destroyed once the findings have been fully reported.

With your permission, we would like to digitally record the audio of the interview in order to accurately capture your ideas. You name will not be mentioned on the recording, nor will any identifying information other than your ID number be associated with the recording. The data generated by your interview may only be used in the present study and any future studies directly related to this topic, but the interview recording itself will be destroyed once all of the reports from the present study are completed.

Furthermore, your name and personal information will not be divulged in any report of the findings of this study. Statistical results will only be reported in the aggregate so that no individual's responses can be linked to the individual. Any quotes from your interview that are used in reports will be cited in such a way as to maintain your anonymity.

I understand the purpose of the research and agree to participate in the interview.

I give my permission for a digital audio recording of the interview to be made.

I understand that I can stop the interview at any time and that the data collected up to that point will not be used in the study and will be destroyed.

This project has been reviewed and received ethics clearance through the Carleton University Research Ethics Committee. If you have any comments or concerns regarding the ethical administration of this study, please address them to the chair of the Carleton University Ethics Board: 
Prof. Andy Adler \& Prof. Louise Heslop, Co-Chairs

Carleton University Research Ethics Board

Tel: 613-520-2517

E-mail: ethics@carleton.ca

If you have any questions or comments about the interview process or the research project itself please contact us as indicated below:

$\begin{array}{ll}\text { Allen Brown } & \text { Dr. Gerald Grant } \\ \text { PhD Candidate } & \text { PhD Supervisor, Associate Professor } \\ \text { Sprott School of Business } & \text { Sprott School of Business } \\ \text { Carleton University } & \text { Carleton University } \\ \text { Abrown5@connect.carleton.ca } & \text { Gerald_Grant@carleton.ca } \\ \text { 613-797-4758 } & 613-520-2600 \text { ext. } 8006\end{array}$

Participant Signature:

Researcher Signature:

Date:

Date:

(Duplicate Copies - 1 Copy for Participant, 1 Copy for Researcher) 


\section{APPENDIX G - TRANSCRIPTION PRIVACY AND CONFIDENTIALITY AGREEMENT}

Name of Transcriber:

Address of Transcriber:

Contact information:

$\checkmark \quad$ I have agreed to transcribe the following digital audio recordings submitted to me by Allen Brown, PhD Candidate of Carleton University.

$\checkmark$ I understand that all the content of these recordings are confidential and must be treated with utmost care so that none of the content will be revealed to anyone other than Allen Brown, PhD Candidate of Carleton University.

$\checkmark$ I confirm that the digital audio recording is being store in secure computer files on a secure computer environment that is protected by a strong password known only to me.

$\checkmark$ I will destroy and completely remove all the files from my computer and other secure storage locations when the transcriptions are complete and accepted by Allen Brown.

Signed:

Date:

Upon Completion of the Transcription:

Name of Transcriber:

$\nabla \quad$ I certify that I have completely removed all data files for (transcriptions) from my computers and other secure storage locations and am no longer able to retrieve them from these locations.

$\checkmark$ I also certify that I have not transmitted the files to anyone else other than Allen Brown, PhD Candidate of Carleton University.

Signed:

Date: 


\section{APPENDIX H - CITY A GOVERNANCE ARTEFACTS}

\begin{tabular}{|l|l|}
\hline City A Artefact & Format \\
\hline City Strategic Plan & electronic \\
\hline City Plan and Action Items & electronic \\
\hline City Organizational Chart & electronic \\
\hline Capital Budget 2013 & electronic \\
\hline Operating Budget 2013 & electronic \\
\hline CAO Organizational Memorandum & electronic \\
\hline Report to Council 14067 & electronic \\
\hline Report to Council 14087 & electronic \\
\hline Report to Council 14104 & electronic \\
\hline Report to Council 14106 & electronic \\
\hline IMIT Governance Framework & electronic \\
\hline Policy on Project Intake Governance & electronic \\
\hline Managers Guide to IM/IT Gov & electronic \\
\hline Project Intake and Selection FAQ & electronic \\
\hline Project Scoring Template & electronic \\
\hline Project Approval List - April 2014 & electronic \\
\hline Opportunity Definition Template & electronic \\
\hline Opportunity Definition Guide & electronic \\
\hline Project Statement 1 Template & electronic \\
\hline Project Statement 2 Template & electronic \\
\hline Architecture Principles & electronic \\
\hline Small Project Explanation & electronic \\
\hline Small Project - Eclipse Screen Cap & electronic \\
\hline Sample OPD - Election Management & electronic \\
\hline Sample OPD - AIMS & electronic \\
\hline Sample Project Statements - CEG & electronic \\
\hline Sample OPD - CAFSES & hard copy \\
\hline
\end{tabular}




\section{APPENDIX I - CITY B GOVERNANCE ARTEFACTS}

\begin{tabular}{|l|l|}
\hline City B Artefact & Format \\
\hline City Strategic Plan 2011-2014 & electronic \\
\hline City Budget 2014-2016 & electronic \\
\hline Technology Strategic Plan & electronic \\
\hline Project Charter Template & electronic \\
\hline Scoping Document Template & electronic \\
\hline Project Tracking Sheet (June) & electronic \\
\hline CLT IT Update - June 2014 & electronic \\
\hline IT PEC - Governance Proposal & electronic \\
\hline IT PEC - Ranking / Prioritization & electronic \\
\hline IT PEC - Governance Update & electronic \\
\hline Project Information Form - 14/15 & electronic \\
\hline Corporate Application Roadmap & electronic \\
\hline Governance Master Document & electronic \\
\hline SAP Support Issue Process & hard copy \\
\hline INS Steering Committee TOR & hard copy \\
\hline Project Proposal SAP Upgrade & hard copy \\
\hline Business Planning Guidelines & hard copy \\
\hline
\end{tabular}




\section{APPENDIX J - CITY A GOVERNANCE OWNER EXPECTATIONS}

\begin{tabular}{|c|c|}
\hline Expected Behaviour & Evidence or Source \\
\hline $\begin{array}{l}\text { IT Investments directly } \\
\text { and overtly aligned to } \\
\text { city priorities and } \\
\text { strategic direction. }\end{array}$ & $\begin{array}{l}\text { - "aligned and support the City's priorities and strategic } \\
\text { - "abjectives" (ITGF p. 21) } \\
\text { corporate administrative priorities and as well as any } \\
\text { departmental strategies and priorities that the } \\
\text { department is able to, to bring forward" (A1G10) } \\
\text { - "attempt to align our city's strategic plan to requests } \\
\text { from departments for new systems or I.T solutions" } \\
\text { (A1G101) } \\
\text { "making sure that we are working on the right projects at } \\
\text { the right time, and when I say that, when I say what is the } \\
\text { right project, it's a project that's, that's advancing the, the } \\
\text { business priorities of the organization in some way, shape } \\
\text { or form" (A1G101) } \\
\text { "we are working on the, on the right projects that } \\
\text { advance the corporate agenda if you will and just council } \\
\text { priorities." ( A1G101) } \\
\text { "(IT Group) operating plans for the next four or five years } \\
\text { integrated with the divisional and departmental plans, so } \\
\text { we are there, we are working towards that." (A1G110) } \\
\text { "high level overview and understanding of the } \\
\text { costs/benefits of each projects and the extent to which it } \\
\text { supports the business life cycle and strategic objectives of } \\
\text { the organization" (PSP p. 9) } \\
\text { "Identifying and reviewing technology investment } \\
\text { proposals to ensure that they are aligned with the City's } \\
\text { priorities and strategic objectives" (ITGF p. 22) }\end{array}$ \\
\hline $\begin{array}{l}\text { IT Investments based on } \\
\text { clearly articulated } \\
\text { business value } \\
\text { propositions }\end{array}$ & $\begin{array}{l}\text { - "Proposed technology investments are designed to } \\
\text { - "Definitely the goal is to work on projects with the higher } \\
\text { priority." (A1G108) } \\
\text { - "decisions related to...which projects get approved, which } \\
\text { get completed as a higher priority, and which ones may } \\
\text { have to wait until there are resources available to } \\
\text { undertake them" (PSP, p. 5) } \\
\text { - "for the high level we will indicate within what year we } \\
\text { might be able to work on it and we try and obviously } \\
\text { organize the, the higher value projects first" (A1G101) } \\
\text { "High priority projects will be initiated as soon as possible } \\
\text { in conjunction with the business sponsor and (the IT } \\
\text { group)." ( ITGF FAQ) } \\
\text { "Well that we are working on high priority projects." }\end{array}$ \\
\hline
\end{tabular}




\begin{tabular}{|c|c|}
\hline & $\begin{array}{l}\text { (A1G108) } \\
\text { "Projects that are approved by the ITSC through this } \\
\text { process and categorized as a Corporate priority and "high } \\
\text { value" will be initiated as soon as possible...(The IT Group) } \\
\text { and business sponsors will allocate and prioritize } \\
\text { resources to meet project timelines within fiscal and } \\
\text { resource constraints" (PSP, p. 8) } \\
\text { "Decisions related to determining the annual priorities } \\
\text { and projects undertaken by IS\&T including which projects } \\
\text { get approved, which get completed as a higher priority } \\
\text { and which ones may have to wait until there are } \\
\text { resources available to undertake them" (ITGF, p.5) }\end{array}$ \\
\hline $\begin{array}{l}\text { IT Investments that } \\
\text { reflect the need to } \\
\text { balance between } \\
\text { corporate-wide and } \\
\text { business-specific } \\
\text { benefits }\end{array}$ & $\begin{array}{l}\text { - "I think the right balance of alignment between the } \\
\text { corporate objectives and business unit objectives, } \\
\text { because my fear is if it is too heavily weighted towards } \\
\text { the business unit objectives and not enough presence } \\
\text { given to the enterprise objectives we can still continue to } \\
\text { have silo solutions." (A1G104) } \\
\text { "(that the business lines) appreciate that our priorities are } \\
\text { driven corporately not with the goal of trying to be, be, } \\
\text { do something for everybody in the organization." } \\
\text { (A1G101) } \\
\text { "helpful to ensure that IT investment is balanced across } \\
\text { the portfolio" (ITGF FAQ) } \\
\text { "It's speaking as I guess a department head, there's } \\
\text { always, and this exists everywhere, there is always } \\
\text { tension between the allocation of resources to corporate } \\
\text { needs and technology versus meeting the more unique or } \\
\text { specialized needs or desires of a department. If you live } \\
\text { and breathe that career and that tension is a healthy } \\
\text { tension." (A1G210, CMT Member) } \\
\text { "I'd certainly say we are focused on and pushing } \\
\text { enterprise solutions that hopefully address many but not } \\
\text { all of the most important departmental needs." (A1G210, } \\
\text { C T Member) }\end{array}$ \\
\hline $\begin{array}{l}\text { IT investment decisions } \\
\text { favourable to projects } \\
\text { that promote horizontal } \\
\text { alignment and existing } \\
\text { system reuse }\end{array}$ & $\begin{array}{l}\text { - "New system implementations will reuse existing } \\
\text { corporate services, applications, and infrastructure } \\
\text { components whenever possible." (Architecture } \\
\text { Principles) } \\
\text { - "We obviously also try and look at existing... what we } \\
\text { already have in place to see if we can actually leverage } \\
\text { then use that route in bringing up something new " } \\
\text { (A1G101) } \\
\text { "(IT group) tries to maybe provide us a solution for one } \\
\text { business that is a very good solution for another business } \\
\text { as well." (A1G110) }\end{array}$ \\
\hline
\end{tabular}




\begin{tabular}{|c|c|}
\hline $\begin{array}{l}\text { IT Investments } \\
\text { prioritized by the } \\
\text { business, for the } \\
\text { business and based on } \\
\text { business needs }\end{array}$ & $\begin{array}{l}\text { - Increase business participation in the management and } \\
\text { oversight of IT-enabled projects. (IT Strategic Vision - as } \\
\text { discussed with A1 Sponsor, FN A1 Sponsor) } \\
\text { "Ensuring business accountability for realizing the } \\
\text { planned benefits from information and technology" } \\
\text { (ITGF, p. 21) } \\
\text { - Identifies/confirms key corporate strategic priorities, } \\
\text { approve workplan and provide direction to (IT Group)" } \\
\text { (Description of responsibility of ITSC in PSP, p. 10) } \\
\text { "Well, I guess another criteria for the 'what looks good' } \\
\text { too is that ideally we would want the projects that we are } \\
\text { working on also to be flagged but then ITAB approved." } \\
\text { (A1G108) }\end{array}$ \\
\hline $\begin{array}{l}\text { IT Investment decision- } \\
\text { making established as } \\
\text { part of the bi-annual } \\
\text { corporate planning } \\
\text { process }\end{array}$ & $\begin{array}{l}\text { - "assessment of new projects occur June/July and } \\
\text { January/February to coincide with operational planning, } \\
\text { budget development and budget approval timelines" } \\
\text { (PSP, p. 8) } \\
\text { - And so my goal is to over the course of a year, to set } \\
\text { some targets around, no more than a certain percentage } \\
\text { of our total intake or our total project list would fall into } \\
\text { that category (Unplanned investments) so as much as } \\
\text { possible would be properly planned and approved." } \\
\text { (A1G101) } \\
\text { "I think at the end of the day I would like to see } \\
\text { something that is little more manageable, over maybe } \\
\text { more of a critical path, you know, maybe a five to ten } \\
\text { year, maybe planning horizon and it doesn't mean that } \\
\text { there aren't twenty five items on list but there won't be } \\
\text { forty or fifty, and they will be at various stages of the } \\
\text { critical path in terms of the requirements" (A1G110) }\end{array}$ \\
\hline
\end{tabular}




\section{APPENDIX K - CITY A DESIRED BEHAVIOUR}

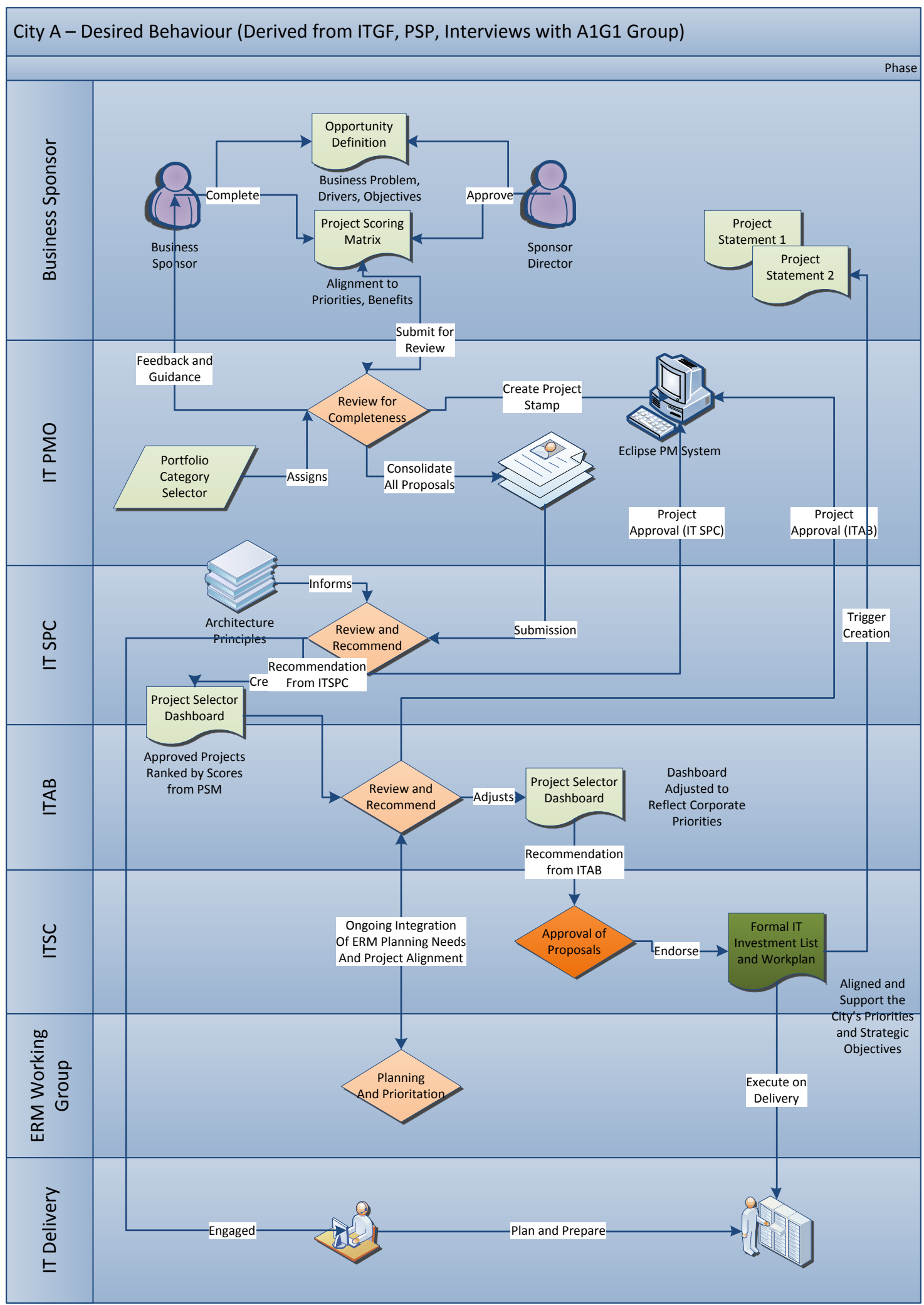




\section{APPENDIX L - CITY A ACTUAL BEHAVIOUR}

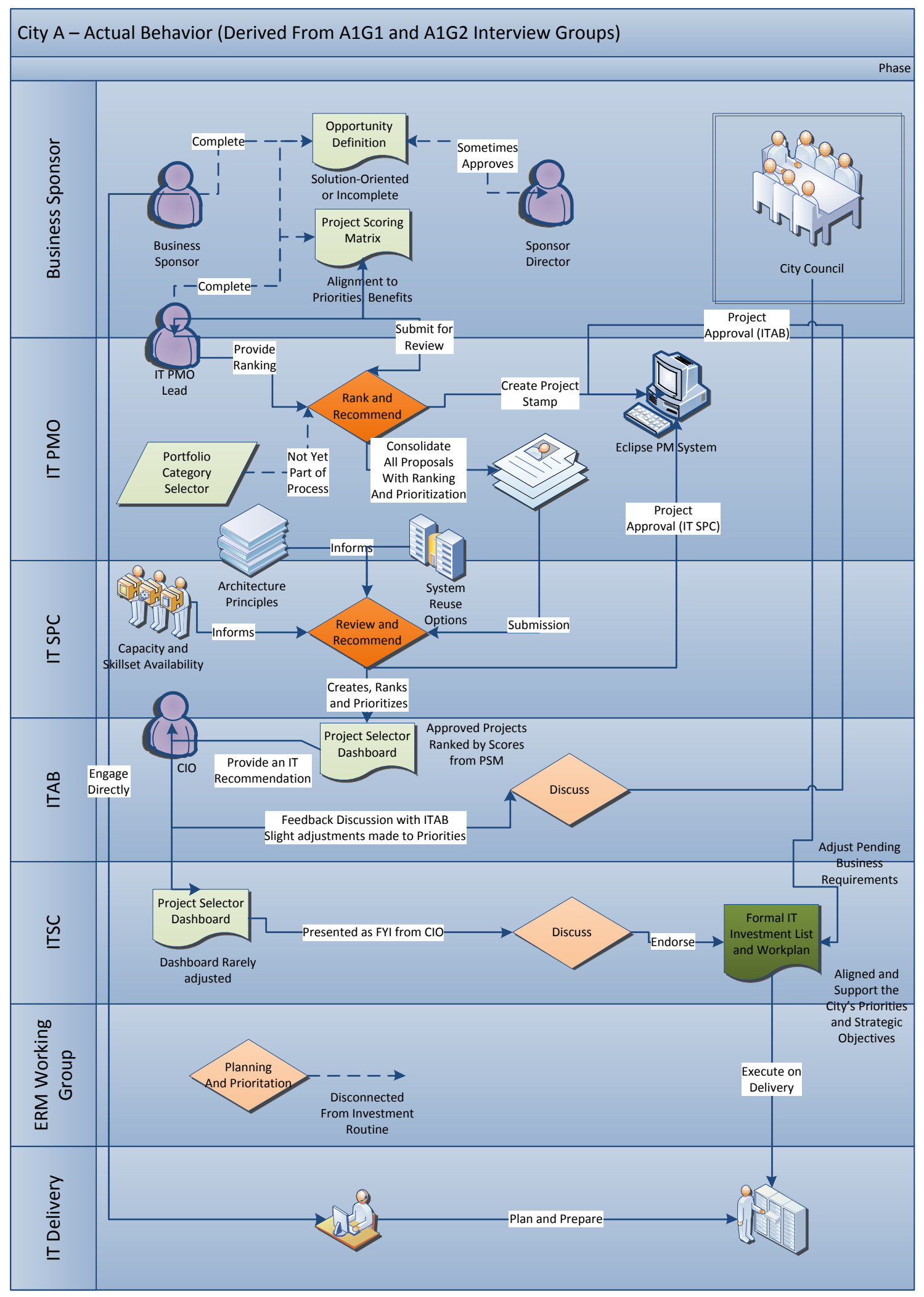




\section{APPENDIX M - CITY A DIVERGENCE}

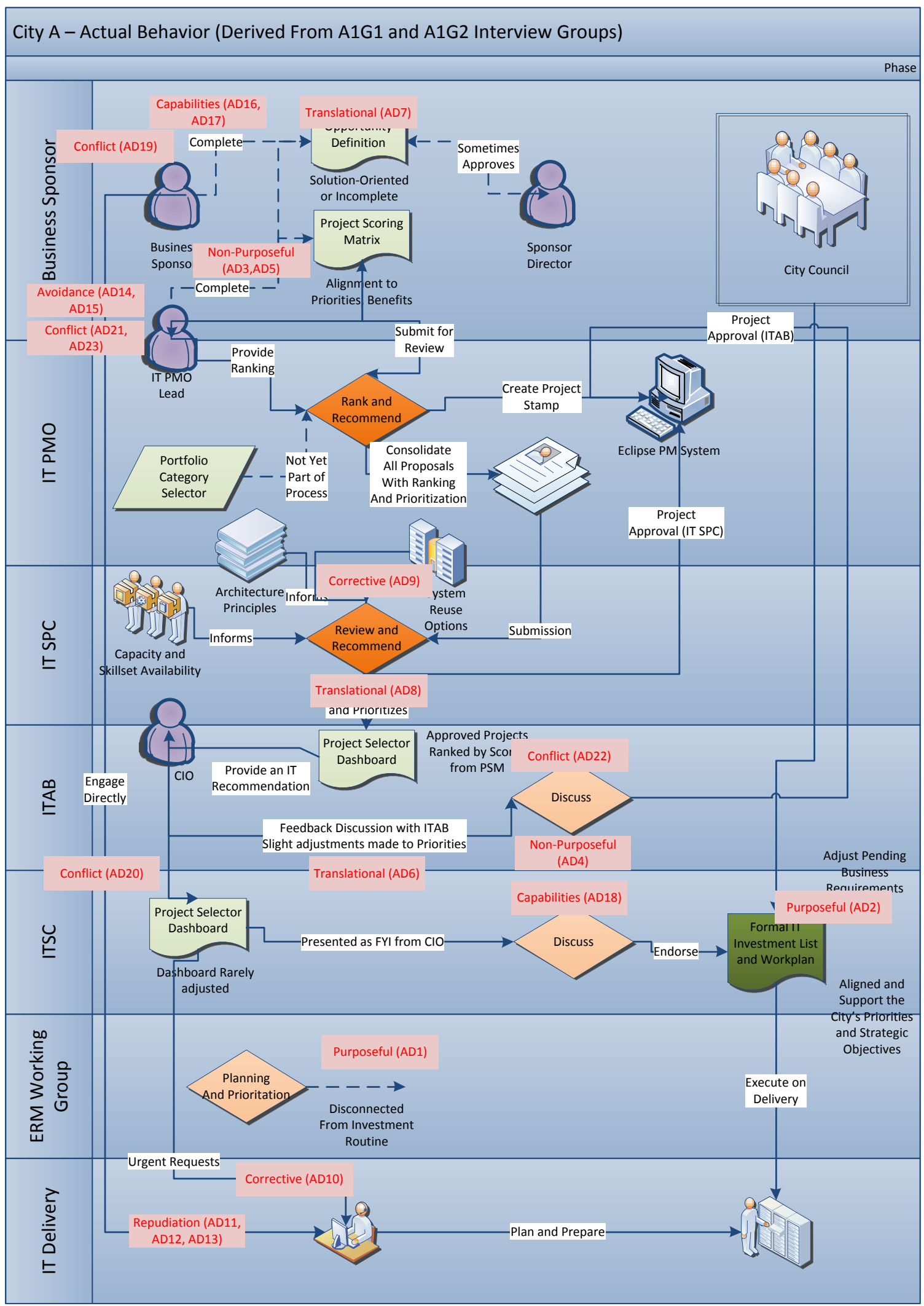




\section{APPENDIX N - CITY B GOVERNANCE OWNER EXPECTATIONS}

\begin{tabular}{|c|c|}
\hline Expected Behaviour & Evidence or Source \\
\hline $\begin{array}{l}\text { Provide the city with } \\
\text { cost savings or cost } \\
\text { avoidance }\end{array}$ & $\begin{array}{l}\text { - A2G106 - Council priorities = efficiencies and cost savings } \\
\text { - A2G108 - Council priorities = cost saving, service, } \\
\text { reputation, risk } \\
\text { - A2G109 - Council is fiscally conservative - projects must } \\
\text { show savings or efficiencies }\end{array}$ \\
\hline $\begin{array}{l}\text { Prioritization and } \\
\text { approval made by } \\
\text { business and not IT }\end{array}$ & $\begin{array}{l}\text { - A2G101 - Purpose of the PPS process is shift burden of IT } \\
\text { decisions out of IT } \\
\text { - A2G103 - Clients own the project and are part of the } \\
\text { project - they own the project } \\
\text { - A2G107 - Want business to take ownership of project } \\
\text { - A2G108 - Decision making is responsibility of business } \\
\text { not IT (feels it is working well) } \\
\text { - IT Plan - IT investment decisions are made by corporation } \\
\text { as a whole, not by the IT group } \\
\text { - IT Plan - IT investment planning process integrated in } \\
\text { larger business planning cycle }\end{array}$ \\
\hline $\begin{array}{l}\text { Prioritized based on } \\
\text { overall corporate } \\
\text { benefits, and not by } \\
\text { individual business unit } \\
\text { need (horizontal) }\end{array}$ & $\begin{array}{l}\text { - A2G107 - IT PEC owns the process and is responsible for } \\
\text { providing corporate prioritization } \\
\text { - A2G107 - Prioritization based on horizontality of benefits } \\
\text { - A2G102 - Should enforce horizontality - horizontal } \\
\text { benefits } \\
\text { - A2G103 - Should look at horizontal solutions }\end{array}$ \\
\hline $\begin{array}{l}\text { Aligned with and } \\
\text { support the } \\
\text { achievement of business } \\
\text { unit and city direction / } \\
\text { objectives }\end{array}$ & $\begin{array}{l}\text { - A2G104 - All IT investments directly linked to business } \\
\text { priorities } \\
\text { - A2G107 - All IT projects tied to direction of the city } \\
\text { - A2G108 - All IT investments must be aligned to corporate } \\
\text { community objectives (strat plan) } \\
\text { - A2G109 - All investments (IT and non-IT) must be aligned } \\
\text { to goals in strategic plan } \\
\text { - IT Plan - All IT decisions within the governance process } \\
\text { aligned with corporate goals } \\
\text { - IT Plan - Projects ranked by strategic alignment, } \\
\text { return/performance, risk mitigation }\end{array}$ \\
\hline $\begin{array}{l}\text { Leverage existing core } \\
\text { enterprise systems } \\
\text { whenever possible }\end{array}$ & $\begin{array}{l}\text { - A2G106 - Reuse existing systems wherever possible } \\
\text { - A2G107 - Prioritization based on reuse of existing } \\
\text { systems } \\
\text { - A2G110 - Look at core systems first - prioritization } \\
\text { against current systems } \\
\text { - IT Plan - Investments should capitalize on existing } \\
\text { investments - reuse existing systems }\end{array}$ \\
\hline
\end{tabular}




\begin{tabular}{|c|c|}
\hline & $\begin{array}{l}\text { - IT Plan - Investment focus should be consolidating within } \\
\text { core business applications }\end{array}$ \\
\hline $\begin{array}{l}\text { Provide clear value to } \\
\text { the citizens and the } \\
\text { organization }\end{array}$ & $\begin{array}{l}\text { - A2G104 - Ensure only IT projects that provide value to } \\
\text { the business are selected } \\
\text { - A2G203 - Invest only projects that show a clear benefit } \\
\text { for citizens } \\
\text { - A2G105 - Clear impact analysis for projects - clear what } \\
\text { the impact will be } \\
\text { - A2G108 - Council expects IT to provide leadership in } \\
\text { innovation - suggest innovative solutions that benefit } \\
\text { citizens }\end{array}$ \\
\hline $\begin{array}{l}\text { Balance between } \\
\text { strategic and tactical } \\
\text { investments }\end{array}$ & $\begin{array}{l}\text { - A2G108 - Process must provide balance between } \\
\text { program and internal IT projects } \\
\text { - A2G108 - Investment list must balance between small } \\
\text { and big projects } \\
\text { - IT Plan - Portfolio of investments balanced between } \\
\text { strategic }\end{array}$ \\
\hline
\end{tabular}




\section{APPENDIX O - CITY B DESIRED BEHAVIOUR}

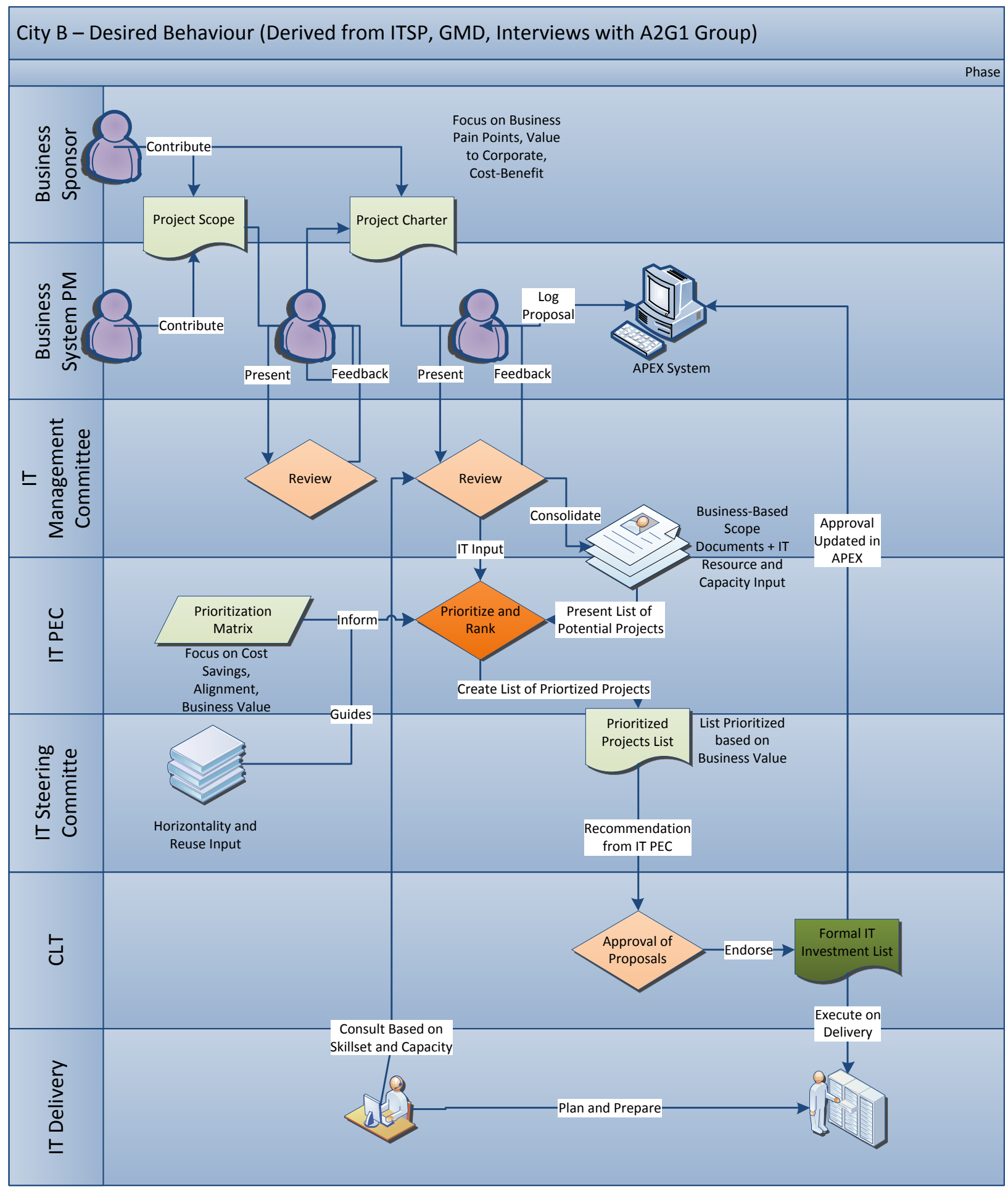




\section{APPENDIX P - CITY B ACTUAL BEHAVIOUR}

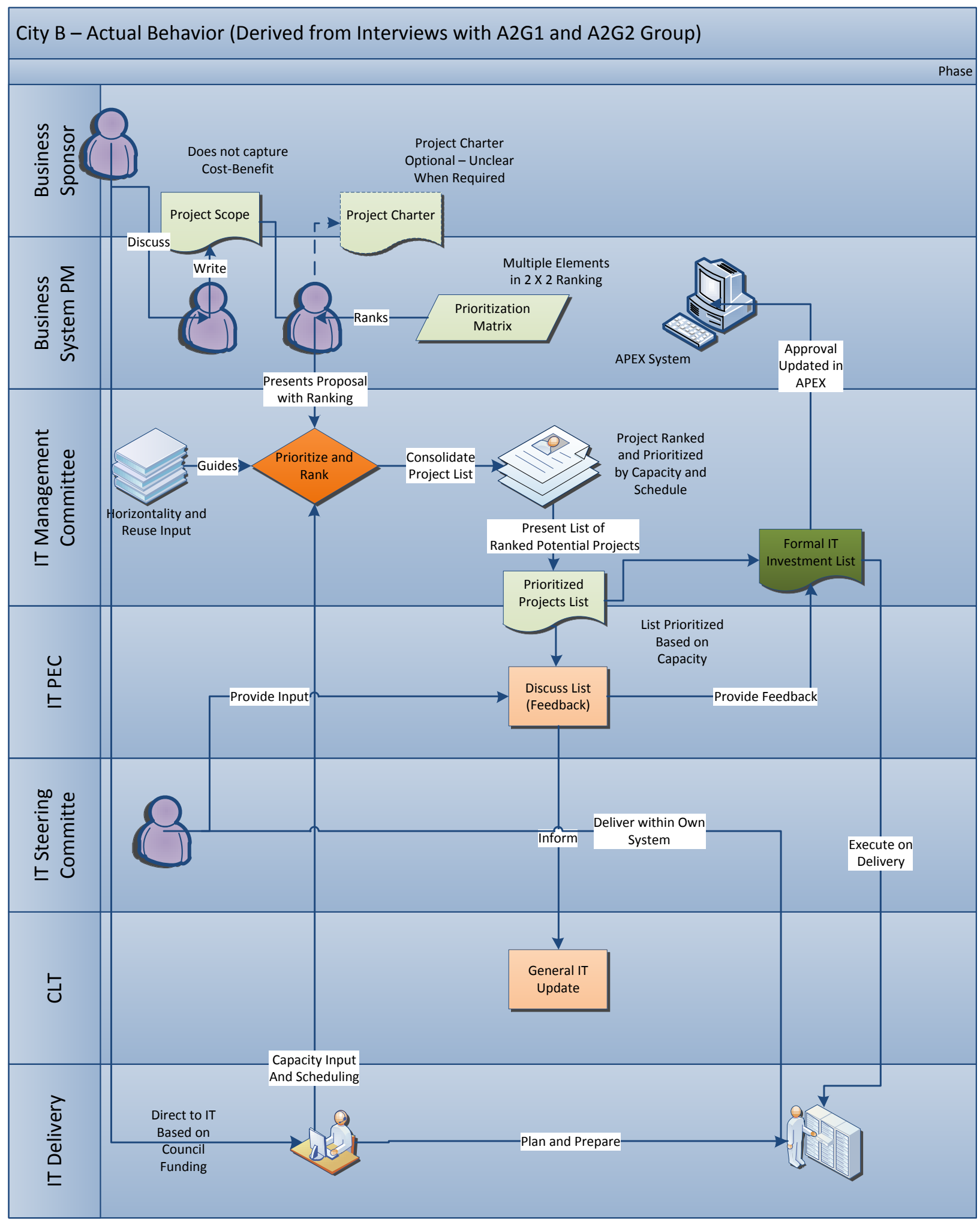




\section{APPENDIX Q - CITY B DIVERGENCE}

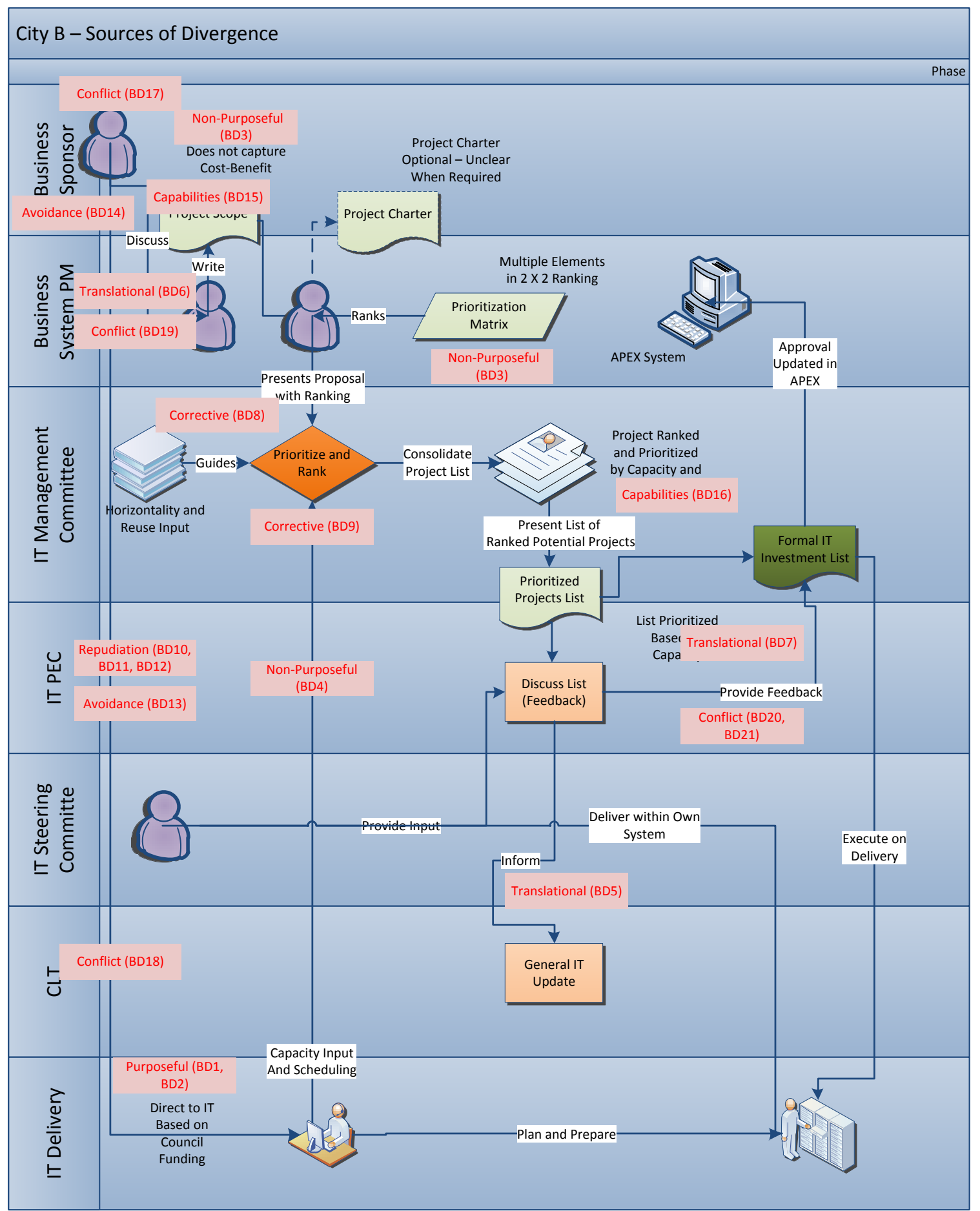




\section{APPENDIX R - CITY A FINAL DIVERGENCE CODES}

\begin{tabular}{|l|l|l|l|l|}
\hline Code & Type & Divergence Code & References & Sources \\
\hline AD1 & Purposeful & Council approval vs. IT approval & 14 & 19 \\
\hline AD2 & Purposeful & Council trumps prioritization & 4 & 4 \\
\hline AD3 & Non-Purposeful & Artefact disconnect of expectations & 6 & 6 \\
\hline AD4 & Non-Purposeful & ITAB role in prioritization & 5 & 5 \\
\hline AD5 & Non-Purposeful & Business ownership mandate & 19 & 28 \\
\hline AD6 & Translational & Prioritization not done by ITAB/ITSC & 12 & 13 \\
\hline AD7 & Translational & Interpretation of scoping forms & 13 & 23 \\
\hline AD8 & Translational & Prioritization done by IT?? & 4 & 4 \\
\hline AD9 & Corrective & Horizontality as objective & 14 & 22 \\
\hline AD10 & Corrective & Start without approval & 1 & 1 \\
\hline AD11 & Repudiation & I have my own funding & 10 & 15 \\
\hline AD12 & Repudiation & Process is burdensome & 6 & 9 \\
\hline AD13 & Repudiation & Reject the response & 4 & 6 \\
\hline AD14 & Avoidance & Lack of awareness & 9 & 11 \\
\hline AD15 & Avoidance & Don't understand when to engage & 6 & 8 \\
\hline AD16 & Capabilities & Poor business planning & 4 & 5 \\
\hline AD17 & Capabilities & Business unable to articulate value & 3 & 3 \\
\hline AD18 & Capabilities & Committee member shortcomings & 1 & 1 \\
\hline AD19 & Conflict & Cultural norms - decentralization & 2 & 3 \\
\hline AD20 & Conflict & Informal norms - relationships & 5 & 5 \\
\hline AD21 & Conflict & Self-interest - game the prioritization & 5 & 6 \\
\hline AD22 & Conflict & Power and clout - prioritization & 14 & 15 \\
\hline AD23 & Conflict & Self-interest - Personal Incentives & 8 & 9 \\
\hline & Total & & 169 & 221 \\
\hline
\end{tabular}




\section{APPENDIX S - CITY B FINAL DIVERGENCE CODES}

\begin{tabular}{|l|l|l|l|l|}
\hline Code & Type & Divergence Code & References & Sources \\
\hline BD1 & Purposeful & Council approval vs. IT approval & 10 & 14 \\
\hline BD2 & Purposeful & Budget sets prioritization & 3 & 3 \\
\hline BD3 & Non-Purposeful & No artefacts support cost saving & 4 & 5 \\
\hline BD4 & Non-Purposeful & Business don't approve projects & 7 & 7 \\
\hline BD5 & Translational & IT PEC and CLT rubberstamp & 7 & 7 \\
\hline BD6 & Translational & Scoping document completion & 7 & 7 \\
\hline BD7 & Translational & Prioritization based on capacity & 1 & 1 \\
\hline BD8 & Corrective & Horizontality as objective & 3 & 3 \\
\hline BD9 & Corrective & Prioritization done by IT & 4 & 5 \\
\hline BD10 & Repudiation & Funding prioritization mechanism & 4 & 10 \\
\hline BD11 & Repudiation & Loss of Control & 7 & 10 \\
\hline BD12 & Repudiation & Business don't accept decisions & 1 & 1 \\
\hline BD13 & Avoidance & Lack of awareness & 6 & 6 \\
\hline BD14 & Avoidance & Suppression of demand & 1 & 1 \\
\hline BD15 & Capabilities & Business can't scope needs & 2 & 2 \\
\hline BD16 & Capabilities & Unable to adequately assess work & 1 & 1 \\
\hline BD17 & Conflict & Cultural norms - embeddedness & 2 & 2 \\
\hline BD18 & Conflict & Prefer informal relationships & 7 & 8 \\
\hline BD19 & Conflict & $\begin{array}{l}\text { Self-interest - game the } \\
\text { prioritization }\end{array}$ & 1 & 1 \\
\hline BD20 & Conflict & Power and clout - prioritization & 5 & 2 \\
\hline BD21 & Conflict & Self-interest - favouritism & 2 & 101 \\
\hline & Total & & 85 & \\
\hline & & & & 2 \\
\hline
\end{tabular}




\section{APPENDIX T - TABLE OF ACRONYMS}

\begin{tabular}{|c|c|}
\hline Acronym & Definition \\
\hline \multicolumn{2}{|l|}{ General } \\
\hline CAO & Chief Administration Officer \\
\hline $\mathrm{ClO}$ & Chief Information Officer \\
\hline CoBIT & Control Objects for Information and Related Technology \\
\hline ERP & Enterprise Resource Planning System \\
\hline IAD & Institutional Analysis and Design \\
\hline ISACA & Information Systems Audit and Control Association \\
\hline IT & Information Technology \\
\hline ITGI & IT Governance Institute \\
\hline ITIL & IT Infrastructure Library \\
\hline ITPPS & IT Planning, Prioritization and Selection \\
\hline NASCIO & National Association of State Chief Information Officers (US) \\
\hline OAG & Office of the Auditor General (Canada) \\
\hline OR & Organizational Routine \\
\hline PerfDiv & Performative Divergence \\
\hline RepDiv & Representational Divergence \\
\hline SubDiv & Substantive Divergence \\
\hline TranDiv & Translational Divergence \\
\hline \multicolumn{2}{|l|}{ Case $\mathbf{A}$} \\
\hline CMT & Corporate Management Team \\
\hline ERM & Enterprise Resource Management \\
\hline ITAB & IT Advisory Board \\
\hline ITGF & IT Governance Framework \\
\hline ITSC & IT Steering Committee \\
\hline ODP & Opportunity Definition Form \\
\hline PMO & Project Management Office \\
\hline PSM & Project Scoring Matrix \\
\hline PSP & Project Planning, Selection and Prioritization Policy \\
\hline SPC & Strategy and Planning Committee \\
\hline \multicolumn{2}{|l|}{ Case B } \\
\hline BSPM & Business Systems Project Manager \\
\hline CBP & Corporate Business Plan \\
\hline CLT & Corporate Leadership Team \\
\hline CTSP & Corporate Technology Strategic Plan \\
\hline DCAO & Deputy Chief Administration Officer \\
\hline GMD & Governance Master Document \\
\hline IT-PEC & IT Portfolio Evaluation Committee \\
\hline SDLC & System (Solution) Development Lifecycle \\
\hline
\end{tabular}

